\title{
Cardiac Recovery by Stem and Progenitor Cells
}

Herstel van het hart door stam- en voorlopercellen

Linda Wilhelmina van Laake 
ISBN: $\quad$ 978-90-9022808

Lay-out: Gildeprint BV, Enschede, the Netherlands

Print: Gildeprint BV, Enschede, the Netherlands 


\title{
Cardiac Recovery by Stem and Progenitor Cells
}

\author{
Herstel van het hart door stam- en voorlopercellen \\ (met een samenvatting in het Nederlands)
}

\author{
Proefschrift
}

ter verkrijging van de graad van doctor aan de Universiteit Utrecht op gezag van de rector magnificus, prof.dr.J.C. Stoof, ingevolge het besluit van het college voor promoties in het openbaar te verdedigen op vrijdag II april 2008 des middags te I 4.30 uur

door

\section{LindaW ilhelmina van Laake}

geboren op 31 mei 1980 te Vierlingsbeek 


\section{Promotoren: Prof.dr. C.L. Mummery Prof.dr. P.A. Doevendans}

Financial support by the Prof. R.L.J.van Ruyven Foundation for the publication of this thesis is gratefully acknowledged.

Financial support by the Netherlands Heart Foundation and the Jurriaanse Foundation for the publication of this thesis is gratefully acknowledged.

Additional financial support was granted by: Novartis, Boehringer Ingelheim BV, Servier Nederland Farma BV. 


\section{Contents}

$\begin{array}{lll}\text { Chapter } 1 & \text { General Introduction } & 7\end{array}$

$\begin{array}{lll}\text { Chapter } 2 \text { Heart repair and stem cells } & 19\end{array}$

Chapter 3 Monitoring of cell therapy and assessment of cardiac 43 function using magnetic resonance imaging in a mouse model of myocardial infarction.

Chapter 4 Human embryonic stem cell-derived cardiomyocytes survive and mature in the mouse heart and transiently improve function after myocardial infarction.

Chapter 5 Improvement of cardiac function by transplantation of hESC-derived cardiomyocytes in infarcted mouse heart correlates with improved vascularization but not graft size.

Chapter 6 Extracellular matrix formation after transplantation of hESC-derived cardiomyocytes in mice and a pro-survival mechanism through donor-derived neovascularization.

Chapter 7 Endoglin has a crucial role in blood cell-mediated vascular repair.

Chapter 8 Human cardiomyocyte progenitor cells regenerate infarcted myocardium and preserve long-term cardiac function in mice.

Chapter 9 General discussion. 
Summary

Samenvatting

Dankwoord / Acknowledgements

Curriculum vitae

246

List of publications 


\section{Introduction}

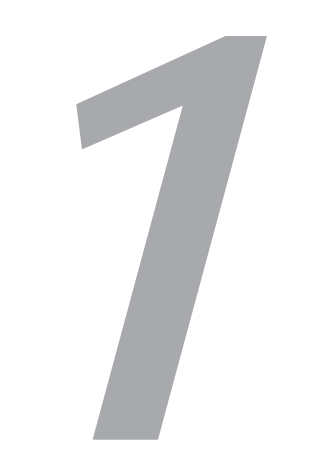

Published in part as

L.W. van Laake, D.Van Hoof, C.L. Mummery. Cardiomyocytes derived from stem cells. Annals of Medicine. 2005;37(7):499-5 I2 


\section{Clinical background}

Prevention and treatment of cardiovascular diseases is an important issue, especially in the Western world where ischemic heart disease and its consequences rank first in the mortality list '. With aging of the population and an improved short-term survival after myocardial infarction (MI) over the past decades, the number of patients with heart failure is increasing. In spite of major efforts to improve their condition with life-style alterations and medication, the natural course of the disease cannot be halted and gradual progress towards severely impaired cardiac function and death is generally inevitable. The mammalian heart is unable to regenerate the large number of cardiomyocytes lost after infarction. Adaptation mechanisms, such as hypertrophy, that are initially beneficial become detrimental in the end. The only curative option is heart transplantation but this is limited by donor availability and transplant rejection. If it were possible to reconstitute the myocardium, even in part, by replacing lost cardiomyocytes, these problems could be circumvented.

\section{Cell-based cardiac repair}

Among the potential sources of myocytes for cardiac repair, skeletal muscle has been used as a support to damaged hearts, first with surgical attachment of large patches of muscle to the heart ${ }^{2}$ and later as cell therapy using skeletal myoblasts (SM), the precursors of skeletal muscle ${ }^{3}$. The clinical use of SMs has, however, been limited even though they improved the contractile force of the heart, because the myoblasts differentiated only into skeletal myocytes, were unable to couple functionally with the host myocardium and may therefore be a potential cause of arrhythmias ${ }^{4-6}$. Although arrhythmias were not evident in rats used for preclinical experiments, probably because of their high beat rate and ability to override the effect of arrhythmic substrates, this was an issue in the first clinical tests ${ }^{5}$.

A better and safer approach seemed to emerge when transplantation of bone marrow cells (BMCs) in the infarcted hearts of wild type mice appeared to induce their transdifferentiation into cardiomyocytes ${ }^{7}$. The green fluorescent protein (GFP)-marked BMCs co-expressed cardiac proteins, regenerated 
most of the infarct area and restored heart function. This spectacular finding was translated with unprecedented rapidity to cardiac patients and the first randomized clinical trials were completed within 5 years. However, as increasing numbers of reports on the outcome of these trials become available ${ }^{8}$, it seems questionable whether this rapid clinical translation was justified. Although some early non-controlled pilot studies were unanimously positive with respect to improved cardiac function, the outcomes of recent randomized (placebo-) controlled trials have not provided confirmation, especially after longer follow-up times. In patients receiving injections of various numbers of cells from different cellular fractions of their own bone marrow, there was no increase in ejection fraction (EF; the fraction of blood within the (left) ventricle ejected during one contraction) or the increase did not exceed 5 percentage points ${ }^{9-12}$, the minimum change required for improvement of symptoms and survival ${ }^{13 ; 14}$. On the other hand, parameters such as infarct remodeling ${ }^{13}$ or exercise capacity ${ }^{15}$, which may be more predictive of long term outcome, were positively affected by BMCs treatment, at least up to 4-6 months. Patients with the largest infarcts generally benefited most ${ }^{10 ; 12}$. Concurrent repeats of the earlier studies injecting BMCs into mice with MI failed to confirm transdifferentiation as the mechanism underlying the apparent expression of cardiac markers by BMCs, but rather indicated that BMCs could fuse at low frequency with host cardiomyocytes and express both sets of markers ${ }^{16-19}$. The original results may also have been influenced by autofluorescence from scar tissue and/or dead cells. Whether transdifferentiation takes place in humans is more difficult to investigate, but it would seem unlikely. If BMCs improve cardiac function, this is more likely to result from early salvage of ischemic myocardium by some kind of paracrine action from the transplanted cells rather than by increasing the number of contractile cells by replacing those lost after damage.

This does not leave the concept of cardiac regeneration or repair (although often used randomly in this field of research, in the strict sense of the word regeneration refers to an intrinsic process by the damaged organ itself or cells thereof, while repair would be the appropriate word for building tissue from an exogenous or ectopic cell source) forgotten: On the contrary, now that several sources of stem cells have become available for in vitro use and true cardiomyocyte differentiation from some of these has been achieved, cell-based cardiac repair has in fact become a realistic prospect. 


\section{Stem cell types: cardiomyocyte differentiation and vascular repair}

Stem cells are defined as being capable of self-renewal and differentiation into at least one other cell type. Experimental proof of multipotentiality normally requires clonal analysis at the single cell level. Stem cells can be broadly divided into two categories: embryonic stem cells (or stem cells with embryonic properties: the recently induced pluripotent stem cells (iPS cells) ${ }^{20-22}$ and adult (or somatic) stem cells. Based on their developmental potential they may be termed totipotent (cells that can differentiate into all cell lineages including all extra-embryonic cell types); pluripotent (differentiation into all somatic cell lineages and germ cells but only the extra-embryonic tissues that derive from the inner cell mass); or multipotent (differentiation into a few cell lineages, generally those present in the organ from which the stem cell is derived); and unipotent (differentiation of progenitor cells into one specific cell lineage) (Figure I).

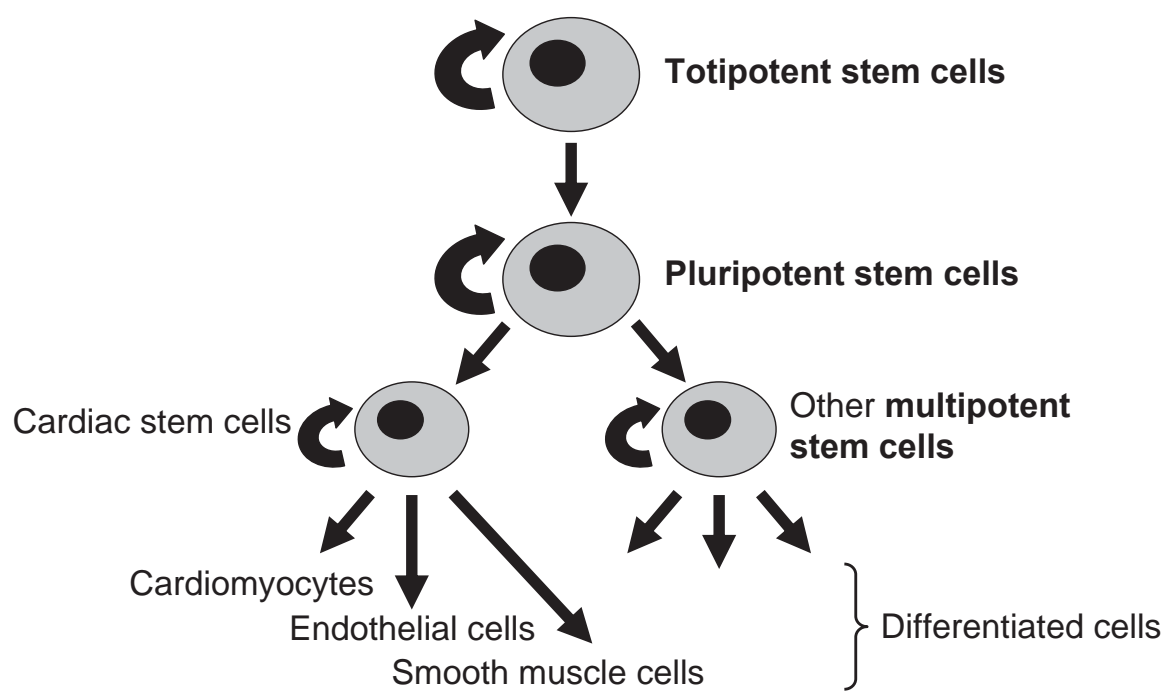

Figure 1

Human embryonic stem cells (hESCs) are pluripotent cells derived from the inner cell mass of blastocyst-stage embryos ${ }^{23}$ and proliferate indefinitely in vitro in an undifferentiated state when cultured under appropriate conditions. They 
have the potential to differentiate into derivatives of all three primary germ layers that arise during development (ectoderm, endoderm and mesoderm) and thus all somatic cells of the adult individual as well as germ cells. Mesoderm is the embryonic origin of the four major cell types of the heart: cardiomyocytes, vascular smooth muscle cells, endothelial cells and cardiac fibroblasts. HESCs are therefore a potential cell source for tissue regeneration including that necessary in the heart following $\mathrm{MI}$.

More than 400 independent HESC lines are now thought to exist worldwide, derived under a variety of (partially) defined conditions. HESCs can differentiate into multiple cell types generally with an immature or fetal phenotype, including human fetal-like cardiomyocytes. Induction of cardiomyocyte differentiation in $\mathrm{hES} 2$ and $\mathrm{hES} 3 \mathrm{hESC}$ lines, that rarely undergo spontaneous cardiogenesis, has been achieved by co-culturing hESCs with an endoderm-like cell line (END2 ), that is thought to mimic the effect of extra-embryonic visceral endoderm in the embryo ${ }^{24}$. The cardiomyocytes obtained express sarcomeric proteins, cardiac transcription factors and multiple cardiac ion channel genes. They have ventricular action potentials, respond as expected to positive and negative chronotropic agents, and form gap-junctions ${ }^{24}$. Omitting serum, a standard component of culture medium, in this differentiation assay resulted in a more than 20 -fold increase in efficiency of generating hESC-derived cardiomyocytes (hESC-CM) ${ }^{25}$. This was further enhanced by leaving out insulin, since this hormone inhibited early endoderm and (cardiac) mesoderm formation while promoting differentiation into ectodermal lineages ${ }^{26}$. The effect of the END-2 cells could be reproduced in part by culturing hESCs as aggregates (embryoid bodies) in END-2 conditioned medium, without the presence of the endoderm cells themselves. Addition of a specific p38 MAP kinase inhibitor improved the efficiency without changing the distribution of phenotypes of the hESC-CM, which included more cells with atrial electrophysiological characteristics than hESC-CM from the END-2 coculture, but were still predominantly ventricular 27. In other hESC lines, cardiomyocyte differentiation can be achieved by embryoid body formation only, generating a mixture of nodal, atrial and ventricular cells albeit with a very low efficiency in the order of $1 \%{ }^{28 ; 29}$. Several approaches were taken to improve this, including treatment with 5-azacytidine which gave a 10 -fold enhancement in combination with culture as hanging drops instead of regular aggregates ${ }^{30}$. The method of aggregation also proved 
important in a study testing the cardiomyogenic potential of several hESC lines in standard embryoid body formation or centrifugation-driven forced aggregation. While the latter resulted in higher numbers of cardiomyocytes in several lines, one was specifically responsive to additional stimulation by activin $\mathrm{A}$ and basic fibroblast growth factor ${ }^{31}$. Differentiation in monolayer is another method potentially suitable for bulk culture. By adding activin $A$ and bone morphogenetic protein 4, both factors involved in embryonic mesoderm development, the yield of cardiomyocytes was over $30 \%{ }^{32}$. However, selection was necessary to obtain more pure populations and this was demonstrated feasible by Percoll gradient purification, although with variable success ${ }^{29: 32}$, or fluorescence activated cell sorting (FACS) based on GFP expression under the control of a cardiac myosin light chain $2 \mathrm{~V}$ promoter. Significant progress has thus been made in directing hESC differentiation towards cardiomyocytes and selecting those cells of interest. However, other issues such as immunological incompatibility and ethical questions -the derivation of a hESC line involves destroying a human embryo, even though it is surplus to requirements ("rest material") after standard in vitro fertilization (IVF) procedures - might impede their future clinical application, certainly if this has a commercial basis as would seem necessary at some point.

Somatic stem cells on the other hand can be derived from both adult and fetal tissue although their properties and abundance may depend on the specific source. While often difficult to obtain and expand because of their small numbers in vivo and more limited proliferative capacity compared to hESCs (they rarely form permanent cell lines in culture), adult stem cells have the advantage of being potentially autologous and perhaps safer because of the absence of an induced immune response. If expanded in culture prior to use they will acquire some risk associated with spontaneous mutation, adaptation and use of xenoreagents but in contrast to hESCs, residual stem cells will not lead to teratoma formation. Stem cells hypothesized to have benefits for cardiac repair are being discovered in an ever-increasing numbers of tissues in the mammalian body, including bone marrow, testis, skeletal muscle, adipose tissue and cord blood 7:33-36. The only unambiguous source of cardiomyogenic cells however is the heart itself and hESCs. The adult mammalian heart was previously considered to contain no dividing muscle cells. Recently, several cardiac-derived 
stem cell populations have been described ${ }^{37-39}$. Although they appear to be distinct from one another, based on gene expression profile and the expression of cell surface markers, they may all represent subpopulations of one major cardiac stem cell population, since it seems unlikely that an organ known for its lack of regenerative capacity would harbor so many different cardiomyocyte progenitor cell (CMPC) types. Among the cells of high interest are CMPCs isolated by clonal derivation or binding of an antibody recognizing Sca-I; these cells have the ability to differentiate into relatively mature cardiomyocytes in vitro after addition of 5 -azacytidine, ascorbic acid and TGF $\beta$ I without the need for feeder cells ${ }^{40}$.

Whether other adult stem cells are able to differentiate into bona fide cardiomyocytes is still a matter of contention but they certainly have importance if they act through other mechanisms that may support regeneration of the heart, such as neovascularization in the acute phase after myocardial infarction, or providing perfusion to large grafts or engineered heart tissue. Mononuclear cells derived from bone marrow or blood and containing populations with the capacity to form vascular endothelial cells and macrophages, for example, are essential in the healing process of the injured heart, in particular its vascular repair ${ }^{41}$. Transplantation of these and other bone marrow-and peripheral blood derived cells has already entered clinical trials, but their mechanism of action is unclear ${ }^{42}$. It is also unknown which subset of (autologous or heterologous) cells is optimal for transplantation in which type of patient so that it is clear that small and large animal experiments are still required to identify the best cell type to support each of the potential underlying mechanisms.

The very recently described iPS cells are potentially the best of both worlds. Derived from postnatal skin fibroblasts, they could be reprogrammed into a pluripotent state by transduction of Oct3/4, Sox2 and KIf4 with or without Myc 43;4 or by Oct4, Sox2, Nanog and Lin28 ${ }^{45}$. The iPS cells are similar to hESCs in many respects, including their ability to form cell types of the three germ layers in vitro and in teratomas. However, although their capacity to differentiate into cardiomyocytes and other cardiac cells has been shown, the long term stability of iPS cell lines and alternatives to viral introduction of genes, still needs to be demonstrated. 


\section{Scope of the thesis}

Taken together, stem- and progenitor cells are considered to have significant potential with regard to meeting the enormous need for novel methods of cardiac repair. In vivo studies in this field, however, are just beginning while interpretation of results is complex and in some cases contradictory. Therefore, creating a consistent model to investigate cell-based cardiac regeneration is one of the aims of the studies described in this thesis. Using this model, transplantations of $\mathrm{hESC}$ derivatives and adult cell types are described, all studies revolving around the question: what is the fate and functional outcome of treatment with each of the different cells, what are the underlying mechanisms and how does this information translate to the development of future clinical application?

Chapter 2 gives an overview of recent progress in stem cell therapy for cardiac repair. The multiple cell sources proposed as candidates for cardiac regeneration are critically evaluated with regard to their capacity to differentiate into cardiomyocytes and the efficacy and safety of their (pre)clinical application. This results in formulation of a set of unanswered questions and controversial issues in this field, some of which are explored in the subsequent chapters.

Chapter 3 describes the development of a mouse model of myocardial infarction based on permanent left anterior descending coronary artery occlusion which allows long term functional analysis of engrafted stem cell-derived cardiomyocytes and other cells. This includes the adaptation of magnetic resonance imaging (MRI) for use in mice to monitor cardiac function noninvasively and repeatedly.

In Chapter 4, the regenerative and repair capacity of hESC-derived cardiomyocytes is assessed using this model. The cells are injected in noninjured mouse hearts to evaluate their capacity to survive and monitor phenotypic alterations. Cardiomyocyte-specific effects are distinguished from more general cell-based functional improvements by comparing transplantation of $\mathrm{hESC}$-derived cardiomyocytes with non-cardiomyocytes derived from the same stem cell population in the infarcted heart. Additional control groups and attempts to increase or prolong the beneficial effect of cardiomyocyte transplantation are described in Chapter 5. This leads to the identification of particular mechanisms involved in the observed functional improvement, 
which are also presented here. The study in Chapter 6 is accomplished to map the formation of extracellular matrix around grafts, which may impair the functionality of the grafts, in relation to the expression of surface integrins on grafted cells. Donor-derived neovascularization reveals itself as a compensatory mechanism that appears to enhance survival of donor cells.

To specify the role and suitability of vasculogenic cells in cardiac regeneration, the function of a gene encoding for endoglin, an accessory TGF $\beta$-receptor present on mononuclear cells, is studied in relation to vascular repair after myocardial infarction. To this end, transplantations of normal and diseased human mononuclear cells were carried out in transgenic and normal mice; the results are presented in Chapter 7.

Chapter 8 evaluates the capacity of transplanted human CMPCs to differentiate into cardiomyocytes in the mouse heart and improve heart function after myocardial infarction. The effects of these in vivo differentiated cells and their in vitro differentiated counterparts are collated.

Finally, the findings of the experimental chapters are reflected on in the concluding discussion in Chapter 9.

\section{References}

I. International Cardiovascular Disease Statistics. American Heart Association. 2007.

2. Sola OM, Dillard DH, Ivey TD, Haneda K, Itoh T, Thomas R. Autotransplantation of skeletal muscle into myocardium. Circulation. 1985;7I:34I-348.

3. Koh GY, Klug MG, Soonpaa MH, Field LJ. Differentiation and long-term survival of $\mathrm{C} 2 \mathrm{CI} 2$ myoblast grafts in heart. J Clin Invest. 1993;92: I548-I554.

4. Leobon B, Garcin I, Menasche P,Vilquin JT,Audinat E, Charpak S. Myoblasts transplanted into rat infarcted myocardium are functionally isolated from their host. Proc Natl Acad Sci U SA. 2003; I00:7808-78I I.

5. Menasche P, Hagege AA, Vilquin JT, Desnos M,Abergel E, Pouzet B, Bel A, Sarateanu S, Scorsin M, Schwartz K, Bruneval P, Benbunan M, Marolleau JP, Duboc D. Autologous skeletal myoblast transplantation for severe postinfarction left ventricular dysfunction. J Am Coll Cardiol. 2003;4I:1078-1083.

6. Reinecke H, Poppa V, Murry CE. Skeletal muscle stem cells do not transdifferentiate into cardiomyocytes after cardiac grafting. J M ol Cell Cardiol. 2002;34:24I-249.

7. Orlic D, Kajstura J, Chimenti S, Jakoniuk I, Anderson SM, Li B, Pickel J, McKay R, Nadal-Ginard B, Bodine DM, Leri A, Anversa P. Bone marrow cells regenerate infarcted myocardium. Nature. 200 I;4I 0:70I-705.

8. Guan K, Hasenfuss G. Do stem cells in the heart truly differentiate into cardiomyocytes? J M ol Cell Cardiol. 2007;43:377-387.

9. Assmus B, Honold J, Schachinger V, Britten MB, Fischer-Rasokat U, Lehmann R, Teupe C, Pistorius K, Martin H, Abolmaali ND, Tonn T, Dimmeler S, Zeiher AM. Transcoronary transplantation of progenitor cells after myocardial infarction. N Engl J Med. 2006;355:I222-I232. 
10. Janssens S, Dubois C, Bogaert J, Theunissen K, Deroose C, Desmet W, Kalantzi M, Herbots L, Sinnaeve P, Dens J, Maertens J, Rademakers F, Dymarkowski S, Gheysens O,Van Cleemput J, Bormans G, Nuyts J, Belmans A, Mortelmans L, Boogaerts M,Van de WF.Autologous bone marrow-derived stem-cell transfer in patients with ST-segment elevation myocardial infarction: double-blind, randomised controlled trial. Lancet. 2006;367:113-121.

II. Lunde K, Solheim S, Aakhus S, Arnesen H, Abdelnoor M, Egeland T, Endresen K, llebekk A, Mangschau A, Fjeld JG, Smith HJ,Taraldsrud E, Grogaard HK, Bjornerheim R, Brekke M, Muller C, Hopp E, Ragnarsson A, Brinchmann JE, Forfang K. Intracoronary injection of mononuclear bone marrow cells in acute myocardial infarction. N Engl J Med. 2006;355:I I99-1209.

12. Schachinger V, Erbs S, Elsasser A, Haberbosch W, Hambrecht R, Holschermann H, Yu J, Corti R, Mathey DG, Hamm CW, Suselbeck T, Assmus B, Tonn T, Dimmeler S, Zeiher AM. Intracoronary bone marrowderived progenitor cells in acute myocardial infarction. N Engl J M ed. 2006;355:1210-1221.

13. Adler ED, Maddox TM. Cell therapy for cardiac disease: where do we go from here? Nat Clin Pract Cardiovasc Med. 2007;4:2-3.

14. Cintron G, Johnson G, Francis G, Cobb F, Cohn JN. Prognostic significance of serial changes in left ventricular ejection fraction in patients with congestive heart failure. The V-HeFT VA Cooperative Studies Group. Circulation. 1993;87:VII7-VI23.

15. Lunde K, Solheim S, Aakhus S, Arnesen H, Moum T, Abdelnoor M, Egeland T, Endresen K, llebekk A, Mangschau A, Forfang K. Exercise capacity and quality of life after intracoronary injection of autologous mononuclear bone marrow cells in acute myocardial infarction: results from the Autologous Stem cell Transplantation in Acute Myocardial Infarction (ASTAMI) randomized controlled trial. Am Heart J. 2007;154:710-718.

16. Balsam LB, Wagers AJ, Christensen JL, Kofidis T, Weissman IL, Robbins RC. Haematopoietic stem cells adopt mature haematopoietic fates in ischaemic myocardium. Nature. 2004;428:668-673.

17. Murry CE, Soonpaa MH, Reinecke H, Nakajima H, Nakajima HO, Rubart M, Pasumarthi KB, Virag Jl, Bartelmez SH, Poppa V, Bradford G, Dowell JD, Williams DA, Field LJ. Haematopoietic stem cells do not transdifferentiate into cardiac myocytes in myocardial infarcts. Nature. 2004;428:664-668.

18. Nygren JM, Jovinge S, Breitbach M, Sawen P, Roll W, Hescheler J, Taneera J, Fleischmann BK, Jacobsen SE. Bone marrow-derived hematopoietic cells generate cardiomyocytes at a low frequency through cell fusion, but not transdifferentiation. N at M ed. 2004;10:494-50।.

19. Terada N, Hamazaki T, Oka M, Hoki M, Mastalerz DM, Nakano Y, Meyer EM, Morel L, Petersen BE, Scott EW. Bone marrow cells adopt the phenotype of other cells by spontaneous cell fusion. Nature. 2002;416:542-545.

20. Park IH, Zhao R, West JA, Yabuuchi A, Huo H, Ince TA, Lerou PH, Lensch MW, Daley GQ. Reprogramming of human somatic cells to pluripotency with defined factors. Nature. 2007.

21. Yu J,Vodyanik MA, Smuga-Otto K, Antosiewicz-Bourget J, Frane JL, Tian S, Nie J, Jonsdottir GA, Ruotti V, Stewart R, Slukvin II,Thomson JA. Induced pluripotent stem cell lines derived from human somatic cells. Science. 2007;318:1917-1920.

22. Takahashi K, Tanabe K, Ohnuki M, Narita M, Ichisaka T, Tomoda K, Yamanaka S. Induction of pluripotent stem cells from adult human fibroblasts by defined factors. Cell. 2007;131:861-872.

23. Thomson JA, Itskovitz-Eldor J, Shapiro SS, Waknitz MA, Swiergiel JJ, Marshall VS, Jones JM. Embryonic stem cell lines derived from human blastocysts. Science. 1998;282: I I45-I I 47.

24. Mummery C, Ward-van Oostwaard D, Doevendans P, Spijker R, van den BS, Hassink R, van der HM, Opthof T, Pera M, de la Riviere AB, Passier R, Tertoolen L. Differentiation of human embryonic stem cells to cardiomyocytes: role of coculture with visceral endoderm-like cells. Circulation. 2003;107:2733-2740. 
25. Passier R, Oostwaard DW, Snapper J, Kloots J, Hassink RJ, Kuijk E, Roelen B, de la Riviere AB, Mummery $C$. Increased cardiomyocyte differentiation from human embryonic stem cells in serum-free cultures. Stem Cells. 2005;23:772-780.

26. Freund C, Ward-van Oostwaard D, Monshouwer-Kloots J, van den Brink CE, van Rooijen MA, Xu X, Zweigerdt R, Mummery CL, Passier R. Insulin redirects differentiation from cardiogenic mesoderm and endoderm to neuroectoderm in differentiating human embryonic stem cells. Stem Cells. 2008.

27. Graichen R, Xu X, Braam SR, Balakrishnan T, Norfiza S, Sieh S, Soo SY, Tham SC, Mummery C, Colman $A$, Zweigerdt R, Davidson BP. Enhanced cardiomyogenesis of human embryonic stem cells by a small molecular inhibitor of $\mathrm{P} 38$ MAPK. Differentiation. 2007.

28. He JQ, Ma Y, Lee Y,Thomson JA, Kamp TJ. Human embryonic stem cells develop into multiple types of cardiac myocytes: action potential characterization. Circ Res. 2003;93:32-39.

29. Xu C, Police S, Rao N, Carpenter MK. Characterization and enrichment of cardiomyocytes derived from human embryonic stem cells. Circ Res. 2002;91:501-508.

30. Yoon BS, Yoo SJ, Lee JE, You S, Lee HT, Yoon HS. Enhanced differentiation of human embryonic stem cells into cardiomyocytes by combining hanging drop culture and 5 -azacytidine treatment. Differentiation. 2006;74:149-159.

31. Burridge PW, Anderson D, Priddle H, Barbadillo M, Chamberlain S, Allegrucci C, Young LE, Denning C. Improved human embryonic stem cell embryoid body homogeneity and cardiomyocyte differentiation from a novelV-96 plate aggregation system highlights interline variability. Stem Cells. 2007;25:929-938.

32. Laflamme MA, Chen KY, Naumova AV, MuskheliV, Fugate JA, Dupras SK, Reinecke H, Xu C, Hassanipour M, Police S, O'sullivan C, Collins L, Chen Y, Minami E, Gill EA, Ueno S, Yuan C, Gold J, Murry CE. Cardiomyocytes derived from human embryonic stem cells in pro-survival factors enhance function of infarcted rat hearts. Nat Biotechnol. 2007;25:1015-1024.

33. Winitsky SO, Gopal TV, Hassanzadeh S, Takahashi H, Gryder D, Rogawski MA, Takeda K, Yu ZX, Xu YH, Epstein ND.Adult murine skeletal muscle contains cells that can differentiate into beating cardiomyocytes in vitro. PLoS Biol. 2005;3:e87.

34. Guan K, Wagner S, Unsold B, Maier LS, Kaiser D, Hemmerlein B, Nayernia K, Engel W, Hasenfuss G. Generation of functional cardiomyocytes from adult mouse spermatogonial stem cells. Circ Res. 2007;100:1615-1625.

35. Planat-Benard V, Menard C, Andre M, Puceat M, Perez A, Garcia-Verdugo JM, Penicaud L, Casteilla L. Spontaneous cardiomyocyte differentiation from adipose tissue stroma cells. Circ Res. 2004;94:223-229.

36. Nishiyama N, Miyoshi S, Hida N, Uyama T, Okamoto K, Ikegami Y, Miyado K, Segawa K, Terai M, Sakamoto M, Ogawa S, Umezawa A.The significant cardiomyogenic potential of human umbilical cord blood-derived mesenchymal stem cells in vitro. Stem Cells. 2007;25:2017-2024.

37. Beltrami AP, Barlucchi L, Torella D, Baker M, Limana F, Chimenti S, Kasahara H, Rota M, Musso E, Urbanek K, Leri A, Kajstura J, Nadal-Ginard B, Anversa P. Adult cardiac stem cells are multipotent and support myocardial regeneration. Cell. 2003; I 14:763-776.

38. Laugwitz KL, Moretti A, Lam J, Gruber P, Chen Y,Woodard S, Lin LZ, Cai CL, Lu MM, Reth M, Platoshyn O, Yuan JX, Evans S, Chien KR. Postnatal isl I+ cardioblasts enter fully differentiated cardiomyocyte lineages. Nature. 2005;433:647-653.

39. Messina E, De Angelis L, Frati G, Morrone S, Chimenti S, Fiordaliso F, Salio M, Battaglia M, Latronico MV, Coletta M,Vivarelli E, Frati L, Cossu G, Giacomello A. Isolation and expansion of adult cardiac stem cells from human and murine heart. Circ Res. 2004;95:91 I-92I.

40. Goumans MJ. Human cardiac progenitor cells are able to differentiate into cardiomcyocytes in vitro. American Heart Association 2005 Scientific Sessions. 2005. 
4I. Nahrendorf M, Swirski FK, Aikawa E, Stangenberg L, Wurdinger T, Figueiredo JL, Libby P, Weissleder R, Pittet MJ. The healing myocardium sequentially mobilizes two monocyte subsets with divergent and complementary functions.J Exp M ed. 2007;204:3037-3047.

42. Rosenzweig A. Cardiac cell therapy--mixed results from mixed cells. N Engl J M ed. 2006;355:I 274-I 277.

43. Park IH, Zhao R, West JA, Yabuuchi A, Huo H, Ince TA, Lerou PH, Lensch MW, Daley GQ. Reprogramming of human somatic cells to pluripotency with defined factors. Nature. 2007.

44. Takahashi K, Tanabe K, Ohnuki M, Narita M, Ichisaka T, Tomoda K, Yamanaka S. Induction of pluripotent stem cells from adult human fibroblasts by defined factors. Cell. 2007;131:861-872.

45. Yu J,Vodyanik MA, Smuga-Otto K, Antosiewicz-Bourget J, Frane JL, Tian S, Nie J, Jonsdottir GA, Ruotti V, Stewart R, Slukvin II,Thomson JA. Induced pluripotent stem cell lines derived from human somatic cells. Science. 2007;318:1917-1920. 


\section{Heart repair and stem cells}

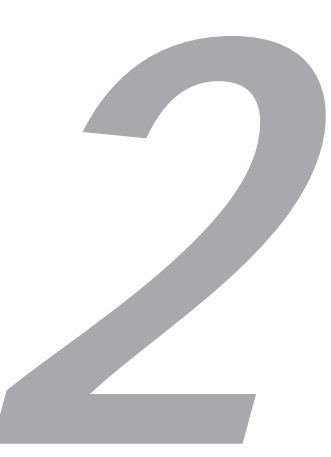

Published as

L.W. van Laake, R. Hassink, P.A. Doevendans, C. Mummery. Heart repair and stem cells. Journal of Physiology. 2006 Dec I;577(Pt 2):467-78 


\section{Abstract}

Of the medical conditions currently being discussed in the context of possible treatments based on cell transplantation therapy, few have received more attention than the heart. Much focus has been on the potential application of bone marrow-derived cell preparations, which have already been introduced into double-blind, placebo-controlled clinical trials. The consensus is that bone marrow may have therapeutic benefit but that this is not based on the ability of bone marrow cells to transdifferentiate into cardiac myocytes. Are there potential stem cell sources of cardiac myocytes that may be useful in replacing those lost or dysfunctional after myocardial infarction? Here, this question is addressed with a review of the recent literature.

\section{Introduction}

Cell transplantation is an area of growing interest in clinical cardiology as a potential means of treating patients with myocardial infarction or cardiac failure. The interest is based on the assumption that left ventricular dysfunction is largely due to the loss of a critical number of cardiomyocytes and that it may be partly reversed by implanting new contractile cells into the postinfarction scars or regions of wall thinning. Four categories of stem cells have been examined for their ability to promote cardiac repair in animal models: bone marrowderived/circulating progenitor cells (BMPCs) and their subpopulations, skeletal myoblasts (SMs), embryonic stem cells (ESCs) and resident cardiac stem (or cardiomyocyte progenitor) cells (CMPCs) '. Three of these cell types (BMPCs, SMs and CMPCs) are potentially autologous. Partly for this reason, BMPCs and skeletal muscle cells have been the first to be used in clinical trials. Their use is now considered feasible and for BMPCs safe. In contrast, SMs fail to integrate electromechanically within the recipient heart and their use is associated with risk of arrhythmias. Efficacy data are now emerging from ongoing randomized double-blind studies. However, a note of caution has arisen with BMPC since early claims that they were able to transdifferentiate in cardiac cells have now been refuted and attributed to fusion with recipient cardiac cells. Their ability to induce neovascularization and rescue ischemic myocardium when introduced 
at the correct time post myocardial infarction, is considered a potential mechanism underlying any beneficial effects. Resident CMPCs by contrast have only relatively recently been identified, but are already generating excitement because they appear to differentiate into bona fide cardiomyocytes in vitro with high efficiency. This is exceptional for any adult stem cell source studied to date. The question being addressed in preclinical experiments is whether ex vivo or in vivo expansion might be the best approach to increasing their numbers and improving contractile function of the heart. ESCs are at present the major heterologous source of cells being considered and ethically the most sensitive as their derivation requires the destruction of early human embryos. ESCs are developmentally the most versatile of stem cells forming all of several hundreds of cell types in the adult body. They are however associated with the risk of tumor formation if not fully differentiated.

While experimental studies and early-phase clinical trials tend to support the concept that cell therapy may enhance cardiac repair, several key issues still need to be addressed before introduction into routine clinical practice. These include (I) the optimal type of donor cells in relation to the clinical profile (2) the mechanism by which cell engraftment improves cardiac function, (3) optimization of cell survival, (4) development of less invasive cell delivery techniques and (5) the relevance to nonischemic heart failure. Here the background and current status of cardiac cell therapy are reviewed and perspectives for improving the prognosis of heart failure discussed.

\section{Pre-clinical studies}

Among the most important issues being addressed at present is identifying the most suitable stem cells for replacing muscle mass and finding out which mechanisms might contribute to stem cell-mediated improvement in cardiac function after myocardial infarction (MI) so that they could be used additionally or alternatively to vital muscle replacement. Several studies have described enhanced cardiac function after $\mathrm{MI}$, sometimes sustained, in animals following stem cell transplantation but the transplanted cells were often barely dectable postoperatively ${ }^{2}$ with no evidence of integration into either the vasculature or muscle. However, in some cases heart remodeling and extracellular matrix deposition appeared altered, so unknown paracrine mechanisms have been proposed as underlying functional improvement ${ }^{3-5}$. Enhanced blood vessel formation has 
frequently been observed concomitant with salvage of the myocardial tissue at risk in the infarct region ${ }^{6}$ and subsequent preservation of left ventricular function by increased recovery of hibernating myocardium ${ }^{7}$. This could be mediated by incorporation of transplanted angioblasts ${ }^{6}$ or endothelial precursor cells (EPCs; ${ }^{8-10}$ into the neovasculature or be the result of a local inflammation upregulating signaling pathways associated with angiogenesis ". MI itself increases the circulating levels of EPCs which in turn correlates with increased levels of granulocyte-colony stimulating factor (G-CSF). Therapy based on G-CSF injection intially appeared safe in patients with acute MI but did not improve functional recovery ${ }^{12}$ although later studies show that adverse side effects may result. Stromal-derived factor- $I$ is also expressed in the ischemic myocardium ${ }^{13}$ and plays an important role in recruiting EPCs from bone marrow via chemotaxis to the ischemic site. Indirect mechanisms for enhancing cardiac function may thus operate independent of possible contributions to muscle mass. Here, we consider the principal candidate cell types for cell therapy in turn for their potential to contribute to growth of new myocardium and/or improve cardiac function. Since BMPCs and SMs have recently been the subject of numerous reviews ${ }^{4 ; 14-18}$, we will focus on the only two human stem cells types that have been shown convincingly and robustly to convert to cardiac muscle cells: embryonic stem cells (ESCs) and CMPCs.

\section{BM PCs, transdifferentiation and angiogenesis}

Orlic et al. first suggested that BMPCs transdifferentiate (i.e. convert to another lineage by differentiation) into cardiomyocytes when injected into infarcted mouse myocardium ${ }^{19}$. The transplanted BMPCs expressed cardiac-specific markers troponin I and cardiac myosin but it was later shown that they could fuse with somatic cells and adopt aspects of the phenotype of the somatic cell 20;21. The interpretation of the data appeared flawed; it is now clear that BMPCs do not transdifferentiate into cardiomyocytes (reviewed in ${ }^{4}$ ). Nevertheless, functional improvement post-MI has been described after BMPC transplantation possibly due to an EPC subpopulation enhancing angiogenesis and the local blood supply in ischemic tissue 22-26. An alternative hypothesis has centered on pro-arteriogenic paracrine signaling from mononuclear cells also found in circulating blood (Rehman et al, 2003; Kinnaird et al 2004) rather than direct incorporation of an EPC subpopulation into neovasculature (Ziegelhoeffer 
et al, 2004). These "circulating angiogenic cells" were described as secreting multiple proangiogenic cytokines, including vascular endothelial growth factor, hepatocyte growth factor, granulocyte- and granulocyte-macrophage colony stimulating factor, with secretion increasing under hypoxic conditions. Neovascularization in turn may inhibit apoptosis of cardiomyocytes (Kocher et al, 200I). Mesenchymal stem cells, present in BMPCs, cord blood and adipose tissue, have also been described as possibly having cardiomyogenic potential ${ }^{27}$. Overall, their efficiency of cardiomyogenic conversion is low.

\section{Skeletal muscle cells}

SM satellite cells (or myoblasts), normally mediate regeneration of skeletal muscle but there were some initial hopes that these cells would transdifferentiate into cardiomyocytes. These cells can be expanded in culture and up to $10^{9}$ cells have been grown from a few grams of muscle tissue but it appeared later that they remain committed to a skeletal muscle fate ${ }^{28}$ although exceptionally rare fusion events between skeletal muscle cells and cardiomyocytes were observed in rat hearts after transplantation ${ }^{29}$. SM cells failed to express the adhesion and gap junction proteins that would be necessary to couple electromechanically with each other or with host myocardium and, as a result, the grafts did not beat in synchrony with host rat myocardium ${ }^{30}$.

\section{Embryonic stem cells}

\section{: differentiation to cardiomyocytes}

Human ESCs (HESCs) ${ }^{31 ; 32}$, like mouse ESCs ${ }^{33 ; 34}$ are derived from the inner cell mass of blastocyst stage embryos. ESCs grow indefinitely in an undifferentiated state whilst retaining the ability to differentiate to all cell types in the adult body. Among the cells that form in culture, rhythmically contracting cardiomyocytes are particularly striking (reviewed in Passier and Mummery, 2003; 2005). The first report of cardiomyocyte differentiation ${ }^{35}$ appeared almost 3 years after HESCs were first derived. To induce cardiomyogenesis, this cell line was dispersed into small clumps of 3-20 cells and grown for 7-10 days in suspension to form structures like embryoid bodies (EBs) from mESCs. After plating onto culture dishes, beating areas were observed in $~ 8 \%$ of the outgrowths 20 days later. This spontaneous differentiation to cardiomyocytes in aggregates was also observed by others using different cell lines ${ }^{36}$ but in this case approximately 
$25 \%$ of the EBs were beating after 8 days of differentiation and $70 \%$ after 20 days. Other reports described spontaneous differentiation of cardiomyocytes from HESCs with I-25\% of the embryoid bodies beating after several weeks ${ }^{37}$. The reasons for these differences in efficiency are not clear but counting beating EBs may not accurately reflect the conversion of HESCs to cardiomyocytes; variable numbers of cardiac cells and non-cardiomyocytes may be present. An alternative differentiation method is based on co-culture of HESCs with a visceral endoderm like cell line (END-2) or growth of HESC EBs in END-2 conditioned medium ${ }^{38 ; 39}$. (Visceral) endoderm plays an important role in the differentiation of cardiogenic precursor cells in the adjacent mesoderm in vivo during the development of species as diverse as chick, mouse and zebrafish, suggesting that the mechanism is apparently conserved (reviewed in Passier et al, 2006).

A cause for concern in relation to clinical applicability is that each HESC line may require a different protocol for optimal maintenance of self renewal and efficient differentiation (reviewed ${ }^{40}$. Significant upscale will also be required before HESC cardiomyocytes (HESC-CM) can undergo extensive preclinical testing in large animal models like sheep and pigs. This could involve increasing the efficiency of cardiomyocyte differentiation, promoting proliferation of the emerging cardiac precursor cells or cardiomyocytes or developing methods of purification of the required cardiac cell type ${ }^{41}$. Methods for upscaling have been described for mESCs using drug selection in combination with a cardiac specific promoter on EBs grown in a bioreactor: pure populations of up to $10^{9}$ cardiomyocytes have thus been generated ${ }^{42}$. Of note, $10^{8}-10^{9}$ cardiomyocytes may be lost after sublethal $\mathrm{MI}$ in humans. The only enrichment method described to date for HESC-CM used Percoll gradient purification ${ }^{36}$ although others have found this difficult to reproduce. Fluorescent or magnetic sorting based on a cell surface antibody binding would be useful improvements for quantification and selection of HESC-CM. However, to date few, if any, suitable cell surface protein-antibody combinations have been identified for cardiomyocytes. Genetically marked HESC-CM, as described in mice ${ }^{43-45}$, have also not yet been reported and even if available for experimental use, would be unlikely to be clinically acceptable due to the perceived risk associated with genetic modification. 


\section{: characteristics of HESC-CM}

Although functional cardiomyocytes can easily be identified in vitro by their beating phenotype, only more detailed interrogation can establish the identity of the specific cardiac cell types generated, their degree of maturity compared with cardiomyocytes developing in vivo and whether they possess fully functional excitation-contraction coupling machinery that responds appropriately to pharmacological agents. Primary adult cardiomyocytes do not survive transplantation or beat spontaneously in culture, in contrast to HESCCM and primary fetal CMs. On the other hand, beating in culture indicates spontaneous, pacemaker-like activity which may result in arrhythmias if there is electrical "mismatch" with the recipient heart, as indeed occurred when SMs were transplanted to human hearts. To realize the scientific and therapeutic potential of HESC-CM, therefore, comprehensive characterization of their phenotype is essential.

Differentiation of human ES cells to the cardiac lineage creates a characteristic gene expression profile ${ }^{46}$ reminiscent of both $\mathrm{mESC}$ differentiation and the early stages of normal mouse heart development ${ }^{47}$. Analysis of HESC-CM RNA and proteins has demonstrated the presence of cardiac transcription factors including GATA-4, myocyte enhancer factor (MEF-2) and Nkx2 transcription factor related locus 5 ( $\mathrm{Nk} \times 2.5)^{36 ; 46 ; 48}$. Correspondingly, structural components of the myofibers are appropriately expressed. These include $\alpha-, \beta$ - and sarcomeric-myosin heavy chain (MHC), atrial and ventricular forms of myosin light chain (MLC-2a and -2v), tropomyosin, $\alpha$-actinin and desmin although in contrast to mouse, heart chamber restricted expression of structural proteins is less well defined in human heart; MLC-2v for example is restricted to the ventricle in mouse and human fetal hearts but MLC-2a is expressed in both atrium and ventricle in humans and not just in atria as in mice ${ }^{49}$. This implies that using protein or gene expression profiles alone to determine the phenotype of HESC-CM in culture should be done with caution. Antibody reactivity to two members of the tropinin complex, cardiac tropinin $\mathrm{T}$ (cTnT), which binds to tropomyosin, and cardiac tropinin I (cTnl), which provides a calcium sensitive molecular switch for the regulation of striated muscle contraction, has been demonstrated. cTnl appears to be truly cardiac specific as antibodies to this protein only react with cells arising from beating and not non-beating regions. In addition, upregulation of atrial natriuretic factor (ANF), a hormone expressed 
in both atrial and ventricular cardiomyocytes in the developing heart, has also been observed during cardiac differentiation of HESCs. Moreover, these cells express creatine kinase-MB (CK-MB) and myoglobin ${ }^{36}$. Thus, many of the transcription factors, structural proteins and metabolic regulators of cardiac development are found within HESC-CM although they also react with antibodies to smooth muscle actin, a protein found in embryonic and fetal, but not adult cardiomyocytes suggesting a limited degree of maturation ${ }^{36}$. Single HESC cardiomyocytes display various morphologies in culture and may be spindle-shaped, round, tri- or multi-angular, rather than the rod shape of mature cells, sarcomeric immunostaining shows striations in separated bundles, rather than the highly organized parallel bundles, as in human adult cardiomyocytes, and the action potentials determined by patch-clamp electrophysiology show ventricular phenotypes with upstroke velocities $\sim 10$ times lower than those of adult cardiomyocytes ${ }^{39}$. It is of interest to note that not only are HESCCM connected to each other by connexin-43 expressing gap junctions ${ }^{39}$, they are also capable of forming de novo gap junctions with primary human cardiomyocytes. Figure I shows HESC-CM co-cultured with primary human fetal cardiomyocytes; injection of the dye "Lucifer Yellow" into the HESC-CM results in rapid transfer of the dye via gap junctions, into the underlying primary cardiomyocytes. Counterstaining the cells post-fixation with an antibody recognizing tropomyosin confirms that dye transfer takes place between the cardiomyocytes. This ability to couple with primary cardiomyocytes was not observed in skeletal myoblasts. Despite their immaturity, HESC-CM may still be useful in understanding the activity of some pharmacological agents in (adult) human CMs e.g. the L-type $\mathrm{Ca}^{2+}$ channel is inhibited by verapamil, indicating that it is already coupled to downstream signaling pathways, as in postnatal CMs. For other purposes, mature human CMs may be required. Possibilities for achieving this in culture range from prolonged cyclic stretch, to forced electrical pacing and biochemical activation of Reactive Oxygen Species (ROS). ROS are considered downstream mediators of mechanical stress signals in cells ${ }^{50}$. HESCs can provide useful information on the molecular mechanisms controlling early differentiation in the human heart. Analysis of gene expression by microarray during HESC-CM differentiation ${ }^{46}$ showed that apart from identifying most known cardiac transcription factors and structural protein genes, we observed upregulation of phospholamban, MEF2C, TBX2 and TBX5 and multiple 
known genes not previously associated with cardiac development and several unexpected genes enriched or even uniquely expressed in the heart. Some of these are conserved across species and included the synaptopodin like-2 gene, related to myopodin, and SRD5A2L2, a gene primarily known for its function in converting testosterone to its active form, hydroxy-testosterone. The restricted expression pattern of this gene in both mouse and human fetal heart is intriguing; further analysis by deletion in the mouse should shed light on its function, not only in mice but also in relation to congenital heart defects in humans. This reflects a more general strategy using HESCs for functional analysis and gene mining in human development.

\section{: transplantation of ESCS}

Whilst promising as a potential new therapeutic strategy, several questions need to be answered before clinical application of HESC-CM. Assuming they can be produced homogeneously in sufficient numbers, the best way and site to deliver them would still need to be determined. Another important issue is graft rejection. Furthermore, the fate of transplanted ESCs or their derivatives would have to be examined in terms of efficacy and safety. Importantly, several authors report transplantation of $\mathrm{mESCs}^{43 ; 51-58}$, but experience with transplantation of HESC-CM is still very limited ${ }^{48 ; 59-61}$.

\section{Animal models}

Rodents have mainly been used for transplantation of ESCs into either uninjured 43:51;56;60;62 or infarcted ${ }^{51-54: 57-59 ; 63}$ hearts. Gentically marked transgenic animals are available and fewer cells are needed for relatively large cardiac grafts. However, larger animals will eventually be indispensable for testing compatibility with human physiology. Studies in mice may not reliably predict generation of arrhythmias by transplanted cells, since at a beating frequency of $\sim 500 \mathrm{bpm}$ the mouse heart may well override any arrhythmia caused by ectopic pacemaker activity. One group has specifically created an AV-block in a swine model to evaluate the (ar)rhythmogenic potential of HESC-derived cardiomyocytes ${ }^{48}$. 
Table 1

\begin{tabular}{lll}
\hline Cell type & Abbreviation & Origin \\
\hline Bone marrow derived cell & BMPC & Bone marrow \\
Skeletal myoblast & SM & Adult skeletal muscle \\
Cardiomyocyte progenitor cel & CMPC & Adult or fetal heart \\
Cardiac stem cell & & \\
Endothelial progenitor cell/ & EPC & Bone marrow/ \\
endothelial precursor cell & & peripheral blood \\
Embryonic stem cell & ESC & Blastocyst stage embryos \\
\hline
\end{tabular}

\section{Methods of cell delivery}

Intramyocardial injection of $10,000-500,000 \mathrm{mESCs}$ or 5-150 beating areas from HESCs with a small needle ( 21 to 30 gauge, depending on the size of the animal) is the most commonly used technique to deliver ESCs to the heart. Target regions can be either the normal myocardium, the infarcted area or the border zone, or a combination of these. Unfortunately, a variable and often relatively small proportion of the transplanted cells is successfully delivered to and survives in the host myocardium. An alternative approach would be the combination of cells with a (degradable) matrix compound ${ }^{64}$ or a cocktail of survival factors that may inhibit apoptosis (Laflamme, Murry 2006, personal communication). Such a strategy may have the advantage of both preventing cell loss and forming a temporary support for the thinned infarcted wall. Upscale methods for HESCs are still under development.

\section{Immune rejection}

It has been postulated that HESCs, like mESCs ${ }^{65}$, lack MHC protein expression and, therefore, do not evoke an immune response in the host. However, a recent study showed that HESCs do express MHC class I molecules ${ }^{66}$ albeit at low levels and expression increased upon differentiation in vitro, an effect enhanced by interferon- $\gamma$. Transplantation of differentiated ESCs in an in vivo model could enhance MHC protein levels in a similar way. On the other hand, the myocardium may be a relatively hospitable environment in terms of immune response ${ }^{67}$. However, after injury (Ml or needle stick manipulation), inflammation 
occurs which could trigger the recruitment of immunoreactive cells.

Several authors used immune competent, though in some cases syngeneic, wildtype animals and yet reported graft integration. However, direct comparisons of immunodeficient mice with immunocompetent counterparts have supported the view that mESCs do trigger the immune system ${ }^{58 ; 68 ; 69}$. In a study with mESCs, cyclosporin was administered to rats in order to prevent immune rejection ${ }^{56}$. HESCs were reported to be less susceptible to immune rejection than adult cells, even when differentiated. Yet, the studies undertaken with HESCs published so far do not reflect confidence in this immune privilege: a combination of cyclosporin and methylprednisolon was administered to pigs ${ }^{48}$ or immunodeficient rodents were used ${ }^{59 ; 60}$. It is not clear whether these were purely preventive measures or previous trials with immune competent hosts had been unsuccessful. Of note is the difference in MHC protein expression between mESCs and HESCs; their immunogenic potentials are therefore not equivalent. The degree of immunosuppression necessary thus remains to be determined for HESC-CM. A possible solution for graft rejection is banking of HECS with a range of HLA profiles or induction of immunotolerance in the recipient ${ }^{67}$. Nuclear transfer could in principle be used to create patientspecific non-immunogeneic stem cell lines. The nucleus of an adult cell from a recipient patient would be transferred into a donated oocyte. When the oocytes reach the blastocyst stage, HESC lines could be derived that were genetically identical to the donor of the nucleus. Recently discredited reports from Korea have made clear that this has not yet been achieved in humans and is likely to remain highly inefficient and ethically sensitive. A better strategy, also in terms of cost-effectiveness and availability in acute disease, would be to modify ESCs to become universal non-immunogenic cells, for example by knockout of the $\beta-2$ microglobulin gene which controls $\mathrm{MHC}-\mathrm{I}$ presentation ${ }^{70}$.

\section{Functional assessment}

The goal of cardiomyocyte cell transplantation is to improve survival rate of patients following $\mathrm{MI}$ and to improve cardiac performance. Methods of assessing cardiac function include electrocardiography (ECG) ${ }^{48: 53 ; 61}$, measurements of cardiac pressure ${ }^{58: 63}$, echocardiography ${ }^{53 ; 54 ; 58 ; 63}$, and electrophysiological mapping 
48;61. Magnetic resonance imaging (MRI) has been performed to locate transplanted $\mathrm{mESCs}{ }^{52}$. Each of these methods has its own advantages and drawbacks. ECG is inexpensive and widely available, but has no value in assessing dynamic function. Direct pressure measurements provide more information on left ventricular function but are limited unless combined with volume measurements, and are technically more challenging. However, with the requisite specialized equipment and a skilled investigator, measuring pressure-volume loops with a conductancemicromanometer is an outstanding way to evaluate cardiac performance after ESC transplantation ${ }^{71}$. Echocardiography and MRI are both appealing techniques as they present direct and easily interpretable images of both cardiac kinetics and morphology. Although to date there is significantly more experience with the commonly used echocardiographic visualization, MRI is expected eventually to become the method of first choice because of its higher resolution and accuracy and additional options such as in vivo infarct size measurements ${ }^{72}$.

\section{Tissue engineering}

Direct injection of pre-differentiated cardiomyocytes may be one approach to a cell-based therapy but the concept of regenerating diseased myocardium by implantation of tissue-engineered heart muscle is also intriguing. The first convincing evidence that heart tissues can be produced at a size and with contractile properties that would lend support to a failing heart was recently described by Zimmerman et al. ${ }^{73}$. Large, thick rings of force-generating heart tissue were created by seeding fetal rat heart cells with liquid collagen type I and Matrigel in moulds and culturing them at elevated ambient oxygen under autotonic load. The rings were then stacked and stitched onto infarcted rat hearts. After a month, the engineered tissue had survived, coupled to the underlying myocardium and prevented further dilation of the heart compared to noncontractile control rings without cells or shams. In addition, systolic wall thickening was induced and fractional shortening of the infarcted hearts was improved. The next steps are taking these studies towards using human embryonic stem cells differentiating to cardiomycoytes in tissue engineered structures which may ultimately provide a better strategy for treating heart failure which may be less amenable to direct cell therapy than myocardial infarction. 


\section{CMPCs}

Increasing evidence indicates that the myocardium harbors several different types of precursor cells (i.e. CPCs and CSCs) that can (re)enter the cell cycle and differentiate to mature cardiomyocytes. Although their name suggests otherwise, the distinction between CPCs and CSCs is not always clear; they may very well represent different stages of the same type of cell or subsets of a more broadly defined cell population found in the heart.

A population of stem cells that possessed the ability to efflux Hoechst was isolated from post-natal mouse hearts. These cells, representing $\sim 1 \%$ of the total cell number in the adult heart, were shown to enter the cell cycle when growth of the heart was attenuated and be capable of cell fusion ${ }^{74}$.

In another study, small stem cells with a high nucleus-to-cytoplasm ratio were isolated from hearts of $\sim 2$-year-old Fischer rats using fluorescence activated cell sorting and immunomagnetic microbeads ${ }^{75}$. These cells were self-renewing, clonogenic, multipotent, and positive for stem cell markers like c-kit, while negative for markers of the blood lineage (Lin), myocytes, endothelial cells and fibroblasts. Notably, 7-10\% of the Lin- c-kit ${ }^{+}$cells showed positive for transcription factors Nkx2.5, GATA-4 and MEF2C, which are expressed early in the myocyte lineage ${ }^{76-78}$, suggesting that the population is heterogeneous and contains cells already committed to the cardiomyocyte lineage. In vitro, the Lin $^{-}$c-kit ${ }^{+}$cells gave rise to immature cardiac myocytes, smooth muscle cells, and endothelial cells. Remarkably, they not only formed new myocardium, but also exhibited improved cardiac function, when injected into the myocardium of infarcted rats ${ }^{75}$.

As the study described above, a cell population expressing stem cell antigenI (Sca-l) was isolated from adult mouse hearts ${ }^{79}$. As the rat Lin $^{-} \mathrm{c}^{-\mathrm{kit}^{+}}$cells, these mouse Sca- $\mathrm{I}^{+}$cells were negative for cardiac structural genes and blood cell lineage markers as well as hematopoetic stem cell markers. In contrast to the rat cardiac progenitors, however, the mouse cells did not express c-kit but did express high levels of cardiogenic transcription factors like GATA-4, MEF$2 \mathrm{C}$ and TEF-I. In response to 5 '-azacytidine, the cells differentiated in vitro to cardiomyocytes and expressed $\mathrm{Nkx2.5, \alpha -myosin} \mathrm{heavy} \mathrm{chain,} \beta$-myosin heavy chain and bone morphogenetic protein (BMP) receptor IA, which are involved in cardiac development. Sca- $\mathrm{I}^{+}$cells delivered intravenously homed to injured 
myocardium after ischemia/reperfusion injury, and were found to differentiate as well as fuse with the host cells ${ }^{79}$. Almost simultaneously, an independent study confirmed the presence of a Sca- $I^{+}$stem cell population in the adult mouse heart. This study described the isolation of Sca- $\mathrm{I}^{+}$cells that expressed cardiac transcription factors and contractile proteins, and showed sarcomeric structure as well as spontaneous beating when treated with oxytocin ${ }^{80}$. This aspect of showing sarcomeric structure is essential in distinguishing reports describing stem cells with a bona fide capacity to form cardiomyocytes from those in which structural protein (and gene) expression is found but the cells show no sarcomeric organization. Several reports claiming the ability of mesenchymal cells of various origins (e.g. bone marrow, umbilical cord blood) to differentiate to cardiac myocytes in fact only show that sarcomeric protein is detectable; the cells do not develop sarcomeres and, probably as a consequence, they do not beat spontaneously.

A heterogenous population of cardiac stem cells was isolated by mild enzymatic digestion of human atrial and ventricular biopsy specimens, and embryo, fetal, and post-natal mouse hearts ${ }^{8}$. These cells formed clonal spherical clusters referred to as cardiospheres expressing endothelial as well as stem cell markers, like c-kit, Sca-I and CD-34. When cultured as single cells on collagen-coated dishes, cardiosphere-derived cells expressed cardiac differentiation markers and, in the case of mouse cells, started spontaneous beating.

Recently, a novel population of cells that are able to proliferate as well as differentiate into cardiac cells has been isolated from rat, mouse and human post-natal hearts. These cells, marked by the expression of isll and the absence of both Sca-I and c-kit, are also abundantly present in the embryonic heart ${ }^{82}$. Whereas is $\mathrm{Il}^{+}$cells express early cardiac differentiation markers like $\mathrm{Nk} \times 2.5$ and GATA-4 they lack transcripts of mature myocytes. When cocultured in vitro with differentiated myocytes, they spontaneously acquired myocyte characteristics, like expression of cardiac specific proteins, contractile activity and electromechanical coupling ${ }^{82}$.

\section{Clinical trials}

Clinical trials of stem cells for cardiac repair have so far used two types of cell: SMs and BMPCs. BMPCs also include a subpopulation of $\mathrm{CD} 34^{+}, \mathrm{CDI} 33^{+}$ cells with hematopoietic and angiogenic potential, referred to as circulating or BMPC-derived EPCs earlier. 


\section{Skeletal myoblasts}

SMs represent an autologous source of cells that demonstrate a contractile phenotype. As such, they represent a logical target when attempting to repair damaged myocardium. To date, SM cells have only been used in trials of heart failure, and not for acute Ml owing to the method of preparation and route of delivery. The use of SMs in humans was first reported by Hagege et al. ${ }^{83}$ in a single patient with recalcitrant heart failure who showed symptomatic and echocardiographic improvement following the epicardial injection (i.e. at the time of bypass surgery) of these autologous cells. Subsequently, a Phase I nonrandomized study of transepicardial myoblast transplantation during coronary artery bypass grafting showed an improvement in symptoms (e.g. breathlessness) and left ventricular ejection fraction (LVEF), as measured by echocardiography. Unfortunately, four out of the ten patients treated experienced ventricular arrhythmia. These patients received internal cardioverter defibrillators ${ }^{84}$. By contrast, no significant ventricular arrhythmias were observed in another Phase I study that recruited 12 patients and again used the transepicardial approach to deliver autologous SMs. This study demonstrated a significant increase in LVEF, as well as improved cardiac viability on positron emission tomography (PET) at three months, suggesting that the recovery of myocardial function was associated with an increase in functional cell mass ${ }^{85}$. A one-year follow-up showed maintenance of the global improvement in cardiac function with no adverse events, including absence of arrythmias ${ }^{86}$. Nevertheless, pre-operative use of anti-arrhythmic therapy or simultaneous implantation of internal defibrillators has been used to address these possible safety issues. Menasche ${ }^{87}$ has recently provided a comprehensive overview of both the controlled trials and case reports studies. As a result of the inconclusive early studies a larger scale clinical trial was undertaken but unfortunately the incidence of arrhythmias was high and sufficient cause for concern that the trial was terminated prematurely. The future of this approach to therapy is presently unclear and awaits careful comparison with the outcome (safety and efficacy) of trials with alternative autologous sources.

\section{BM PCS}

Variable results have been reported in the first clinical trials, four of which are presently complete. Probably the most important trial is the BOOST trial, 
which used MRI to determine LVEF and infarct size. In this study 30 patients were treated with BMPCs intracoronarily within one week of the MI and 30 patients received standard treatment. The early results at 6 months showed a significant improvement of LVEF in the stem cell treated group compared to the controls ${ }^{88}$. This beneficial effect was in part due to an increased end diastolic volume in the stem cell group. More importantly, however, by 18 months the control group had undergone a gradual recovery of LVEF and there was no longer a significant difference between the stem cell treated and control groups ${ }^{89}$. The early modest positive effect that had been observed (6.7\%) was therefore apparently not sustained. In the much larger REPAIR AMI trial, which included 95 patients in the stem cell group, a much smaller early beneficial effect was reported ${ }^{90}$. Unfortunately, however, the LVEF was determined by angiography, a technique not ideal for the assessment of LVEF or infarct size ${ }^{91}$. A third trial with a neutral outcome was conducted in Norway. In this ASTAMI trial 49 patients received stem cells with a similar number as controls. The treatment was safe and, as in the previous studies, no adverse events were reported. However, no beneficial effects of the additional treatment on heart function were observed by nuclear imaging or MRI. Interestingly, a group in Leuven reported on a fourth, smaller, trial $(n=33)$ where no benefit on LVEF was measured by MRI in the stem cell treated group versus controls ${ }^{92}$. However, a reduction of infarct size was observed, together with local improvement of cardiac wall motion. This last study was in fact the only one of the four with a correct placebo control group. Although all four of these trials had shown no adverse effects of stem cell treatment on patients and the consensus was that they appeared safe, enthusiasm was tempered somewhat by a recent report which showed that the application of selected BMPCs enhanced atherosclerotic lesion formation in vessels treated with stem cells ${ }^{93}$. Overall however, it seems that intracoronary BMPC injections are safe and if they have a beneficial effect it is small and not sustained. For the future more larger trials with proper placebo controls will be necessary for a definitive conclusion. Guidelines for such trials were recently published and some of these trials are ongoing (HEBE in the Netherlands, and BOOST II in Germany) ${ }^{18}$.

Selected populations of EPCs, usually derived from peripheral blood of the patient following G-CSF mobilization, have also been included in recent clinical trials. An early study showed no significant difference between using these selected 
cells and unselected BMCs (Dobert et al, 2004), both showing improvement in myocardial viability and perfusion in combination with coronary stenting although no control group was included. Two more recent studies, however, did include a control group. In combination with (drug eluting) stents, significant increases in LVEF (Bartunek et al, 2005; Numaguchi et al, 2006) were observed following intracoronary infusion of cells in patients with acute MI, although there were no differences with controls in patients with "old" MI. However, in one of the studies (Bartunek et al, 2005), cell infusion was associated with increased incidence of intracoronary events. Most of the trials to date assessed cardiac function at 4-6 months after treatment and the long term outcome has not yet been described.

\section{Conclusions}

This review illustrates the complexity of mechanisms underlying recovery from myocardial infarction and the different ways in which transplanted cells might be of benefit. The crucial questions requiring an answer are whether the nature of cells used for transplantation is important, whether their long term survival in the infarct is essential for sustaining functional recovery or is only necessary transiently to rescue ischemic tissue or, indeed, whether effects seen can be attributed to the presence of cells at all. One experiment to test this in animals would be the incorporation of a "suicide gene" into the genome of the cells to be transplanted, transplanting the cells post myocardial infarction and at various times thereafter determining what effect removal of the cells by activation of the suicide pathway has on cardiac function. Observation of reduction towards controls would suggest the presence of cells was necessary at that time point; lack of an effect would suggest the requirement for cells had been lost.

The results of several clinical studies have shown that several different approaches relating to cell-type and delivery appear safe and in some cases there is a statistically significant improvement in parameters of cardiac function. This appears to be related to the size of the initial infarct and the time after infarct at which the cells are delivered to the heart. The question remains on whether this results in a significant biological improvement and which approach to cell therapy, muscle replacement, vascular generation, or both, is most likely 
to improve the prognosis of cardiac patients. It is clear that to date HESCs and CMPCs are the only independently validated source of human cardiomyocytes but the question is still open on whether they will "perform" better in the clinic than the probably safer option of autologous bone marrow.

\section{Acknowledgements}

We thank Leon Tertoolen and Dorien Ward for contributing to figure I. PD and CLM are supported in part by grants from the Bsik programmes "Dutch Platform for Tissue Engineering" and "Stem Cells in Development and Disease", and from ES Cell International.

\section{References}

I. van Laake LW,Van Hoof D, Mummery CL. Cardiomyocytes derived from stem cells. Ann M ed. 2005;37:499512.

2. Muller-Ehmsen J, Whittaker P, Kloner RA, Dow JS, Sakoda T, Long TI, Laird PW, Kedes L. Survival and development of neonatal rat cardiomyocytes transplanted into adult myocardium. J Mol Cell Cardiol. 2002;34:107-116.

3. Dowell JD, Rubart M, Pasumarthi KB, Soonpaa MH, Field LJ. Myocyte and myogenic stem cell transplantation in the heart. Cardiovasc Res. 2003;58:336-350.

4. Laflamme MA, Murry CE. Regenerating the heart. Nat Biotechnol. 2005;23:845-856.

5. Dai W, Hale SL, Kloner RA. Stem cell transplantation for the treatment of myocardial infarction. Transpl Immunol. 2005;15:91-97.

6. Kocher AA, Schuster MD, Szabolcs MJ, Takuma S, Burkhoff D, Wang J, Homma S, Edwards NM, Itescu S. Neovascularization of ischemic myocardium by human bone-marrow-derived angioblasts prevents cardiomyocyte apoptosis, reduces remodeling and improves cardiac function. Nat M ed. 200I;7:430-436.

7. Kloner RA, Jennings RB. Consequences of brief ischemia: stunning, preconditioning, and their clinical implications: part I. Circulation. 200 I; 104:298I-2989.

8. Asahara T, Murohara T, Sullivan A, Silver M, van der ZR, Li T, Witzenbichler B, Schatteman G, Isner JM. Isolation of putative progenitor endothelial cells for angiogenesis. Science. 1997;275:964-967.

9. Crosby JR, Kaminski WE, Schatteman G, Martin PJ, Raines EW, Seifert RA, Bowen-Pope DF. Endothelial cells of hematopoietic origin make a significant contribution to adult blood vessel formation. Circ Res. 2000;87:728-730.

10. Ceradini DJ, Kulkarni AR, Callaghan MJ, Tepper OM, Bastidas N, Kleinman ME, Capla JM, Galiano RD, Levine JP, Gurtner GC. Progenitor cell trafficking is regulated by hypoxic gradients through HIF-I induction of SDF-I. Nat M ed. 2004;10:858-864.

II. Lebrin F, Goumans MJ, Jonker L, Carvalho RL, Valdimarsdottir G, Thorikay M, Mummery C, Arthur HM, ten Dijke P. Endoglin promotes endothelial cell proliferation and TGF-beta/ALKI signal transduction EM BO J. 2004;23:40I8-4028. 
12. Ripa RS, Jorgensen E,Wang Y,Thune J], Nilsson JC, Sondergaard L, Johnsen HE, Kober L, Grande P, Kastrup J. Stem cell mobilization induced by subcutaneous granulocyte-colony stimulating factor to improve cardiac regeneration after acute ST-elevation myocardial infarction: result of the double-blind, randomized, placebo-controlled stem cells in myocardial infarction (STEMMI) trial. Circulation. 2006; I I3: 1 983-1 992.

13. Askari AT, Unzek S, Popovic ZB, Goldman CK, Forudi F, Kiedrowski M, Rovner A, Ellis SG, Thomas JD, DiCorleto PE, Topol EJ, Penn MS. Effect of stromal-cell-derived factor I on stem-cell homing and tissue regeneration in ischaemic cardiomyopathy. Lancet. 2003;362:697-703.

14. Davani S, Deschaseaux F, Chalmers D, Tiberghien P, Kantelip JP. Can stem cells mend a broken heart? Cardiovasc Res. 2005;65:305-316.

15. Dimmeler S, Zeiher AM, Schneider MD. Unchain my heart: the scientific foundations of cardiac repair. J Clin Invest. 2005; I 15:572-583.

16. Smits AM, van Vliet P, Hassink RJ, Goumans MJ, Doevendans PA. The role of stem cells in cardiac regeneration.J Cell M ol M ed. 2005;9:25-36.

17. Dimarakis I, Habib NA, Gordon MY. Adult bone marrow-derived stem cells and the injured heart: just the beginning? Eur J Cardiothorac Surg. 2005;28:665-676.

18. Bartunek J, Dimmeler S, Drexler H, Fernandez-Aviles F, Galinanes M, Janssens S, Martin J, Mathur A, Menasche P, Priori S, Strauer B, Tendera M, Wijns W, Zeiher A. The consensus of the task force of the European Society of Cardiology concerning the clinical investigation of the use of autologous adult stem cells for repair of the heart. Eur Heart J. 2006;27:1338-1340.

19. Orlic D, Kajstura J, Chimenti S, Jakoniuk I, Anderson SM, Li B, Pickel J, McKay R, Nadal-Ginard B, Bodine DM, Leri A, Anversa P. Bone marrow cells regenerate infarcted myocardium. Nature. 200 I;4 I0:70 I-705.

20. Balsam LB, Wagers AJ, Christensen JL, Kofidis T, Weissman IL, Robbins RC. Haematopoietic stem cells adopt mature haematopoietic fates in ischaemic myocardium. Nature. 2004;428:668-673.

21. Murry CE, Soonpaa MH, Reinecke H, Nakajima H, Nakajima HO, Rubart M, Pasumarthi KB, Virag Jl, Bartelmez SH, Poppa V, Bradford G, Dowell JD, Williams DA, Field LJ. Haematopoietic stem cells do not transdifferentiate into cardiac myocytes in myocardial infarcts. Nature. 2004;428:664-668.

22. Amado LC, Saliaris AP, Schuleri KH, St John M, Xie JS, Cattaneo S, Durand DJ, Fitton T, Kuang JQ, Stewart G, Lehrke S, Baumgartner WW, Martin BJ, Heldman AW, Hare JM. Cardiac repair with intramyocardial injection of allogeneic mesenchymal stem cells after myocardial infarction. Proc Natl Acad Sci U S A. 2005; I02: I I 474-I I 479 .

23. Li TS, Hayashi M, Ito H, Furutani A, Murata T, Matsuzaki M, Hamano K. Regeneration of infarcted myocardium by intramyocardial implantation of ex vivo transforming growth factor-beta-preprogrammed bone marrow stem cells. Circulation. 2005; I I :2438-2445.

24. Limbourg FP, Ringes-Lichtenberg S, Schaefer A, Jacoby C, Mehraein Y, Jager MD, Limbourg A, Fuchs M, Klein G, Ballmaier M, Schlitt HJ, Schrader J, Hilfiker-Kleiner D, Drexler H. Haematopoietic stem cells improve cardiac function after infarction without permanent cardiac engraftment. Eur J Heart Fail. 2005;7:722-729.

25. Piao H, Youn TJ, Kwon JS, Kim YH, Bae JW, Bora S, Kim DW, Cho MC, Lee MM, Park YB. Effects of bone marrow derived mesenchymal stem cells transplantation in acutely infarcting myocardium. Eur J Heart Fail. 2005;7:730-738.

26. Tomita S, Li RK, Weisel RD, Mickle DA, Kim EJ, Sakai T, Jia ZQ. Autologous transplantation of bone marrow cells improves damaged heart function. Circulation. 1999; 100:11247-II256.

27. Mangi AA, Noiseux N, Kong D, He H, Rezvani M, Ingwall JS, Dzau VJ. Mesenchymal stem cells modified with Akt prevent remodeling and restore performance of infarcted hearts. Nat M ed. 2003;9:1 195-I 20 I.

28. Reinecke H, Poppa V, Murry CE. Skeletal muscle stem cells do not transdifferentiate into cardiomyocytes after cardiac grafting.J M ol Cell Cardiol. 2002;34:24I-249. 
29. Reinecke H, Minami E, Poppa V, Murry CE. Evidence for fusion between cardiac and skeletal muscle cells. Circ Res. 2004;94:e56-e60.

30. Leobon B, Garcin I, Menasche P,Vilquin JT,Audinat E, Charpak S. Myoblasts transplanted into rat infarcted myocardium are functionally isolated from their host. Proc Natl Acad Sci U SA. 2003; 100:7808-78I I.

31. Reubinoff BE, Pera MF, Fong CY,Trounson A, Bongso A. Embryonic stem cell lines from human blastocysts: somatic differentiation in vitro. Nat Biotechnol. 2000; 18:399-404.

32. Thomson JA, Itskovitz-Eldor J, Shapiro SS, Waknitz MA, Swiergiel JJ, Marshall VS, Jones JM. Embryonic stem cell lines derived from human blastocysts. Science. 1998;282: I I 45- I I 47.

33. Evans MJ, Kaufman MH. Establishment in culture of pluripotential cells from mouse embryos. Nature. 1981;292:154-156.

34. Martin GR. Isolation of a pluripotent cell line from early mouse embryos cultured in medium conditioned by teratocarcinoma stem cells. Proc N atl Acad Sci U SA. I98I;78:7634-7638.

35. Kehat I, Kenyagin-Karsenti D, Snir M, Segev H, Amit M, Gepstein A, Livne E, Binah O, Itskovitz-Eldor J, Gepstein L. Human embryonic stem cells can differentiate into myocytes with structural and functional properties of cardiomyocytes. J Clin Invest. 2001;108:407-4I4.

36. Xu C, Police S, Rao N, Carpenter MK. Characterization and enrichment of cardiomyocytes derived from human embryonic stem cells. Circ Res. 2002;91:50I-508.

37. He JQ, Ma Y, Lee Y, Thomson JA, Kamp TJ. Human embryonic stem cells develop into multiple types of cardiac myocytes: action potential characterization. Circ Res. 2003;93:32-39.

38. Mummery C, Ward D, van den Brink CE, Bird SD, Doevendans PA, Opthof T, Brutel dIR, Tertoolen L, van der HM, Pera M. Cardiomyocyte differentiation of mouse and human embryonic stem cells. J Anat. 2002;200:233-242.

39. Mummery C, Ward-van Oostwaard D, Doevendans P, Spijker R, van den BS, Hassink R, van der HM, Opthof T, Pera M, de la Riviere AB, Passier R, Tertoolen L. Differentiation of human embryonic stem cells to cardiomyocytes: role of coculture with visceral endoderm-like cells. Circulation. 2003; 107:2733-2740.

40. Allegrucci C, Young LE. Differences between human embryonic stem cell lines. RBM Online. 2006;in press.

4I. Passier R, Denning C, Mummery C. Cardiomyocytes from human embryonic stem cells. Handb Exp Pharmacol. 2006;101-122.

42. Dang SM, Zandstra PW. Scalable production of embryonic stem cell-derived cells. M ethods Mol Biol. 2005;290:353-364.

43. Klug MG, Soonpaa MH, Koh GY, Field LJ. Genetically selected cardiomyocytes from differentiating embronic stem cells form stable intracardiac grafts. J Clin Invest. 1996;98:216-224.

44. Meyer N, Jaconi M, Landopoulou A, Fort P, Puceat M. A fluorescent reporter gene as a marker for ventricular specification in ES-derived cardiac cells. FEBS Lett. 2000;478:I5I-I 58.

45. Muller M, Fleischmann BK, Selbert S, Ji GJ, Endl E, Middeler G, Muller OJ, Schlenke P, Frese S, Wobus AM, Hescheler J, Katus HA, Franz WM. Selection of ventricular-like cardiomyocytes from ES cells in vitro. FASEB J. 2000; I 4:2540-2548.

46. Beqqali A, Kloots J, Ward-van Oostwaard D, Mummery C, Passier R. Genome-wide transcriptional profiling of human embryonic stem cells differentiating to cardiomyocytes. Stem Cells. 2006.

47. Fijnvandraat AC, van Ginneken AC, Schumacher CA, Boheler KR, Lekanne Deprez RH, Christoffels VM, Moorman AF. Cardiomyocytes purified from differentiated embryonic stem cells exhibit characteristics of early chamber myocardium. J M ol Cell Cardiol. 2003;35: I46I-I472.

48. Kehat I, Khimovich L, Caspi O, Gepstein A, Shofti R, Arbel G, Huber I, Satin J, Itskovitz-Eldor J, Gepstein L. Electromechanical integration of cardiomyocytes derived from human embryonic stem cells. $\mathrm{Nat}$ Biotechnol. 2004;22:1282-1289. 
49. Chuva de Sousa Lopes SM, Hassink RJ, Feijen A, van Rooijen MA, Doevendans PA, Tertoolen L, Brutel dIR, Mummery CL. Patterning the heart, a template for human cardiomyocyte development. Dev Dyn. 2006;235: 1994-2002.

50. Hool LC. Reactive oxygen species in cardiac signalling: from mitochondria to plasma membrane ion channels. Clin Exp Pharmacol Physiol. 2006;33:146-151.

5I. Behfar A, Zingman LV, Hodgson DM, Rauzier JM, Kane GC, Terzic A, Puceat M. Stem cell differentiation requires a paracrine pathway in the heart. FASEB J. 2002;16:1558-1566.

52. Himes N, Min JY, Lee R, Brown C, Shea J, Huang X, Xiao YF, Morgan JP, Burstein D, Oettgen P. In vivo MRI of embryonic stem cells in a mouse model of myocardial infarction. Magn Reson Med. 2004;52:12।41219.

53. Hodgson DM, Behfar A, Zingman LV, Kane GC, Perez-Terzic C, Alekseev AE, Puceat M, Terzic A. Stable benefit of embryonic stem cell therapy in myocardial infarction. Am J Physiol Heart Circ Physiol. 2004;287: H47I-H479.

54. Kofidis T, de Bruin JL, Yamane T, Balsam LB, Lebl DR, Swijnenburg RJ, Tanaka M, Weissman IL, Robbins RC. Insulin-like growth factor promotes engraftment, differentiation, and functional improvement after transfer of embryonic stem cells for myocardial restoration. Stem Cells. 2004;22:1239- 1245.

55. Min JY,Yang Y, Converso KL, Liu L, Huang Q, Morgan JP, Xiao YF.Transplantation of embryonic stem cells improves cardiac function in postinfarcted rats. J Appl Physiol. 2002;92:288-296.

56. Naito H, Nishizaki K, Yoshikawa M, Yamada T, Satoh H, Nagasaka S, Kiji T, Taniguchi S. Xenogeneic embryonic stem cell-derived cardiomyocyte transplantation. Transplant Proc. 2004;36:2507-2508.

57. Singla DK, Hacker TA, Ma L, Douglas PS, Sullivan R, Lyons GE, Kamp TJ. Transplantation of embryonic stem cells into the infarcted mouse heart: formation of multiple cell types.J M ol Cell Cardiol. 2005.

58. Yang Y, Min JY, Rana JS, Ke Q, Cai J, Chen Y, Morgan JP, Xiao YF.VEGF enhances functional improvement of postinfarcted hearts by transplantation of ESC-differentiated cells. J Appl Physiol. 2002;93: I 140-I I5I.

59. Kofidis T, LebI DR, Swijnenburg RJ, Greeve JM, Klima U, Gold J, Xu C, Robbins RC.Allopurinol/uricase and ibuprofen enhance engraftment of cardiomyocyte-enriched human embryonic stem cells and improve cardiac function following myocardial injury. Eur J Cardiothorac Surg. 2006;29:50-55.

60. Laflamme MA, Gold J, Xu C, Hassanipour M, Rosler E, Police S, Muskheli V, Murry CE. Formation of human myocardium in the rat heart from human embryonic stem cells. Am J Pathol. 2005;167:663-67I.

6I. Xue T, Cho HC, Akar FG, Tsang SY, Jones SP, Marban E, Tomaselli GF, Li RA. Functional integration of electrically active cardiac derivatives from genetically engineered human embryonic stem cells with quiescent recipient ventricular cardiomyocytes: insights into the development of cell-based pacemakers. Circulation. 2005; I I I: I -20.

62. Kofidis T, de Bruin JL, Hoyt G, LebI DR, Tanaka M, Yamane T, Chang CP, Robbins RC. Injectable bioartificial myocardial tissue for large-scale intramural cell transfer and functional recovery of injured heart muscle. JThorac Cardiovasc Surg. 2004;128:571-578.

63. Min JY, Sullivan MF, Yang Y, Zhang JP, Converso KL, Morgan JP, Xiao YF. Significant improvement of heart function by cotransplantation of human mesenchymal stem cells and fetal cardiomyocytes in postinfarcted pigs. Ann Thorac Surg. 2002;74:I568-1575.

64. Kofidis T, Lebl DR, Martinez EC, Hoyt G, Tanaka M, Robbins RC. Novel injectable bioartificial tissue facilitates targeted, less invasive, large-scale tissue restoration on the beating heart after myocardial injury. Circulation. 2005; I I 2:1 I73-II77.

65. Tian L, Catt JW, O'Neill C, King NJ. Expression of immunoglobulin superfamily cell adhesion molecules on murine embryonic stem cells. Biol Reprod. 1997;57:56I-568.

66. Drukker M, Katz G, Urbach A, Schuldiner M, Markel G, Itskovitz-Eldor J, Reubinoff B, Mandelboim O, Benvenisty N. Characterization of the expression of MHC proteins in human embryonic stem cells. Proc Natl Acad Sci U S A. 2002;99:9864-9869. 
67. Drukker M, Benvenisty N.The immunogenicity of human embryonic stem-derived cells. Trends Biotechnol. 2004;22:|36-|4|.

68. Kofidis T, deBruin JL, Tanaka M, Zwierzchoniewska M, Weissman I, Fedoseyeva E, Haverich A, Robbins RC. They are not stealthy in the heart: embryonic stem cells trigger cell infiltration, humoral and Tlymphocyte-based host immune response. Eur J Cardiothorac Surg. 2005;28:46I-466.

69. Swijnenburg RJ, Tanaka M, Vogel H, Baker J, Kofidis T, Gunawan F, Lebl DR, Caffarelli AD, de Bruin JL, Fedoseyeva EV, Robbins RC. Embryonic stem cell immunogenicity increases upon differentiation after transplantation into ischemic myocardium. Circulation. 2005; I I2:II 66-II 72.

70. Zijlstra M, Bix M, Simister NE, Loring JM, Raulet DH, Jaenisch R. Beta 2-microglobulin deficient mice lack CD4-8+ cytolytic T cells. Nature. 1990;344:742-746.

7I. Lips DJ, van der NT, Steendijk P, Palmen M, Janssen BJ, van Dantzig JM, de Windt LJ, Doevendans PA Left ventricular pressure-volume measurements in mice: comparison of closed-chest versus open-chest approach. Basic Res Cardiol. 2004;99:35I-359.

72. Devlin AM, Moore NR, Ostman-Smith I.A comparison of MRI and echocardiography in hypertrophic cardiomyopathy. Br J Radiol. 1999;72:258-264.

73. Zimmermann WH, Melnychenko I,Wasmeier G, Didie M, Naito H, Nixdorff U, Hess A, Budinsky L, Brune K, Michaelis B, Dhein S, Schwoerer A, Ehmke H, Eschenhagen T. Engineered heart tissue grafts improve systolic and diastolic function in infarcted rat hearts. Nat M ed. 2006; 12:452-458.

74. Hierlihy AM, Seale P, Lobe CG, Rudnicki MA, Megeney LA. The post-natal heart contains a myocardial stem cell population. FEBS Lett. 2002;530:239-243.

75. Beltrami AP, Barlucchi L, Torella D, Baker M, Limana F, Chimenti S, Kasahara H, Rota M, Musso E, Urbanek K, Leri A, Kajstura J, Nadal-Ginard B, Anversa P. Adult cardiac stem cells are multipotent and support myocardial regeneration. Cell. 2003; I 14:763-776.

76. Lin Q, Schwarz J, Bucana C, Olson EN. Control of mouse cardiac morphogenesis and myogenesis by transcription factor MEF2C. Science. 1997;276: I 404-1407.

77. Lints TJ, Parsons LM, Hartley L, Lyons I, Harvey RP. Nkx-2.5: a novel murine homeobox gene expressed in early heart progenitor cells and their myogenic descendants. Development. 1993;1 19:4 19-43I.

78. Watt AJ, Battle MA, Li J, Duncan SA. GATA4 is essential for formation of the proepicardium and regulates cardiogenesis. Proc Natl Acad Sci U S A. 2004; 101:12573-12578.

79. Oh H, Bradfute SB, Gallardo TD, Nakamura T, Gaussin V, Mishina Y, Pocius J, Michael LH, Behringer RR, Garry DJ, Entman ML, Schneider MD. Cardiac progenitor cells from adult myocardium: homing, differentiation, and fusion after infarction. Proc Natl Acad Sci U SA. 2003; 100:123 |3-123 I8.

80. Matsuura K, Nagai T, Nishigaki N, Oyama T, Nishi J, Wada H, Sano M, Toko H, Akazawa H, Sato T, Nakaya $\mathrm{H}$, Kasanuki H, Komuro I. Adult cardiac Sca-I-positive cells differentiate into beating cardiomyocytes. J Biol Chem. 2004;279: | |384- I |39|.

8I. Messina E, De Angelis L, Frati G, Morrone S, Chimenti S, Fiordaliso F, Salio M, Battaglia M, Latronico MV, Coletta M,Vivarelli E, Frati L, Cossu G, Giacomello A. Isolation and expansion of adult cardiac stem cells from human and murine heart. Circ Res. 2004;95:911-921.

82. Laugwitz KL, Moretti A, Lam J, Gruber P, Chen Y,Woodard S, Lin LZ, Cai CL, Lu MM, Reth M, Platoshyn O, Yuan JX, Evans S, Chien KR. Postnatal isl I + cardioblasts enter fully differentiated cardiomyocyte lineages. Nature. 2005;433:647-653.

83. Hagege AA, Carrion C, Menasche P,Vilquin JT, Duboc D, Marolleau JP, Desnos M, Bruneval P.Viability and differentiation of autologous skeletal myoblast grafts in ischaemic cardiomyopathy. Lancet. 2003;361:491492.

84. Menasche P, Hagege AA, Vilquin JT, Desnos M,Abergel E, Pouzet B, Bel A, Sarateanu S, Scorsin M, Schwartz K, Bruneval P, Benbunan M, Marolleau JP, Duboc D. Autologous skeletal myoblast transplantation for severe postinfarction left ventricular dysfunction. J Am Coll Cardiol. 2003;4I:I078-1083. 
85. Herreros J, Prosper F, Perez A, Gavira JJ, Garcia-Velloso MJ, Barba J, Sanchez PL, Canizo C, Rabago G, Marti-Climent JM, Hernandez M, Lopez-Holgado N, Gonzalez-Santos JM, Martin-Luengo C, Alegria E. Autologous intramyocardial injection of cultured skeletal muscle-derived stem cells in patients with non-acute myocardial infarction. Eur Heart J. 2003;24:2012-2020.

86. Gavira JJ, Herreros J, Perez A, Garcia-Velloso MJ, Barba J, Martin-Herrero F, Canizo C, Martin-Arnau A, Marti-Climent JM, Hernandez M, Lopez-Holgado N, Gonzalez-Santos JM, Martin-Luengo C, Alegria E, Prosper F.Autologous skeletal myoblast transplantation in patients with nonacute myocardial infarction: I-year follow-up. JThorac Cardiovasc Surg. 2006; 131:799-804.

87. Menasche P. Skeletal myoblast transplantation for cardiac repair. Expert Rev Cardiovasc Ther. 2004;2:2128.

88. Wollert KC, Meyer GP, Lotz J, Ringes-Lichtenberg S, Lippolt P, Breidenbach C, Fichtner S, Korte T, Hornig B, Messinger D, Arseniev L, Hertenstein B, Ganser A, Drexler H. Intracoronary autologous bonemarrow cell transfer after myocardial infarction: the BOOST randomised controlled clinical trial. Lancet. 2004;364:141-148.

89. Meyer GP,Wollert KC, Lotz J, Steffens J, Lippolt P, Fichtner S, Hecker H, Schaefer A,Arseniev L, Hertenstein B, Ganser A, Drexler H. Intracoronary bone marrow cell transfer after myocardial infarction: eighteen months' follow-up data from the randomized, controlled BOOST (BOne marrOw transfer to enhance ST-elevation infarct regeneration) trial. Circulation. 2006; I 13:1 287-1 294.

90. Cleland JG, Freemantle N, Coletta AP, Clark AL. Clinical trials update from the American Heart Association: REPAIR-AMI, ASTAMI, JELIS, MEGA, REVIVE-II, SURVIVE, and PROACTIVE. Eur J Heart Fail. 2006;8:105-II0.

91. Schachinger V, Tonn T, Dimmeler S, Zeiher AM. Bone-marrow-derived progenitor cell therapy in need of proof of concept: design of the REPAIR-AMI trial. Nat Clin Pract Cardiovasc M ed. 2006;3 Suppl I:S23-S28.

92. Janssens S, Dubois C, Bogaert J, Theunissen K, Deroose C, Desmet W, Kalantzi M, Herbots L, Sinnaeve P, Dens J, Maertens J, Rademakers F, Dymarkowski S, Gheysens O, Van Cleemput J, Bormans G, Nuyts J, Belmans A, Mortelmans L, Boogaerts M,Van de WF.Autologous bone marrow-derived stem-cell transfer in patients with ST-segment elevation myocardial infarction: double-blind, randomised controlled trial. Lancet. 2006;367:II3-121.

93. Mansour S,Vanderheyden M, De Bruyne B,Vandekerckhove B, Delrue L,Van H, I, Heyndrickx G, Carlier S, Rodriguez-Granillo G,Wijns W, Bartunek J. Intracoronary delivery of hematopoietic bone marrow stem cells and luminal loss of the infarct-related artery in patients with recent myocardial infarction. J Am Coll Cardiol. 2006;47:1727-1730. 


\section{Monitoring of cell therapy and assessment of cardiac function using magnetic resonance imaging in a mouse model of myocardial infarction}

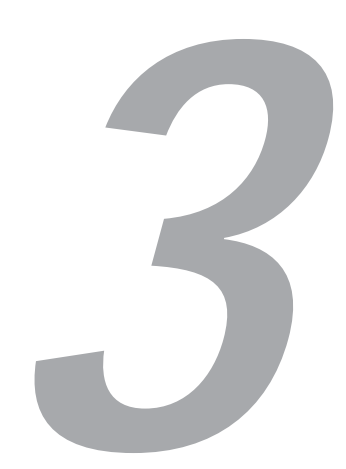

Published as

L.W. van Laake, R. Passier, J. Monshouwer-Kloots, M.G. Nederhoff, D.Ward-Van Oostwaard, L.J. Field, C. J.Van Echteld, P. A. Doevendans, C. L. Mummery. Monitoring of cell therapy and assessment of cardiac function using magnetic resonance imaging in a mouse model of myocardial infarction. Nature Protocols. 2007;2(10):255I-67 


\section{Abstract}

We have developed a mouse (SCID; severe combined immunodeficient) model of myocardial infarction based on permanent left anterior descending coronary artery occlusion which allows long term functional analysis of engrafted human embryonic stem cell-derived cardiomyocytes, genetically marked with green fluorescent protein (GFP), in the mouse heart. We describe methods for delivery of dissociated cardiomyocytes to the left ventricle that minimize scar formation, visualization and validation of the identity of the engrafted cells using the GFP emission spectrum, and histological techniques compatible with GFP epifluorescence, for monitoring phenotypic changes in the grafts in vivo. In addition, we describe how magnetic resonance imaging (MRI) can be adapted for use in mice to monitor cardiac function non-invasively and repeatedly. The model can be adapted to include multiple control or other cell populations. The procedure for a cohort of 6 mice can be completed in 13 weeks maximum, depending on follow-up time, with 30 hours of hands-on time.

\section{Introduction}

Cardiomyocyte (CM) replacement as a potential therapy for cardiac failure is of growing interest now that mechanisms underlying the possible benefit of interventions with cells lacking intrinsic cardiomyogenic activity are becoming clear. The most prevalent form of heart failure follows myocardial infarction (MI). It is thought that damage to the heart may be prevented, attenuated or repaired by cell-mediated myocardial regeneration or paracrine effects from the transplanted cells'. Strategies to date have tested several cell types, including skeletal myoblasts, fetal cardiomyocytes, bone marrow-derived cells (BMCs), mesenchymal stem cells (MSCs) and embryonic stem cells (ESCs) or their derivatives, in experimental animals and determined their capacity to improve structural and kinetic function of the infarcted heart. Most studies have reported positive effects of cell transplantation on cardiac structure or function post-MI, independent of the cell type used and whether injection was intravenously or intramyocardially. Beneficial effects have also been reported even when transplanted cells were no longer detectable in the myocardium ${ }^{2 ; 3}$. 
However, in nearly all cases follow-up was limited to short- and mid-term (2 to 6 weeks) ${ }^{4-7}$. Recent translation of BMC treatments to the clinic in controlled trials has also shown in some cases transient early functional improvements but disappointing late effects ${ }^{8}$. We recently found that in cell transplantation studies, mid-term results may differ considerably from and not predict long term outcome even when using myocytes for replacement ${ }^{9}$. As a consequence, reported short- and mid-term functional improvements by any cell type should be re-evaluated, as sustained enhancement of heart function and prevention of heart failure should also be the "holy grail" in pre-clinical studies just as in translation to the clinic. Unfortunately, in experimental animals large Mls are a prerequisite for keeping infarct size constant; as a result long term survival is often low and large numbers of animals are needed to obtain meaningful results for changes in heart function. With the technically refined protocol we provide here, large infarcts can be made that are compatible with long-term survival, reducing overall the numbers of animals necessary for statistically significant conclusions on the outcome of treatment.

Previously, an ischemia-reperfusion model of $\mathrm{MI}$ in rats was described in which intramyocardially injected human mesenchymal stem cells were monitored using immunohistochemical techniques ${ }^{10}$. We have extended the Ml model to mice but now using permanent occlusion which gives larger and even more reproducible infarct size. Although operations on mice are more difficult because of their size, they are of special interest because of the repertoire of mutants available. In order to prevent the need for immunosuppressive therapy, which is very difficult to maintain in mice for longer periods without inducing toxicity and local irritation, we use non-obese diabetic severe combined immunodeficient (NOD-SCID) mice. These mice lack B-cells, T-cells and natural killer cells and therefore are protected from immune rejection of transplanted cells. It is of note that immunodeficiency may also slow or reduce the response to myocardial infarction and therefore a long follow-up is strongly recommended. Other mutants of interest are mice susceptible to (age-related) cardiac hypertrophy or dilatation", impaired neo-angiogenesis ${ }^{12}$ or other clinically relevant defects (for review see ${ }^{13}$ ). 
The most commonly used non- or minimally-invasive methods for analysis of cardiac function are echocardiography and pressure-volume loop analyses. These approaches may provide complementary information and can be valuable as an addition to MRI, yet they have a number of drawbacks. Echocardiography has limited accuracy due to low resolution and an intrinsic subjectivity with respect to external placement of the probe; it thus requires relatively large animal groups to generate statistically significant data. Pressure-volume loop analysis on the other hand is a gold standard for assessing cardiac function accurately but it is not readily amenable to longitudinal studies and is technically very challenging. MRI represents a state-of-the-art alternative with superior resolution as compared to echocardiography and once adapted to mice, as here, can be used repeatedly on the same cohort of mice without major impact on their well being.

The mouse MI model we describe is compatible with high survival rates over extended periods (tested up to 3 months) and can be adapted to include multiple control or other cell populations. We used human ESCs (HESCs) since these, in spite of their ethical sensitivity, have several important properties that make them excellent candidates for cardiac regeneration therapies. They proliferate indefinitely in culture whilst retaining pluripotency and can be directed to differentiate reproducibly and now with reasonable efficiency into CMs, for example by co-culturing them with a visceral endoderm-like cell line END-2. 14;15. Only CMs or their precursors ${ }^{16 ; 17}$, whether originating from donor cells directly or from host cells activated in situ, will be able to contribute long term contractile activity to the myocardium.

Methods for genetic modification of HESCs have been improved and cell lines are available now that express GFP stably in all progeny. Among these is the HES3GFP cell line Envy $18 ; 19$ we have used here. We and others reported previously that injection of a mixed population of differentiated HESCs, surprisingly results in mainly the cardiomyocytes surviving in the heart ${ }^{9 ; 20}$. We therefore used these cardiomyocyte-enriched differentiated HESC populations to illustrate the procedures for long term tracking of the cells and analysis of their effect on cardiac function. HESC culture and cardiomyocyte differentiation using the END-2 co-culture system have been described in detail previously ${ }^{21: 22}$. 
Tracking of transplanted cells is complicated by several potential sources of artifacts (Supplementary data) that may be introduced by unintentional or intentional injury (needle manipulation or infarction) and inflammation of the tissue, immune activation, and cell death ${ }^{23-27}$. This is especially true when relying on fluorescent read-out, which is in principle a desired approach as it allows multiple antibody staining on the same tissue section. The protocol presented here minimizes tissue damage and thereby not only enhances donor and host cell viability but also reduces damage-induced auto-fluorescence. The chances of misinterpreting data arising from artifacts such as autofluorescence, nonspecific antibody staining and dye-transfer of injected cells when using nongenetic methods for cell marking are further reduced by the combination of genetic tracking with GFP validation and human-specific antibody staining accompanied by multiple controls which should be included to allow robust conclusions (listed in Table 1).

Table 1. Controls

\begin{tabular}{|c|c|c|}
\hline Procedure & Type of control & Description \\
\hline Myocardial infarction & Negative (sham) & $\begin{array}{l}\text { Thoracotomy and opening of } \\
\text { the pericardium }\end{array}$ \\
\hline \multirow[t]{6}{*}{$\begin{array}{l}\text { Cell injection, } \\
\text { immunofluorescence and MRI }\end{array}$} & $\begin{array}{l}\text { Negative (functional improvement, GFP, } \\
\text { human nuclei) }\end{array}$ & No injection \\
\hline & $\begin{array}{l}\text { Negative (functional improvement, GFP, } \\
\text { human nuclei) }\end{array}$ & $\begin{array}{l}\text { Injection of vehicle (e.g. HESC } \\
\text { medium) }\end{array}$ \\
\hline & $\begin{array}{l}\text { Negative (human nuclei, in presence of } \\
\text { inflammation) }\end{array}$ & $\begin{array}{l}\text { Injection of non-human GFP- } \\
\text { expressing cells }\end{array}$ \\
\hline & $\begin{array}{l}\text { Comparison (functional improvement, cell } \\
\text { survival) }\end{array}$ & $\begin{array}{l}\text { Injection of non- } \\
\text { cardiomyocyte HESC-derived } \\
\text { GFP-expressing cells }\end{array}$ \\
\hline & Negative (GFP) & $\begin{array}{l}\text { Injection of human non-GFP } \\
\text { cells }\end{array}$ \\
\hline & Positive (GFP, human nuclei) & $\begin{array}{l}\text { Injection of experimental } \\
\text { human GFP-expressing cells } \\
\text { as usual; sacrifice the mouse } \\
\text { directly after surgery }\end{array}$ \\
\hline \multirow[t]{3}{*}{ Immunofluorescence } & Negative & $\begin{array}{l}\text { Incubation with lgG isotype- } \\
\text { matched control for primary } \\
\text { antibody }\end{array}$ \\
\hline & Positive (GFP, human nuclei, Ki67) & $\begin{array}{l}\text { Cryosections from GFP- } \\
\text { expressing HESCs or beating } \\
\text { areas of GFP-expressing } \\
\text { HESCs }\end{array}$ \\
\hline & Positive (human nuclei) & $\begin{array}{l}\text { Cryosections from human } \\
\text { tissue }\end{array}$ \\
\hline $\begin{array}{l}\text { GFP emission wave length } \\
\text { spectrum }\end{array}$ & Positive & $\begin{array}{l}\text { Cryosections from GFP- } \\
\text { expressing HESCs or beating } \\
\text { areas of GFP-expressing } \\
\text { HESCs }\end{array}$ \\
\hline
\end{tabular}




\title{
Materials
}

\author{
REAGENTS
}

- $\mathrm{NaCl}$ (JT Baker)

- $\mathrm{KCl}$ (Merck)

- $\mathrm{MgSO}_{4}(\mathrm{BDH})$

- Glucose (JT Baker)

- Taurine (Sigma) CAUTION Irritant, wear protective goggles, clothing and gloves as appropriate

- HEPES (Sigma)

- $\mathrm{CaCl}_{2}$ (JT Baker)

- Collagenase A (Roche, cat. no. II08879300I) CAUTION Irritant, wear protective goggles, clothing and gloves as appropriate

- $\mathrm{Na}_{2}$ ATP (Sigma, cat. no. A5394)

- EGTA (Sigma)

- Na pyruvate (Sigma, cat. no. P5280)

- Creatine (Sigma) CAUTION Irritant, wear protective goggles, clothing and gloves as appropriate

- Trypan blue solution (0.4\% (vol/vol), Sigma)

- $\mathrm{Na}_{2} \mathrm{HPO}_{4} \cdot 2 \mathrm{H}_{2} \mathrm{O}$ (JT Baker)

- $\mathrm{NaH}_{2} \mathrm{PO}_{4} \cdot \mathrm{H}_{2} \mathrm{O}$ (Merck)

- Paraformaldehyde (Merck, cat. no. 104005) CAUTION Irritant, wear protective goggles, clothing and gloves as appropriate

- PBS without magnesium and calcium (Sigma, or self-made and autoclaved when used for injection into animals)

- Sucrose (JT Baker)

- Isoflurane (Abbott, cat. no. B506)

- Ethanol $70 \%$ (vol/vol) for disinfection

- Acetone (JT Baker)

- Triton X-I00 (Sigma) CAUTION Irritant, wear protective goggles, clothing and gloves as appropriate

- BSA (Sigma)

- Tween 20 (Sigma)

- Topro-3 (Molecular probes, cat. no. T3605)

- Vectashield (Vector labs)

- Solid drink (Triple A Trading) 


\section{EQUIPM ENT}

- For cell culture: see EQUIPMENT SETUP

- $\mathrm{CO}_{2}$ incubator $\left(\mathrm{CO}_{2}\right.$ at $5 \%$ (vol/vol); humidified, $\mathrm{T} 37^{\circ} \mathrm{C}$, e.g. Incutherm, type Queue)

- $\quad 1.5 \mathrm{ml}$ microcentrifuge tubes (Eppendorf)

- Stereotactic microscope (e.g. Leica MZ6)

- Micro-spring scissors (Fine Science Tools, cat. no. 15000-03)

- Centrifuge (e.g. MSE, type Mistral 1000)

- Surgical tools (see EQUIPMENT SETUP)

- Shaver (Wella, type Contura)

- Stereotactic operation microscope (Leica MZ 9.5) with incorporated light source

- Anesthesia system and compressed oxygen regulator (Vet Tech Solutions, UK) (see EQUIPMENT SETUP)

- Sterile gloves (Kimberly Clark, type Safeskin)

- Mouth masks (3M)

- Mouse ventilator (Hugo-Sacks Elektronik, Germany, type Minivent 845)

- Betadine ointment

- 7-0 Prolene suture BVI75-8, 9.3mm 3/8c (Ethicon, cat.no. EH7402H)

- 5-0 Silk suture (Serag Wiessner, type Seraflex, cat. no. IOI0I7I3)

- Syringes, I ml (BD)

- Needles, 26 G (BD)

- Heating plate or pad to put under surgery panel (custom made or e.g. Inventum, type HNK5I3)

- Heating lamp (Philips, type Intraphil)

- Heating pad for recovery (Inventum, type HNK5I3)

- Thin elastic rubber band

- Tape (Scotch, type 3M pressure sensitive)

- Cotton tip applicators

- MRI 9.4T magnet and accessories (see EQUIPMENT SETUP)

- $10 \mathrm{ml}$ tubes (Greiner)

- Roller bank (Stuart Scientific, type SRTI)

- Tissue freezing medium (Jung)

- Molding cups (Klinipath, cat. no. 305I-P)

- Cryostat (Leica CM 3050)

- Cryostat mounting disc 
- Microtome blades (Feather S35)

- Coated microscope slides (Starfrost, Germany)

- Coplin jars (Omnilabo)

- Glass coverslips (Menzel)

- Confocal laser scanning microscope (see EQUIPMENT SETUP)

\section{REAGENT SETUP}

Dissociation buffers

Three buffers are needed. Volumes are for making $100 \mathrm{ml}$ of each buffer. Buffers should be filtered for sterilization $(0.22 \mu \mathrm{m}$ filter; for enzyme buffer pre-filter with $0.8 \mu \mathrm{m}$ and then $0.22 \mu \mathrm{m}$ filter) and can be stored at $-20{ }^{\circ} \mathrm{C}$. Buffer I (low Ca): IM NaCl $12 \mathrm{ml}, I M \mathrm{KCl} 0.54 \mathrm{ml}$, IM MgSO $0.5 \mathrm{ml}$, IM glucose $2 \mathrm{ml}$, IM Na pyruvate $0.5 \mathrm{ml}, 0.1 \mathrm{M}$ taurine $20 \mathrm{ml}$, IM HEPES I ml. Correct $\mathrm{pH}$ to 6.9 with $\mathrm{NaOH}$. Buffer 2 (enzyme): IM NaCl $12 \mathrm{ml}, \mathrm{IM} \mathrm{KCl} 0.54 \mathrm{ml}, \mathrm{IM} \mathrm{MgSO}_{4} 0.5 \mathrm{ml}$, IM glucose $2 \mathrm{ml}$, IM Na pyruvate $0.5 \mathrm{ml}, 0.1 \mathrm{M}$ taurine $20 \mathrm{ml}$, IM HEPES I ml, $\mathrm{IM} \mathrm{CaCl} 3 \mu \mathrm{l}$, Collagenase A $100 \mathrm{mg}$. Correct $\mathrm{pH}$ to 6.9 with $\mathrm{NaOH}$. Buffer 3 (KB): IM KCl $8.5 \mathrm{ml}, \mathrm{Na}_{2}$ ATP $2 \mathrm{mmol} / \mathrm{L}$, IM $\mathrm{MgSO}_{4} 0.5 \mathrm{ml}$, IM EGTA $0.1 \mathrm{ml}$, IM Na pyruvate $0.5 \mathrm{ml}, 0.1 \mathrm{M}$ creatine $5 \mathrm{ml}$, $0.1 \mathrm{M}$ taurine $20 \mathrm{ml}$. Correct PH to 7.2. Add IM $\mathrm{K}_{2} \mathrm{HPO}_{4} 3 \mathrm{ml}$ as the last step (otherwise a precipitate may form). Just prior to use (after thawing), add IM glucose $20 \mu \mathrm{l}$ per $\mathrm{ml}$ to buffer 3 (if added before freezing this may cause precipitation).

HESC culture medium

DMEM (High Glucose; Invitrogen, cat. no. I1960-044) containing: 2mM Iglutamine (from 200 mM stock; Invitrogen, cat. no. 25030-024; Ix Penicillin/ Streptomycin (from 200x stock; Invitrogen, cat. no. 15070-063); Ix MEM-non essential amino acids (from 100x stock; Invitrogen, cat. no. III40-035); Ix Insulin/Transferrin/Selenium (from 100x stock; Invitrogen, cat. no. 4I400-045); 2-mercapto-ethanol I.8 $\mu \mathrm{l} / \mathrm{ml}$ medium (Invitrogen, cat. no. 3I350-0I0); and 20\% (vol/vol) Fetal Bovine Serum (Hyclone-Perbio)

Mice

12 weeks of age, NOD-SCID males, Charles River Laboratories). Younger mice can be used, but survival is lower. In older mice, the risk of thymoma development increases ${ }^{28}$. NOD-SCID mice are deficient in B-cells, T-cells and 
NK cells to reduce immune rejection of transplanted cells.

CAUTION NOD-SCID mice should be kept under semi-sterile conditions (autoclaved cage, bedding, food and water) and handled with clean gloves, suit and mouth mask.

CAUTION All work involving human or animal subjects must be done in accordance with institutional guidelines and regulations.

Fixation and cryo-protection solutions

- Three stock buffers, one stock fixative and two solutions are needed ${ }^{29}$. Volumes are for making $1000 \mathrm{ml}$ of stock buffer and $1000 \mathrm{ml}$ of each solution. Buffers and solutions can be stored at $-20^{\circ} \mathrm{C}$. Stock buffer I: $0.2 \mathrm{M}$ $\mathrm{Na}_{2} \mathrm{HPO}_{4}: 35.6 \mathrm{~g} \mathrm{Na} \mathrm{HPO}_{4} \cdot 2 \mathrm{H}_{2} \mathrm{O}$ in $1000 \mathrm{ml}$ of ${ }_{d d} \mathrm{H}_{2} \mathrm{O}$ (double-distilled water). Stock buffer 2: $0.2 \mathrm{M} \mathrm{NaH}_{2} \mathrm{PO}_{4} \cdot \mathrm{H}_{2} \mathrm{O}: 27.6 \mathrm{~g} \mathrm{NaH} \mathrm{PO}_{4} \cdot \mathrm{H}_{2} \mathrm{O}$ in 1000 $\mathrm{ml}$ of ${ }_{d d} \mathrm{H}_{2} \mathrm{O}$. Stock buffer 3: $0.24 \mathrm{M}$ Phosphate buffer stock solution $\mathrm{pH}$ 7.2: $6.4 \mathrm{~g} \mathrm{NaH} \mathrm{PO}_{4} \cdot \mathrm{H}_{2} \mathrm{O}+33.8 \mathrm{~g} \mathrm{Na} \mathrm{HPO}_{4} \cdot \mathrm{H}_{2} \mathrm{O}$ in $1000 \mathrm{ml}{ }_{d d} \mathrm{H}_{2} \mathrm{O}$. Stock fixative: $20 \%$ (wt/vol) paraformaldehyde (PFA) in PBS (without calcium and magnesium). Dissolve on a magnetic stirrer at $50{ }^{\circ} \mathrm{C}$. Note: this may take up to 12 hours. Solution I: $385 \mathrm{ml}$ of stock buffer I, II $15 \mathrm{ml}$ of stock buffer 2, sucrose $40 \mathrm{~g}, \mathrm{IM} \mathrm{CaCl} / 20 \mu \mathrm{l}$. Adjust volume to $1000 \mathrm{ml}$ with ${ }_{d d} \mathrm{H}_{2} \mathrm{O}$. Adjust $\mathrm{pH}$ to 7.4; Solution 2: $500 \mathrm{ml}$ of stock buffer $3,500 \mathrm{ml}{ }_{d d} \mathrm{H}_{2} \mathrm{O}$, sucrose $100 \mathrm{~g}$.

CRITICAL STEP the 20\% PFA stock can be frozen in small aliquots and thawed (at $50^{\circ} \mathrm{C}$ ) only once.

Temgesic (Buprenorfinehydrochloride $0.324 \mathrm{mg} / \mathrm{ml}$, Schering-plough)

Dilute I:I0 in PBS. This working solution can be stored at $4{ }^{\circ} \mathrm{C}$ for one month.

\section{Antibodies and dilutions}

The following primary antibodies are needed: mouse anti-human nuclei (Chemicon, cat. no. MABI28I) I:200, mouse anti- $\alpha$-actinin (Sigma, cat. no. A78II) I:800, rabbit anti-Ki67 (Abcam, cat. no. ab833) I:500. The following secondary antibodies are needed: donkey anti-mouse Cy3 (Jackson lab, cat. no. 
7I5-I65-I50) I:250, donkey anti-rabbit Cy3 (Jackson lab, cat. no. 7II-I65-I52) $\mathrm{I}: 250$

\section{EQUIPM ENT SETUP}

Cell Culture

For all culture procedures described here tissue culture, reagent preparation and sterilizing facilities are necessary. Class II Biological Hazard Flow Hoods and laminar flow horizontal draft hoods are used.

\section{Anesthesia system}

See Figla. The system should be connected to a compressed oxygen tank and an isoflurane reservoir. Tubing should connect the system to an induction chamber, nose mask and ventilator. Each of these should be closable separately.

\section{Surgical tools}

See Fig $\mathbf{1 b}$. The following micro-surgical tools are recommended: 2 pairs of small curved forceps, (Fine Science Tools, cat. no. II065-07); Thinner tipped forceps (to perforate intercostal muscles), (Fine Science Tools, cat. no. III5I10); 2 pairs of angled sharp forceps (can be practical to fasten or manipulate with the 7-0 Prolene) (Adument \& Fils Switzerland, 5/45); Needle holder (Fine Science Tools, cat. no. 12060-0I); Blunt Scissors (Fine Science Tools, cat. no. 14018-13); Large iris spring scissors (Aesculap, cat. no. OC482R); Retractor (Fine Science Tools, cat. no. 17002-02)

\section{Surgery Panel}

Surgery panel made from notice-board $(30 \mathrm{~cm} \times 30 \mathrm{~cm}$, hardware shop) laminated with plastic (Fig. 1c). This is used to attach the muscle retractors while retaining maximum flexibility in positioning the mouse.

\section{Anesthesia mask}

To make an anesthesia mask (Fig. 1c) make a tubing connection from the anesthesia outflow to a $10 \mathrm{ml}$ syringe (or similar). To drain the isoflurane, put a $50 \mathrm{ml}$ tube (or similar) around the $10 \mathrm{ml}$ tube and connect it to the air drainer. 
Tube

Hold the sharp end of a $20 \mathrm{G}$ needle against a bench grinder until it is blunt. Remove protuberances with sand paper and flush the tube.

Muscle retractors

These can be hand made by twisting a metal thread around a drawing-pin (Fig. 1d).

Pro Ophta sponge points (Lohmann-Rauscher, cat. no. 14915)

Just before surgery, cut one sponge in thin $(\mathrm{Imm})$ ribbons and halve these using a sterile pair of scissors.

Insulin syringe with incorporated $29 \mathrm{G}$ needle (for cell transplantation) (BD, cat. no. 320926)

The minimum size of the needle depends on the cell type injected; test in vitro recovery of the cells after aspirating and re-plating. Always use the same needle size for all experimental groups. The needle end may be bent, with the lumen at the convex side (Fig. 1e), with the help of a large needle holder (e.g. Fine Science Tools, cat. no. 12010-14) or another pair of other tongs.

MRI

A schematic drawing of the required equipment is shown in Figure 2. It comprises: Water cooling unit for gradients (Haake); 9.4T magnet (Bruker); Pre-amplifiers for RF-signals (Bruker); Console including temperature controlunit and 3 gradient amplifiers (Bruker); PC for registration of physiological parameters; Probe head with $30 \mathrm{~mm}$ quadrature coil (Bruker); PC for MRI and MRS data acquisition and processing; Anesthesia units: 3 gas flow meters and isoflurane vaporizer; Powerlab unit (signal converter/amplifier) (AD Instruments); Trigger unit (in/out ECG, respiration and body temperature) (Rapid Biomedical); Mouse container fitting in probe head with $30 \mathrm{~mm}$ imaging coil; Biosafety cabinet with anesthesia unit. The following software packages are required: Paravision 4 (Bruker); Chart 5 (AD Instruments) and Qmass MR6.I.5 (Medis). We recommend you use the following scanning protocols: (i) "I-Tripilot-i.g.modified" (scout-scan). This protocol employs a non-triggered FLASH sequence with an echo time $T E=1.2 \mathrm{~ms}$, a repetition time $\mathrm{TR}=8.8$ 
ms, a $15^{\circ}$ Gauss pulse with a 0.7 ms duration, a matrix size of $128 \times 128$, a field of view FOV of $30 \mathrm{~mm}, 24$ averages and a total scan time of $26 \mathrm{~s}$, yielding 3 orthogonal I mm slices. (ii) "Cine GEFCZF". This protocol employs a cardiac and respiratory triggered gradient-echo sequence with flow compensation, with $\mathrm{TE}=2 \mathrm{~ms}, \mathrm{TR}=14 \mathrm{~ms}$, a $22^{\circ}$ sinc 3 pulse with a I ms duration, a matrix size of $256 \times 128$ zero-filled to $256, \mathrm{FOV}=30 \mathrm{~mm}, 4$ averages and a total scan time of $80-120 \mathrm{sec}$ (depending on heart rate), yielding a 10 frames cine cycle of a I mm slice.

Confocal laser scanning microscope (e.g. Leica TCS SP2 AOBS confocal on a DM -IRE2 microscope using LCS software (Leica confocal software), or Leica TCS SPE confocal on a DM I4000B microscope using LAS-AF software (Leica application suite- advanced fluorescence)

At least 3 laser lines should be included, e.g. $488 \mathrm{~nm}$ (required for GFP), $532 \mathrm{~nm}$ (cy3), and $633 \mathrm{~nm}$ (Topro-3). Software should include programs for sequential scanning and emission wave length spectrum analysis (lambda scan).

\section{Procedure}

\section{Preparation of cells}

(I) Isolate beating areas or other cell aggregates/ embryoid bodies from (differentiated) HESCs with micro-spring scissors and collect in culture medium. To maximize comparability between the experimental groups of mice, we recommend that in each series of operations several different cell- and control treatments are given. Therefore, isolate and -if appropriate- dissociate experimental cells, control cells, medium injection and other controls in parallel (steps 2-7).

CRITICAL STEP Cell culture, isolation and dissociation steps should be done under sterile conditions

(2) Wash excised tissue in low-Ca (buffer I) at RT (I8-25 ${ }^{\circ} \mathrm{C}$ ) for 30 minutes.

(3) Incubate in enzyme medium (buffer 2) at $37{ }^{\circ} \mathrm{C}$ for 45 minutes (close plate with parafilm before putting in $\mathrm{CO}_{2}$-incubator).

(4) Shake gently in KB medium (buffer 3) at RT for one hour at $100 \mathrm{rpm}$ on a 
non pivoting shaker.

(5) Resuspend aggregates/ clumps in culture medium (hold PI000 pipette with tip against the bottom of the dish and pipette up and down to break up clumps - about 2 to 5 times.

CRITICAL STEP Resuspension of the aggregates is the most important and exacting step: cardiomyocytes can be damaged if they are handled too roughly but pipetting up and down several times is necessary to break up the aggregate and obtain single cardiomyocytes. However for transplantation some small clumps (5-10 cells) are acceptable.

(6) Count the cells, determining cell viability by Trypan blue, and pipette the desired quantity per injection (maximum I million) in a I $\mathrm{ml}$ tube. Centrifuge the cells at a maximum of $450 \mathrm{~g}$ for 4 minutes at RT. Aspirate the supernatant and adjust the final volume to $5 \mu \mathrm{l}$ with fresh culture medium. Gently resuspend the cells in the medium.

CRITICAL STEP Keep the total volume constant and as small as possible, since larger volumes result in more extensive scar formation.

(7) Mark the tubes with a code and put them on ice. Preferably, this is done by someone other than the surgeon so that he/she is blinded and can set up the operation room during the final cell preparation steps.

$M$ yocardial infarction and cell injection

(8) Clean the working area, surgical tools and accessories.

CRITICAL STEP Wear mouth mask, clean white coat or disposable suit and clean gloves and work aseptically throughout this section. Clean instruments before each operation.

(9) Turn on the heating plate so that the overlying surgery panel can warm up, and the heating pad with recovery cage on top of it.

(10) Turn on the anesthesia system, with inflow to the induction chamber open, at $98.2 \% \mathrm{O}_{2} / \mathrm{l} .8 \%$ (vol/vol) isoflurane with flow approximately 2 liter/min (depending on the force of the outflow). 
CRITICAL STEP Keep isoflurane at I.8\% throughout the whole procedure.

(II) Weigh and mark (rings around tail with marker pen) the mouse.

(I2) Place the mouse in the induction chamber.

(13) When the mouse has become unconscious (within I-2 minutes), remove it from the chamber and shave the left side of the chest and the throat area. Wipe away the loose hairs, and then place the mouse back in the chamber.

(14) Open the flow to the mask and ventilator and close the flow to the induction chamber.

(I5) Place the mouse on the surgery panel in a supine position with its nose in the mask and tape both forelimbs. The orientation from the surgeon's viewpoint is vertical, tail down head up (Fig. 3a).

(16) Inject $0.1 \mathrm{ml}$ of diluted Temgesic in the hind limb muscle.

(I7) Cover the shaved area with Betadine using a cotton tip applicator.

(18) Focus the microscope on the throat area.

(19) With blunt scissors and fine rounded forceps, make a midline ventral skin incision of about $\mathrm{I} \mathrm{cm}$ length slightly below the cricoid cartilage. Separate the skin from connective tissue. You now see the salivary glands.

(20) Split the salivary glands on their natural midline division by simultaneously pulling each part sideward with forceps.

(2I) With the same maneuver, split the paratracheal muscles on the midline fascia to expose the trachea in the larynx area (Fig. 3b). Avoid pinching the trachea itself or the adjoining vessels and nerves.

(22) Ensure that the tube is open.

(23) Turn on the ventilator at $200 \mu \mathrm{l} / \mathrm{min}, 200$ strokes/min and move the mouse to a horizontal position, tail left head right, fixed at its front teeth by a rubber band.

CRITICAL STEP Steps 23-25 have to be performed rapidly to prevent the mouse from regaining consciousness during intubation.

(24) Expose the trachea with forceps in the left hand, while sliding the intubation tube carefully into the trachea with the right hand (Fig. 3c). The tube tip is visible through the displayed larynx and trachea. TROUBLESHOOTING 
CRITICAL STEP If the tube is in, but not clearly visible, it is in the esophagus. Remove it and try again. Do not try to force entry by pressure, but change the position of the tube tip.

(25) Connect the tube to the ventilation machine. Close the flow to the mask and re-open flow to the induction chamber (to prevent overflow to the ventilator). Reduce flow rate to $0.8 \mathrm{l} / \mathrm{min}$. Secure the ventilation tubing on the surgery panel with tape.

(26) To position the mouse adequately for the surgery, fix both forelimbs sideward; fix the right hind leg in parallel with the tail and the left hind leg turned to the right side.

(27) With blunt scissors and forceps, make a $\mathrm{I}-\mathrm{I} .5 \mathrm{~cm}$ long skin incision over the left thorax area starting from $\mathrm{I} \mathrm{cm}$ medial of the left axilla in a 45 degrees angle cranialward to the sternum (Fig. 3d). Loosen the skin from the connective tissue/muscle layers by blunt dissection (prodding the scissors under the skin and opening them).

(28) Loosen the major pectoral muscle, move it upward (to the right side of the mouse) using rounded forceps and fix it with a muscle retractor. Carefully cut the sheets of connective tissue which prevent moving the muscle layer with fine scissors. Similarly, loosen up the minor pectoral muscle, move it downward (to the left side of the mouse) and fix it using a second muscle retractor (Fig. 3e). (29) Choose the intercostal space for thoracotomy based on a) curvature (after first rib that is less curved than the rib above), b) vessel landmark (a large vessel runs from outside to inside the thoracic cavity; take the intercostal space just cranially of this vessel), c) lungs (the lower edge of the left lung should be one intercostal space distal, or left from the surgeon's viewpoint, to the thoracotomy). This is usually the space between the $3^{\text {rd }}$ and the $4^{\text {th }}$ rib (Fig 3e).

(30) Perforate the intercostal muscle layer, I mm away from the sternum, by pinching and lightly scratching with small rounded forceps. Once a hole has been made, slide the tips of the (still closed) forceps into it from medial to lateral with the tips parallel to the muscle, thereby avoiding contact with the lungs. Let the forceps tips re-appear through the lateral side of the intercostal muscles, open them slightly and cut along the tips (parallel to the adjacent ribs) with spring scissors (Fig 3f). TROUBLESHOOTING 
(3I) Wet a piece of sponge with PBS and insert it into the thorax to protect the lungs. Now place the chest retractor with 2 of the 3 blunt hooks inserted, open it maximally, and lock it using the screw. Rearrange the sponge if necessary to push away the lung and expose the heart. It may also be helpful to attach an extra hook to the chest retractor (Fig. $\mathbf{3 g}$ ).

(32) Zoom in on the heart. Open the pericardium using two pairs of small rounded forceps. The upper and middle part of the left ventricle with its partly overlying auricle (atrium) and blood vessels are now visible. The left anterior descending (LAD) coronary artery is bright red to orange/pink, as opposed to the veins which are dark red, is pulsatile and runs from below the left auricle to the apex. It has several side branches which may also be visible, but the occlusion should be proximal to these branches to obtain a maximal reproducibility of infarct size. Ligation site is just distal to the left auricle; the distance from the ligation site to the left auricle being the length of both tips of a pair of rounded forceps (see EQUIPMENT SETUP).

(33) Hold a 7-0 Prolene suture with a small needle holder and insert it into the myocardium, enclosing the LAD and approximately 4 times its diameter of surrounding myocardium (Fig. 3h). Avoid entering the LV cavity, but go deep enough to see the LAD pulsate over the needle. Close the suture using a double surgeon's knot, fixed with two extra half hitches. Cut the sutures quite short, just long enough to prevent slipping (Fig. 3i). TROUBLESHOOTING

CRITICAL STEP Ensure that the ligation successfully caused a large myocardial infarction (see ANTICIPATED RESULTS).

(34) This step can be done using option A or option B

\section{(A) Cell transplantation directly after MI}

(i) Select an Eppendorf tube with or without cells or control randomly. If it contains cells or fluid, pipette it as one drop onto a piece of parafilm. Aspirate the cell suspension or control fluid with an insulin syringe (see EQUIPMENT SETUP); avoid aspiration of air.

(ii) Inject the contents into the infarcted LV wall or borderzone as desired; insert the needle with the lumen facing up until it is just under the surface (Fig. 3j), then empty the syringe and note if the injection was successful as evidenced 
by the appearance of a white area and the absence of major backwash of the cells (if the injection was not successful, exclude the animal from functional analysis). TROUBLESHOOTING

CRITICAL STEP Even if the procedure for control mice (MI without cell injection) could be faster than for mice which do receive cells, wait some minutes before proceeding to equalize anesthesia- and pneumothorax times.

\section{(B) Delayed cell transplantation}

(i) Skip steps I-7.

(ii) At the chosen time-point, perform steps I-7 and repeat steps 8-3I. Depending on the timing stitches from the first surgery will still be present; cut and remove these.

(iii) Perform step 34(A).

(35) Remove the retractor. Close the thoracic wall by enclosing the two separated ribs with two stitches of 5-0 silk suture. Keep some distance to the ribs to prevent damage to the intercostal vessels and nerves (Fig 3k). Remove the sponge before tightening the stitches (one double surgeon's knot, secured with two single knots) (Fig. 31).

(36) Unfold the lungs by closing the exit tube three times very briefly; this will generate a positive end expiratory pressure ('PEEP”) which helps the small airways fill with air again.

(37) Moisturize the pectoral muscles and skin with a cotton tip drenched in PBS and gently put the muscles back into he original position (first the minor, then the major partly overlying it) with the forceps.

(38) Close the skin with 3-4 stitches of 5-0 silk suture.

(39) Turn off the isoflurane and increase flow to $3 \mathrm{l} / \mathrm{min}$.

(40) Suture the throat incision with I-2 stitches in the skin.

(4I) Turn on the heating lamp directed at the mouse and remove all tapes.

CRITICAL STEP Keep the lamp at $30 \mathrm{~cm}$ distance and feel with your hand to check the mouse is not being overheated $\left(37-40^{\circ} \mathrm{C}\right.$ air temperature maximum).

(42) Disconnect the tube from the ventilator and wait a few seconds to test 
whether the mouse can breathe autonomously. If not, connect and try again a minute later. TROUBLESHOOTING

(43) If the mouse is breathing, take out the tube. Hold the outflow of the ventilator close to the mouth and nose for extra oxygen. Cut ear tags for identification and put the mouse on its right side.

(44) The mouse is expected to recover within minutes. When it starts to turn and walk, put it in the warm recovery cage for an hour before returning it to its own cage. Fill a dish with solid drink to support recovery during the first two days after surgery.

CRITICAL STEP Do not keep pre- and post-operative NOD-SCID mice in one cage.

M RI

(45) Switch on equipment that needs to warm up for about 15 minutes (Fig 2a-b and 2f) as follows: Water cooling system for gradients, set temperature at $27^{\circ} \mathrm{C}$ to maintain mouse body temperature; Trigger unit (fig $x x, E C G$, respiration and temperature). Settings: ECG-trigger enable: resp.; resp-trigger enable: cont. (now triggering is from ECG while respiration artifacts are filtered out); Powerlab for recording cardiac and respiratory motion; 3 gradient amplifiers ( $X Y Z$ ) a few seconds after each other; Push "reset protection" (red button on the left side) once $X Y Z$ amplifiers are running; Temperature control unit; Set gas flow $\mathrm{O}_{2}:$ Air $=1: 2(0.15 / 0.3 \mathrm{~L} / \mathrm{min})$ in the anesthesia system.

(46) Prepare the mouse container (Fig. 2C-d) by cleaning the inside and outside of the container with ethanol and connecting the container to an anesthesia supply. Direct gas flow (3-way valve) to the anesthesia mask. Clean a plastic transport box (for weighing) and lid with ethanol. Position the sensor balloon for registration of respiration and heart frequency).

(47) Start up software: Chart 5 for Windows (to monitor cardiac and respiratory motion); and Paravision 4 for MRI scans. For each new mouse: select "New Patient" in "Scan Control" (under "System Control" $\rightarrow$ "Tools"). For "Entry" select: feet first, for "Position" select: prone; this matches the vertical position of the mouse.

(48) Select "I-Tripilot-i.g.modified" as a scout-scan protocol.

(49) Weigh the mouse. 
(50) Turn anesthesia gas on: $\mathrm{O}_{2}: 0.15$ and air: $0.3 \mathrm{~L} / \mathrm{min}$ with $3 \%$ isoflurane and anesthetize the mouse with the mask, then direct the isoflurane flow from the mask to container (3-way valve) and turn concentration to $2 \%$.

(5I) Place the mouse in the container (Fig. 2e), hook upper teeth on the ring in the anesthesia cone, and slide the cone over the mouse's head so that it is fixed and breathes the anesthesia gas.

(52) Position the mouse with its heart at the black mark to coincide with the center of the Radio Frequency coil. Secure the position by fastening the screw cap on the slide bar.

(53) Put the respiratory balloon under the mouse's thorax. The balloon should be situated right at the heart's position for a proper registration of both respiration and heart frequency. By placing a piece of cardboard under the balloon, more pronounced peeks will be acquired. Make sure that the forelimbs are not between body and balloon.

(54) Cover the mouse with a piece of gauze.

(55) Close the container. Make sure that tail, limbs and ears are not between the container and lid. Clean the outside of the container with ethanol.

(56) Switch off the isoflurane.

(57) Disconnect the container and carry it over to the MRI coil.

(58) Put the container with the mouse carefully into the coil and connect to anesthesia. Set isoflurane at $3 \%$ and after $5-10 \mathrm{~min}$, turn it to $2 \%$. Then connect tubing for respiratory sensor and cooling airflow. Turn the container in such a way that the black marks on both container and coil match.

CRITICAL STEP Check registration of respiration and heart frequency (Fig. 2f). If the signal is unusable, remove the container from the probe and reposition the mouse or balloon. TROUBLESHOOTING

(59) Slide the probe, with the container and mouse in it, into the magnet and fix it to the magnet with 3 brass screws. For repeatable positioning, make sure that the upper part of the yellow sticker matches the one on the bottom of the insert of the magnet (Fig. 2g).

(60) Tune and match (tuning for correct frequency; matching for optimal signal) by disconnecting the Rx-cable and attaching the $50 \mathrm{Ohm}$ cap. Open the Topspin I.5-window by right mouse clicking on the scan (=Tripilot) in the scan list, select 
"export to Topspin". Go to the Topspin window, type "w" in command bar (= wobble) $\rightarrow$ enter $\rightarrow$ screen shows "connect probe head" $\rightarrow$ click "close". The signal curve appears on screen. If the curve is not visible adjust the scaling by using the $* 2, / 2, * 8$ and $/ 8$ buttons. "Connect probe head" should appear after a few seconds $\rightarrow$ click "close". Tune and match both channels of the quadrature driven coil separately by connecting the Rx-cable to each channel. Have a 50 Ohm cap attached to one channel while the other is adjusted by turning carefully the brass tune- en match- regulators at the bottom of the probe head.

CRITICAL STEP Adjust until the curve at the computer screen has an amplitude as deep as possible (match) and the tip is set as close as possible to the $400 \mathrm{MHz}$ line (tune) at the same time.

(6I) Reconnect the Rx-cable to the quadrature splitter and each of the two measuring cables to its matching probe (Fig. $\mathbf{2 h}$ ). When an optimal curve is achieved, type "stop", push "enter", type "ii" (= killing all running programs) and push "enter" in command bar.

CRITICAL STEP Before the first measurement, check the triggering of the heart frequency peaks and the gating of the respiration signal and adjust when necessary (use gain, trigger level, cut off low or high filtering). TROUBLESHOOTING

(62) Start the recording of the ECG in the Chart 5 program. To do this, click "start" and click on the recording button in the lower right corner of the screen.

(63) Select the "I-Tripilot-ig-modified" scan in Scan Control (= first orientation scan). Click "Traffic light". Now the following steps are automatically performed: auto shim: optimization of the magnetic field; auto SF: adjustment of the spectrometer frequency; Auto RF gain: setting of transmitter attenuators for optimal flip angle; Auto RG: setting of the optimal receiver gain. The selected scan (Tripilot) is automatically started

CRITICAL STEP The Tripilot orthogonal scout-scan yields three slices: sagittal, coronal and axial. With these three slices the position of the heart can be determined and the final geometrical orientation set for cine scans. If the result 
of the Tripilot scan is not adequate reposition the slices in a repeated scan using the "Geometry Editor" ("globe" button in scan control), see step 65 below.

(64) To display the images, hold the mouse wheel and drag the completed scan to the Image Display. This will show one slice. With the arrow buttons in the task bar (to the left and to the right) you can obtain the other orientations. Push "shift" while dragging the scan to see all three pictures in the Image Display.

(65) For the next measurement, in the scan control tool: select the last scan with the mouse, click on the right mouse button and choose "clone scan" in the "scan list"-window. The copied scan will be added in "ready" mode.

(66) Choose Geometry Editor (globe) to orient the three slices in a better position. Set slice thickness at I $\mathrm{mm}$.

(67) Click in the picture on the right mouse button and select " $2 \times 2$ windows". All three orientations with all axes are shown simultaneously. Select the image in which the axes have to be adjusted and select an axis. The other two images show what happens with the orientation of the axis in that particular view.

(68) By using the last scans as reference (select "reference" scan in reference bar) make a perfect 2 -chamber and 4-chamber and, in $90^{\circ}$ orientation to both these slices, an axial slice. The axes of the 2 - and 4-chamber slices have to be positioned through the apex and aortic valves.

(69) Click "accept" and then "Traffic light" to start the scan.

2- and 4-chamber cine:

(70) When the orientation is correct, the cine-scans (movies) can be made. To do this: right mouse button on last scan and: "clone scan". Cloned scan will be added to scan list as "Ready".

(7I) Click with right mouse button on the new scan and choose: "load scan protocol" Then, load "Cine GEFCZF". Now there is only one slice to position. It is easier to use one reference image at the time: click right mouse button (in the image): " $|x|$ windows".

(72) The first long axis cine is the easiest to define with the last Tripilot as a reference. To define the 2-chamber cine ( sagittal), use both the coronal and axial slices of the Tripilot as a reference. In the Geometry Editor, click the "upside-down $\mathbf{T}$ " to place the orientation $90^{\circ}$ (perpendicular) to the reference image. Make sure that this long axis goes through the apex and aortic valves in 
such a way that axial slices perpendicular to this axis intersect with both the septum and the left ventricular free wall at angles as close as possible to $90^{\circ}$ to minimize partial volume effects.

(73) Start scan by clicking "Shift + Traffic light" which will perform the optimizations again for this new scan followed by the scan itself.

(74) Check the movie after scanning by moving "completed scan" to Image Display (hold mouse wheel) and play it with the camera button. Stop playing with "ok". If the movie is not correct, adjust settings (for triggering, scan or slice orientation) and repeat scan. TROUBLESHOOTING

(75) Clone scan and select "Geometry Editor".

(76) The slice for the 4-chamber cine can be defined with the references of both the axial slice of the Tripilot and the 2-chamber cine scan. Load reference images in the 'reference' bar.

(77) Click the perpendicular symbol (upside-down $\mathbf{T}$ ) and position the slice through the apex and the aorta valves, again in such a way that axial slices perpendicular to this axis intersect with both the septum and the left ventricular free wall at angles as close as possible to $90^{\circ}$ to minimize partial volume effects.

(78) Accept and start scan with "Traffic Light".

Axial movies:

(79) Clone scan.

(80) For the axial slice orientation, use both long axis cines as a reference in the "Geometry Editor".

(81) Click "perpendicular"-symbol to place the first axial slice at $90^{\circ}$ to the apex-aorta-axis.

(82) Position the first slice in such a way that the lowest part of the left ventricular volume (closest to the apex) is in the slice.

(83) Accept and start the scan with "Traffic Light". TROUBLESHOOTING

(84) The next scans can be copied ("clone scan") and only the slice position per scan is adjusted I mm towards the aorta. This can be done in the "Geometry Editor" - Isodist $\mathrm{H}$ every time $+\mathrm{I} \mathrm{mm}$ upward until the aortic valves are reached.

(85) Insert a comment (or note the time) in the ECG recording to calculate the heart rate during the axial slice measurements. 
(86) When all scans are done and the experiment is over, stop ECG-recording and save. Remove the mouse container from the magnet, take the mouse out of the container and let the animal recover. This will take about 5 minutes.

(87) Convert the scan files to DICOM format.

PAUSE POINT The scans can be saved and analyzed later.

Ventricular volume and wall thickness/motion analysis with Qmass contour detection

(88) Open Qmass MR6.I.5.

(89) Open the study: All scans are loaded now (= orientation scans (Tripilot) and all cines (GEFCZF)).

(90) Choose "multiple select".

(91) Select all axial scans (the first 2 cines are often the 2- and 4 chamber scans).

(92) Click Right mouse button: "combine studies": All axial cines are combined into one "Combined study".

(93) Double-click on "COMBINE".

(94) Click on "load": All axial slices (in all phases) are loaded; the scans are shown in a grid. The slices are put in line vertically and the phases horizontally. The slice on top (= near aortic valves) and the bottom one (apex) are sometimes not determinable.

(95) In the "action panel", select the "move" button (hand and arrows) to move the heart to the center of the window.

(96) Determine the systolic and diastolic phase.

(97) Determine and draw the circumference of the endocardial wall (LV endo) and epicardial wall (LV epi) (Fig 2i) in these 2 phases, in all possible slices. First select the button with the arrow towards the middle (center point). Next put the cursor in the middle of the inside of the LV and click once with mouse. The program draws a line (red) on the inside of the LV. Select the button for determination of the inside of the LV and adjust the red line when or where necessary. Select the button for determination of the outside of the LV and draw this line by yourself (green). Repeat for every slice (in the systolic and the diastolic phase).

(98) Click: View - Report - Text 
(99) Mark: patient info, study info, scan info, LV volume, wall thickness, wall thickening, wall motion

(I00) Click "Generate" to see the results (Table 2).

Table 2. Functional parameters by MRI

\begin{tabular}{|c|c|c|c|c|}
\hline Parameter & Abbreviation & Units & Determination & Calculation \\
\hline Body weight & BW & $g$ & Measurement & - \\
\hline Heart rate & $H R$ & beats per minute & Measurement & - \\
\hline $\begin{array}{l}\text { End diastolic } \\
\text { volume }\end{array}$ & EDV & $\mu l$ & $\begin{array}{l}\text { Measurement/ } \\
\text { reconstruction by } \\
\text { software }\end{array}$ & - \\
\hline $\begin{array}{l}\text { End systolic } \\
\text { volume }\end{array}$ & ESV & $\mu l$ & $\begin{array}{l}\text { Measurement/ } \\
\text { reconstruction by } \\
\text { software }\end{array}$ & - \\
\hline Stroke volume & SV & $\mu l$ & Calculation & EDV-ESV \\
\hline $\begin{array}{l}\text { Ejection } \\
\text { fraction }\end{array}$ & $\mathrm{EF}$ & $\%$ & Calculation & SV/EDV*I00 \\
\hline Cardiac output & $\mathrm{CO}$ & $\mathrm{ml} / \mathrm{min}$ & Calculation & SV*HR/I000 \\
\hline $\begin{array}{l}\text { End diastolic } \\
\text { volume index }\end{array}$ & EDVI & $\mathrm{ml} / \mathrm{kg}(\mu \mathrm{l} / \mathrm{g})$ & Calculation & EDV/BW \\
\hline $\begin{array}{l}\text { End systolic } \\
\text { volume index }\end{array}$ & ESVI & $\mathrm{ml} / \mathrm{kg}(\mu \mathrm{l} / \mathrm{g})$ & Calculation & ESV/BW \\
\hline $\begin{array}{l}\text { Stroke volume } \\
\text { index }\end{array}$ & SVI & $\mathrm{ml} / \mathrm{kg}(\mu \mathrm{l} / \mathrm{g})$ & Calculation & SV/BW \\
\hline Cardiac index & $\mathrm{Cl}$ & $\begin{array}{l}1 / \mathrm{min} / \mathrm{kg}(\mathrm{ml} / \\
\mathrm{min} / \mathrm{g})\end{array}$ & Calculation & $\mathrm{CO} / \mathrm{BW}$ \\
\hline $\begin{array}{l}\text { LV myocardial } \\
\text { mass }\end{array}$ & MM & $\mathrm{mg}$ & $\begin{array}{l}\text { Measurement/ } \\
\text { reconstruction by } \\
\text { software }\end{array}$ & - \\
\hline
\end{tabular}

Isolation and processing of the hearts

(I0I) Make solution I+ by adding $100 \mu \mathrm{l}$ of $20 \%$ PFA stock to $10 \mathrm{ml}$ of solution I for each mouse (final concentration: $0.2 \%$ PFA). Store on ice.

(I02) Euthanize the mouse by cervical dislocation.

(103) Place the mouse in a supine position.

(104) Lift the abdominal skin and muscle with forceps and make cuts through skin and muscle with blunt scissors: first a median incision up to the sternum, then bilaterally to the most lateral point of the rib cage.

(105) While holding and lifting the lower end of the sternum, pinch and open the diaphragm following the curve of the most inferior pair of ribs.

(106) Keep lifting the sternum and cut through the middle of all ribs on each side. 
(107) Hold the large vessels attached to the basis of the heart and lift slightly; then excise the heart while continuously pulling the vessels upwards very gently. TROUBLESHOOTING

(108) Remove remainders of vessels and loose pericardium.

(109) Blot the heart on tissue paper and gently squeeze with blunt forceps to remove most of the blood. Keep the anterior side of the heart up to avoid contact with the graft.

(II0) Weigh the heart.

(III) Rinse the heart in PBS. For better removal of the blood, fill a syringe with PBS and slowly inject this in the LV via the apex using a $26 \mathrm{G}$ needle.

(II2) Put the heart in solution I+ on ice.

(II3) Remove and freeze or fix other organs if desired for analysis.

(II4) Keep the heart in solution I+ for 24 hours at $4{ }^{\circ} \mathrm{C}$ on a roller bank or in a rotator.

(II5) Wash and refill with solution I- (without PFA) and leave for 24 hours at 4 ${ }^{\circ} \mathrm{C}$ on a roller bank or in a rotator.

(II6) Wash and refill with solution 2 and leave for 24 hours at $4{ }^{\circ} \mathrm{C}$ on a roller bank or in a rotator.

(II7) Fill an icebox with dry ice so that it forms a horizontal surface.

(II8) Fill a $5 \mathrm{ml}$ syringe with tissue freezing medium and attach a $23 \mathrm{G}$ needle.

(II9) Partly fill a plastic base mold with tissue freezing medium. Place the heart in the mold.

(I20) Carefully inject tissue freezing medium, via the entry site of the aorta, into the LV cavity until the convexity of the LV wall is restored.

(I2I) Place the heart in the mold with the posterior side facing the air, then cover the heart completely with tissue freezing medium. Mark basal and apical side and the location of the inferior border of the left auricle on the mold.

(122) Place horizontally on dry ice. When completely frozen, store in a sealed plastic bag at $-20^{\circ} \mathrm{C}$.

PAUSE POINT cryo-blocks can be stored at $-20{ }^{\circ} \mathrm{C}$ until sectioning.

\section{Cryosectioning}

(I23) For cryosectioning, cut the heart transversally just below the left auricle. Fix the apical side on a mounting disk with tissue freezing medium. 
(I24) When the tissue freezing medium is frozen, cut $6 \mu \mathrm{m}$ sections and transfer these to coated glass slides.

PAUSE POINT slides can be stored at $-20^{\circ} \mathrm{C}$ until immunostained.

Immunofluorescent staining

(125) Thaw slides with box closed for $30 \mathrm{~min}$.

(I26) Post-fix slides in cold $\left(4^{\circ} \mathrm{C}\right)$ acetone for $10 \mathrm{~min}$.

(I27) Air dry for at least 15 min.

(128) Dip in PBS.

(129) Permeabilize with $100 \mu \mathrm{l}$ Triton X-100 $0.2 \%$ (vol/vol) on slides for 5 minutes.

(130) Wash 3 times, for 5 min each wash, in PBS.

(I3I) Block with $100 \mu \mathrm{l} \%$ (wt/vol) BSA/PBS on slides for 45 minutes.

(132) Incubate with first antibody in $2 \%$ BSA/PBS $100 \mu \mathrm{l}$ for I hour at room temperature or overnight at $4^{\circ} \mathrm{C}$.

(133) Wash 3 times, for 5 min each wash, in PBS/0.05\% (vol/vol) Tween.

(I34) Incubate with second antibody in $2 \%$ BSA/PBS $100 \mu$ for I hour at room temperature.

(I35) Wash 3 times, for 5 min each wash, in PBS/0.05\% Tween.

(I36) Wash in PBS.

(137) Counterstain nuclei with Topro-3 I/I000 with Triton X-100 2/1000 in ${ }_{d d} \mathrm{H}_{2} \mathrm{O} 100 \mu \mathrm{l}$ for 5 minutes.

(I38) Dip in ${ }_{d d} \mathrm{H}_{2} \mathrm{O}$.

(I39) Cover with a drop of Vectashield and a glass coverslip.

PAUSE POINT slides can be stored at $-20{ }^{\circ} \mathrm{C}$ until analysis.

\section{M icroscopy and emission wave length spectrum analysis}

(140) Have the switch set for manual control and direct vision with fluorescent light (mercury lamp), then center and focus the area of interest with the objective of choice (e.g. 40x).

(I4I) In the acquisition menu, select xyz-mode, sequential scanning, and the desired zoom (usually I for the first scan); set pinhole at I Airy Unit (depending on the strength of the signal; increasing the Airy Unit will enhance the signal 
but also the background and risk of analyzing two overlying structures instead of one small confocal plane); set frame average at 3 to filter noise.

(142) In the beam path menu, select sequential stack-by-stack scanning. Activate the settings for GFP (with $488 \mathrm{~nm}$ laser), Cy3 (532 nm laser) and topro or Cy5 (633 nm laser); make sure the detection windows do not overlap.

(I43) By clicking "live" or "continuous" scanning adjust the settings for each laser separately. To do so, select the Q-LUT (quantitative look up table) mode, adjust the focus to the correct plane and increase or decrease the laser voltage and offset so that blue pixels are just gone.

(144) Return to the acquisition menu to set the Z-plane. Take $0.5 \mu \mathrm{m}$ for Z-step size.

(I45) Click "start" to obtain a Z-series.

(146) View the maximum projection of the series including the overlay by clicking "max" and "overview". Revert to the original view to compare the respective color signals in each confocal plane and verify that separate signals (e.g. from GFP and $\alpha$-actinin) are in the same plane and cell. TROUBLESHOOTING

(I47) Scan the isotype control with the same settings.

(148) To distinguish between GFP (Fig 4a) and autofluorescence (Fig. 4b), perform an emission wave length spectrum analysis (lambda scan). First focus on a green cell that is unstained or negative for the staining applied. In the lambda mode, select the $488 \mathrm{~nm}$ laser. Set a detection window range of 498 to $600 \mathrm{~nm}$ with $10 \mathrm{~nm}$ band width, 30 steps and 3 scans per step. To set the gain, put the detection band at $510 \mathrm{~nm}$ and adjust the voltage so that there is just a little overexposure (some "blue" spots in the quantitative look-up table mode) Run the scan and let the software analyze it in the "quantify stack profile" mode. Select several regions of interest, including at least a green cell and background. TROUBLESHOOTING

\section{Timing}

Preparation of cells (steps I-7): 4 hours

Myocardial infarction and cell injection (steps 8-44): 30 minutes per mouse MRI (steps 45-87): 45 minutes per mouse per time-point Isolation and processing of the hearts (steps 10I-122): 4 days with 30 minutes 
hands-on time

Immunofluorescent staining (steps 125-139): 6 hours

Microscopy and emission wave length spectrum analysis (steps 140-148): 15

minutes or more

\section{TROUBLESH OOTIN G}

\section{See Table 3.}

Table 3. Trouble shooting

\begin{tabular}{|c|c|c|c|}
\hline Step & Problem & Possible reason & Solution \\
\hline \multirow[t]{3}{*}{$\begin{array}{l}18-25 \\
\text { (Intubation) }\end{array}$} & \multirow[t]{3}{*}{$\begin{array}{l}\text { Mouse breathes or gasps } \\
\text { while ventilation is on. } \\
\text { (Also: lungs or abdomen } \\
\text { may blow up.) }\end{array}$} & $\begin{array}{l}\text { Blockage of intubation } \\
\text { tube, tubing to or from the } \\
\text { respirator, or airway of the } \\
\text { mouse. }\end{array}$ & Check and unblock all tubing. \\
\hline & & $\begin{array}{l}\text { Intubation tube is in } \\
\text { esophagus or at the } \\
\text { tracheal carina (too distal; } \\
\text { this is where the trachea } \\
\text { splits into left and right } \\
\text { main bronchus). }\end{array}$ & $\begin{array}{l}\text { Check position of the } \\
\text { intubation tube. Retract and } \\
\text { reposition if necessary. }\end{array}$ \\
\hline & & $\begin{array}{l}\text { Perforation of trachea at } \\
\text { the carina. }\end{array}$ & $\begin{array}{l}\text { Euthanize the mouse. Next } \\
\text { time, make sure the tip of } \\
\text { the intubation tube is visible } \\
\text { proximal to the carina. }\end{array}$ \\
\hline $\begin{array}{l}\text { 26-3I } \\
\text { (Thoracotomy) }\end{array}$ & $\begin{array}{l}\text { Thorax is filled with fluid } \\
\text { and a solid white tumor } \\
\text { is present above the } \\
\text { basis of the heart. }\end{array}$ & $\begin{array}{l}\text { Thymoma (very rare in } \\
\text { I } 2 \text { weeks old mice, more } \\
\text { common in mice }>20 \\
\text { weeks of age) }\end{array}$ & Euthanize the mouse. \\
\hline \multirow[t]{2}{*}{$\begin{array}{l}32-33 \\
\text { (Infarction) }\end{array}$} & \multirow[t]{2}{*}{$\begin{array}{l}\text { Tear or rupture of the } \\
\text { myocardium or vessel } \\
\text { when fastening the LAD } \\
\text { ligation. }\end{array}$} & $\begin{array}{l}\text { Too little or too much } \\
\text { myocardium surrounding } \\
\text { the LAD included in the } \\
\text { ligation. }\end{array}$ & $\begin{array}{l}\text { Include more or less (see step } \\
\text { 32) myocardium. }\end{array}$ \\
\hline & & $\begin{array}{l}\text { Heart is lifted during the } \\
\text { ligation procedure. }\end{array}$ & $\begin{array}{l}\text { Keep forceps tips low and } \\
\text { close to the heart at all times } \\
\text { when manipulating with the } \\
\text { needle and suture for ligation. } \\
\text { Hold the } 7-0 \text { prolene close to } \\
\text { the heart and pull in a more } \\
\text { horizontal plane to fasten the } \\
\text { ligation. }\end{array}$ \\
\hline $\begin{array}{l}34 \text { (Injection of } \\
\text { cells or vehicle) }\end{array}$ & $\begin{array}{l}\text { Bleeding after injection } \\
\text { of cells or vehicle. } \\
\text { (Also: absence of grafted } \\
\text { cells in cryosections.) }\end{array}$ & $\begin{array}{l}\text { The injection needle } \\
\text { perforated the LV wall and } \\
\text { injection was in the LV } \\
\text { cavity. }\end{array}$ & $\begin{array}{l}\text { Inject more superficially. Bend } \\
\text { the needle (see EQUIPMENT } \\
\text { SETUP). }\end{array}$ \\
\hline
\end{tabular}


Chapter 3 | 71

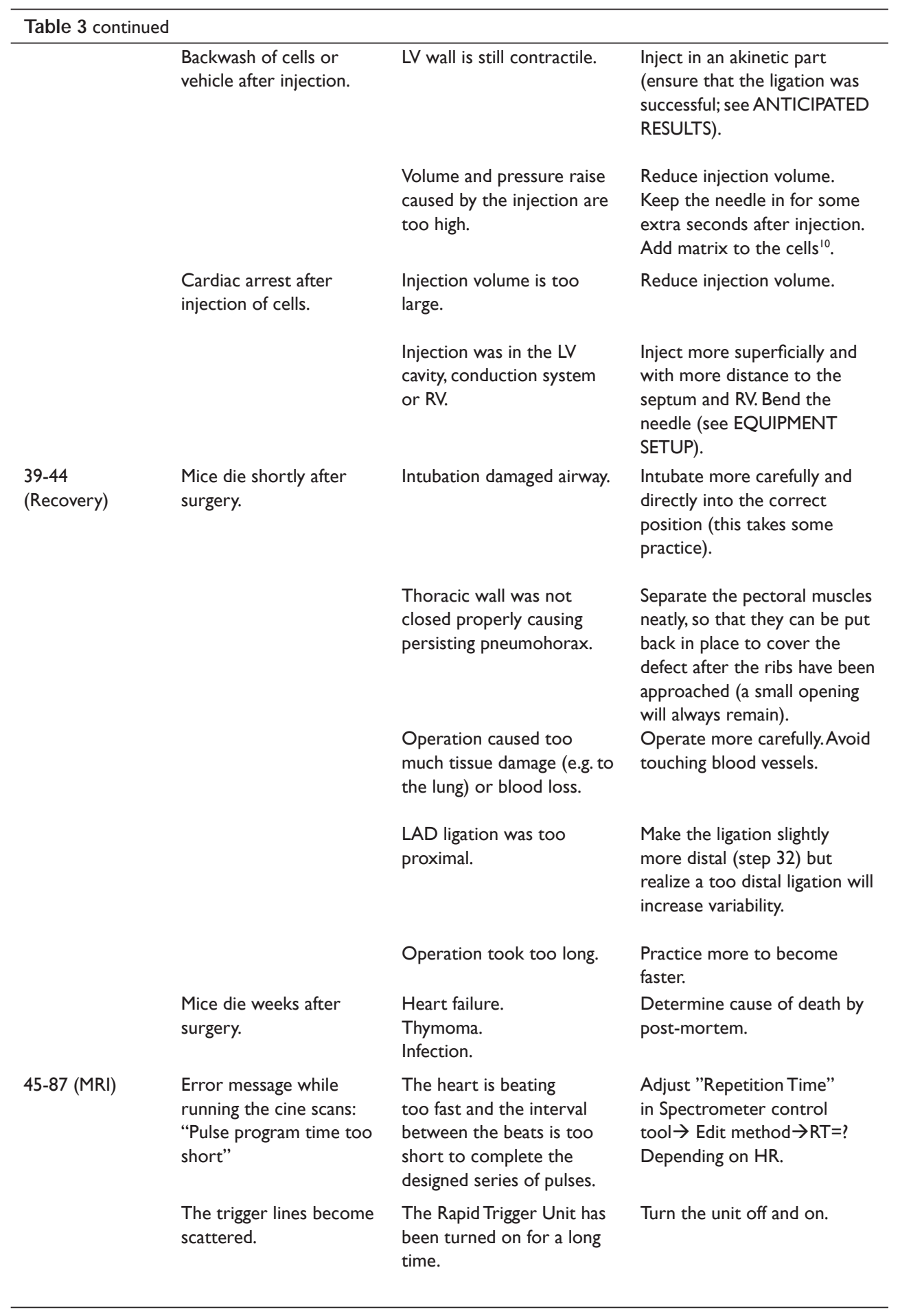




\begin{tabular}{|c|c|c|c|}
\hline \multicolumn{4}{|c|}{ Table 3 continued } \\
\hline & $\begin{array}{l}\text { There is a lot of noise in } \\
\text { the scans. }\end{array}$ & $\begin{array}{l}\text { The initial settings are } \\
\text { suboptimal. }\end{array}$ & $\begin{array}{l}\text { Run "Auto Optimizations" } \\
\text { again (as in step 64) }\end{array}$ \\
\hline $\begin{array}{l}101-110 \\
\text { (Isolation of } \\
\text { hearts) }\end{array}$ & $\begin{array}{l}\text { Hearts are attached to } \\
\text { the thoracic wall. }\end{array}$ & $\begin{array}{l}\text { Adhesions from surgery } \\
\text { and/or infection. }\end{array}$ & $\begin{array}{l}\text { Reduce tissue damage during } \\
\text { operation. Work more sterile. }\end{array}$ \\
\hline \multirow[t]{10}{*}{$\begin{array}{l}\text { I I I-I48 (GFP } \\
\text { and immuno- } \\
\text { fluorescence) }\end{array}$} & $\begin{array}{l}\text { GFP is present, but } \\
\text { human nuclei staining is } \\
\text { negative. }\end{array}$ & Fixation failed. & $\begin{array}{l}\text { Make fresh PFA and use only } \\
\text { once. Take a positive control } \\
\text { sample. }\end{array}$ \\
\hline & & GFP is false positive. & $\begin{array}{l}\text { Exclude this with emission } \\
\text { wave length spectrum. }\end{array}$ \\
\hline & $\begin{array}{l}\text { Staining for human nuclei } \\
\text { is positive, but GFP is } \\
\text { absent. }\end{array}$ & Fixation failed. & $\begin{array}{l}\text { Make fresh PFA and use only } \\
\text { once. }\end{array}$ \\
\hline & & $\begin{array}{l}\text { GFP fluorescence } \\
\text { extinguished (unlikely). }\end{array}$ & $\begin{array}{l}\text { Keep hearts and slides in the } \\
\text { dark. Stain slides with GFP } \\
\text { antibody (e.g. rabbit anti-GFP } \\
\text { I:500,Abcam ab290) (Fig. }\end{array}$ \\
\hline & & $\begin{array}{l}\text { Contact of cells or heart } \\
\text { with ethanol. }\end{array}$ & $\begin{array}{l}\text { Avoid contact with ethanol. } \\
\text { Stain slides with GFP antibody } \\
\text { (Fig. } \mathbf{5 d - f ) .}\end{array}$ \\
\hline & & $\begin{array}{l}\text { Human nuclei staining is } \\
\text { false-positive. }\end{array}$ & $\begin{array}{l}\text { Compare with isotype- } \\
\text { matched control. }\end{array}$ \\
\hline & & Cells are dead. & $\begin{array}{l}\text { Check viability of the cells } \\
\text { after dissociation, aspiration } \\
\text { and replating on coverslips. If } \\
\text { this is ok, sacrifice a mouse } \\
\text { briefly after injection of cells, } \\
\text { when they should be alive. }\end{array}$ \\
\hline & $\begin{array}{l}\text { No grafted cells are } \\
\text { detected. }\end{array}$ & $\begin{array}{l}\text { Cells were dead before } \\
\text { transplantation. }\end{array}$ & $\begin{array}{l}\text { Check viability of the cells } \\
\text { after dissociation, aspiration } \\
\text { and replating on coverslips. }\end{array}$ \\
\hline & & $\begin{array}{l}\text { Injection was not into the } \\
\text { LV wall. }\end{array}$ & $\begin{array}{l}\text { See "injection of cells or } \\
\text { vehicle" in this table. }\end{array}$ \\
\hline & & $\begin{array}{l}\text { Cells died or were rejected } \\
\text { after injection. }\end{array}$ & $\begin{array}{l}\text { Sacrifice a mouse briefly after } \\
\text { injection of cells, when they } \\
\text { should be alive. }\end{array}$ \\
\hline
\end{tabular}

\section{ANTICIPATED RESULTS}

$M$ yocardial infarction and recovery (Steps 8-44)

A successful infarction is characterized by (I) discoloration of the LV free wall (2) clear border between ischemic and non-affected area over the interventricular septum and at the basal-posterior side (3) reduced or absent motility of the 
infarct area. Peri-operative mortality should be close to $0 \%$. Four-week survival should be $80-95 \%$ and twelve-week survival $50-85 \%$, depending on the injected cell type or control.

\section{Cell injection (Step 34)}

The injected cells will form a whitish bleb in the infarct. Viable GFP-fluorescent cells (cardiomyocytes) are retained for at least 12 weeks after injection.

M RI analysis (Steps 88-100)

Mice will have impaired cardiac contraction (reduced EF) and dilation of the LV (increased EDV) as early as 2 days post-MI. In the following 4 weeks, heart function decreases and then stabilizes or further declines, depending on the injected cell type or control.

\section{GFP-epifluorescence (Step 141)}

GFP-fluorescent patches of cells will be visible in whole mount hearts before and after fixation and in cryosections with or without immunofluorescence staining. In both situations, the wave length emission spectrum will be characteristic for GFP (Fig. 4a-b). The signal should not be visible when using a filter for red or blue fluorescence.

Immunofluorescent staining (Steps 125-139) (Fig. 5a-c)

Beating areas or fresh human tissue specimens fixed and frozen according to Step 64-77 can be used as positive control for anti-human-nuclei and antiKi-67 (nuclear pattern). Human fetal hearts (if available) or cryosections of undifferentiated HESC-colonies are an alternative positive control for $\mathrm{Ki}-67$ staining. The mouse cardiomyocytes in the recipient heart serve as an internal positive control for anti- $\alpha$-actinin (sarcomeric pattern).

\section{Effects of cell transplantation}

Many cell types may preserve cardiac function to some extent, especially at mid-term (4 week MRI) ${ }^{4-7}$. However we found that the long-term (I2 week) outcome may vary substantially from short- or mid-term readouts and therefore we strongly recommend that the 12 week measurements are included. We observed a transient functional improvement resulting from post-MI injection of I million cardiomyocyte -enriched (25\%) HESCs from END-2 co-culture 
compared to control cells (differentiated non-cardiomyocyte HESCs) ${ }^{9}$. We also observed selective survival of cardiomyocytes and loss of other differentiated HESCs from the END-2 co-culture system (predominantly extraembryonic endoderm cells: Passier et al, 2005), in accordance with a previous report on transplantation of HESC-derived cells in rats ${ }^{20}$. It remains to be determined whether similar or improved results can be obtained with other cell types, pre-treatment or larger quantities of cells or other modifications, which can all easily be implied and compared in the model described here.

\section{Acknowledgements}

We are grateful to Liesbeth Winter, Krista den Ouden and Sandra Bovens for their help with validation of the MI and MRI protocol and to Daan Lips for surgical training.

\section{References}

I. van Laake LW, Hassink R, Doevendans PA, Mummery C. Heart repair and stem cells.J Physiol. 2006;577:467478.

2. Iso Y, Spees JL, Serrano C, Bakondi B, Pochampally R, Song YH, Sobel BE, Delafontaine P, Prockop DJ. Multipotent human stromal cells improve cardiac function after myocardial infarction in mice without long-term engraftment. Biochem Biophys Res Commun. 2007;354:700-706.

3. Muller-Ehmsen J, Krausgrill B, Burst V, Schenk K, Neisen UC, Fries JW, Fleischmann BK, Hescheler J, Schwinger RH. Effective engraftment but poor mid-term persistence of mononuclear and mesenchymal bone marrow cells in acute and chronic rat myocardial infarction.J M ol Cell Cardiol. 2006;41:876-884.

4. Menard C, Hagege AA, Agbulut O, Barro M, Morichetti MC, Brasselet C, Bel A, Messas E, Bissery A, Bruneval P, Desnos M, Puceat M, Menasche P. Transplantation of cardiac-committed mouse embryonic stem cells to infarcted sheep myocardium: a preclinical study. Lancet. 2005;366:1005-1012.

5. Orlic D, Kajstura J, Chimenti S, Jakoniuk I, Anderson SM, Li B, Pickel J, McKay R, Nadal-Ginard B, Bodine DM, Leri A, Anversa P. Bone marrow cells regenerate infarcted myocardium. Nature. 200 I;4 I0:70I-705.

6. Orlic D, Kajstura J, Chimenti S, Limana F, Jakoniuk I, Quaini F, Nadal-Ginard B, Bodine DM, Leri A,Anversa P. Mobilized bone marrow cells repair the infarcted heart, improving function and survival. Proc $\mathrm{N}$ atl Acad Sci U SA. 2001;98:10344-10349.

7. Zhang S, Ge J, Zhao L, Qian J, Huang Z, Shen L, Sun A, Wang K, Zou Y. Host vascular niche contributes to myocardial repair induced by intracoronary transplantation of bone marrow CD34+ progenitor cells in infarcted swine heart. Stem Cells. 2007;25:1 195- 203.

8. Rosenzweig A. Cardiac cell therapy--mixed results from mixed cells. N Engl J M ed. 2006;355:I274-I 277. 
9. van Laake LW, Passier R, Monshouwer-Kloots J, Verkleij AJ, Lips DJ, Freund C, Den Ouden K, Wardvan Oostwaard D, Korving J, Tertoolen LG, van Echteld CJ, Doevendans PA, Mummery CL. Human embryonic stem cell-derived cardiomyocytes survive and mature in the mouse heart and transiently improve function after myocardial infarction . Stem Cell Research. 2007;1:9-24.

10. Huang NF, Sievers RE, Park JS, Fang Q, Li S, Lee RJ. A rodent model of myocardial infarction for testing the efficacy of cells and polymers for myocardial reconstruction. Nat Protoc. 2006; 1:1596-1609.

II. van Oort RJ, van Rooij E, Bourajjaj M, Schimmel J, Jansen MA, van der NR, Doevendans PA, Schneider MD, van Echteld CJ, de Windt LJ. MEF2 activates a genetic program promoting chamber dilation and contractile dysfunction in calcineurin-induced heart failure. Circulation. 2006; I 14:298-308.

12. van Laake LW, van den DS, Post S, Feijen A, Jansen MA, Driessens MH, Mager J,, Snijder RJ,Westermann CJ, Doevendans PA, van Echteld CJ, ten Dijke P, Arthur HM, Goumans MJ, Lebrin F, Mummery CL. Endoglin has a crucial role in blood cell-mediated vascular repair. Circulation. 2006; I 4:2288-2297.

13. Yutzey KE, Robbins J. Principles of genetic murine models for cardiac disease. Circulation. 2007; I 15:792799.

14. Mummery C, Ward-van Oostwaard D, Doevendans P, Spijker R, van den BS, Hassink R, van der HM, Opthof T, Pera M, de la Riviere AB, Passier R, Tertoolen L. Differentiation of human embryonic stem cells to cardiomyocytes: role of coculture with visceral endoderm-like cells. Circulation. 2003; 107:2733-2740.

15. Passier R, Oostwaard DW, Snapper J, Kloots J, Hassink RJ, Kuijk E, Roelen B, de la Riviere AB, Mummery $C$. Increased cardiomyocyte differentiation from human embryonic stem cells in serum-free cultures. Stem Cells. 2005;23:772-780.

16. Behfar A, Perez-Terzic C, Faustino RS, Arrell DK, Hodgson DM, Yamada S, Puceat M, Niederlander N Alekseev AE, Zingman LV, Terzic A. Cardiopoietic programming of embryonic stem cells for tumor-free heart repair.J Exp M ed. 2007;204:405-420.

17. Tomescot A, Leschik J, Bellamy V, Dubois G, Messas E, Bruneval P, Desnos M, Hagege AA,Amit M, Itskovitz J, Menasche P, Puceat M. Differentiation in vivo of Cardiac Committed Human Embryonic Stem Cells in Post-myocardial Infarcted Rats. Stem Cells. 2007;25:2200-2205.

18. Costa M, Dottori M, Ng E, Hawes SM, Sourris K, Jamshidi P, Pera MF, Elefanty AG, Stanley EG. The hESC line Envy expresses high levels of GFP in all differentiated progeny. Nat M ethods. 2005;2:259-260.

19. Doevendans PA, Becker KD,An RH, Kass RS. The utility of fluorescent in vivo reporter genes in molecular cardiology. Biochem Biophys Res Commun. 1996;222:352-358.

20. Laflamme MA, Gold J, Xu C, Hassanipour M, Rosler E, Police S, Muskheli V, Murry CE. Formation of human myocardium in the rat heart from human embryonic stem cells. Am J Pathol. 2005; 167:663-67l.

21. Costa M, Sourris K, Hatzistavrou T, Elefanty AG, Stanley EG. Expansion of human embryonic stem cells in vitro. Current Protocols in Stem Cell Biology. 2007.

22. Mummery CL, Ward D, Passier R. Differentiation of human embryonic stem cells to cardiomyocytes by coculture with endoderm in serum-free medium. Current Protocols in Stem Cell Biology. 2007.

23. Balsam LB, Wagers AJ, Christensen JL, Kofidis T, Weissman IL, Robbins RC. Haematopoietic stem cells adopt mature haematopoietic fates in ischaemic myocardium. Nature. 2004;428:668-673.

24. Brazelton TR, Blau HM. Optimizing techniques for tracking transplanted stem cells in vivo. Stem Cells. 2005;23:125I-1265.

25. Burns TC, Ortiz-Gonzalez XR, Gutierrez-Perez M, Keene CD, Sharda R, Demorest ZL, Jiang Y, NelsonHolte M, Soriano M, Nakagawa Y, Luquin MR, Garcia-Verdugo JM, Prosper F, Low WC, Verfaillie CM. Thymidine analogs are transferred from prelabeled donor to host cells in the central nervous system after transplantation: a word of caution. Stem Cells. 2006;24: | |2 I-I I 27. 
26. Murry CE, Soonpaa MH, Reinecke H, Nakajima H, Nakajima HO, Rubart M, Pasumarthi KB, Virag Jl, Bartelmez SH, Poppa V, Bradford G, Dowell JD, Williams DA, Field LJ. Haematopoietic stem cells do not transdifferentiate into cardiac myocytes in myocardial infarcts. Nature. 2004;428:664-668.

27. Nygren JM, Jovinge S, Breitbach M, Sawen P, Roll W, Hescheler J, Taneera J, Fleischmann BK, Jacobsen SE. Bone marrow-derived hematopoietic cells generate cardiomyocytes at a low frequency through cell fusion, but not transdifferentiation. Nat Med. 2004; 10:494-50I.

28. Shultz LD, Schweitzer PA, Christianson SW, Gott B, Schweitzer IB, Tennent B, McKenna S, Mobraaten L, Rajan TV, Greiner DL, . Multiple defects in innate and adaptive immunologic function in NOD/LtSz-scid mice. J Immunol. 1995; I54:180-191.

29. Bajanca F, Luz M, Duxson MJ,Thorsteinsdottir S. Integrins in the mouse myotome: developmental changes and differences between the epaxial and hypaxial lineage. Dev Dyn. 2004;23 I:402-4I 5.

\section{Supplementary data: validation and sources of artifacts}

\section{Supplementary methods}

Autofluorescence was detected after deparaffinization and rehydration of 4\% PFA-fixed paraffin sections. For immunohistochemical staining standard procedures were used as previously described '. Mouse anti-human-mitochondria antibody (hu-mito, Chemicon) and mouse-anti tropomyosin antibody (Sigma) were used at I:100 and I:50, respectively. Mouse IgG isotype control (DAKO) was used at matching concentrations. Antigen retrieval was done by boiling heart sections for $20 \mathrm{~min}$ in $0.1 \mathrm{M}$ citric acid and $0.1 \mathrm{M}$ sodium citrate. To avoid non-specific staining with mouse antibodies in mouse tissue, binding of primary and secondary antibody and blocking with normal mouse serum (NMS) preceded incubation on sections ${ }^{2}$.

For PKH-26 labeling dissociated HES3 were incubated in 4x10-6 M PKH-26 for 2 to $5 \mathrm{~min}$ at RT. The labeling reaction was stopped by adding an equal volume of serum. Following two washes in PBS, labeled cells were injected in transgenic GFP-mice. As a control, HES3-GFP cells were also labeled with PKH-26 and injected in NOD-SCID mice. Hearts were isolated and frozen for cryosections I week after transplantation. 


\section{Supplementary results}

In routine histological processing, ethanol incubation during dehydration results in loss of GFP epifluorescence. This can sometimes be restored by rehydration. We therefore initially tried to regain GFP fluorescence of GFP-expressing HESC-derived cells after transplantation in mouse hearts by deparaffinizing and rehydrating PFA-fixed paraffin sections. This resulted in brightly green fluorescent cells, that contrasted sharply with neighboring non-fluorescent cardiomyocytes. However, staining with mouse anti-human mitochondria antibody did not overlap with green fluorescence (Supplementary fig. IA-C). Isotype controls (mouse $\operatorname{lgG}$ ) demonstrated that the staining on these fixed sections was non-specific. The antibody and the isotype control gave the same cytoplasmic staining, instead of the expected punctate mitochondrial pattern (Supplementary fig. ID-G). Even secondary antibody alone reproduced this staining (Supplementary fig. IH-I). We then applied a modified protocol, specifically developed for using mouse antibodies in mouse tissue (ref Hierck), which completely blocked the non-specific staining of both mouse anti-human mitochondria and mouse anti- (mouse and human) tropomyosin antibodies (Supplementary fig. IJ-K), demonstrating that in fact no HESC-derived cells were present in these particular sections. Analysis of the emission wave length spectrum of the green fluorescence in the sections was, however, compatible with auto-fluorescence (data not shown; similar result in Fig. IO-Q). All subsequent analysis was therefore based on cryo- instead of paraffin embedding. In addition to genetic marking by GFP, dye- or iron-labeling of cells before transplantation is often used for tracking after transplantation ${ }^{3 ; 4}$. We also used dye-labeling to determine whether fusion took place between host and transplanted cells. PKH-26-labeled differentiated HESC (without GFP) were injected into hearts of transgenic GFP-mouse cells; an occasional PKH-26 $/ 6^{+} \mathrm{GFP}^{+}$cell was observed (Supplementary fig. IL-N). However, when differentiated HES3-GFP cells were labeled with PKH-26, it became clear that the dye does not necessarily stay within the labeled cells after transplantation (Supplementary fig. IO-Q). 


\section{Supplementary references}

I. van Laake LW, van den DS, Post S, Feijen A, Jansen MA, Driessens MH, Mager JJ, Snijder RJ,Westermann CJ, Doevendans PA, van Echteld CJ, ten Dijke P, Arthur HM, Goumans MJ, Lebrin F, Mummery CL. Endoglin has a crucial role in blood cell-mediated vascular repair. Circulation. 2006; I 4:2288-2297.

2. Hierck BP, Iperen LV, Gittenberger-De Groot AC, Poelmann RE. Modified indirect immunodetection allows study of murine tissue with mouse monoclonal antibodies. J Histochem Cytochem. 1994;42:1499_ 1502.

3. Burns TC, Ortiz-Gonzalez XR, Gutierrez-Perez M, Keene CD, Sharda R, Demorest ZL, Jiang Y, NelsonHolte M, Soriano M, Nakagawa Y, Luquin MR, Garcia-Verdugo JM, Prosper F, Low WC, Verfaillie CM. Thymidine analogs are transferred from prelabeled donor to host cells in the central nervous system after transplantation: a word of caution. Stem Cells. 2006;24: I I I - I I 27.

4. Pearson H. Stem-cell tagging shows flaws. Nature. 2006;439:5I9. 


\section{Human Embryonic Stem Cell -Derived Cardiomyocytes Survive and Mature in the Mouse Heart andTransiently Improve Function after Myocardial Infarction}

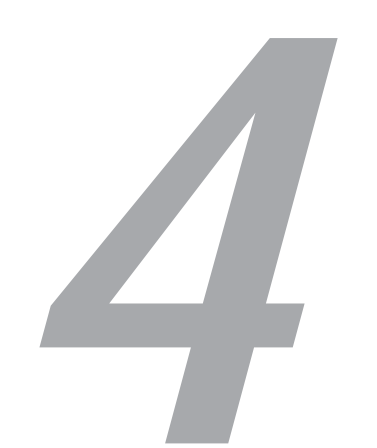

Published as

L.W. van Laake, R. Passier, J. Monshouwer-Kloots, A.J.Verkleij, D.J. Lips, C. Freund, K. den Ouden, D.Ward-van Oostwaard, J. Korving, L.G. Tertoolen, C.J. van Echteld, P.A. Doevendans, C.L. Mummery. Human Embryonic Stem Cell-Derived Cardiomyocytes Survive and Mature in the Mouse Heart and Transiently Improve Function after M yocardial Infarction. Stem Cell Research. 2007; I ( I):9-24 


\section{Abstract}

Regeneration of the myocardium by transplantation of cardiomyocytes is an emerging therapeutic strategy. Human embryonic stem cells (HESC) form cardiomyocytes readily but until recently at low efficiency so that preclinical studies on transplantation in animals are only just beginning. Here, we show the results of the first long term (I2 weeks) analysis of the fate of HESCderived cardiomyocytes (HESC-CM) transplanted intramyocardially in healthy, immunocompromised (NOD-SCID) mice and NOD-SCID mice that had undergone myocardial infarction (MI). Transplantation of mixed populations of differentiated HESC containing 20-25\% cardiomyocytes in control mice resulted in rapid formation of grafts in which the cardiomyocytes became organized and matured over time and the non-cardiomyocyte population was lost. Grafts also formed in mice that had undergone MI. Four weeks after transplantation and $\mathrm{Ml}$, this resulted in significant improvement in cardiac function measured by Magnetic Resonance Imaging (MRI). However, at 12 weeks, this was not sustained despite graft survival. This suggested that graft size was still limiting despite maturation and organization of the transplanted cells. More generally, the results argued for requiring minimally 3 months follow up in studies claiming to observe improved cardiac function, independent of whether HESC or other (adult) cell types are used for transplantation.

\section{Introduction}

The adult human heart has a minimal ability to regenerate myocardium, so that the loss of viable cardiomyocytes in cardiac disease, precipitated by myocardial infarction (MI), leads to heart failure. Cell transplantation for cardiomyocyte replacement represents a potential opportunity for a new treatment strategy ${ }^{1 ; 2}$. The transplantation of adult (bone marrow) stem cells has already entered clinical trials, based on reports of improved cardiac function in animals ${ }^{3 ; 4}$, although the robustness of these results have been questioned and there is no evidence that the transplanted cells form cardiomyocytes or contribute to the myocardium ${ }^{5-7}$. Fusion of bone marrow stem cells with cardiomyocytes in the heart in situ and misinterpretation of autofluorescence artifacts from 
dying cells and macrophages have been proposed as explanations for their apparent transdifferentiation ${ }^{5-8}$. The functional improvements reported may have resulted from cell-independent mechanisms and/or neovascularization 9 The outcomes of clinical trials with various bone marrow fractions have so far been inconsistent and suggested mainly modest, temporary enhancement of cardiac function ${ }^{10-13}$. In almost all pre-clinical experiments in rodents and larger animals such as swine and sheep, follow-up has been limited to short- and mid-term, usually a maximum of 2 to 6 weeks ${ }^{3 ; ; ; 14 ; 15}$. Most investigators have found a positive effect of cell transplantation post-MI at these early time points, independent of whether bone marrow cells (BMCs), mesenchymal stem cells (MSCs) or mouse embryonic stem cells (mESCs) were used and whether they were injected intravenously or intramyocardially. Beneficial effects have also been reported even when transplanted cells were no longer detectable in the myocardium ${ }^{16 ; 17}$.

Human embryonic stem cells (HESCs), have clearly been shown to have the capacity to differentiate into cardiomyocytes in vitro ${ }^{18-21}$. We and others have shown that HESC-derived cardiomyocytes (HESC-CM) have a fetal rather than adult phenotype, based on their expression of sarcomeric proteins and electrophysiological characteristics ${ }^{18 ; 19 ; 22}$. In previous reports, HESC-CM have also been engrafted into uninjured rat hearts ${ }^{23}$ and in electrophysiologically silenced guinea pig and swine hearts ${ }^{24,25}$. Cells were found to survive and pace the recipient myocardium. However, the long term effects of transplantation, particularly whether functional improvement and graft survival are sustained, are not known.

Here, we describe results of the first long term study of HESC-CM in uninjured and infarcted mouse hearts. By immunohistological and ultrastructural analysis of grafts over time, we demonstrated that HESC-CM survive, integrate and mature in the host myocardium for at least 12 weeks. Magnetic Resonance Imaging (MRI) showed that HESC-CM transplantation improved heart function after $\mathrm{Ml}$ at 4 weeks, but this was not sustained at 12 weeks despite the continued presence of healthy grafts. 


\section{Methods}

Cell culture, differentiation and dissociation

HES3-GFP cells ${ }^{26}$ were cultured and induced to form cardiomyocytes by coculture with END2 cells $19 ; 20$. This procedure consistently gives rise to beating areas within 12 days of culture. Beating areas consist of approximately $20-25 \%$ CM and $75-80 \%$ endo- or other mesodermal derivates ${ }^{20 ; 55}$. Beating areas were dissected and dissociated with collagenase as described previously 20;56. For control experiments HES3-GFP cells were cultured on gelatin for 12 days. Under these conditions HES3-GFP cells underwent spontaneous differentiation and did not form $\alpha$-actinin positive cells after 12 days of culture (non-CM differentiated control cells). 200,000 (histology experiments) or I,000,000 cells (myocardial infarction and histology experiments) were taken up in a final volume of $15 \mu \mathrm{l}$ fresh medium and used for transplantation.

\section{Animals and surgical procedures}

All procedures involving experimental animals were approved by the Institute Animal Care Committee. Male NOD-SCID mice (Charles River) of II-12 weeks of age were used for all surgical procedures. Myocardial infarction (MI) was induced by ligation of the left anterior descending coronary artery (LAD) after left-sided thoracotomy, as described previously ${ }^{33}$. Ligation site was I mm below the left auricle. Non-infarcted mice underwent the same procedure but without ligation of the LAD. In the same operation, cells were injected in the infarcted (MI mice; $n=28$ ) or healthy (non-MI mice; $n=36$ ) myocardium of the free left ventricular wall using an insulin syringe with incorporated 29G needle. The surgeon (LL) was blinded for the cell type injected. At 2.5 days, I week, 3 weeks, 10 weeks and 12 weeks after surgery, animals were euthanized and the hearts were fixed and processed for cryosections as described ${ }^{57}$ with minor modification (sectioning in tissue-tec). Lungs, liver, kidneys, spleen and brain were also examined for the presence of tumors.

\section{RI analysis of cardiac function}

2 days, 4 weeks and 12 weeks post-MI, magnetic resonance images were acquired on a 9.4-T scanner (Bruker Biospin GmbH, Rheinstetten, Germany) as described ${ }^{33}$; up to 10 short-axis slices were required to image the dilated LV. 
Analysis was performed using Q-mass digital imaging software (Medis, Leiden, the Netherlands) by two independent blinded investigators ( $\mathrm{KdO}$ and $\mathrm{LvL}$ ).

\section{Immunofluorescence}

The complete GFP cell-containing area of each heart was cut into $6 \mu \mathrm{m}$ cryosections, which were stained as described ${ }^{33}$ using the following antibodies and dilutions: human nuclei (I:200) and human mitochondria (I:200) (both mouse, Chemicon), GFP (I:500) (rabbit, Abcam), $\alpha$-actinin (I:200) (rabbit, a kind gift from Elisabeth Ehler) or (I:800) (mouse, Sigma), tropomyosin (I:I00) (mouse, Sigma), troma-I (I:500) (rat, Developmental Studies Hybridoma Bank), PECAM-I (I:I00) (goat, Santa Cruz), MLC2A (I:100) (mouse, Synaptic Systems), MLC2V (I:50) (mouse, Synaptic Systems), Ki-67 (I:500) (rabbit, Abcam), smooth muscle actin (I:100) (rabbit, Abcam), connexin-43 (I:200) (rabbit, Zymed) and desmoplakin (undiluted) (mouse, Progen Biotechnik), laminin (I:500) (rabbit, Sigma). Isotype controls (DAKO) were performed for each class of antibody used. Cy-3 and Cy-5 labeled secondary antibodies were from Jackson Immuno Research Laboratories. WGA-TRITC (Sigma) was used for membrane staining and topro-3 (I:1000) (molecular probes) for nuclear counterstaining.

\section{M icroscopical analysis}

A Leica MZ I6FA / DFC480 fluorescence microscope was used to image whole hearts. Confocal scanning (with sequential scanning for GFP with excitation laser $488 \mathrm{~nm}$, Cy3/TRITC with $543 \mathrm{~nm}$ and Cy5 with $633 \mathrm{~nm}$, respectively, to avoid signal leakage) and emission wave length spectrum analysis were performed on a Leica SP2 AOBS confocal laser scanning microscope. For quantification of cell survival and expression of phenotype markers, all GFP-cells in at least 9 evenly distributed sections of each heart were counted by two independent blinded investigators (JM and LvL). Only nuclei-containing cells were included to avoid double counting in multiple sections. Non-fluorescent stainings were imaged on a Nikon Eclipse E600 / DXMI200 microscope.

For electron microscopy, hearts were perfusion- and subsequently immersionfixed with $2 \%$ formaldehyde $/ 0.05 \%$ glutaraldehyde in $100 \mathrm{mM}$ phosphate buffer $\mathrm{pH}$ 7.4, and processed for Tokuyasu cryo-sectioning ${ }^{58 ; 59}$. The $60 \mathrm{~nm}$ sections were labeled with anti-GFP antibody (I:I00) (rabbit, Abcam), which was detected with protein A $10 \mathrm{~nm}$ gold (Utrecht Medical Center, Cell Microscopy Center) ${ }^{60}$, and imaged with a JEOL 1010 electron microscope at $80 \mathrm{kV}$. 


\section{Statistical analysis}

Statistical significance was evaluated with SPSS vII.5 for Windows using ANOVA or Mann-Whitney $U$ test with correction for multiple-group comparisons by Bonferroni or Median test, respectively, where applicable. Results are expressed as mean \pm SEM. A value of $p<0.05$ was considered statistically significant.

\section{Results}

Tracking of transplanted human cells in the mouse heart

HESCs expressing GFP ubiquitously (HES3-GFP 26:27) were induced to differentiate in serum free medium as previously ${ }^{19 ; 20}$. Single cell suspensions containing 20-25\% cardiomyocytes were prepared from beating areas for injection. Within three weeks of intramyocardial injection in NOD-SCID mice, the differentiated cells had formed stable grafts, enabling us to validate methods for unambiguous graft identification at all other time points ( 2.5 days to 12 weeks) after transplantation, avoiding artifacts that easily arise in these experiments ${ }^{28}$. The human origin of GFP-expressing cells was confirmed by staining with antibodies recognizing only human, and not mouse, nuclei and mitochondria in matching patterns (Fig. IA-H). By analyzing wave length emission spectra, GFP fluorescence could be distinguished from non-specific autofluorescence of blood and dead cells, which were also present in the graft area (Fig. II-Q). Finally, staining with anti-GFP-antibody overlapped with GFP epifluorescence, demonstrating that in the HES3-GFP cell line, GFP was bright enough to be used as the primary cell tracking marker (Fig. IR-U). All antibody isotype controls were negative.

HESC-derived grafts are maintained in the mouse heart for at least 12 weeks independently of fusion with host cells

The superficial part of the grafts (close to the epicardium) could be visualized in whole mount hearts as islands of GFP-fluorescent cells which remained detectable up to 12 weeks, the latest time-point examined (Fig. 2A-F and 2J-O). Transverse division and sectioning of the hearts showed transmural incorporation of HESC-CM in the left ventricular wall where the cells had been injected (Fig. 2G-I). Since all nuclei in $\mathrm{GFP}^{+}$-cells stained with human- 
nuclei antibody (except those in metaphase, a known characteristic of the antibody as indicated by the manufacturer), survival of the transplanted cells was unlikely to be the result of fusion between donor and host cells (Fig. 3A-C). Further, HESC-CM in vitro have an immature phenotype comparable to early human fetal cardiomyocytes ${ }^{19}$. Despite ventricular action potentials ${ }^{19}$, HESCCM express only myosin light chain $2 \mathrm{~A}$ (MLC2A), and not MLC2V protein in sufficient quantities to be recognized by an antibody (Supplementary fig. I); mouse ventricular cardiomyocytes by contrast express MLC2V exclusively. This differential expression pattern, compatible with differences described between human and mouse fetal heart ${ }^{29}$ was evident at all early time-points after transplantation; this again corroborated the improbability of cell fusion taking place on a large scale (Fig. 3D-I).

\section{Selective survival of HESC-CM and proliferation of transplanted cells}

Since the injected cell preparations contained only $20-25 \%$ cardiomyocytes, we examined the fate of HESC-CM versus other cell types present in the injected suspensions after transplantation. Over a period of 2.5 days to 10 weeks, an increasing proportion of GFP-expressing cells with validated emission spectra stained positive for cardiac markers; these included cardiac $\alpha$-actinin (Fig. 4AL), tropomyosin (data not shown) and MLC2 (examples of staining in Fig. 3 and Fig. 6). The organization of the grafts improved from an incoherent cluster of multiple cell types (Fig. 4A-D) to more rod-shaped cardiomyocytes aligned with the mouse myocardium (Fig. 4E-H). However, large clusters of grafted cardiomyocytes in varying orientations were also seen at later time-points (Fig. 4I-L). Concurrently, the number of cells with an endoderm-like phenotype staining for cytokeratin 8/troma-I (Fig. 4M-P) rapidly decreased. No endothelial differentiation from HESC-derived cells was found. Instead, blood supply to the grafts seemed to occur from mouse-derived vessels through local angiogenesis (Fig. 4Q-T). Quantification of cardiac marker versus endodermal marker expression in grafted GFP cells confirmed the retention of cardiomyocytes and disappearance of other cell types in the weeks after transplantation (Fig. $4 \mathrm{U}$ $\mathrm{V})$. We next calculated the efficiency of the cell transplantation as the ratio of GFP-cells present at a given time point to the total number of cells that were injected. Overall, cell survival diminished over time, leaving a final efficiency of only $2.3 \pm 0.6 \%$, but the absolute number of cardiomyocytes remained stable in 
the order of 10\% (Fig. 5A-C and Supplementary table I). Thus, selective survival of cardiomyocytes rather than (trans)differentiation of non-cardiomyocytes would seem the likely mechanism underlying the over representation of cardiomyocyte phenotype over time. Indeed, when we injected HES3-GFP from non-beating areas of HES3-GFP / END2 co-culture, containing only very few cardiomyocytes, no or only extremely small grafts were found after more than 3 weeks ( $n=12$, data not shown).

Cell cycle activity in graft cells was observed at all time-points, with a peak at I week post-transplantation, and increasingly predominantly in cardiomyocytes parallel to the rise in representation of the cardiomyocyte phenotype over time (Fig. 5D-M). No HESC related tumor formation was observed at any time-point in any organ (data not shown).

\section{Maturation of $\mathrm{HESC}-\mathrm{CM}$ in vivo.}

In beating areas in vitro, $\alpha$-actinin positive HESC-CM express smooth muscle actin (SMA) indicating their immaturity ${ }^{30 ; 31}$ (Supplementary fig. I). Within I week of transplantation however, SMA was completely downregulated (Fig. 6A$D$ and Table I). In addition, 3 weeks after transplantation all grafted GFP cells still expressed MLC2A, as in vitro and at I week post transplantation (Fig. 3), but many of them had become double positive for MLC2A and MLC2V (Fig. $6 \mathrm{E}-\mathrm{J})$. This maturation continued and at 10 weeks double positive cells were only occasionally observed; most GFP cells were either MLC2A positive or had become MLC2V positive (Fig. 6K-R and Table I)

Table 1. Maturation of HESC-CM in vivo after transplantation in the mouse heart

\begin{tabular}{lllll}
\hline & MLC2 & SMA & Cx-43 & Desmoplakin \\
\hline In vitro & A & + & - or $+/-$ & + \\
$\mathbf{2 . 5}$ days & $\mathrm{A}$ & $+/-$ & - & $+/-$ \\
$\mathbf{1}$ week & $\mathrm{A}$ & - & - or $+/-$ & $+/-$ or + \\
$\mathbf{3}$ weeks & A or A and V & - & $+/-$ & + (hu-hu) \\
$\mathbf{1 0}$ weeks & A and V or A or V & - & $+/-$ or + (hu-hu) & + (hu-hu) or + (hu-ms $)$ \\
\hline
\end{tabular}

Functional coupling after transplantation

As the HESC-CM were injected as single cells, they would need to re-establish intercellular contacts in order to form a functional syncytium. Connexin-43 (Cx43), normally located at gap junctions between mature cardiomyocytes ${ }^{32}$, was 
upregulated over time. Up to 3 weeks after transplantation $C_{x}-43$ was present, but not in the clear pattern of gap-junctional structures (Fig. 7A-D). Only after 10 weeks, were gap junctions with $\mathrm{Cx}-43$ seen between adjoined HESC-CM (Fig. 7E-H and Table I). The organization of desmoplakin, a desmosomal protein, was already clear at 3 weeks after transplantation and sporadically some desmosome formation was observed between HESC-CM and mouse cardiomyocytes (Fig. 7I-T and Table I). In agreement with the antibody staining, electron microscopy demonstrated that HESC-CM were connected to each other via desmosomes, but were usually separated from mouse cardiomyocytes by a thin $(0.5-20 \mu \mathrm{m})$ layer of extracellular matrix (Fig. 7U-V).

HESC-CM improved mid-term, but not long-term, heart function after myocardial infarction

To assess the effect of HESC-CM on cardiac function, we injected I $\times 10^{6}$ cells from beating areas of HES3-GFP (HESC-CM group) or differentiated nonCM cells from the same origin (non-CM group) in mice with acute myocardial infarction (MI) and measured heart function after 2 days (acute phase), 4 weeks (mid-term) and 12 weeks (long-term) by MRI as previously ${ }^{33}$. Twelve weeks after injection, GFP-fluorescent grafts were found in all mouse hearts that received HESC-CM and in none of the non-CM transplanted hearts (Fig. 8AC). GFP'-cells were mostly localized in the border zone of the infarct but also in the middle of the infarct surrounded by scar tissue (Fig. 8A-C). Although we created large infarcts to obtain maximum reproducibility, 12 week survival of the mice was $>80 \%$ and similar in the two experimental groups of mice (Fig. 8D). Heart function 2 days post-MI was equal in the HESC-CM and nonCM groups, showing a comparable baseline situation. Four weeks after MI, HESC-CM mice had a significantly greater ejection fraction (EF) than non-CM mice. Stroke volume (SV) was also larger, resulting from improved contractility because dilatation was even slightly less pronounced in HESC-CM mice. The natural reduction in EF from 2 days to 4 weeks post-MI (serial measurements in each mouse) was similarly attenuated in the HESC-CM group. Nevertheless, at 12 weeks after induction of $\mathrm{MI}$ and cell transplantation, these beneficial effects of cardiomyocytes were not retained whether the absolute 12 weeks or the change from 2 days to 12 weeks comparison was made (Fig. $8 \mathrm{E}-\mathrm{Q}$ and Supplementary table 2 ). 


\section{Discussion}

We have demonstrated that HESC-CM can survive, integrate and mature after intramyocardial injection in immunodeficient mice, presenting for the first time a series with follow-up of up to 12 weeks. The importance of this extended follow-up was emphasized by the significant beneficial effect of HESC-CM on heart function after $\mathrm{MI}$ when analysis was at mid-term, but its failure to be sustained when analysis was long-term.

In any cell transplantation study, great care should be taken to avoid misinterpretation of data arising from artifacts that can occur as a consequence of injury (by needle manipulation or infarction) and inflammation of the tissue, potential immune activation, and cell death ${ }^{5-8 ; 34}$. We excluded non-specific staining and autofluorescence and circumvented the need for indirect tracking methods such as dye-labeling by using the HES3-GFP cell line Envy, which maintains strong GFP-fluorescence in all undifferentiated as well as differentiated cells ${ }^{26}$. Combining this genetic tracking with emission finger printing and humanspecific antibody staining, we confirmed the presence of cells of human origin in the mouse heart for at least 12 weeks after transplantation. This is by far the longest follow-up that has been reported to date for HESC transplantation studies in heart. No addition of matrix or pro-survival factors was required to sustain grafts even as long as 12 weeks after $\mathrm{MI}$, contrary to findings by others (Laflamme and Murry, abstract AHA Scientific Sessions 2006).

The immaturity of the HESC-CM generated in our END2 co-culture system, with a phenotype resembling that of end first trimester human fetal cardiomyocytes ${ }^{20 ; 29}$, may contribute to the reasonably good graft survival that was essentially independent of fusion with host cardiomyocytes ${ }^{35}$. Transplanted fetal cardiomyocytes have been shown by others to survive and integrate much better than primary adult cardiomyocytes into adult myocardium ${ }^{36}$ and have a better capacity for proliferation, just as we observed in the HESC-CM grafts. However, in terms of long term compatibility (for example electrophysiological matching), a more mature phenotype would eventually be required. It was therefore encouraging that the HESC-CM matured in vivo after transplantation, even in a xeno-transplantation model where the paracrine, structural and mechanical factors may not be optimally suited to meet the needs of human cardiomyocytes. Nevertheless, these factors were apparently sufficient to result 
in selective survival of cardiomyocytes and loss of other differentiated HESC from the END-2 co-culture system, in accordance with a previous report on transplantation of HESC-derived cells in rats ${ }^{23}$. However, differentiated cultures of HESC arising from END-2 co-culture are, for example, devoid of neural cells (Beqqali et al, 2006); we cannot therefore exclude the possibility that some HESC-derivatives would be able to escape a selective survival mechanism, so that efforts to derive pure cardiomyocyte populations are still justified.

The maturation of HESC-CM observed here was not only evident from the morphological appearance of cells within the graft, which showed improved sarcomeric organization and alignment within the host myocardium over time, but also from downregulation of markers associated with immaturity (SMA and MLC2A), upregulation of markers of more mature cells (MLC2V, Cx-43) and increased intercellular contacts (desmosomes and gap junctions).

The mechanisms by which selective survival and maturation of HESC-CM in vivo is accomplished have yet to be determined, but may be based on integrinmediated cell-cell and cell-extracellular matrix interactions, also including stretch and stiffness ${ }^{37-41}$. Furthermore, paracrine factors ${ }^{42}$ and electrophysiological signals ${ }^{43}$ may play an additional role.

Selection of HESC-CM from mixed differentiated cell populations has recently been described ${ }^{44}$ and will certainly be invaluable for in vitro studies, but it remains to be seen whether pure cardiomyocyte populations would be preferable to mixed populations with respect to transplantation efficiency. For example, coinjection of fibroblasts with $\mathrm{mESCs}$ greatly improved survival and restoration of cardiac function compared to $\mathrm{mESCs}$ alone ${ }^{45}$.

HESC-CM have been reported previously after transplantation in the heart to drive the myocardium electrically when it has been electrophysiologically silenced or slowed down, thus functioning as biological pacemakers ${ }^{24,25}$. This implies that HESC-CM can functionally couple to the host myocardium. We found that HESC-CM generally form intra-graft desmosomes and gap junctions, but only rarely were they connected to mouse cardiomyocytes by desmosomes, even in 12 week grafts. More often, a thin layer of extracellular matrix separated donor and host cells. Even so, this does not exclude the possibility of extensive functional coupling since electrophysiological signaling can be conducted through much thicker layers of fibrotic tissue ${ }^{46}$. Of note is the enormous difference between mouse and human heart rates: a mouse heart may beat 
400-600 times per minute whereas in humans, this is $60-100$ beats per minute. The question therefore arises whether matured human cardiomyocytes could actually be expected to couple functionally to adult mouse cardiomyocytes in vivo. Nevertheless, even though we found no evidence for arrhythmias induced by the transplanted cells, the (ar)rhythmogenic potential of HESC-CM in infarcted hearts should be investigated in larger animals models with slower heart rates than the mouse. A note of caution is also warranted with respect to the absence of evidence for tumor formation, particularly teratomas or teratocarcinomas, in the present study. Whilst reassuring that the differentiation method used did not result in residual expression of stem cell markers at the time of transplantation or teratomas in the heart or elsewhere, even in SCIDmice ${ }^{47}$ without preselection of cardiomyocytes, reported as essential when transplanting $\mathrm{mESC}$-derived cardiomyocytes ${ }^{45}$, xeno-transplantation may be less likely to induce teratomas than intra-species transplantations ${ }^{48}$. In our study, immune rejection was prevented by using NOD-SCID mice. In preliminary experiments with wildtype mice (data not shown) we found no evidence for a major immune privilege of transplanted differentiated HESCs compared to adult progenitor cells ${ }^{33}$ : immune suppression by the cyclosporinanalogue Tacrolimus was necessary to avoid rejection, but daily injections and the small therapeutic range of the agent made its use not feasible for studies with long term follow-up. HESCs however, may be suitable for immunogenicityreducing strategies, including induction of tolerance in the recipient, or HLAmatched transplantation from stem cell banks ${ }^{49 ; 50}$.

Since in the light of their unambiguous cardiac phenotype, fetal characteristics and selective survival in the adult mouse heart, HESC-CM seemed to be a promising cell source for cardiac regeneration, we investigated this potential capacity in a mouse model of myocardial infarction. However, because multiple cell types have now been shown to induce short term improvement in cardiac function in this $\mathrm{Ml}$ model, we anticipated that there may be beneficial effects of any cell type (Merx and Weber, abstract World Congress of Cardiology 2006). To assess specifically the effects of additional cardiomyocytes in the infarcted myocardium, we injected differentiated non-CM as a control. Serial measurements by high-resolution MRI-scanning enabled us to follow the heart function of each mouse at 2 days, 4 weeks and 12 weeks after MI. In spite of the hostile ischemic environment in which the cells were injected, small but 
clearly visible grafts were present in all hearts 12 weeks after treatment with HESC-CM, reflecting the relative robustness of these cells when transplanted in the heart.

Reduction of contractile capacity, indicated by ejection fraction (EF), and dilation of the infarcted LV wall, indicated by increased end diastolic volume (EDV), are in the natural course of events after $\mathrm{MI}^{51}$. Stroke volume (SV) may also be reduced depending on the ratio between dilation and impaired contraction. Remarkably, transplantation of HESC-CM after MI resulted in a significantly better EF and SV at 4 weeks post-MI when compared to non-CM transplanted controls. Also when the reduction of these parameters from 2 days to 4 weeks was analyzed, the HESC-CM treated mice had an unmistakably better outcome than controls. However, at 12 weeks post-MI there was no longer a difference in EF and SV between the two groups, although there was some evidence of a sustained anti-remodeling effect (less dilation and compensatory hypertrophy in the HESC-CM group; Supplementary results). Hence, HESC-CM had only temporarily preserved heart function after MI. The beneficial mid-term effect may have been caused by paracrine factors from the transplanted HESC, advantageous effects of inflammation, passive support or actual contribution of the grafted cells to contraction. It seems likely that for long term improvement, larger grafts, consisting of functional and integrated cardiomyocytes, would be required.

Comparing these results to previous data in mice using BMCs which have already been transferred to clinical trials ${ }^{10-13}$, it is of note that the extent of the transient mid-term improvement we report here was comparable to several of these BMC studies, where the effects were generally unrelated to cellular engraftment and long term data are lacking ${ }^{52-54}$.

It remains to be determined how precisely these experiments using a MI model in mice can be translated to patients and whether they will benefit from such therapeutic interventions of which the effects are substantial but nevertheless, at present, transient. Sustained enhancement of heart function and prevention of heart failure should be the holy grail in pre-clinical studies just as in translation to the clinic. We show here that mid-term results may differ considerably from and not predict long term outcome. As a consequence reported short- and mid-term functional improvements by any cell type should be re-evaluated, raising the bar for this field of research. 
Taken together, the results showed that intramyocardially transplanted HESCCM are able to integrate and mature in vivo in the myocardium of adult mice. HESC-CM also survive in infarcted hearts for at least 12 weeks and improve heart function at 4 weeks, but not 12 weeks post-MI in the current application, demonstrating the requirement for long-term follow-up in all cardiac cell transplantation studies. Alternative transplantation protocols with larger numbers of cardiomyocytes, multiple grafts or methods to prevent cells eluting into the circulation after transplantation, could eventually lead to realization of further and sustained enhancement of heart function post-MI.

\section{Acknowledgements}

J.M. and C.F. were supported by Embryonic Stem Cell International, L.v.L in part by the Dutch Platform for Tissue Engineering and R.P. by the EU (Heart Development and Heart Repair). We are grateful to E.G. van Donselaar and B.M. Humbel for expertise in electron microscopy, S. van den Brink for cell culture, W. Hage and J. Kuipers for assistance with confocal microscopy, M. Nederhoff for help with MRI, and M-J. Goumans and L. Timmers for fruitful discussions.

\section{References}

I. Dimmeler S, Zeiher AM, Schneider MD. Unchain my heart: the scientific foundations of cardiac repair. J Clin Invest. 2005; I 15:572-583.

2. van Laake LW, Hassink R, Doevendans PA, Mummery C. Heart repair and stem cells.J Physiol. 2006;577:467478.

3. Orlic D, Kajstura J, Chimenti S, Jakoniuk I, Anderson SM, Li B, Pickel J, McKay R, Nadal-Ginard B, Bodine DM, Leri A, Anversa P. Bone marrow cells regenerate infarcted myocardium. Nature. 200 I;4I 0:70I-705.

4. Orlic D, Kajstura J, Chimenti S, Limana F, Jakoniuk I, Quaini F, Nadal-Ginard B, Bodine DM, Leri A, Anversa P. Mobilized bone marrow cells repair the infarcted heart, improving function and survival. Proc Natl Acad Sci U SA. 2001;98:10344-10349.

5. Balsam LB, Wagers AJ, Christensen JL, Kofidis T, Weissman IL, Robbins RC. Haematopoietic stem cells adopt mature haematopoietic fates in ischaemic myocardium. Nature. 2004;428:668-673.

6. Murry CE, Soonpaa MH, Reinecke H, Nakajima H, Nakajima HO, Rubart M, Pasumarthi KB, Virag J, Bartelmez SH, Poppa V, Bradford G, Dowell JD, Williams DA, Field LJ. Haematopoietic stem cells do not transdifferentiate into cardiac myocytes in myocardial infarcts. Nature. 2004;428:664-668. 
7. Nygren JM, Jovinge S, Breitbach M, Sawen P, Roll W, Hescheler J, Taneera J, Fleischmann BK, Jacobsen SE. Bone marrow-derived hematopoietic cells generate cardiomyocytes at a low frequency through cell fusion, but not transdifferentiation. Nat M ed. 2004; 10:494-50।.

8. Brazelton TR, Blau HM. Optimizing techniques for tracking transplanted stem cells in vivo. Stem Cells. 2005;23:125I-1265.

9. Fazel S, Cimini M, Chen L, Li S,Angoulvant D, Fedak P,Verma S, Weisel RD, KeatingA, Li RK. Cardioprotective c-kit + cells are from the bone marrow and regulate the myocardial balance of angiogenic cytokines.J Clin Invest. 2006; | 16:1865-1877.

10. Assmus B, Honold J, Schachinger V, Britten MB, Fischer-Rasokat U, Lehmann R, Teupe C, Pistorius K, Martin H, Abolmaali ND, Tonn T, Dimmeler S, Zeiher AM. Transcoronary transplantation of progenitor cells after myocardial infarction. N Engl J M ed. 2006;355:I222-I 232.

II. Lunde K, Solheim S, Aakhus S, Arnesen H, Abdelnoor M, Egeland T, Endresen K, llebekk A, Mangschau A, Fjeld JG, Smith HJ,Taraldsrud E, Grogaard HK, Bjornerheim R, Brekke M, Muller C, Hopp E, Ragnarsson A, Brinchmann JE, Forfang K. Intracoronary injection of mononuclear bone marrow cells in acute myocardial infarction. N Engl J Med. 2006;355:I I99-1209.

12. Rosenzweig A. Cardiac cell therapy--mixed results from mixed cells. N Engl J M ed. 2006;355: I274-I 277.

13. Schachinger V, Erbs S, Elsasser A, Haberbosch W, Hambrecht R, Holschermann H, Yu J, Corti R, Mathey DG, Hamm CW, Suselbeck T, Assmus B, Tonn T, Dimmeler S, Zeiher AM. Intracoronary bone marrowderived progenitor cells in acute myocardial infarction. N Engl J M ed. 2006;355:1210-1221.

14. Menard C, Hagege AA, Agbulut O, Barro M, Morichetti MC, Brasselet C, Bel A, Messas E, Bissery A, Bruneval P, Desnos M, Puceat M, Menasche P. Transplantation of cardiac-committed mouse embryonic stem cells to infarcted sheep myocardium: a preclinical study. Lancet. 2005;366:1005-1012.

15. Zhang S, Ge J, Zhao L, Qian J, Huang Z, Shen L, Sun A, Wang K, Zou Y. Host vascular niche contributes to myocardial repair induced by intracoronary transplantation of bone marrow CD34+ progenitor cells in infarcted swine heart. Stem Cells. 2007;25: I 195-I 203.

16. Iso Y, Spees JL, Serrano C, Bakondi B, Pochampally R, Song YH, Sobel BE, Delafontaine P, Prockop DJ. Multipotent human stromal cells improve cardiac function after myocardial infarction in mice without long-term engraftment. Biochem Biophys Res Commun. 2007;354:700-706.

17. Muller-Ehmsen J, Krausgrill B, Burst V, Schenk K, Neisen UC, Fries JW, Fleischmann BK, Hescheler J, Schwinger RH. Effective engraftment but poor mid-term persistence of mononuclear and mesenchymal bone marrow cells in acute and chronic rat myocardial infarction.J M ol Cell Cardiol. 2006;4I:876-884.

18. Kehat I, Kenyagin-Karsenti D, Snir M, Segev H, Amit M, Gepstein A, Livne E, Binah O, Itskovitz-Eldor J, Gepstein L. Human embryonic stem cells can differentiate into myocytes with structural and functional properties of cardiomyocytes. J Clin Invest. 200 I; 108:407-4I4.

19. Mummery C, Ward-van Oostwaard D, Doevendans P, Spijker R, van den BS, Hassink R, van der HM, Opthof T, Pera M, de la Riviere AB, Passier R, Tertoolen L. Differentiation of human embryonic stem cells to cardiomyocytes: role of coculture with visceral endoderm-like cells. Circulation. 2003; 107:2733-2740.

20. Passier R, Oostwaard DW, Snapper J, Kloots J, Hassink RJ, Kuijk E, Roelen B, de la Riviere AB, Mummery $C$. Increased cardiomyocyte differentiation from human embryonic stem cells in serum-free cultures. Stem Cells. 2005;23:772-780.

21. Xu C, Police S, Rao N, Carpenter MK. Characterization and enrichment of cardiomyocytes derived from human embryonic stem cells. Circ Res. 2002;91:501-508.

22. He JQ, Ma Y, Lee Y, Thomson JA, Kamp TJ. Human embryonic stem cells develop into multiple types of cardiac myocytes: action potential characterization. Circ Res. 2003;93:32-39. 
23. Laflamme MA, Gold J, Xu C, Hassanipour M, Rosler E, Police S, Muskheli V, Murry CE. Formation of human myocardium in the rat heart from human embryonic stem cells. Am J Pathol. 2005; I67:663-67I.

24. Kehat I, Khimovich L, Caspi O, Gepstein A, Shofti R, Arbel G, Huber I, Satin J, Itskovitz-Eldor J, Gepstein L. Electromechanical integration of cardiomyocytes derived from human embryonic stem cells. $\mathrm{Nat}$ Biotechnol. 2004;22:1282-1289.

25. Xue T, Cho HC, Akar FG, Tsang SY, Jones SP, Marban E, Tomaselli GF, Li RA. Functional integration of electrically active cardiac derivatives from genetically engineered human embryonic stem cells with quiescent recipient ventricular cardiomyocytes: insights into the development of cell-based pacemakers. Circulation. 2005; I II:II-20.

26. Costa M, Dottori M, Ng E, Hawes SM, Sourris K, Jamshidi P, Pera MF, Elefanty AG, Stanley EG. The hESC line Envy expresses high levels of GFP in all differentiated progeny. N at M ethods. 2005;2:259-260.

27. Doevendans PA, Becker KD,An RH, Kass RS. The utility of fluorescent in vivo reporter genes in molecular cardiology. Biochem Biophys Res Commun. 1996;222:352-358.

28. van Laake LW, Passier R, Monshouwer-Kloots J, Nederhoff MG, Ward-van Oostwaard D, Field LJ, van Echteld CJ, Doevendans PA, Mummery CL. Monitoring of cell therapy and assessment of cardiac function using magnetic resonance imaging in a mouse model of myocardial infarction. Nat Protoc. 2007;2:255 I2567.

29. Chuva de Sousa Lopes SM, Hassink RJ, Feijen A, van Rooijen MA, Doevendans PA, Tertoolen L, Brutel dIR, Mummery CL. Patterning the heart, a template for human cardiomyocyte development. Dev Dyn. 2006;235: 1994-2002.

30. Clement S, Stouffs M, Bettiol E, Kampf S, Krause KH, Chaponnier C, Jaconi M. Expression and function of alpha-smooth muscle actin during embryonic-stem-cell-derived cardiomyocyte differentiation. J Cell Sci. 2007; 120:229-238.

3I. Ya J, Markman MW, Wagenaar GT, Blommaart PJ, Moorman AF, Lamers WH. Expression of the smoothmuscle proteins alpha-smooth-muscle actin and calponin, and of the intermediate filament protein desmin are parameters of cardiomyocyte maturation in the prenatal rat heart. Anat Rec. 1997;249:495505.

32. Peters NS, Severs NJ, Rothery SM, Lincoln C, Yacoub MH, Green CR. Spatiotemporal relation between gap junctions and fascia adherens junctions during postnatal development of human ventricular myocardium. Circulation. 1994;90:713-725.

33. van Laake LW, van den DS, Post S, Feijen A, Jansen MA, Driessens MH, Mager JJ, Snijder RJ,Westermann CJ, Doevendans PA, van Echteld CJ, ten Dijke P, Arthur HM, Goumans MJ, Lebrin F, Mummery CL. Endoglin has a crucial role in blood cell-mediated vascular repair. Circulation. 2006; I I 4:2288-2297.

34. Burns TC, Ortiz-Gonzalez XR, Gutierrez-Perez M, Keene CD, Sharda R, Demorest ZL, Jiang Y, NelsonHolte M, Soriano M, Nakagawa Y, Luquin MR, Garcia-Verdugo JM, Prosper F, Low WC, Verfaillie CM. Thymidine analogs are transferred from prelabeled donor to host cells in the central nervous system after transplantation: a word of caution. Stem Cells. 2006;24: I I 2 I- I I 27.

35. Soonpaa MH, Koh GY, Klug MG, Field LJ. Formation of nascent intercalated disks between grafted fetal cardiomyocytes and host myocardium. Science. 1994;264:98-101.

36. Reinecke H, Zhang M, Bartosek T, Murry CE. Survival, integration, and differentiation of cardiomyocyte grafts: a study in normal and injured rat hearts. Circulation. 1999;100:193-202.

37. Baharvand H, Azarnia M, Parivar K, Ashtiani SK. The effect of extracellular matrix on embryonic stem cell-derived cardiomyocytes. J M ol Cell Cardiol. 2005;38:495-503.

38. Chen SS, Fitzgerald W, Zimmerberg J, Kleinman HK, Margolis L. Cell-cell and cell-extracellular matrix interactions regulate embryonic stem cell differentiation. Stem Cells. 2007;25:553-56I.

39. Dallabrida SM, Ismail N, Oberle JR, Himes BE, Rupnick MA.Angiopoietin-I promotes cardiac and skeletal myocyte survival through integrins. Circ Res. 2005;96:e8-24. 
40. Macfelda K, Kapeller B, Wilbacher I, Losert UM. Behavior of cardiomyocytes and skeletal muscle cells on different extracellular matrix components--relevance for cardiac tissue engineering. Artif Organs. 2007;31:4-12.

4I. Zhuang J, Yamada KA, Saffitz JE, Kleber AG. Pulsatile stretch remodels cell-to-cell communication in cultured myocytes. Circ Res. 2000;87:316-322.

42. Song YH, Gehmert S, Sadat S, Pinkernell K, Bai X, Matthias N, Alt E. VEGF is critical for spontaneous differentiation of stem cells into cardiomyocytes. Biochem Biophys Res Commun. 2007;354:999-1003.

43. Ellison GM, Torella D, Karakikes I, Purushothaman S, Curcio A, Gasparri C, Indolfi C, Cable NT, Goldspink DF, Nadal-Ginard B.Acute beta-adrenergic overload produces myocyte damage through calcium leakage from the ryanodine receptor 2 but spares cardiac stem cells.J Biol Chem. 2007;282: I 3 397-I I 409.

44. Huber I, Itzhaki I, Caspi O,Arbel G, Tzukerman M, Gepstein A, Habib M,Yankelson L, Kehat I, Gepstein L. Identification and selection of cardiomyocytes during human embryonic stem cell differentiation. FASEB J. 2007.

45. Kolossov E, Bostani T, Roell W, Breitbach M, Pillekamp F, Nygren JM, Sasse P, Rubenchik O, Fries JW, Wenzel D, Geisen C, Xia Y, Lu Z, Duan Y, Kettenhofen R, Jovinge S, Bloch W, Bohlen H, Welz A, Hescheler J, Jacobsen SE, Fleischmann BK. Engraftment of engineered ES cell-derived cardiomyocytes but not BM cells restores contractile function to the infarcted myocardium. J Exp M ed. 2006;203:23 I5-2327.

46. Gaudesius G, Miragoli M, Thomas SP, Rohr S. Coupling of cardiac electrical activity over extended distances by fibroblasts of cardiac origin. Circ Res. 2003;93:42I-428.

47. Thomson JA, Itskovitz-Eldor J, Shapiro SS, Waknitz MA, Swiergiel JJ, Marshall VS, Jones JM. Embryonic stem cell lines derived from human blastocysts. Science. 1998;282:I I45-I I 47.

48. Erdo F, Buhrle C, Blunk J, Hoehn M, Xia Y, Fleischmann B, Focking M, Kustermann E, Kolossov E, Hescheler J, Hossmann KA, Trapp T. Host-dependent tumorigenesis of embryonic stem cell transplantation in experimental stroke. J Cereb Blood Flow M etab. 2003;23:780-785.

49. Drukker M, Benvenisty N.The immunogenicity of human embryonic stem-derived cells. Trends Biotechnol. 2004;22:|36-|4|.

50. Zijlstra M, Bix M, Simister NE, Loring JM, Raulet DH, Jaenisch R. Beta 2-microglobulin deficient mice lack CD4-8+ cytolytic T cells. Nature. 1990;344:742-746.

51. Lutgens E, Daemen MJ, de Muinck ED, Debets J, Leenders P, Smits JF. Chronic myocardial infarction in the mouse: cardiac structural and functional changes. Cardiovasc Res. 1999;41:586-593.

52. Templin C, Kotlarz D, Marquart F, Faulhaber J, Brendecke V, Schaefer A, Tsikas D, Bonda T, Hilfiker-Kleiner D, Ohl L, Naim HY, Foerster R, Drexler H, Limbourg FP.Transcoronary delivery of bone marrow cells to the infarcted murine myocardium: feasibility, cellular kinetics, and improvement in cardiac function. Basic Res Cardiol. 2006;101:301-310.

53. Uemura R, Xu M, Ahmad N, Ashraf M. Bone marrow stem cells prevent left ventricular remodeling of ischemic heart through paracrine signaling. Circ Res. 2006;98:1414-I42I.

54. Yoshioka T, Ageyama N, Shibata H, Yasu T, Misawa Y, Takeuchi K, Matsui K, Yamamoto K, Terao K, Shimada K, Ikeda U, Ozawa K, Hanazono Y. Repair of infarcted myocardium mediated by transplanted bone marrow-derived CD34+ stem cells in a nonhuman primate model. Stem Cells. 2005;23:355-364.

55. Beqqali A, Kloots J, Ward-van Oostwaard D, Mummery C, Passier R. Genome-wide transcriptional profiling of human embryonic stem cells differentiating to cardiomyocytes. Stem Cells. 2006.

56. Moore JC, van Laake LW, Braam SR, Xue T, Tsang SY,Ward D, Passier R, Tertoolen LL, Li RA, Mummery CL. Human embryonic stem cells: Genetic manipulation on the way to cardiac cell therapies. Reprod Toxicol. 2005;20:377-39I.

57. Bajanca F, Luz M, Duxson MJ,Thorsteinsdottir S. Integrins in the mouse myotome: developmental changes and differences between the epaxial and hypaxial lineage. Dev Dyn. 2004;231:402-415. 
58. Liou W, Geuze HJ, Slot JW. Improving structural integrity of cryosections for immunogold labeling. Histochem Cell Biol. 1996;106:41-58.

59. Tokuyasu KT.A technique for ultracryotomy of cell suspensions and tissues.J Cell Biol. 1973;57:55 I-565.

60. Slot JW, Geuze HJ. Sizing of protein A-colloidal gold probes for immunoelectron microscopy. J Cell Biol. 1981;90:533-536

\section{Supplementary methods}

Beating areas were dissected and processed for cryosections in the same way as the mouse hearts (see Methods section)

\section{Supplementary results}

Remodeling after MI

In mice injected with HESC-CM, there was a trend towards reduced dilation of the LV wall, one of the negative characteristics of remodeling after MI, (Supplementary table 2). Moreover, HESC-CM mice had significantly lower heart weights and heart weight-to-body weight ratios than control mice, indicating reduced compensatory hypertrophy. (Supplementary table 3)

SupplementaryTable 3. Body, lung and heart weight I 2 weeks after myocardial infarction

\begin{tabular}{lllll}
\hline & Body weight (g) & Lung weight (g) & Heart weight (g) & Heart weight / Body weight \\
\hline CM & $33.5 \pm 0.46$ & $0.22 \pm 0.02$ & $0.20 \pm 0.01$ & $0.0060 \pm 0.0002$ \\
Non-CM & $32.0 \pm 0.69$ & $0.23 \pm 0.02$ & $0.25 \pm 0.02$ & $0.0079 \pm 0.0008$ \\
P-value & 0.080 & 0.857 & $0.018^{*}$ & $0.042^{*}$ \\
\hline
\end{tabular}

(CM) injected with cardiomyocytes; (non-CM) controls injected with non-cardiomyocytes 


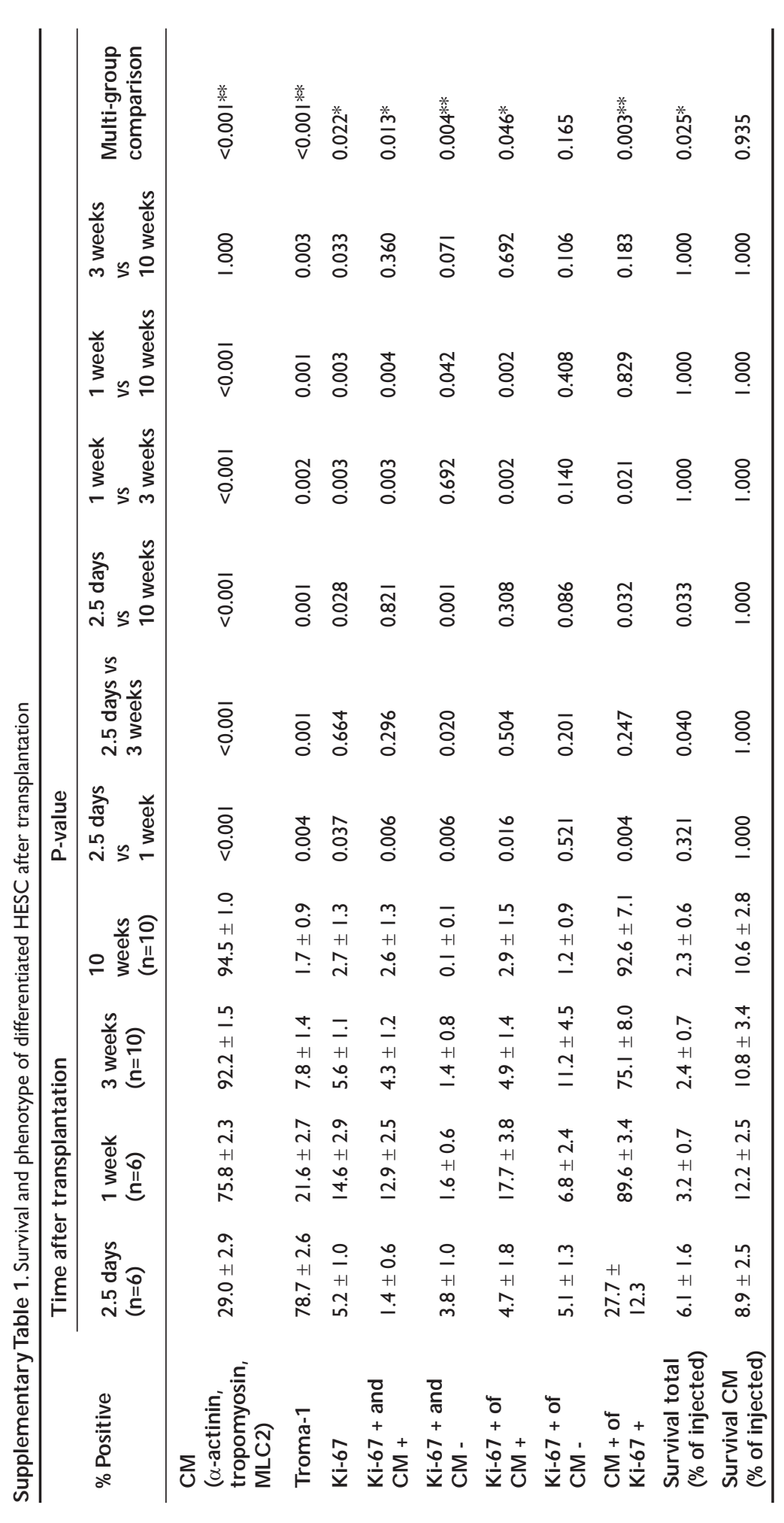

Chapter 4 | 97 


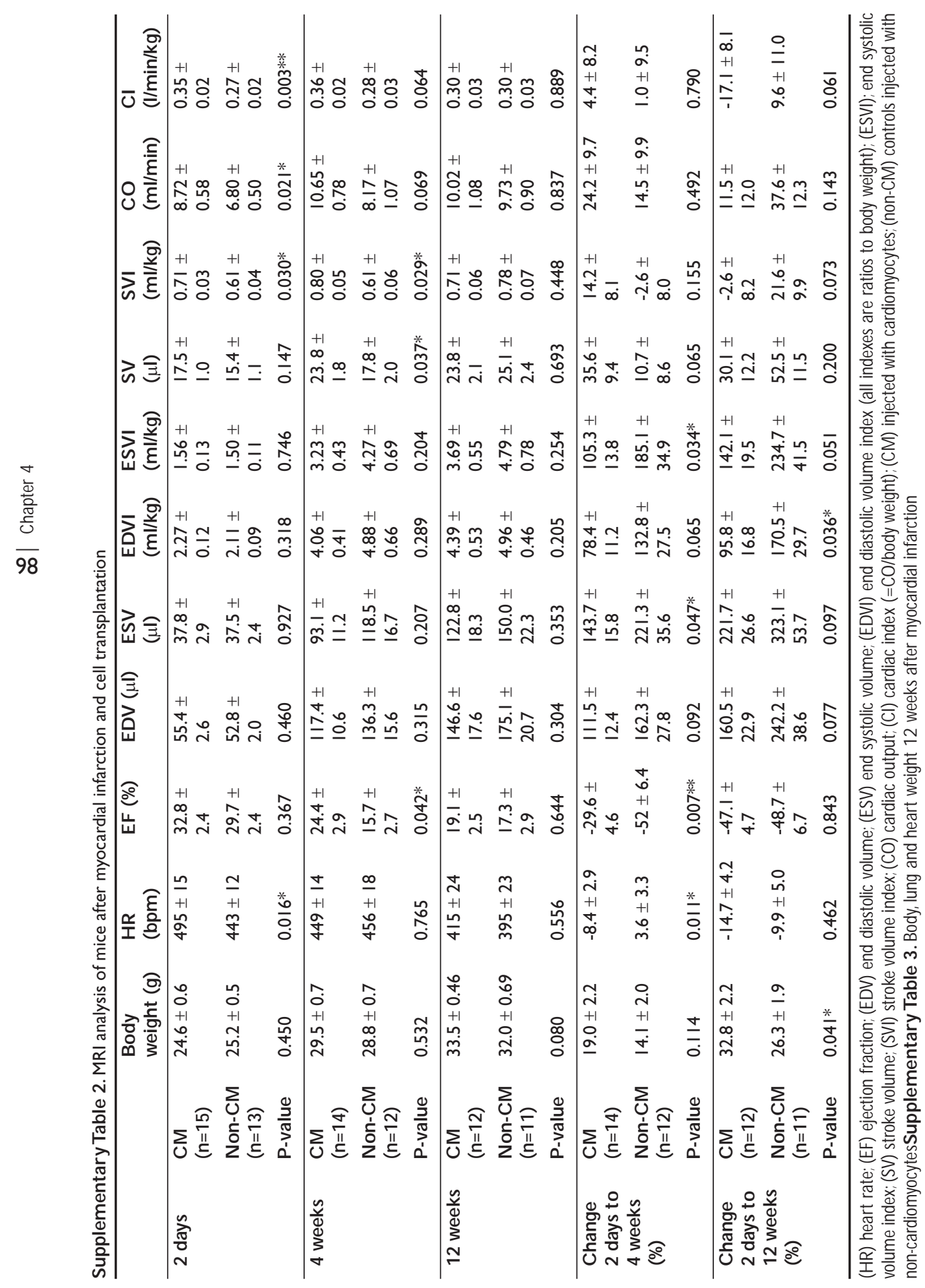




\section{Improvement of cardiac function by transplantation of hESC-derived cardiomyocytes in infarcted mouse heart correlates with improved vascularization but not graft size.}

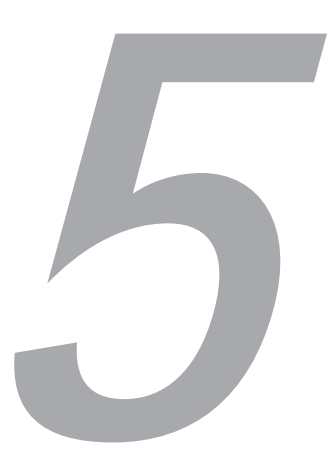

Submitted

L.W. van Laake, R. Passier, K. den Ouden, C. Schreurs, J. Monshouwer-Kloots, D. Ward-van Oostwaard, C.J. van Echteld, P.A. Doevendans, C.L. Mummery. 


\section{Abstract}

Aims

Transplantation of human embryonic stem cell-derived cardiomyocytes (hESC-

CM) has been shown to improve function of the rodent heart one month after myocardial infarction. Since optimal delivery strategies and the mechanistic basis are unclear, we investigated the influence of the number of injected cells, resulting graft size and possible paracrine mechanisms in this process.

\section{M ethods}

Myocardial infarction was induced in NOD-SCID mice $(n=84)$ followed by injection of hESC-CM at different dosages, hESC-non-CM derivatives, culture medium or no injection at all. Serial high resolution (9.4 T) magnetic resonance images were acquired after 2 days, 4 weeks and 12 weeks to assess cardiac function ( $n=70)$. Graft sizes were quantified, identified by epifluorescence of a transgenic GFP-marker and characterized by immunofluorescent co-staining. Possible paracrine contributions of the donor cells were investigated using (immuno-)histochemical staining.

\section{Results}

Transplantation of either hESC-CM or other differentiated hESC-derivatives improved short, mid- and long term cardiac performance and survival, although cardiomyocyte-containing populations provided additional functional benefit above other cells at mid-term (4 weeks). These were also the only cells present in significant numbers in grafts 12 weeks after injection. The temporary cardiomyocyte-specific enhancement was associated with elevated vascular density around the graft and attenuated compensatory remodeling. However, increasing the number of hESC-CM for injection failed to enhance heart function further. Moreover, we observed that small graft size was associated with a better functional outcome.

\section{Conclusions}

Our results showed that $\mathrm{hESC}-\mathrm{CM}$ increased myocardial vascularization and improved heart function in an immunodeficient mouse model of myocardial infarction but that their functional advantage over differentiated hESC-non-CM 
was lost at the long term. Since doubling graft size did not further enhance cardiac function future studies should focus on advanced delivery strategies and mechanisms of action rather than increasing graft size.

\section{Introduction}

Cell therapy for cardiac regeneration has recently emerged as a potential solution for heart disease associated with loss of vital cardiomyocytes, as with myocardial infarction (MI) and subsequent heart failure. These diseases remain amongst the major causes of disability and death worldwide ', despite advances in medical and surgical treatment because no method to date has been able to reverse the compensatory processes that develop over time to preserve tissue perfusion. These include hormonal changes and remodeling that are temporarily beneficial, but ultimately become fatally detrimental. The inability to regenerate autonomously appears to be the reason why the mammalian heart employs these compensatory processes in the first place, although limited proliferation of cells in the heart has now been described ${ }^{2}$. The origins and fates of these cells are however, still unclear ${ }^{3 ; 4}$. Several cell types are being investigated for their regenerative capacity in animal models and transplantation of some autologous cell sources (bone marrow stem cells, mesenchymal stem cells, skeletal myoblasts), has already entered the clinical arena with limited success ${ }^{5 ; 6}$. A major drawback of these cells may in part be their intrinsic lack of cardiomyogenic potential or sustained engraftment, although this remains equivocal ${ }^{7-11}$. Leaving aside ethical issues, human embryonic stem cells (hESCs) are amongst the most promising candidates to realize cardiac regeneration because of their capacity to proliferate indefinitely and undergo directed differentiation into bona fide cardiomyocytes ${ }^{12-15}$ and supportive cardiac cells 16-18 in vitro with high efficiency. The recently described induced pluripotent stem cells (iPS) derived from human skin fibroblasts ${ }^{19-21}$ may in the future become an alternative since they can also be expanded as pluripotent cells and differentiate to cardiomyocytes. Transplantation of hESC-derived cells would likely be heterologous and sensitive to immune rejection whereas iPS could be patient derived and hence immunologically matched. Whatever the cell source however, issues of correct integration and coupling with the host myocardium 
remain to be addressed.

For example, the optimal dose of cells and the best application method for high cell survival have not been established. While the in vivo pacemaker activity of hESC-derived cells has been investigated in pigs and guinea pigs ${ }^{22 ; 23}$, studies on their regenerative abilities have so far only been carried out in rats and mice ${ }^{13 ; 24-26}$. Although the number and composition of injected cells, the timing of injection after MI, the method of immune suppression and the functional read-outs have varied, all studies reported substantial mid-term (4 weeks post$\mathrm{MI})$ improvements in cardiac function resulting from transplantation of hESCderived cell populations containing cardiomyocytes (hESC-CM) compared to vehicle injection or transplantation of non-cardiomyocyte derivatives. Major differences between the studies were however the follow-up times: when this was extended to 12 weeks, the advantage of hESC-CM over hESC-non-CM was no longer present ${ }^{26}$ and thus functional enhancement by hESC-CM with the current strategies may be limited to mid-term (4 weeks) at best. In view of the unknown optimal dose of cells for transplantation, the small graft size observed in all studies may be a possible explanation for the lack of sustained improvement in cardiac function despite cardiomyocyte survival even at 3 months post-MI and transplantation ${ }^{27}$. Alternatively, the cardiomyocyte content of grafts at later time-points may be too low to compensate for the loss of contractile activity in the infarcted heart ${ }^{27}$. Another possibility is that hESC-CM exert paracrine effects which may be beneficial to cardiac performance, as has been shown with mesenchymal stem cells ${ }^{28 ; 29}$.

Here, we explored these hypotheses by comparing the effects of injection of hESC-CM at different dosages with hESC-non-CM derivatives, culture medium or no injection at all after experimental MI in immunodeficient NOD-SCID mice. In a longitudinal follow-up of 12 weeks using serial high resolution magnetic resonance imaging, we found that both $\mathrm{hESC}-\mathrm{CM}$ and $\mathrm{hESC}$-non-CM provide long term functional improvement compared to vehicle- or no injection even though only cardiomyocytes formed persistent grafts. We showed, for the first time, that merely increasing numbers of hESC-CM for transplantation resulted in no functional benefit and in fact, smaller grafts were associated with the best functional outcome. In addition, we confirmed evidence of a paracrine contribution of the transplanted hESC-CM by demonstrating increased vascularization in the infarcted heart associated specifically with transplantation of these cells. 


\section{Methods}

Cell culture, differentiation and dissociation

Cardiomyocyte differentiation of hES3-GFP cells, which express GFP in both undifferentiated and all differentiated derivatives ${ }^{30 ; 31}$, was induced by co-culture with END2 cells ${ }^{14 ; 15}$. Large numbers of beating areas were obtained within 12 days that consist of approximately $25 \%$ cardiomyocytes and $75 \%$ endodermal or other mesodermal derivates ${ }^{15}$. For control experiments hES3-GFP cells were induced to differentiate by plating on gelatin for 12 days. Under these conditions $\leq 5 \% \alpha$-actinin positive cells formed after 12 days of culture (hESCnon-CM differentiated control cells). Beating areas were dissected from the hESC-END2 co-cultures or clusters of non-CM control cells from the gelatin plates and dissociated with collagenase as described ${ }^{15 ; 32 ; 33}$. One or three million cells were taken up in a final volume of $15 \mu \mathrm{l}$ of fresh culture medium (DMEM + $20 \%$ FCS) and used for transplantation.

\section{Animals and surgical procedures}

The investigation involving experimental animals conforms to the Guide for the Care and Use of Laboratory Animals published by the US National Institutes of Health (NIH Publication No. 85-23, revised 1996). All procedures were also approved by the Institute Animal Care Committee. Male NOD-SCID mice (Charles River) of II-12 weeks of age were used for all surgical procedures and control experiments ( $n=13$ to 23 per group; total $n=84$ ). Myocardial infarction (MI) was induced by ligation of the left anterior descending coronary artery (LAD) after lateral thoracotomy, as described previously (natprot); ligation site was I mm below the left auricle. Directly afterwards, cells or culture medium were injected in the infarcted myocardium of the free left ventricular wall using an insulin syringe with incorporated 29G needle. In the "no injection" control group, the injection step was omitted. For experiments with $3 \times 10^{6}$ cells, one injection was in the infarct and two were in the borderzone. The surgeon (L.v.L) was blinded for the cell type injected. At 4 weeks or 12 weeks after surgery, animals were euthanized and the hearts were fixed and processed for cryosections as described ${ }^{33}$. Lungs, liver, kidneys, spleen and brain were also examined for the presence of tumors. 


\section{RI analysis of cardiac function}

2 days, 4 weeks and 12 weeks post-MI ( $n=13$ to 15 per group; total $n=70$ ), magnetic resonance images were acquired on a 9.4-T scanner (Bruker Biospin $\mathrm{GmbH}$, Rheinstetten, Germany) as described ${ }^{33}$; up to 10 short-axis slices were required to image the dilated left ventricle. Analysis was performed with Q-mass digital imaging software (Medis, Leiden, the Netherlands) by two independent blinded investigators (K.d.O and L.v.L).

\section{Immunofluorescence, immunohistochemistry and histological staining}

Hearts were cut into $6 \mu \mathrm{m}$ cryosections ( $n=6$ to 8 per group), which were stained as described using the following antibodies and dilutions: $\alpha$-actinin (I:800) (mouse, Sigma), troma-I (I:500) (rat, Developmental Studies Hybridoma Bank), human CD3I (I:300) (mouse, DAKO), MLC2A (I:I00) (mouse, Synaptic Systems), MLC2V (I:50) (mouse, Synaptic Systems), Ki-67 (I:100) (rabbit, Abcam), smooth muscle actin (1:100) (rabbit, Abcam), and desmoplakin (undiluted) (mouse, Progen Biotechnik). Isotype controls (DAKO) were performed for each class of antibody used. Cy-3 labeled secondary antibodies were from Jackson Immuno Research Laboratories and Alexa 405 labeled secondary antibodies from Invitrogen. Topro-3 (1:1000) (molecular probes) was used for nuclear counterstaining. GFP was recognized by epifluorescence without the need of antibody-based enhancement.

The size of individual cardiomyocytes was measured in non-infarcted regions (septum and right ventricle) using a rabbit-anti laminin antibody (Sigma, I:100) to define cell borders. In five sections from each heart, ten cross-sectional areas at nuclear level per pre-set region were imaged with 400x magnification and measured using Image J software.

For quantification of vessel density, sections were post-fixed with $4 \%$ paraformaldehyde, washed 5 times in phosphate buffered saline (PBS), blocked with peroxidase blocking buffer, washed, blocked with $1 \%$ bovine serum albumin (BSA) in PBS for 30 minutes, and incubated overnight at $4^{\circ} \mathrm{C}$ with rat-anti-mouse CD3I (Cell Signaling) diluted I:20. Sections were then washed in TBS with $0.05 \%$ Tween-20, blocked with TNB (Perkin Elmer TSA-kit) for 30 minutes, incubated with rabbit-anti rat antibody (Dako, diluted I:250) for 30 minutes, washed with 
PBS, incubated with rabbit Powervision (Immunologic) for 30 minutes, washed with PBS, covered with DAB+urea (Sigma) for 10 minutes and washed with tap water. Nuclei were counterstained with hematoxylin after which sections were washed, dehydrated and mounted with Pertex. Vessel density was averaged from 60 high power fields per heart divided over 6 sections at standardized locations along the long axis of the infarct area using an Olympus- $\mathrm{BH} 2$ microscope with AnalySIS software. Infarct, border zone and non-infarcted myocardium were analyzed separately.

Infarct size was measured after AZAN-staining as described ${ }^{34}$ with minor modification (post-fixation with $4 \%$ paraformaldehyde, rehydration through xylene and ethanol). In five sections from each heart, infarct (blue) was distinguished from healthy myocardium (pink) and measured with AnalySIS; the longitudinal dimension of the infarct as measured during cryo-sectioning was used to reconstruct the absolute infarct volume.

Fibrosis in the non-infarcted area was visualized by Picro-Sirius red staining. Pre-treatment was as for AZAN-staining, after which slides were treated for 5 minutes with $0,2 \%$ phosphomolybdicacid, stained for 60 minutes in $0.1 \%$ picrosiriusred-dye $(0.25 \mathrm{~g}$ Sirius red dissolved in $250 \mathrm{ml}$ picrine-acid stock solution consisting of $20 \mathrm{~g}$ picrine-acid in $1000 \mathrm{ml}$ aquadest), faded for 2 minutes in $0.01 \mathrm{~N} \mathrm{HCL}$, differentiated with ethanol $70 \%$, dehydrated through the alcohols $(96 \%, 100 \%)$ and mounted with pertex. The total amount of fibrosis was quantified by measurements in three pre-set regions of the non-infarcted area (interventricular septum and right ventricle) using a Zeiss Axioplan microscope. The sections were imaged with a $20 x$ objective and analyzed semi-quantitatively; the images were classified into five different groups, based on their amount of fibrosis, by two independent blinded investigators (C.S. and L.v.L.)

\section{$M$ icroscopical analysis of GFP-epifluorescence and immunofluorescent staining}

A Leica MZ I6FA / DFC480 fluorescence microscope was used to image whole hearts. Graft size was categorized semi-quantitatively into 10 groups by a blinded investigator (L.v.L). Quantitative graft size was determined by counting GFP-fluorescent cells in cryo-sections as described previously ${ }^{26}$. Confocal scanning (with sequential scanning for GFP with excitation laser $488 \mathrm{~nm}$, 
Alexa 405 with $405 \mathrm{~nm}$, Cy3 with $532 \mathrm{~nm}$ and Topro-3 with $633 \mathrm{~nm}$, respectively) was performed on a Leica TCS SPE confocal with a DMI4000B microscope using LAS-AF software (Leica application suite- advanced fluorescence).

\section{Statistical analysis}

Statistical significance was evaluated with SPSS vll.5 for Windows using ANOVA (with Bonferroni correction for multiple-group comparisons) or MannWhitney $U$ test, as applicable. Survival was analyzed with the Kaplan-Meier test. Correlations were tested with Pearson's correlation coefficient. Results are expressed as mean \pm SEM. A value of $p<0.05$ was considered statistically significant.

\section{Results}

Previously we showed that transplantation of mixed populations of differentiated hESCs containing 20-25\% cardiomyocytes, compared to differentiated hESCs nearly devoid of cardiomyocytes, improved cardiac function 4 weeks after $\mathrm{MI}$ in NOD-SCID mice ${ }^{26}$. However, this advantage of transplanting cardiomyocytes over other hESC-derived cells was lost at the long term (I2 weeks) ${ }^{26}$ even though only cardiomyocytes had formed substantial grafts (Figure la-b and Supplementary figure I). Some cardiomyocytes were still in the cell cycle as indicated by positive nuclear staining for Ki67 (Figure Ic-d) but the majority were post-mitotic. Cardiomyocytes composed $80-95 \%$ of the grafts; the remaining cells expressed the endoderm-marker cytokeratin 18 (troma-I) (Figure le-f). Only rarely $(<1 \%)$ were cells positive for CD3I or smooth muscle actin (not shown). Thus, as in the non-infarcted heart, preferential survival of cardiomyocytes was observed although endodermal derivatives were cleared slightly less rigorously. In general, cell survival appeared lower in infarcted hearts ( $1.46 \pm 1.02 \%$ of all injected cells 4 weeks after transplantation, corresponding to $6.8 \pm 4.6 \%$ of injected cardiomyocytes) than in non-infarcted hearts (midterm survival $2.4 \pm 0.7 \%$ of all cells; $10.8 \pm 3.4 \%$ of cardiomyocytes ${ }^{26}(p=0.062$ and $p=0.118$, respectively)).

To test the hypothesis that the small graft size relative to the total infarct area might be the reason for a lack of long term cardiomyocyte-specific functional 
improvement, we repeated our initial experiment, but now injected three times as many cardiomyocyte-enriched differentiated HESCs directly after coronary artery ligation. Instead of one million cells in one intramyocardial injection, three million cells were injected at different sites in the infarct and borderzone, which resulted in a significant increase in total graft size 12 weeks after $\mathrm{MI}$ and transplantation (mean semi-quantitative score $7.17 \pm 0.44$ arbitrary units (AU) after injection of $3 \times 10^{6}$ cells vs $3.75 \pm 0.72 \mathrm{AU}$ after injection of $1 \times 10^{6}$ cells; $P=0.010)$. Although the resulting initial preservation of cardiac function was again present at 4 weeks, after 12 weeks follow-up this had become insignificant in comparison with the control group receiving hESC-non-CM (Figure 2).

To exclude a possible negative effect of the injection needle manipulation itself, we had also included groups of infarcted mice that received injection with vehicle (culture medium) or no injection at all. Longitudinal follow-up by MRI demonstrated a positive effect of injection of either hESC-CM or hESC-nonCM compared to injection of culture medium or no treatment, as evidenced by improved end diastolic volume (EDV), end systolic volume (ESV) and ejection fraction (EF) (Figure 2; reference data from non-infarcted mice in Supplementary figure 2). While at 4 weeks the benefit from hESC-CM was greater than that of hESC-non-CM, at 12 weeks both cell types had preserved cardiac function equally well compared to the controls without cell injection (Figure 2). In addition, the mice that received injection with culture medium performed better than the non-injected controls (Figure 2). Therefore, intramyocardial injection itself did not impair cardiac function to any significant extent; in fact it may have been beneficial. Furthermore, injection of either cell type or medium increased long-term survival of the mice compared to non-injected controls (Figure 3).

Since increased mean graft size did not improve heart function per experimental group of mice, we investigated whether there was a relationship between graft size and cardiac function in mice within one group. Mice were retrospectively divided in two subgroups with graft size below or above the median of their own group (i.e. Ix106 $\mathrm{hESC}-\mathrm{CM}$ or $3 \times 10^{6} \mathrm{hESC}-\mathrm{CM}$, as the $\mathrm{hESC}$-non-CM only rarely produced a small graft). The average "small" graft size in the $3 \times 10^{6} \mathrm{hESC}$ $\mathrm{CM}$ group (6.14 $\pm 0.40 \mathrm{AU})$ was comparable to the average "large" graft size in the $1 \times 10^{6} \mathrm{hESC}-\mathrm{CM}$ group $(5.57 \pm 0.20 \mathrm{AU})$.

While in the group receiving $1 \times 10^{6} \mathrm{hESC}-\mathrm{CM}$ there was no difference in cardiac 
function between mice with small vs. large grafts, in the $3 \times 10^{6} \mathrm{hESC}-\mathrm{CM}$ group the mice with small grafts had a significantly better cardiac function than the mice with large grafts 2 days after $\mathrm{Ml}$ and at all later time-points (Figure 4).
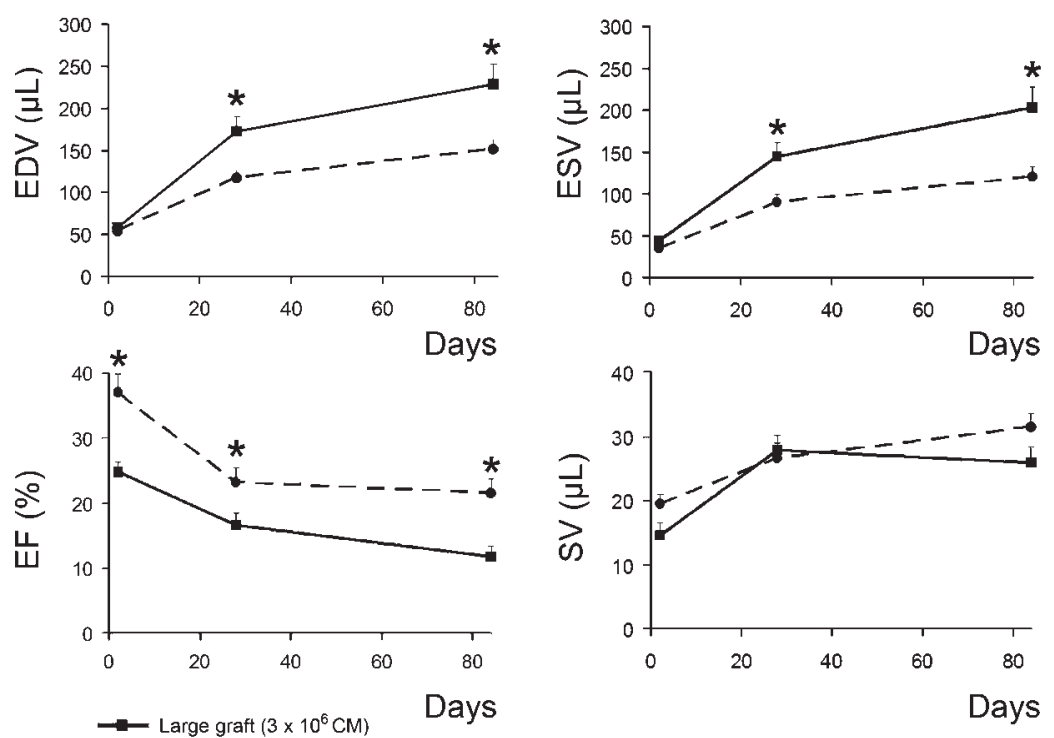

Figure 4. Larger graft size after multiple injections of hESC-CM after myocardial infarction is associated with decreased cardiac function:

Large graft: >p50 for graft size in $3 \times 10^{6} \mathrm{CM}$ group, small graft: $<\mathrm{p} 50$ for graft size in $3 \times 10^{6} \mathrm{CM}$ group. EDV: end diastolic volume, ESV: end systolic volume, EF: ejection fraction, SV: stroke volume. ${ }^{*} p<0.05$ for large graft VS. small graft.

In addition, infarct size at day 2 after coronary artery ligation was larger in the group with large grafts $(42.1 \pm 3.8 \mathrm{mg} ; 45.9 \pm 4.0 \%$ of the LV mass) than in the group with small grafts (3I.2 $\pm 1.9 \mathrm{mg} ; 39.0 \pm 2.7 \%$ of the LV mass) $(p=0.028)$ and the group receiving $1 \times 10^{6} \mathrm{hESC}-\mathrm{CM}(25.7 \pm 0.9 \mathrm{mg} ; 37.7 \pm 1.6 \%$ of the LV mass) $(p=0.00 I)$. There was a clear correlation between infarct size at day 2 and EDV, ESV and EF in measurements after 4 and 12 weeks (4 weeks: $r=0.707, p=0.01$ for EDV; $r=0.756, p=0.004$ for ESV; $r=-0.782, p=0.003$ for $E F ; 12$ weeks: $r=0.83$ I, $p=0.0$ I for EDV; $r=0.834, p=0.00$ I for ESV; $r=-0.725$, $p=0.008$ for EF). Hence, in contrast to the difference between the hESC-CM and hESC-non-CM groups (where function at day 2 was equal), the reduced improvement in the "large graft" group seemed to be established early after MI and injection of the cells. Since cardiac function was equal in the mice with small 
grafts in the $3 \times 10^{6} \mathrm{hESC}-\mathrm{CM}$ group and all mice in the $1 \times 10^{6} \mathrm{hESC}-\mathrm{CM}$ group, the optimum relative graft size was thus approximately 6 , which corresponded to an absolute number of approximately 4,000 cells (based on counting nuclei in GFP-fluorescent cells).

In view of the lack of a positive correlation between graft size and cardiac function, we concluded that active contribution of donor cardiomyocytes to contraction was unlikely to be the only mechanism behind the observed functional benefit 4 weeks after MI. For this reason, we analyzed hearts isolated at this time-point for a comparison of multiple parameters that could be affected by paracrine action of the transplanted cells: infarct size, vascularization, and fibrosis and hypertrophy in areas in the distant non-infarcted myocardium. Infarct circumference was $51.5 \pm 6.2 \%$ and $61.5 \pm 6.0 \%$ in the hESC-CM and hESC-non-CM groups, respectively $(p=0.302)$; infarct volume averaged $9.8 \pm 0.8$ $\mathrm{mm}^{3}$ Vs. $10.8 \pm 1.7 \mathrm{~mm}^{3}(\mathrm{p}=0.519)$. Vascular density was significantly increased in the borderzone of hearts injected with hESC-CM compared to hESC-nonCM (Figure 5 and Supplementary Figure 3), and the same trend was observed in the infarct area. Fibrosis and hypertrophy were not significantly decreased in the hESC-CM group (fibrotic score $2.02 \pm 0.18$ vs. $2.28 \pm 0.30, p=0.560$ and cell size $376 \pm 22$ vs. $442 \pm 35, p=0.197$ in the hESC-CM and hESC-nonCM groups, respectively). Thus, while infarct size and remodeling tended to be attenuated in mouse hearts following injection of hESC-CM, stimulation of vascularization appeared to be a major contributing factor that may underlie the cardiac functional improvement 4 weeks after MI.

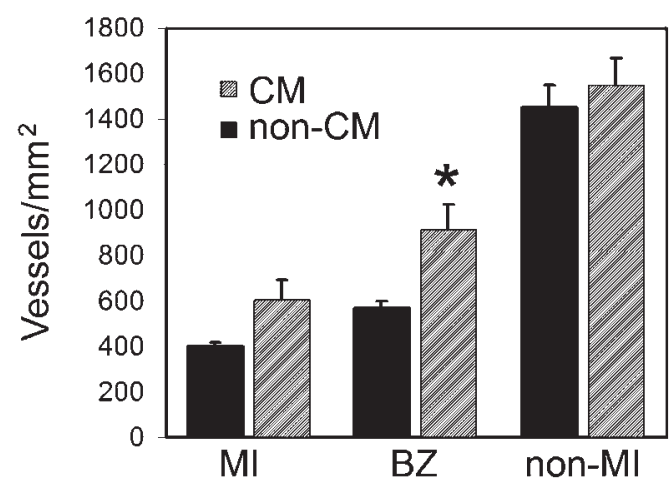

Figure 5. Transplantation of hESC-CM increases vascularization in the infarcted heart: Vascular density in infarct (MI), borderzone (BZ), and non-infarcted myocardium (non-MI), 4 weeks after myocardial infarction and injection of $1 \times 10^{6} \mathrm{hESC}-\mathrm{CM}$ or $1 \times 10^{6} \mathrm{hESC}-$ non-CM. 


\section{Discussion}

We have demonstrated that transplantation of either hESC-CM or other differentiated hESC-derivatives can improve short, mid- and long term cardiac performance and survival in infarcted mice, while the cardiomyocytes provide additional functional benefit at mid term (4 weeks) and are the only cells present in significant numbers in grafts 12 weeks after injection. While the temporary cardiomyocyte-specific enhancement was associated with elevated vascular density and, possibly, attenuated compensatory remodeling, increasing the number of hESC-CM for injection failed to enhance heart function further. Moreover, we observed that small graft size was associated with smaller infarct size early after coronary artery ligation and a better long term outcome. In agreement with previous results from transplantation of hESC-derived cells in uninjured hearts by our own and other groups ${ }^{13 ; 26}$, cardiomyocytes constituted the major proportion of the grafts. As calculated previously ${ }^{26}$ and in view of the low number of Ki-67 positive hESC-derived cells, this most likely results from preferential survival of cardiomyocytes and loss of non-cardiac cells.

In contrast to previous experience with fetal cardiomyocytes ${ }^{27}$, increasing the dose of hESC-CM donor cells 3-fold translated into manifestly increased graft size, even though hESC-CM have a fetal-like phenotype with respect to protein expression and electrophysiological parameters ${ }^{15 ; 32}$. However, cardiac function did not reflect this enhancement. This is in fact consistent when crosscomparing data from the literature, although such an evaluation should obviously be interpreted with great caution and is by far less reliable than the direct comparison we made in our study. Nevertheless, it is remarkable that Laflamme et al. found an almost equal improvement (fractional shortening (FS) 4 weeks post-MI approximately $28 \%$ compared to $13-20 \%$ in the control groups; baseline FS approximately 25\%) as Caspi et al. (FS 4 weeks post-MI approximately $25 \%$ compared to I5\% in the control group; baseline FS 20\%) while the models were quite similar (both performed coronary artery ligation in immunodeficient and/ or immunosuppressed rats followed by cell injection 4 (Laflamme) or 7-10 days (Caspi) later) except that the first group transplanted 10 million cells and the second only 1.5 million ${ }^{13: 24}$.

In fact, independent of the presence of grafts or graft size, both hESC-derived cell preparations injected in the present study significantly improved cardiac 
function from early time-points on and this positive effect persisted for at least 12 weeks. Importantly, survival of the mice was also greater in the cell-injected groups which rules out a possible bias by loss of subjects with the poorest parameters and suggests the reported differences may even underestimate the beneficial consequences of cell transplantation. The lack of necessity of actual cell grafting for functional improvement is corroborated by several other investigations ${ }^{35 ; 36}$ and points to the existence of paracrine actions from the donor cells, as has been found with mouse ESCs ${ }^{37 ; 38}$. However, the mode or at least extent of action is apparently different in hESC-CM and hESC-non-CM, judging from the augmented vascular density in the borderzone and infarct 4 weeks after transplantation in mice receiving the cardiomyocyte-enriched cell preparations. A likely key player in this respect is vascular endothelial growth factor (VEGF), which is known for its capacity to stimulate neoangiogenesis and has been identified as a major contributor to cardiac protection by mesenchymal stem cells ${ }^{28}$. The donor cells may also enhance the production and release of host-derived favorable humoral factors, as shown recently with transplantation of endothelial progenitor cells from bone marrow ${ }^{39}$. Increased vascularity may be sufficient to explain the temporary functional improvement in mice treated with hESC-CM, as we showed previously in a mouse model of impaired and rescued neoangiogenesis ${ }^{34}$. On the other hand, additional growth factors and cytokines may be involved as implied by the consistent trend towards attenuated remodeling and smaller histological infarct size in the functionally privileged hESC-CM group at 4 weeks post-MI. Finally, active contribution of cardiomyocytes to contraction at this time-point could support cardiac performance, although this is unlikely to be a very important factor since there was no extra improvement from larger grafts.

Our unexpected observation that large grafts after 3 injections of $1 \times 10^{6} \mathrm{hESC}$ CM in the acutely infarcted heart were associated with reduced cardiac function seemed to depend at least in part on a larger infarct size 2 days after the procedure. While injection of liquid substances itself did not markedly damage the heart, the presence of multiple large clusters of donor cells may have reduced their positive effects for several reasons. Large dense grafts, especially when present in the borderzone, may block blood supply to the infarct and borderzone area early after $\mathrm{MI}$ and thereby increase infarct size. The large 
grafts may cause more disruption of the borderzone cardiomyocytes, enhancing disorganization (isotropy) because of the stress to which they are subjected 40. Clusters of cells may also secrete more extracellular matrix, augmenting the fibrotic gap between donor and host cells and isolating the graft. Following the "dying stem cell hypothesis" ${ }^{41}$ one may reason that in smaller grafts, more cells have died and secreted favorable paracrine factors. This may then be a cardiomyocyte related effect, considering the functional advantage at 4 weeks of the $\mathrm{hESC}-\mathrm{CM}$ group. However, in that case mice receiving $3 \times 10^{6}$ cells may be expected to do better than those receiving $1 \times 10^{6}$ cells. Finally, we ruled out the possibility that injection was more successful in coincidentally larger infarcts, by comparing the "likelihood of successful cell retention" (considering immediate washout of the cells after injection) that was noted by the surgeon during the procedure, and was identical in the groups with small and large graft size (Supplementary table I).

II Supplementary table 1. Subjective retention of transplanted cells directly after injection of $3 \times 10^{6} \mathrm{hESC}-\mathrm{CM}$

\begin{tabular}{llllll}
\hline & Mean & SEM & Median & Interquartile range & Modus \\
\hline Small graft & 2.4 & 0.3 & 3 & $\mathrm{I}$ & 3 \\
Large graft & 2.6 & 0.2 & 3 & $\mathrm{I}$ & 3 \\
\hline
\end{tabular}

Scale: 0-3 (0: major backwash, 3: very little or no backwash)

In any case, graft size was not the limiting factor in our cell transplantation protocol and the lack of a long term cardiomyocyte-specific advantage might be explained by other shortcomings of the donor cells in this system. We and others showed that the hESC-CM grafts were largely isolated from the host myocardium by a layer of fibrotic tissue ${ }^{13 ; 26 ; 42 ; 43}$ which may prevent the formation of an electrophysiological syncytium. Our staining for desmoplakin, which showed formation of desmosomes between human cells but only rarely between human and mouse, corroborated this. The question remains, whether junction formation is a possibility at all when human cardiomyocytes, designed to beat 60 to 100 times per minute, reside in a rodent heart with frequencies of 300-600 beats per minute. Studies using intracellular calcium imaging to detect or exclude coupling of human and rat or mouse cardiomyocytes ${ }^{44}$ may shed some light on this. If human cells were in fact successfully paced at the rodent's heart rate, this might also account for loss of function as prolonged periods of tachycardia may induce cardiac dysfunction. Experiments in larger animals such 
as pigs or primates (preferably with ESCs of the same species ${ }^{45}$ ) are needed to solve the issue. Grafts may also provide passive support only which could be sufficient to prevent dilatation and retain cardiac function temporarily, but is inadequate for sustained improvement. Similarly, if paracrine mechanisms were the only modus of action for hESC-CM, these may provide a transient protection only.

In conclusion, our results show that $\mathrm{hESC}$-CM increase myocardial vascularization and improve heart function in an immunodeficient mouse model of MI but loose their functional advantage over differentiated hESC-non-CM in the long term. Since increased graft size did not further enhance cardiac function, focus of future studies should be on advanced delivery strategies ${ }^{46 ; 4}$ and unraveling the mechanisms of action rather than increasing graft size.

\section{Funding}

This work is supported by the European Community's Sixth Framework Programme contract ('HeartRepair') LSHM-CT-2005-018630.

\section{Acknowledgements}

We are grateful to Leo Timmers for his help with infarct size analysis from MRI images.

\section{References}

I. International Cardiovascular Disease Statistics. American Heart Association 2007.

2. Anversa P, Leri A, Kajstura J. Cardiac regeneration. J.Am.Coll.Cardiol. 2006;47:I 769-76

3. Massberg S,Schaerli P,Knezevic-Maramica I, Kollnberger M,Tubo N, Moseman EA et al. Immunosurveillance by Hematopoietic Progenitor Cells Trafficking through Blood, Lymph, and Peripheral Tissues. Cell 2007; |31:994-1008.

4. Pouly, J. and Menasche, P. Cardiac stem cells in the real world. J.Thorac.Cardiovasc.Surg. 2008. Ref Type: In Press

5. Rosenzweig A. Cardiac cell therapy--mixed results from mixed cells. N.Engl.J.Med. 2006;355:I274-77.

6. van Laake LW, Hassink R, Doevendans PA, Mummery C. Heart repair and stem cells. J.Physiol 2006;577:467-78. 
7. Balsam LB, Wagers AJ, Christensen JL, Kofidis T, Weissman IL, Robbins RC. Haematopoietic stem cells adopt mature haematopoietic fates in ischaemic myocardium. Nature 2004;428:668-73.

8. Murry CE, Soonpaa MH, Reinecke H, Nakajima H, Nakajima HO, Rubart M et al. Haematopoietic stem cells do not transdifferentiate into cardiac myocytes in myocardial infarcts. Nature 2004;428:664-68.

9. Nygren JM, Jovinge S, Breitbach M, Sawen P, RollW, Hescheler J et al. Bone marrow-derived hematopoietic cells generate cardiomyocytes at a low frequency through cell fusion, but not transdifferentiation. Nat. Med. 2004;10:494-501.

10. Orlic D, Kajstura J, Chimenti S, Limana F, Jakoniuk I, Quaini F et al. Mobilized bone marrow cells repair the infarcted heart, improving function and survival. Proc.Natl.Acad.Sci.U.S.A 200I;98:10344-49.

II. Orlic D, Kajstura J, Chimenti S, Jakoniuk I, Anderson SM, Li B et al. Bone marrow cells regenerate infarcted myocardium. Nature 200 I;4 10:70I-05.

12. Kehat I, Kenyagin-Karsenti D, Snir M, Segev H, Amit M, Gepstein A et al. Human embryonic stem cells can differentiate into myocytes with structural and functional properties of cardiomyocytes. J.Clin.Invest 200I;108:407-I4.

13. Laflamme MA, Chen KY, Naumova AV, Muskheli V, Fugate JA, Dupras SK et al. Cardiomyocytes derived from human embryonic stem cells in pro-survival factors enhance function of infarcted rat hearts. Nat. Biotechnol. 2007;25:1015-24.

14. Mummery C,Ward-van Oostwaard D, Doevendans P, Spijker R, van den BS, Hassink R et al. Differentiation of human embryonic stem cells to cardiomyocytes: role of coculture with visceral endoderm-like cells. Circulation 2003;107:2733-40.

15. Passier R, Oostwaard DW, Snapper J, Kloots J, Hassink RJ, Kuijk E et al. Increased cardiomyocyte differentiation from human embryonic stem cells in serum-free cultures. Stem Cells 2005;23:772-80.

16. Ferreira LS, Gerecht S, Shieh HF, Watson N, Rupnick MA, Dallabrida SM et al. Vascular progenitor cells isolated from human embryonic stem cells give rise to endothelial and smooth muscle like cells and form vascular networks in vivo. Circ. Res. 2007; 101:286-94.

17. Huang $\mathrm{H}$, Zhao X, Chen L, Xu C, Yao X, LuY et al. Differentiation of human embryonic stem cells into smooth muscle cells in adherent monolayer culture. Biochem. Biophys.Res.Commun. 2006;351:321-27.

18. Levenberg S, Golub JS,Amit M, Itskovitz-Eldor J, Langer R. Endothelial cells derived from human embryonic stem cells. Proc.Natl.Acad.Sci.U.S.A 2002;99:4391-96.

19. Yu J,Vodyanik MA, Smuga-Otto K,Antosiewicz-Bourget J, Frane JL, Tian S et al. Induced Pluripotent Stem Cell Lines Derived from Human Somatic Cells. Science 2007.

20. Nakagawa M, Koyanagi M,Tanabe K, Takahashi K, Ichisaka T,Aoi T et al. Generation of induced pluripotent stem cells without Myc from mouse and human fibroblasts. Nat.Biotechnol. 2007.

21. Takahashi K, Tanabe K, Ohnuki M, Narita M, Ichisaka T,Tomoda K et al. Induction of pluripotent stem cells from adult human fibroblasts by defined factors. Cell 2007;131:861-72.

22. Kehat I, Khimovich L, Caspi O, Gepstein A, Shofti R, Arbel G et al. Electromechanical integration of cardiomyocytes derived from human embryonic stem cells. Nat.Biotechnol. 2004;22:1282-89.

23. Xue T, Cho HC,Akar FG, Tsang SY, Jones SP, Marban E et al. Functional integration of electrically active cardiac derivatives from genetically engineered human embryonic stem cells with quiescent recipient ventricular cardiomyocytes: insights into the development of cell-based pacemakers. Circulation 2005; III:II-20.

24. Caspi O, Huber I, Kehat I, Habib M,Arbel G, Gepstein A et al. Transplantation of human embryonic stem cell-derived cardiomyocytes improves myocardial performance in infarcted rat hearts. J.Am.Coll.Cardiol. 2007;50:1884-93.

25. Leor J, Gerecht-Nir S, Cohen S, Miller L, Holbova R, Ziskind A et al. Human embryonic stem cell transplantation to repair the infarcted myocardium. Heart 2007. 
26. van Laake LW, Passier R, Monshouwer-Kloots J, Verkleij AJ, Lips DJ, Freund C et al. Human embryonic stem cell-derived cardiomyocytes survive and mature in the mouse heart and transiently improve function after myocardial infarction. Stem Cell Research 2007;1:9-24.

27. Rubart M, Field LJ. ES cells for troubled hearts. Nat.Biotechnol. 2007;25:993-94.

28. Gnecchi M, He H, Liang OD, Melo LG, Morello F, Mu H et al. Paracrine action accounts for marked protection of ischemic heart by Akt-modified mesenchymal stem cells. Nat.Med. 2005; I I:367-68.

29. Uemura R, Xu M, Ahmad N, Ashraf M. Bone marrow stem cells prevent left ventricular remodeling of ischemic heart through paracrine signaling. Circ.Res. 2006;98:I4I4-2I.

30. Costa M, Dottori M, Ng E, Hawes SM, Sourris K, Jamshidi P et al. The hESC line Envy expresses high levels of GFP in all differentiated progeny. Nat.Methods 2005;2:259-60.

31. Doevendans PA, Becker KD,An RH, Kass RS. The utility of fluorescent in vivo reporter genes in molecular cardiology. Biochem.Biophys.Res.Commun. 1996;222:352-58.

32. Moore JC, van Laake LW, Braam SR, Xue T,Tsang SY,Ward D et al. Human embryonic stem cells: Genetic manipulation on the way to cardiac cell therapies. Reprod.Toxicol. 2005;20:377-91.

33. van Laake LW, Passier R, Monshouwer-Kloots J, Nederhoff MG, Ward-van Oostwaard D, Field LJ et al. Monitoring of cell therapy and assessment of cardiac function using magnetic resonance imaging in a mouse model of myocardial infarction. Nat.Protoc. 2007;2:255I-67.

34. van Laake LW, van den DS, Post S, Feijen A, Jansen MA, Driessens MH et al. Endoglin has a crucial role in blood cell-mediated vascular repair. Circulation 2006; I | 4:2288-97.

35. Iso Y, Spees JL, Serrano C, Bakondi B, Pochampally R, Song YH et al. Multipotent human stromal cells improve cardiac function after myocardial infarction in mice without long-term engraftment. Biochem. Biophys.Res.Commun. 2007;354:700-06.

36. Muller-Ehmsen J, Krausgrill B, Burst V, Schenk K, Neisen UC, Fries JW et al. Effective engraftment but poor mid-term persistence of mononuclear and mesenchymal bone marrow cells in acute and chronic rat myocardial infarction. J.Mol.Cell Cardiol. 2006;41:876-84.

37. Singla DK, Lyons GE, Kamp TJ.Transplanted embryonic stem cells following mouse myocardial infarction inhibit apoptosis and cardiac remodeling. Am.J.Physiol Heart Circ.Physiol 2007;293:HI308-HI 3 I4.

38. Ebelt H, Jungblut M, Zhang Y, Kubin T, Kostin S, Technau A et al. Cellular cardiomyoplasty: improvement of left ventricular function correlates with the release of cardioactive cytokines. Stem Cells 2006.

39. Cho HJ, Lee N, Lee JY, Choi YJ, li M, Wecker A et al. Role of host tissues for sustained humoral effects after endothelial progenitor cell transplantation into the ischemic heart. J.Exp.Med. 2007;204:3257-69.

40. Wu EX, Wu Y, Nicholls JM, Wang J, Liao S, Zhu S et al. MR diffusion tensor imaging study of postinfarct myocardium structural remodeling in a porcine model. Magn Reson.Med. 2007;58:687-95.

4I. Thum T, Bauersachs J, Poole-Wilson PA, Volk HD, Anker SD. The dying stem cell hypothesis: immune modulation as a novel mechanism for progenitor cell therapy in cardiac muscle. J.Am.Coll.Cardiol. 2005;46:1799-802.

42. Dai W, Field LJ, Rubart M, Reuter S, Hale SL, Zweigerdt R et al. Survival and maturation of human embryonic stem cell-derived cardiomyocytes in rat hearts. J.Mol.Cell Cardiol. 2007;43:504-I6.

43. Laflamme MA, Gold J, Xu C, Hassanipour M, Rosler E, Police S et al. Formation of human myocardium in the rat heart from human embryonic stem cells.Am.J.Pathol. 2005; 167:663-7I.

44. Rubart M, Pasumarthi KB, Nakajima H, Soonpaa MH, Nakajima HO, Field LJ. Physiological coupling of donor and host cardiomyocytes after cellular transplantation. Circ.Res. 2003;92:1217-24.

45. Thomson JA, Kalishman J, Golos TG, Durning M, Harris CP, Becker RA et al. Isolation of a primate embryonic stem cell line. Proc.Natl.Acad.Sci.U.S.A 1995;92:7844-48.

46. Zimmermann WH, Melnychenko I, Wasmeier G, Didie M, Naito H, Nixdorff U et al. Engineered heart tissue grafts improve systolic and diastolic function in infarcted rat hearts. Nat.Med. 2006; 12:452-58. 
47. Hao X, Silva EA, Mansson-Broberg A, Grinnemo KH, Siddiqui AJ, Dellgren G et al. Angiogenic effects of sequential release of VEGF-AI65 and PDGF-BB with alginate hydrogels after myocardial infarction. Cardiovasc.Res. 2007;75:178-85. 


\section{Extracellular matrix formation after transplantation of hESC-derived cardiomyocytes in mice and a pro-survival mechanism through donor-derived neovascularization}

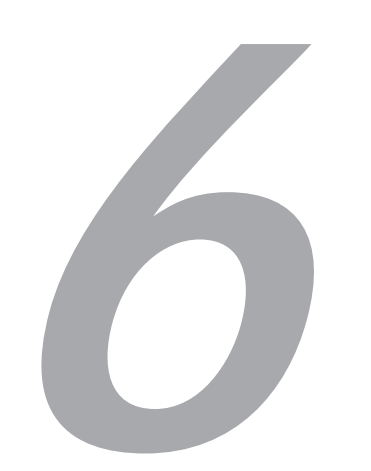

Submitted

L.W. van Laake, E.G. van Donselaar, J. Monshouwer-Kloots, R. Passier, L.M. Zeinstra,

D.Ward-van Oostwaard, F. Lebrin, B.M. Humbel, P.A. Doevendans, A. Sonnenberg, A.J.Verkleij,

C.L. Mummery. 


\section{Abstract}

Transplantation of human embryonic stem cell-derived cardiomyocytes (hESCCM) for cardiac regeneration is hampered by the formation of fibrotic tissue around the grafts, which may prevent coupling of donor- and host cells. We investigated this process in uninjured and infarcted hearts of immunodeficient (NOD-SCID) mice 2 days to 24 weeks after transplantation of hESC-CM and hESC-derived endothelial cells ( $\mathrm{hESC}-\mathrm{EC}$ ). Using immunofluorescence and electron microscopy, we found that (I) hESC-CM in beating areas in vitro are embedded in collagen I, IV and XVIII, laminin and fibronectin, all of which they can bind via appropriate integrins. (2) After transplantation into the mouse heart, hESC-CM continue to secrete extracellular matrix, in particular collagen IV and XVIII and to a lesser extent fibronectin, while the host reaction consists of encapsulation of the graft mainly by collagen I. The donor cell contribution is increased, especially for fibronectin, after transplantation in the infarcted heart. (3) Integrin expression on hESC-CM (before and after transplantation) largely matches the matrix type they encounter or secrete in vivo. (4) Cotransplantation of hESC-EC with hESC-CM can result in the formation of functional capillaries which improves blood supply to the grafts. (5) Possibly through this pro-survival mechanism, hESC-CM survive and mature in vivo for at least 24 weeks. These results form the basis of future developments aiming to reduce the adverse fibrotic reaction that currently complicates cell-based therapies for cardiac disease, and provide an additional clue towards successful engraftment of hESC-CM, and cardiomyocytes in general, by co-transplanting endothelial cells.

\section{Introduction}

Heart failure is one of the most prevalent causes of morbidity and mortality worldwide and is most commonly due to major loss of cardiomyocytes after myocardial infarction (MI) '. Until recently, loss of viable cardiomyocytes was considered irreversible since the adult mammalian myocardium lacks the ability to regenerate. However, with the discovery of sources of stem cells with the capacity to differentiate into cardiomyocytes and other cardiac cells, it may 
become possible to replenish the diseased heart with new myocardium ${ }^{2 ; 3}$. Human embryonic stem cells (hESCs) are one source that hold promise in this respect, since they can proliferate indefinitely in culture and differentiate into cardiomyocytes now with acceptable efficiencies ${ }^{4-6}$, thus providing a potentially "shelfable" source of cells for both chronic and acute applications. However, aside from their ethical sensitivity, several scientific issues need to be addressed before clinical application becomes feasible. Several of these issues have emerged from studies only recently initiated on the engraftment of $\mathrm{hESC}$-derived cardiomyocytes (hESC-CM) in uninjured, infarcted and arrhythmic hearts of experimental animals ${ }^{5 ;-11}$. These concern primarily integration, survival, safety, the immune response and ability to contribute to long term contractile function. When cardiomyocyte-enriched differentiated hESCs were transplanted into electrophysiologically silenced guinea pig and swine hearts, for example, they acted as biological pacemakers for the recipient myocardium ${ }^{8 ; 11}$. This indicated that donor hESC-CM can couple functionally to host cardiomyocytes, which is a prerequisite for a safe and effective outcome of such cell-based therapies. On the other hand, in studies where histological results were more extensively analyzed, grafts consisting of hESC-CM were found to be largely isolated from the host myocardium by a considerable amount of extracellular matrix both in infarcted and in non-infarcted hearts ${ }^{5 ; 7 ; 9 ; 10}$. Whilst extracellular matrix provides a structural, chemical and mechanical substrate that is essential for development and responses to pathophysiological signals ${ }^{12}$, such as myocardial ischemia and infarction, inappropriate or excessive secretion may have adverse effects. It could lead for example to separation of donor- from host cardiomyocytes. Although this would not necessarily exclude functional coupling completely, since electrophysiological signaling can be conducted through relatively thick layers of fibrotic tissue ${ }^{13}$, it would increase the risk of arrhythmias ${ }^{14}$ especially in larger animals and humans if a similar fibrotic layer would develop there. Additionally, impaired coupling of donor and host cells may in part explain why hESC-CM, like other cell types such as bone marrow stem cells ${ }^{15}$, have been more successful in improving short- and midterm cardiac function after MI than in providing sustained long-term functional improvement ${ }^{10 ; 15}$. It would therefore be useful to determine the characteristics and origin of the fibrotic tissue surrounding $\mathrm{hESC}-\mathrm{CM}$ grafts, so that strategies aimed at reducing matrix deposition could be developed. Encapsulation of the graft can be seen as simply 
a foreign body reaction of the host to exogenous cells, but another possibility is that hESC-derived cells produce their own extracellular matrix to create a more suitable local environment, or niche. It is not thought that the fibrotic layer is the result of mouse reaction to human tissue since encapsulation also occurs in transplantations from mouse to mouse ${ }^{16}$.

The capacity of cells to attach to and thrive in a particular matrix depends on the expression of integrins, heterodimeric transmembrane receptors composed of $\alpha$ - and $\beta$-subunits, at their cell surface. Individual cells may express multiple integrins, which allow them to interact with multiple extracellular matrix ligands ${ }^{12}$. The integrin expression pattern of hESC-CM is currently unknown, but would be useful for understanding mechanisms available for anchoring in recipient heart tissue and how they modulate their own environment to create an optimal niche for survival and integration. In addition, it may shed light on a phenomenon recently described by ourselves and others, of selective survival of hESC-CM in the heart compared with other cells types ${ }^{9 ; 10}$. In a recent study we detected a dense fibrotic layer around hESC-CM grafts at the electronmicroscopic (EM) level 12 weeks after transplantation ${ }^{10}$. It is presently unknown when fibrosis develops, when it reaches a maximum and how long grafted cells are under suboptimal conditions. If excessive extracellular matrix formation is a late reaction, graft survival may not significantly exceed 12 weeks, the longest follow-up time reported so far. Alternatively, compensatory mechanisms may develop that support graft survival, for example neovascularization through the fibrotic layer.

Here, we address these questions by analyzing healthy and infarcted mouse hearts at several time-points after intramyocardial transplantation of cardiomyocyteenriched differentiated hESCs, with a follow-up to 24 weeks. We determined the composition of the extracellular matrix surrounding the grafts with respect to matrix type and origin, and found a contribution of both host (mouse) and human donor cells. In addition, we characterized the integrin expression of hESC-CM in vitro before transplantation and at various time points thereafter. We also carried out an extensive EM study using immunogold labeling of GFP to identify the genetically marked human cells and monitor their behavior in the graft over time. In agreement with our previous study ${ }^{10}$ we found that hESCCM were more aligned with the mouse myocardium and displayed a more organized sarcomeric pattern at the later time-points after transplantation, 
indicating maturation of transplanted hESC-CM over time. Of interest was also the observation at the EM level of hESC-derived endothelial cells (hESC-EC), forming a capillary network which communicated with the mouse vasculature, in concurrence with extended graft survival and maturation over a 6 month period.

\section{Material and Methods}

Cell culture, differentiation and dissociation

HES3-GFP cells ${ }^{17 ; 18}$ were co-cultured with END2 cells to induce cardiomyocyte differentiation ${ }^{6: 19}$. Large numbers of beating areas are obtained within 12 days that consist routinely of $20-25 \%$ cardiomyocytes and $75-80 \%$ endodermal or other mesodermal derivates ${ }^{6 ; 20}$. Beating areas were dissected and dissociated with collagenase as previously $6 ; 21 ; 22$. One million cells were taken up in a final volume of $5 \mu \mathrm{l}$ of fresh culture medium (DMEM + 20\% FCS) and used for transplantation. For immunofluorescent staining, beating areas were isolated, fixed and processed for cryosections as described ${ }^{23}$ with minor modification (sectioning in Tissue-tec) ${ }^{22}$ or for electron microscopy (see below).

Animals and surgical procedures

All procedures involving experimental animals were approved by the Institute Animal Care Committee. Male NOD-SCID mice (Charles River) of 12 weeks of age were used. Myocardial infarction (MI) under isoflurane anesthesia was induced by ligation of the left anterior descending coronary artery (LAD) following left-sided thoracotomy, as described previously ${ }^{22}$. The surgical procedure for non-infarcted mice was identical but without ligation of the LAD. In the same operation, cells were injected in the infarcted or healthy myocardium of the free left ventricular wall using an insulin syringe with incorporated 29G needle. At 2 days, 4 weeks, 12 weeks and 24 weeks after surgery, animals were euthanized and the hearts were fixed and processed either for cryosections as described ${ }^{23}$ with minor modification (sectioning in Tissue-tec) ${ }^{22}$ or for electron microscopy (see below). 
Immunofluorescence and confocal microscopy

The entire region containing GFP-expressing cells of each heart was cut into 6 $\mu \mathrm{m}$ cryosections, which were stained as described ${ }^{22 ; 24}$. Antibodies and dilutions are listed in the Supplementary methods.

Confocal laser scanning microscopy (sequential scanning for DAPI and Alexa 405 with excitation laser 405 nm, GFP with 488 nm, Cy3 with 532 nm and Cy5 with $633 \mathrm{~nm}$, respectively, to avoid signal leakage) was performed on a Leica TCS SPE confocal on a DMI4000B microscope using LAS-AF software (Leica application suite- advanced fluorescence). Investigators (L.v.L. and J.M) were blinded for time-point and matrix or integrin type scoring.

\section{Immunogold labeling and electron microscopy}

For EM, hearts were perfusion- and subsequently immersion-fixed with $2 \%$ formaldehyde $/ 0.05 \%$ glutaraldehyde in $100 \mathrm{mM}$ phosphate buffer $\mathrm{pH} 7.4$, and processed for Tokuyasu cryo-sectioning 25;26. Colonies of undifferentiated hESCs or beating areas were immersion-fixed with the same fixatives. The 60 $\mathrm{nm}$ sections were labeled with antibodies against GFP (I:100) (rabbit, Abcam), cytokeratin 8 (troma-I) (I:3) (rat, Developmental Studies Hybridoma Bank), Tra-I-60 (I:60) (mouse, Chemicon), and human von Willebrand Factor (I:300) (mouse, clone CLB-RAg 38, a kind gift from prof. P.H. de Groot). Primary antibodies were detected with protein A 10 or $15 \mathrm{~nm}$ gold (Utrecht Medical Center, Cell Microscopy Center) ${ }^{27}$, and imaged with a JEOL 1010 electron microscope at $80 \mathrm{kV}$.

\section{Results}

To follow development of extracellular matrix around hESC-CM grafts over time (also summarized in Supplementary Table I), we first determined the matrix proteins present in isolated beating areas of hES3-GFP at the 12 day time point when transplantation normally took place. Cardiomyocytes in beating areas were surrounded by collagen I, collagen IV, collagen XVIII, total laminin including laminin I, 8, 10 and other isoforms (laminin) and fibronectin (Fig. I a-e), but laminin-2II was absent. These matrix components are all normally 
present in the mammalian myocardium, where collagen $I$ is secreted by fibroblasts, collagen IV by cardiomyocytes, and laminin and fibronectin by both cardiomyocytes and fibroblasts ${ }^{28}$. Collagen XVIII is present in the adult heart in blood vessels only ${ }^{29}$, but we found it to be highly expressed throughout the human fetal myocardium until 16 weeks of gestational age (Supplementary Fig. I). HESC-CM expressed one or more integrins that enabled binding to each matrix type (Fig. If-m): $\alpha$ II for collagen, little $\alpha 3$ and $\alpha 6$ for laminin (in addition $\alpha 7$ was expressed at the RNA level; no antibody was available) (Supplementary Fig. 2), $\alpha 5$ and $\alpha \bigvee$ for fibronectin and fibronectin/vitronectin, respectively, and integrin $\beta$ I that can heterodimerize with all of these $\alpha$ subunits ${ }^{30}$. HESC-CM did not express $\alpha 4$ or $\alpha 10$.

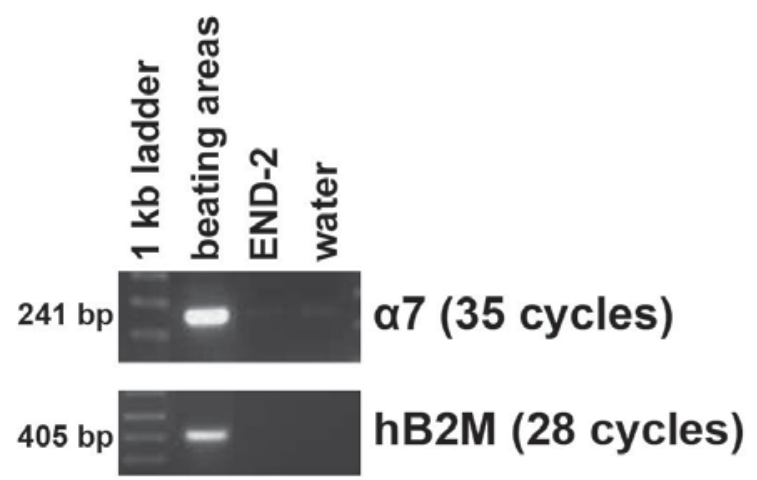

Supplementary Figure 2. Integrin $\alpha 7$ is expressed in beating areas from hESCs, but not in END-2 cells.

We then analyzed grafts, identified by GFP-fluorescence as previously ${ }^{10}, 2$ days, 4 weeks and 12 weeks after transplantation in the non-infarcted hearts of NOD-SCID mice. From 4 weeks onwards these grafts consisted mainly of cardiomyocytes due to their preferential survival, as described ${ }^{10}$. At all timepoints, collagen I was expressed homogeneously throughout the myocardium and in the scar tissue that resulted from the intramyocardial injection (Fig. 2ab). At 4 and 12 weeks, however, excessive quantities of collagen I encapsulated most of the grafted cells (Fig. 2b). Although the antibody recognizes both mouse and human collagen I, this oversecretion was probably host-derived since collagen I is secreted by fibroblasts and not cardiomyocytes, and no human fibroblasts were found in the mouse heart despite an extensive search using 
EM. Using human-specific antibodies, human collagen IV and human collagen XVIII were identified around hESC-CM at all time-points (Fig. 2c-f). Moreover, at 4 and 12 weeks after transplantation patches of human collagen IV and $\mathrm{XVIII}$ were also present at some distance from the grafts. Thus, hESC-CM secreted substantial amounts of collagen IV and XVIII in vivo in the mouse heart. Laminin enveloped hESC-CM at all time-points just as mouse cardiomyocytes, but was not present at excessive levels (Fig. $2 \mathrm{~g}$-h). Laminin-2II was absent in grafts 2 days post-transplantation but became expressed thereafter in the same moderate quantities as laminin (Fig. 2i-j). Thus laminins may be donor or hostderived, or both, but do not contribute significantly to fibrotic tissue separating donor from host cells. Fibronectin filled the graft area abundantly 2 days after transplantation but this decreased over time (Fig. $2 \mathrm{k}-\mathrm{I})$. Human fibronectin was less prevalent by 4 weeks after transplantation, while mouse fibronectin was reduced by 12 weeks and only then no longer contributed to the fibrotic area. Taken together, the results showed that hESC-CM secrete fibronectin, and that this is downregulated after transplantation in the non-infarcted heart. Secretion of mouse fibronectin, on the other hand, appears to be a response to the cell transplantation but is eventually resolved.

Analysis of the integrin expression by hESC-CM in vivo indicated that these cells bind collagens via integrin $\alpha \mathrm{ll}$ at all time-points, just as in vitro (Fig. $3 \mathrm{a}$ ). Laminin-binding integrin $\alpha 3$ was upregulated in vivo, while $\alpha 6$ was slightly downregulated (Fig. 3c,e). Integrins $\alpha 5$ and $\alpha \mathrm{V}$, which bind fibronectin and fibronectin/vitronectin, respectively, were both reduced over time (Fig. 3b,d). Integrin $\beta \mid$ expression remained high at all time-points (Fig. 3f). Staining for $\alpha 4$ and $\alpha / 0$ was negative.

We next investigated whether myocardial infarction triggered a different extracellular matrix response to and by hESC-CM grafts by injecting cardiomyocyte enriched differentiated hESCs into the acutely infarcted mouse myocardium. We have shown previously that transforming growth factor $\beta$ (TGF $\beta$ ) is strongly upregulated in the border zone in mice after myocardial infarction and that it likely contributes to upregulation of one of its target genes fibronectin in the direct vicinity ${ }^{31}$. In order to see whether this might also affect cells in the graft we reexamined matrix expression as above but now after myocardial infarction. Four weeks and 12 weeks post-operatively, collagen I was 
a major matrix component of the infarct area and was even more extensively present around the hESC-CM grafts, as in grafts in the non-infarcted heart (Fig. 4a). Human collagen IV and XVIII were again secreted by hESC-CM, and collagen XVIII in larger quantities than in the non-infarcted heart (Fig. 4c-f). Laminin contributed significantly to the infarct area but laminin-2II to a lesser extent (Fig. 4b,g-h). However, as in the non-infarcted heart neither showed an increase in relation to the transplanted hESC-CM. Fibronectin was abundant in the infarct zone, and this was mainly due to the presence of human fibronectin in areas with hESC-CM grafts (Fig. 4i-j). Unlike in the non-infarcted heart, the human fibronectin content was still high even at 12 weeks after transplantation. This may have been the result of TGF $\beta$ signaling in the host tissue. Integrin expression was similar to that of hESC-CM in the non-infarcted heart.

Since fibrosis was already present at early time-points and was not degraded during a follow-up of 12 weeks, the question arose whether transplanted hESCCM could survive for longer periods at all. We therefore increased follow-up to 24 weeks and found viable grafts that appeared similar to those at 12 weeks in terms of graft size and GFP-fluorescence. At both time-points the hESCCM showed signs of maturation in vivo, including loss of punctuate staining for cytokeratin 8 which was found in intracellular keratin threads and desmosomes in immature hESC-CM in vitro (Fig. 5a-b) as previously reported for human fetal cardiomyocytes ${ }^{32}$. However, EM analysis of the grafted cells 24 weeks after transplantation revealed that the hESC-CM had matured further, evidenced by increased myofibril content and improved sarcomeric organization compared to 12 weeks in vivo maturation (Fig. $5 c-d$ ), indicating that the hESC-CM were healthy and survived in the vicinity of a hypoxic environment. Paradoxically, the fibrotic layer surrounding the graft had not been cleared at all and still largely separated human from mouse myocardium, preventing desmosome formation between human and mouse cells (Fig.5e) even though desmosomes between human cardiomyocytes were abundant (Fig. 5d). It was thus likely that the grafts received oxygen and nutrients through infiltrating vessels, and indeed we observed previously that some mouse-derived vessels were present in the grafts ${ }^{10}$. Surprisingly however, a subset of 24 - and 12 weeks large hESCCM grafts (4 out of 16 hearts) were surrounded by small clusters of GFPexpressing cells which formed a mosaic-like pattern with the native mouse 
cardiomyocytes (Fig. 5f, 6a). The morphology of these hESC-derived cells was typical of endothelial cells: long flat cells aligning capillaries (Fig. 6d) with the typical appearance of caveolae and Weibel-palade bodies which identity could be confirmed with immunogold labeling for human von Willebrand Factor (vWF). The capillaries consisted uniquely of GFP-expressing human endothelial cells but were connected to the mouse vasculature, as evidenced by the presence of mouse leukocytes and erythrocytes in their lumen (Fig. 6b-c), and were associated with an increased vascular density in the area around the grafts.

We next sought to distinguish between in vivo differentiation of any undifferentiated hESCs, hESC-derived endothelial or cardiac progenitor cells (or even transdifferentiation of other differentiated hESC-derived cells) and pre-existing in vitro differentiation of hESCs to endothelial cells. By staining $\mathrm{hESC}$-derived beating areas, the starting material for transplantations, we found that some contained tube-like structures that expressed human von Willebrand factor and human PECAM-I (CD3I) (Fig. 6e). Donor-derived neovascularization was thus most likely to be a result of the supplementary co-injection of hESCendothelial cells (hESC-EC) with hESC-CM, although there may have been bipotent progenitors present as many of the cells expressed IsII 6;33. In addition, a proportion of the hESC-EC population was still proliferating both in vitro and in vivo (Fig. 6f-h).

To exclude the possibility that undifferentiated hESCs were unintentionally co-transplanted and subsequently contributed to neovascularization, we also analyzed their ultrastructural characteristics and compared these with grafted cells and beating areas. In agreement with our micro-array screening of beating areas from the same END-2 co-culture system ${ }^{20}$ which had shown the absence on stem cell markers, we found no similarities in the ultrastructure of GFP-cells in beating areas or in grafts at any time-point with undifferentiated hESCs. Unlike differentiated hESCs, pluripotent hESCs showed strong immunoreactivity with the stem cell marker Tra-I-60 on their apical side and in the endocytotic and biosynthetic systems (Fig. 6i-j). Thus, formation of hESC-derived capillaries was from co-injected hESC-EC, not from undifferentiated hESCs. 
Chapter 6 | 127
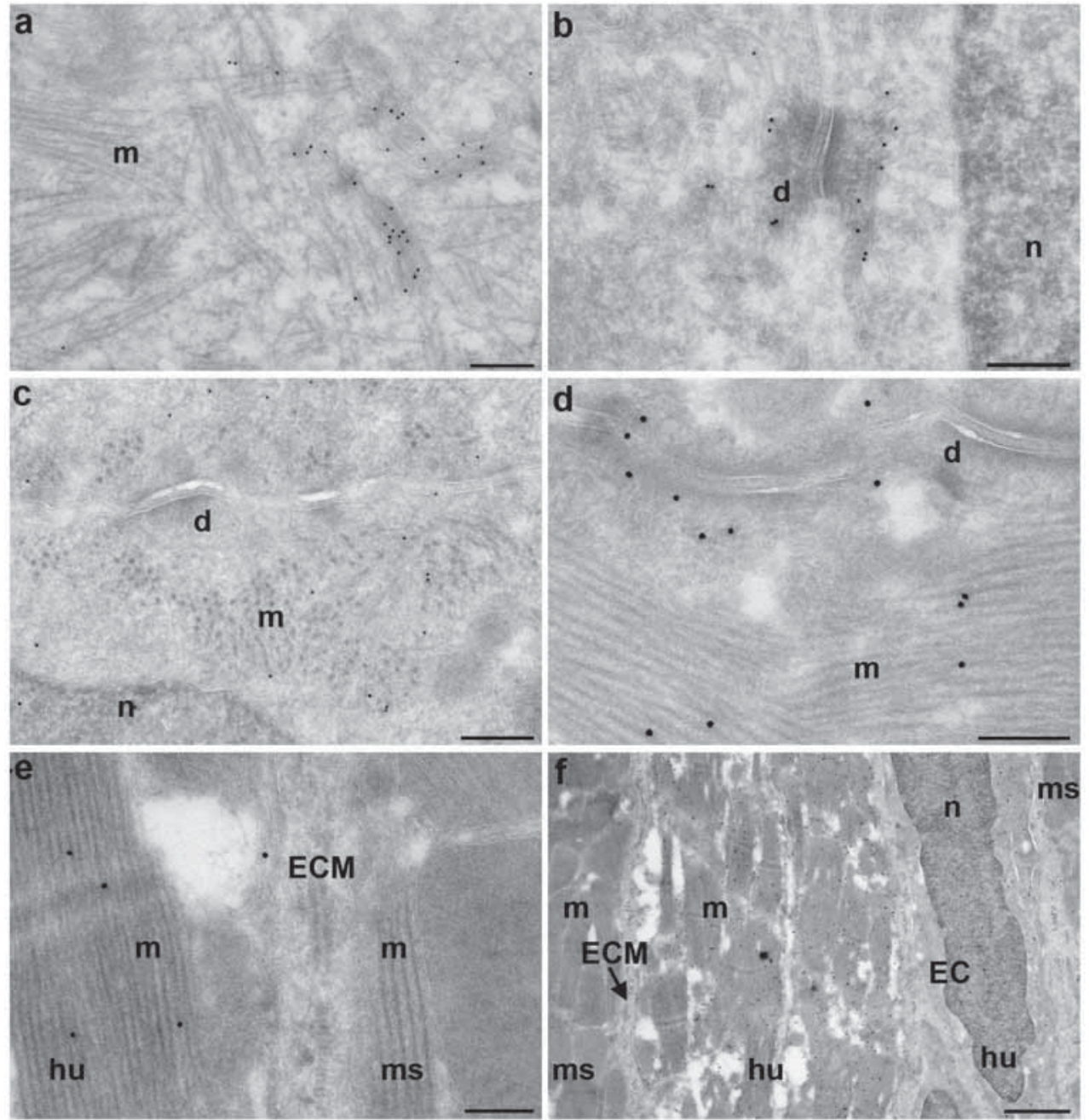

Figure 5. Survival and continuing maturation of transplanted hESC-CM for at least 24 weeks. (a,b) immature hESCCM in vitro containing poorly organized myofibrils and keratin threads; black dots: cytokeratin 8, (c-f) hESC-CM grafts; black dots: GFP; d: desmosome; n: nucleus; m: myofibrils; hu: human; ms: mouse; ECM: extracellular matrix, (c) increased myofibril content and organization and desmosome formation in hESC-CM 12 weeks after transplantation, (d) further increased myofibril content and organization and desmosome formation in hESC-CM 24 weeks after transplantation, (e) extracellular matrix between donor and host cardiomyocytes 24 weeks after transplantation, $(\mathrm{f})$ overview of hESC-CM with flanking hESC-EC 24 weeks after transplantation. Scale bars (a-e) $200 \mathrm{~nm}$, (f) I $\mu \mathrm{m}$. 


\section{Discussion}

This is the first study to date characterizing the fibrotic response after intramyocardial cell transplantation, describing the integrin expression profile in hESC-CM, and documenting neovascularization following co-transplantation of hESC-CM and hESC-EC into the mouse heart. The key findings can be summarized as follows: (I) hESC-CM in beating areas in vitro are embedded in collagen I, IV and XVIII, laminin and fibronectin, all of which they can bind via appropriate integrins. (2) After transplantation into the immunodeficient mouse heart, hESC-CM continue to secrete extracellular matrix, in particular collagen IV and XVIII and to a lesser extent fibronectin, while the host reaction consists of encapsulation of the graft mainly by collagen I. The donor cell contribution is increased, especially for fibronectin, after transplantation in the infarcted heart. (3) Integrin expression on hESC-CM (before and after transplantation) largely matches the matrix type they encounter or secrete in vivo. (4) Co-transplantation of hESC-EC with hESC-CM can result in the formation of functional capillaries which improves blood supply to the grafts. (5) Possibly through this pro-survival mechanism, hESC-CM survive and mature in vivo for at least 24 weeks.

Whilst the extracellular matrix present around hESC-CM beating areas can be secreted by hESC-CM or by other cell types, the human matrix components we identified in grafts of over 4 weeks are most likely to be produced by cardiomyocytes, since these make up over $90 \%$ of the grafts from that time-point ${ }^{10}$. Although collagen IV and some fibronectin are secreted by adult cardiomyocytes ${ }^{28}$, collagen $\mathrm{XVIII}$ is associated with fetal myocardium only, confirming the fetal-like phenotype of hESC-CM ${ }^{34}$ even though they mature significantly after transplantation. This is also in agreement with our observation that fibronectin secretion by $\mathrm{hESC}-\mathrm{CM}$ is more pronounced at early time-points and (like collagen XVIII) after myocardial infarction, when environmental factors upregulate expression of fetal genes ${ }^{35}$, since fibronectin is more important in the early fetal than in the adult heart ${ }^{36 ; 37}$. We cannot rule out the possibility that the increased presence of these matrices is caused by a slower degradation in the infarcted heart, but this seems unlikely considering the large time differences between the points investigated and the shorter turnover time of fibronectin and collagens, especially in myocardial infarction 
when matrix metalloproteinases (MMPs) are abundantly present ${ }^{38}$. In both non-infarcted and infarcted hearts, transplanted hESC-CM were surrounded by a substantial layer of collagen I, probably host-derived, that was not cleared over time. Distant from the grafts, the composition of the extracellular matrix in the infarct zone was unaltered by the hESC-CM transplantation compared to previous reports ${ }^{38-40}$. Laminins were not increased in the graft area, and thus the fibrotic tissue separating donor from host cells consists of host-derived collagen I and donor-derived collagen IV, collagen XVIII -and in the infarcted heart also of fibronectin.

Integrins expressed on HESC-CM mediate binding to each of the matrices described, although we observed some changes in their expression profile after transplantation. The high expression of $\alpha \mathrm{ll}$ is consistent with attachment to collagens, and collagen synthesis by hESC-CM may even be essential for differentiation and proliferation, as described for mouse ESC-CM and human fetal cardiomyocytes ${ }^{41 ; 42}$. Although collagen XVIII is best known as a precursor for endostatin ${ }^{43}$, the high expression in human fetal myocardium at a time in development when angiogenesis is profuse ${ }^{29}$ and our observations indicate that this collagen likely has a different function in hESC-CM unrelated to inhibition of angiogenesis. Nevertheless, it would be interesting to inhibit collagen XVIII production in hESC-CM and search for a potential effect on neo-angiogenesis after myocardial infarction. Laminin-binding integrins $\alpha 3$ and $\alpha 6$ were expressed at low levels by only a few cells in vitro. Based on PCR results, $\alpha 7$ may also be present on hESC-CM. After transplantation however, $\alpha 3$ was markedly upregulated to become the principal lamininbinding integrin, possibly together with $\alpha 7$. Reasons for the excessive human fibronectin secretion early after transplantation could be a response to TGF $\beta$ or suboptimal binding of transplanted hESC-CM to laminin. Since laminin is not secreted in excess, modifying hESC-CM to express more functional lamininbinding and less fibronectin-binding integrins might help to reduce extracellular matrix secretion by hESC-CM and accelerate maturation ${ }^{36 ; 37}$, provided their proliferative capacity can be kept intact. Although integrins $\alpha 5$ and $\alpha \mathrm{V}$, which bind fibronectin/vitronectin, were also spontaneously reduced over time, this took several weeks, when fibronectin secretion had already taken place. Alternatively, co-injecting hESC-CM with a mixture of the extracellular matrix 
proteins they would otherwise secrete themselves and those they encounter in the recipient heart, might provide a more gradual habituation of the donor cells and prevent part of their matrix secretion.

Collagen I forms a layer around patches of grafted hESC-CM, an expected foreign body reaction by mouse fibroblasts. To prevent this in future clinical applications, it is essential that donor and host cell match as closely as possible with regard to immunological, electrophysiological and mechanical characteristics (such as stiffness), since fibroblasts "sense" discrepancies and respond by producing more extracellular matrix ${ }^{44}$. Other options may include upregulating MMP secretion by hESC-CM or co-injecting MMPs or inhibitors of tissue inhibitors of metalloproteinases (TIMPs). However, these interventions need to be accurately timed and dosed, as an excess of particular MMPs results in adverse remodeling such as dilatation ${ }^{38 ; 45}$.

Although the excessive deposition of extracellular matrix around intramyocardial grafts needs to be resolved for electrophysiological reasons, it appeared that oxygen and nutrient supply were spared since survival and ultrastructural maturation were sustained over prolonged periods of even 24 weeks. Benefit to this was the co-injection of hESC-EC leading to the formation of functional human capillaries connected to the mouse vasculature. Mouse ESC-EC and hESC-EC differentiation have been described before ${ }^{46 ; 47}$ and mouse ESCEC increased cardiac function in a mouse model of myocardial infarction ${ }^{46}$. HESC-EC could be selected based on expression of PECAM-I on their surface. However, co-injection of hESC-CM and hESC-EC has not been investigated to date. With improved selection methods to also obtain pure population of hESC-CM ${ }^{48}$, defined co-transplantation of hESC-CM and hESC-EC has now become a realistic possibility that warrants further exploration and holds great promise for eventual clinical application.

One limitation of our study is the interspecies difference that may also prevent functional coupling of donor- and host cardiomyocytes, since human cardiomyocytes are unlikely to sustain prolonged periods of relative tachycardia in a mouse heart beating approximately 500 times per minute. However, the long term survival and maturation and functional benefits of $\mathrm{hESC}-\mathrm{CM}$ in this and 
other rodent in vivo models ${ }^{5: 10}$ suggests that most other factors are likely to be similar in mouse and human hearts. Importantly, extracellular matrix response after injury in the mouse heart is representative for that in the clinical setting, when taking into account that the time course of events is accelerated in mice ${ }^{40}$. Another reason for choosing the mouse as a model system is the availability of NOD-SCID mice, to reduce the influence of specific immune reaction that might otherwise confound results. Nevertheless, these experiments eventually need to be repeated isogenically in larger animals, for example in non-human primates for which ESC are available ${ }^{49}$.

In conclusion, both donor and host cells contribute to excessive extracellular matrix formation after transplantation of hESC-CM into the mouse myocardium, and the donor reaction is more pronounced in the presence of myocardial infarction. Nevertheless, hESC-CM are able to survive and mature after transplantation for prolonged periods of at least 24 weeks, which may be supported by donor-derived capillary formation from co-transplanted hESCEC. These results form the basis of future developments aiming to reduce the adverse fibrotic reaction that currently complicates cell-based therapies for cardiac disease, and provide an additional clue towards successful engraftment of hESC-CM, and cardiomyocytes in general, by co-transplanting endothelial cells.

\section{Acknowledgements}

We are grateful to S. van den Brink for cell culture, J. Korving for histology, C. Reijmer for fetal hearts and R. Scriwanek for processing of EM photographs.

\section{Funding sources}

This work is supported by the European Community's Sixth Framework Programme contract ('HeartRepair') LSHM-CT-2005-018630 (L.v.L, R.P) and the Dutch Platform for Tissue Engineering (J.M, F.L, L.Z.) 


\section{References}

I. International Cardiovascular Disease Statistics. American Heart Association. 2007.

2. Rubart M, Field LJ. Cardiac regeneration: repopulating the heart. Annu Rev Physiol. 2006;68:29-49.

3. van Laake LW, Hassink R, Doevendans PA, Mummery C. Heart repair and stem cells.J Physiol. 2006;577:467478.

4. Burridge PW, Anderson D, Priddle H, Barbadillo M, Chamberlain S, Allegrucci C, Young LE, Denning C. Improved human embryonic stem cell embryoid body homogeneity and cardiomyocyte differentiation from a novel V-96 plate aggregation system highlights interline variability. Stem Cells. 2007;25:929-938.

5. Laflamme MA, Chen KY, Naumova AV, Muskheli V, Fugate JA, Dupras SK, Reinecke H, Xu C, Hassanipour M, Police S, O'sullivan C, Collins L, Chen Y, Minami E, Gill EA, Ueno S, Yuan C, Gold J, Murry CE. Cardiomyocytes derived from human embryonic stem cells in pro-survival factors enhance function of infarcted rat hearts. Nat Biotechnol. 2007;25:1015-1024.

6. Passier R, Oostwaard DW, Snapper J, Kloots J, Hassink RJ, Kuijk E, Roelen B, de la Riviere AB, Mummery $C$. Increased cardiomyocyte differentiation from human embryonic stem cells in serum-free cultures. Stem Cells. 2005;23:772-780.

7. Dai W, Field LJ, Rubart M, Reuter S, Hale SL, Zweigerdt R, Graichen RE, Kay GL, Jyrala AJ, Colman A, Davidson BP, Pera M, Kloner RA. Survival and maturation of human embryonic stem cell-derived cardiomyocytes in rat hearts. J Mol Cell Cardiol. 2007;43:504-516.

8. Kehat I, Khimovich L, Caspi O, Gepstein A, Shofti R,Arbel G, Huber I, Satin J, Itskovitz-Eldor J, Gepstein L. Electromechanical integration of cardiomyocytes derived from human embryonic stem cells. $\mathrm{Nat}$ Biotechnol. 2004;22:1282-1289.

9. Laflamme MA, Gold J, Xu C, Hassanipour M, Rosler E, Police S, Muskheli V, Murry CE. Formation of human myocardium in the rat heart from human embryonic stem cells. Am J Pathol. 2005;167:663-67I.

10. van Laake LW, Passier R, Monshouwer-Kloots J, Verkleij AJ, Lips DJ, Freund C, Den Ouden K, Wardvan Oostwaard D, Korving J, Tertoolen LG, van Echteld CJ, Doevendans PA, Mummery CL. Human embryonic stem cell-derived cardiomyocytes survive and mature in the mouse heart and transiently improve function after myocardial infarction. Stem Cell Research. 2007; 1:9-24.

II. Xue T, Cho HC, Akar FG, Tsang SY, Jones SP, Marban E, Tomaselli GF, Li RA. Functional integration of electrically active cardiac derivatives from genetically engineered human embryonic stem cells with quiescent recipient ventricular cardiomyocytes: insights into the development of cell-based pacemakers. Circulation. 2005; I I I: I I-20.

12. Ross RS. Molecular and mechanical synergy: cross-talk between integrins and growth factor receptors Cardiovasc Res. 2004;63:38I-390.

13. Gaudesius G, Miragoli M, Thomas SP, Rohr S. Coupling of cardiac electrical activity over extended distances by fibroblasts of cardiac origin. Circ Res. 2003;93:42I-428.

14. Breithardt G, Borggrefe M, Martinez-Rubio A, Budde T. Pathophysiological mechanisms of ventricular tachyarrhythmias. Eur Heart J. 1989; 10 Suppl E:9-18.

15. Rosenzweig A. Cardiac cell therapy--mixed results from mixed cells. N Engl J M ed. 2006;355:I274-I 277.

16. Mannon RB, Kopp JB, Ruiz P, Griffiths R, Bustos M, Platt JL, Klotman PE, Coffman TM. Chronic rejection of mouse kidney allografts. Kidney Int. 1999;55: 1935- 1944.

17. Costa M, Dottori M, Ng E, Hawes SM, Sourris K, Jamshidi P, Pera MF, Elefanty AG, Stanley EG. The hESC line Envy expresses high levels of GFP in all differentiated progeny. Nat M ethods. 2005;2:259-260.

18. Doevendans PA, Becker KD,An RH, Kass RS. The utility of fluorescent in vivo reporter genes in molecular cardiology. Biochem Biophys Res Commun. 1996;222:352-358. 
19. Mummery C, Ward-van Oostwaard D, Doevendans P, Spijker R, van den BS, Hassink R, van der HM, Opthof T, Pera M, de la Riviere AB, Passier R, Tertoolen L. Differentiation of human embryonic stem cells to cardiomyocytes: role of coculture with visceral endoderm-like cells. Circulation. 2003;107:2733-2740.

20. Beqqali A, Kloots J, Ward-van Oostwaard D, Mummery C, Passier R. Genome-wide transcriptional profiling of human embryonic stem cells differentiating to cardiomyocytes. Stem Cells. 2006.

21. Moore JC, van Laake LW, Braam SR, Xue T, Tsang SY,Ward D, Passier R, Tertoolen LL, Li RA, Mummery $\mathrm{CL}$. Human embryonic stem cells: Genetic manipulation on the way to cardiac cell therapies. Reprod Toxicol. 2005;20:377-39I.

22. van Laake LW, Passier R, Monshouwer-Kloots J, Nederhoff MG, Ward-van Oostwaard D, Field LJ, van Echteld CJ, Doevendans PA, Mummery CL. Monitoring of cell therapy and assessment of cardiac function using magnetic resonance imaging in a mouse model of myocardial infarction. Nat Protoc. 2007.

23. Bajanca F, Luz M, Duxson MJ,Thorsteinsdottir S. Integrins in the mouse myotome: developmental changes and differences between the epaxial and hypaxial lineage. Dev Dyn. 2004;231:402-4I5.

24. van Laake LW, van den DS, Post S, Feijen A, Jansen MA, Driessens MH, Mager J], Snijder RJ,Westermann CJ, Doevendans PA, van Echteld CJ, ten Dijke P, Arthur HM, Goumans MJ, Lebrin F, Mummery CL. Endoglin has a crucial role in blood cell-mediated vascular repair. Circulation. 2006; | 14:2288-2297.

25. Liou W, Geuze HJ, Slot JW. Improving structural integrity of cryosections for immunogold labeling. Histochem Cell Biol. 1996; 106:41-58.

26. Tokuyasu KT.A technique for ultracryotomy of cell suspensions and tissues.J Cell Biol. 1973;57:55 I-565.

27. Slot JW, Geuze HJ. Sizing of protein A-colloidal gold probes for immunoelectron microscopy.J Cell Biol. 1981;90:533-536.

28. Baharvand H, Azarnia M, Parivar K, Ashtiani SK. The effect of extracellular matrix on embryonic stem cell-derived cardiomyocytes. J Mol Cell Cardiol. 2005;38:495-503.

29. Carvalhaes LS, Gervasio OL, Guatimosim C, Heljasvaara R, Sormunen R, Pihlajaniemi T, Kitten GT. Collagen $\mathrm{XVIII/endostatin} \mathrm{is} \mathrm{associated} \mathrm{with} \mathrm{the} \mathrm{epithelial-mesenchymal} \mathrm{transformation} \mathrm{in} \mathrm{the} \mathrm{atrioventricular}$ valves during cardiac development. Dev Dyn. 2006;235:132-142.

30. Danen $\mathrm{EH}$,SonnenbergA. Integrins in regulation of tissue development and function.J Pathol.2003;200:47I480.

31. Chuva de Sousa Lopes SM, Feijen A, Korving J, Korchynskyi O, Larsson J, Karlsson S, ten Dijke P, Lyons KM, Goldschmeding R, Doevendans P, Mummery CL. Connective tissue growth factor expression and Smad signaling during mouse heart development and myocardial infarction. Dev Dyn. 2004;23 I:542-550.

32. Kuruc N, Franke WW. Transient coexpression of desmin and cytokeratins 8 and 18 in developing myocardial cells of some vertebrate species. Differentiation. 1988;38:177-193.

33. Moretti A, Caron L, Nakano A, Lam JT, Bernshausen A, Chen Y, Qyang Y, Bu L, Sasaki M, Martin-Puig S, Sun Y, Evans SM, Laugwitz KL, Chien KR. Multipotent embryonic isll+ progenitor cells lead to cardiac, smooth muscle, and endothelial cell diversification. Cell. 2006;127:1 I5I-II65.

34. Mummery C, Ward-van Oostwaard D, Doevendans P, Spijker R, van den BS, Hassink R, van der HM, Opthof T, Pera M, de la Riviere AB, Passier R, Tertoolen L. Differentiation of human embryonic stem cells to cardiomyocytes: role of coculture with visceral endoderm-like cells. Circulation. 2003; 107:2733-2740.

35. Thum T, Galuppo P, Wolf C, Fiedler J, Kneitz S, van Laake LW, Doevendans PA, Mummery CL, Borlak J, Haverich A, Gross C, Engelhardt S, Ertl G, Bauersachs J. MicroRNAs in the human heart: a clue to fetal gene reprogramming in heart failure. Circulation. 2007; I 16:258-267.

36. Cachaco AS, Pereira CS, Pardal RG, Bajanca F,Thorsteinsdottir S. Integrin repertoire on myogenic cells changes during the course of primary myogenesis in the mouse. Dev Dyn. 2005;232:1069-1078.

37. Kim H,Yoon CS, Kim H, Rah B. Expression of extracellular matrix components fibronectin and laminin in the human fetal heart. Cell Struct Funct. 1999;24:19-26. 
38. Lindsey ML, Mann DL, Entman ML, Spinale FG. Extracellular matrix remodeling following myocardial injury. Ann M ed. 2003;35:316-326.

39. Cleutjens JP, Verluyten MJ, Smiths JF, Daemen MJ. Collagen remodeling after myocardial infarction in the rat heart. Am J Pathol. 1995; 147:325-338.

40. Dobaczewski M, Bujak M,Zymek P, Ren G, Entman ML, Frangogiannis NG. Extracellular matrix remodeling in canine and mouse myocardial infarcts. CellTissue Res. 2006;324:475-488.

4I. Hornberger LK, Singhroy S, Cavalle-Garrido T,TsangW, Keeley F, Rabinovitch M. Synthesis of extracellular matrix and adhesion through beta(I) integrins are critical for fetal ventricular myocyte proliferation. Circ Res. 2000;87:508-515.

42. Sato H, Takahashi M, Ise H, Yamada A, Hirose S, Tagawa Y, Morimoto H, Izawa A, Ikeda U. Collagen synthesis is required for ascorbic acid-enhanced differentiation of mouse embryonic stem cells into cardiomyocytes. Biochem Biophys Res Commun. 2006;342:107-II 2.

43. Marneros AG, Olsen BR. Physiological role of collagen XVIII and endostatin. FASEB J. 2005; 1 9:71 6-728.

44. MacKenna D, Summerour SR, Villarreal FJ. Role of mechanical factors in modulating cardiac fibroblast function and extracellular matrix synthesis. Cardiovasc Res. 2000;46:257-263.

45. van Laake LW, Vainas T, Dammers R, Kitslaar PJ, Hoeks AP, Schurink GW. Systemic dilation diathesis in patients with abdominal aortic aneurysms: a role for matrix metalloproteinase-9? Eur J Vasc Endovasc Surg. 2005;29:37I-377.

46. Li Z, Wu JC, Sheikh AY, Kraft D, Cao F, Xie X, Patel M, Gambhir SS, Robbins RC, Cooke JP, Wu JC. Differentiation, survival, and function of embryonic stem cell derived endothelial cells for ischemic heart disease. Circulation. 2007; I 16:146-154.

47. Levenberg S, Golub JS,Amit M, Itskovitz-Eldor J, Langer R. Endothelial cells derived from human embryonic stem cells. Proc Natl Acad Sci U S A. 2002;99:439I-4396.

48. Huber I, Itzhaki I, Caspi O,Arbel G, Tzukerman M, Gepstein A, Habib M,Yankelson L, Kehat I, Gepstein L. Identification and selection of cardiomyocytes during human embryonic stem cell differentiation. FASEB J. 2007.

49. Thomson JA, Kalishman J, Golos TG, Durning M, Harris CP, Becker RA, Hearn JP. Isolation of a primate embryonic stem cell line. Proc Natl Acad Sci U S A. 1995;92:7844-7848.

\section{Supplementary information:}

\section{Supplementary methods}

Antibodies and dilutions for immunofluorescence

The following antibodies were used: human von Willebrand Factor (I:300) (mouse, clone CLB-RAg 38, a kind gift from P.H. de Groot), human PECAMI (I:I00) (mouse, DAKO), Ki-67 (I:500) (rabbit, Abcam), fibronectin (I:500) (rabbit, Sigma), human fibronectin (l:200) (mouse, Sigma), laminin (l:200) (rabbit, Sigma), laminin-2II (I:200) (rat, Sigma), collagen I (I:I00) (rabbit, Abcam), human collagen IV (I:40) (rabbit, Chemicon), human collagen XVIII (I:50) (rabbit, Santa Cruz), human integrin $\alpha$ l (undiluted) (mouse, clone TS2/7, NKI), human 
integrin $\alpha 2$ (I:200) (mouse, clone I0GII, NKI), human integrin $\alpha 3$ (undiluted) (mouse, clone Jl43, NKI), human integrin $\alpha 4$ (I:100) (mouse, Chemicon), human integrin $\alpha 5$ (undiluted) (mouse, clone Saml, NKI), human integrin $\alpha 6$ (undiluted) (mouse, clone $\mathrm{J} 8 \mathrm{H}, \mathrm{NKI}$ ), integrin $\alpha \mathrm{l0}(\mathrm{I}: 50)$ (mouse, a kind gift from Evy Lundgren-Åkerlund, Cartela), integrin $\alpha \mathrm{ll}$ (I:I00) (rabbit, a kind gift from Evy Lundgren-Åkerlund, Cartela), human integrin $\alpha \bigvee$ (undiluted) (mouse, clone NKI-M9, NKI), human integrin $\beta I$ (undiluted) (mouse, clone TS2/I6, $N K I), \alpha$-actinin (I:800) (mouse, Sigma), troponinl (I:200) (rabbit, Chemicon). Isotype controls (DAKO) were performed for each class of antibody used. Cy3 and $\mathrm{Cy} 5$ labeled secondary antibodies were from Jackson Immuno Research Laboratories and Alexa 405 labeled secondary antibodies from Molecular Probes. Topro-3 (I:1000) (Molecular probes) or DAPI (Vectashield) was used for nuclear counterstaining.

\section{Human fetal and adult heart tissue}

Human fetal hearts were obtained after elective abortion and with informed consent after approval by the Institutional Ethics Committee. Biopsies from adult human cardiac tissue (kindly provided by J.C. Moore) were obtained from healthy donor hearts after approval by the Institutional Ethics Committee.

\section{RT-PCR for $\alpha 7$ integrin expression in hESC-CM}

Beating areas from 12 days hESC/END-2 co-culture were washed with PBS and RNA was isolated using TRIZOL Reagent (Invitrogen). After DNAse I treatment (Ambion), cDNA was synthesized with Superscript Il (Invitrogen) using poly (dT) oligonucleotides. Amplification conditions for integrin $\alpha 7$ and human B2M were: $94^{\circ} \mathrm{C} 5 \mathrm{~min}$., followed by 35 cycles ( $\alpha 7$ ) or 28 cycles (hB2M) $94^{\circ} \mathrm{C} 30$ sec., $58^{\circ} \mathrm{C}(\alpha 7)$ or $56^{\circ} \mathrm{C}$ (hB2M) $30 \mathrm{sec}$., $72^{\circ} \mathrm{C} 30 \mathrm{sec}$., followed by $72^{\circ} \mathrm{C} 7 \mathrm{~min}$. Primers used for integrin $\alpha 7$ were 5'-gctggtccacgcccgcttctgta-3' and 5'-ggcccggacccctgagtagtgc-3'. Primers used for hB2M were 5'-atacaattaaccctcactaaagggtctactttgagtgctgtctcca3' and 5'-ataggtaatacgactcactatagggcaccagattaaccacaaccatgc-3'. 


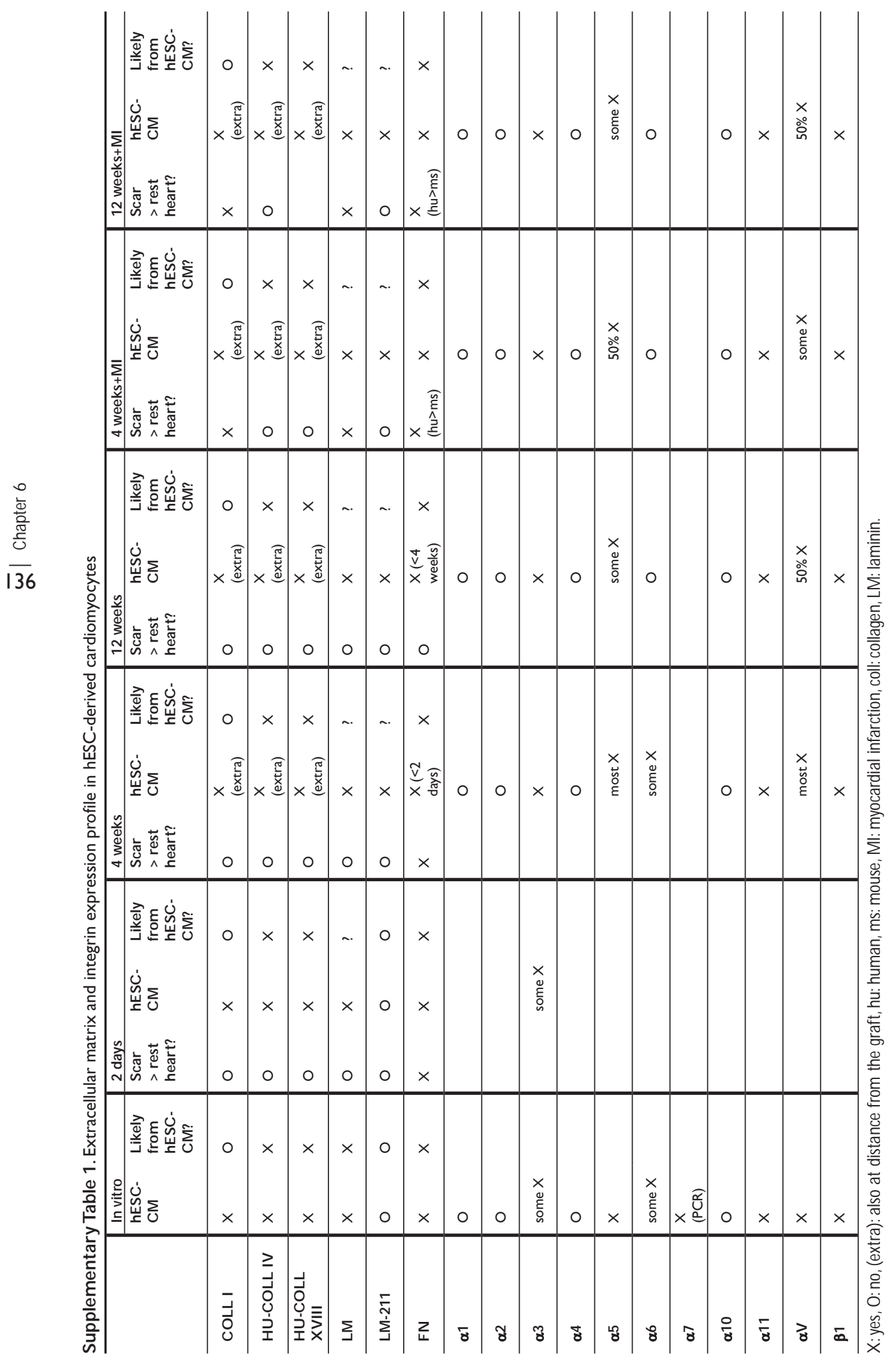




\section{Endoglin has a crucial role in blood cell-mediated vascular repair}

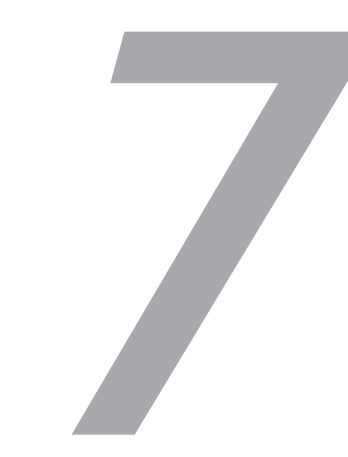

Published as

L.W. van Laake, S. van den Driesche, S. Post,A. Feijen, M.A. Jansen, M.H. Driessens, J.J. Mager, R.J. Snijder, C.J.J. Westermann, P.A. Doevendans, C.J.A. van Echteld, P. ten Dijke, H.M.Arthur, M-J. Goumans, F. Lebrin, C.L. Mummery. Endoglin has a crucial role in blood cell-mediated vascular repair. Circulation. 2006 Nov 2I; I 4(2I):2288-97 


\section{Abstract}

\section{Background}

Endoglin is an accessory receptor for transforming growth factor- $\beta$ in vascular endothelial cells and is essential for angiogenesis during mouse development. Mutations in the human gene cause hereditary hemorrhagic telangiectasia type I (HHTI), a disease characterized by vascular malformations that increase with age. Although haploinsufficiency is the underlying cause of the disease, HHTI individuals show great heterogeneity in age of onset, clinical manifestations and severity.

\section{M ethods and Results}

In situ hybridization and immunohistochemical analysis of mouse and human hearts revealed that endoglin is upregulated in neoangiogenic vessels formed after myocardial infarction (MI). Microvascularity within the infarct zone was strikingly lower in mice with reduced levels of endoglin $\left(\mathrm{Eng}^{+/}\right)$compared to wild-type mice, which resulted in a greater deterioration in cardiac function as measured by Magnetic Resonance Imaging (MRI). This did not appear to be due to defects in host inflammatory cell numbers in the infarct zone, which accumulated to a similar extent in wild-type and heterozygous mice. However, defects in vessel formation and heart function in $\mathrm{Eng}^{+/-}$mice were rescued by injection of mononuclear cells (MNCs) from healthy human donors but not by MNCs from $\mathrm{HHTI}$ patients.

\section{Conclusions}

These results establish defective vascular repair as a significant component of the etiology of HHTI. Since vascular damage or inflammation occurs randomly, they may also explain disease heterogeneity. More generally, the efficiency of vascular repair may vary between individuals because of intrinsic differences in their MNCs. 


\section{Introduction}

Revascularization of injured, ischemic and regenerating organs is essential to restore organ function. Neovascularization resulting from the proliferation, migration and remodeling of terminally differentiated endothelial cells (ECs) from pre-existing blood vessels, is termed angiogenesis '. Evidence suggests that mononuclear cells (MNCs), which include endothelial progenitor cells (EPCs), circulating endothelial cells (CEC) and bone marrow monocytic lineages, home to sites of ischemic damage and contribute to new blood vessel formation through vasculogenesis, transdifferentiation into ECs, and by secretion of cytokines that stimulate neoangiogenesis ${ }^{2,3}$.

Hereditary hemorrhagic telangiectasia (HHT, or Rendu-Osler-Weber syndrome) is an autosomal dominant disorder with low prevalence, estimated to be $\mathrm{I}$ in $10,000^{4}$. It is characterized by epistaxis, telangiectases and multiorgan vascular dysplasia ${ }^{4,5}$. Two variants of $\mathrm{HHT}$, HHTI and HHT2, have been linked to mutations in the ENG (endoglin) and ACVRL1 (activin receptor-like kinase I or ALKI) genes, respectively ${ }^{6,7}$, although recently, two more genes have been implicated ${ }^{8} 9$. Endoglin is highly expressed by active ECs from most blood vessels ${ }^{10}$. Deletion of endoglin in mice revealed its critical role during cardiovascular development. Mutant endoglin $\left(\mathrm{Eng}^{-1}\right)$ mice die at embryonic day (E) 10.5 from defects in vessel and heart development. Vasculogenesis in the Eng 1- mice is normal but angiogenesis is impaired along with the remodeling of the primary vascular plexus ${ }^{11}$, 12. Endoglin is an accessory receptor for transforming growth factor- $\beta$ (TGF- $\beta)^{13}{ }^{14}$, a cytokine controlling proliferation, migration, adhesion and apoptosis of many cell types ${ }^{15}$. The activated form of TGF- $\beta$ binds to type II receptors (T $\beta$ RII) which recruit TGF- $\beta$ type I serine/threonine kinase receptors to the complex and propagate signals to the nucleus by phosphorylating intracellular effectors termed Smads ${ }^{16,17}$. Two type I receptors mediate TGF- $\beta$ signaling: ALKI, mainly expressed in endothelium, and ALK5, widely expressed in most cell types. In ECs, TGF- $\beta / A L K 5$ signaling via Smad2/3 leads to inhibition of cell migration and proliferation, whereas TGF- $\beta / A L K I$ signaling via SmadI/5/8 promotes cell migration and proliferation ${ }^{18}$. Endoglin and ALKI are thought to act in a common pathway and inhibit TGF- $\beta / A L K 5$ signaling indirectly. The combined effect promotes the activation phase of angiogenesis during which vascular permeability increases, basement membrane is degraded 
and ECs proliferate and migrate ${ }^{19,20}$.

Several studies have implied haploinsufficiency as the mechanism responsible for HHT and indicated that disease heterogeneity is not related to the position or type of mutation ${ }^{21,22}$; all mutations in the ENG gene result in reduced functional cell surface protein and deregulation of TGF- $\beta$ signaling pathways ${ }^{4}$, ${ }^{23}$. However, individuals with $\mathrm{HHTI}$ show great variability in age of onset of the disease, clinical manifestations and severity, both within and between families with the same mutation. In addition, epigenetic factors, including exposure to UV light and local inflammation, have been implied as contributing to its diversity, suggesting that $\mathrm{HHT}$ is a complex genetic disorder ${ }^{24}$.

Here, we used experimental myocardial infarction (MI) in wild-type and endoglin heterozygous mice to investigate the effects of the HHTI mutation on angiogenesis and vasculogenesis which are integral components of the remodeling after $\mathrm{MI}^{25}$. Thus, experimental MI represents a useful model for studying these processes in normal and mutant adult mice. In addition, since cardiac biopsies are available from adult humans after $\mathrm{MI}$, there are opportunities to translate the findings in mice to human disease.

\section{Methods}

$M$ ice and coronary artery ligation.

Endoglin mice contain a $\beta$-galactosidase reporter cassette in the disrupted locus ". Analyses were carried out on wild-type $\left(\mathrm{Eng}^{+/+}\right)$and endoglin heterozygous transgenic mice $\left(\mathrm{Eng}^{+/}\right.$) from a C57BI/6J genetic background. Balb/c mice were also used for injection of human MNCs via the tail vein ${ }^{26}$. MI was induced as described ${ }^{27}$. Briefly, adult mice (20-35g) were intubated and ventilated with $2 \%$ isoflurane/98\% oxygen. The left coronary artery (CA) was exposed via left thoracotomy and opening of the pericardium and occluded just below the inferior border of the left auricle using a 7-0 Prolene ligature. Sham-operated mice underwent similar operations without CA ligation. Animal experiments were approved by the Institute Animal Care Committee.

Isolation, culture and injection of human M NCs.

Blood samples from healthy human volunteers or $\mathrm{HHTI}$ patients were collected 
in Potassium/EDTA tubes (Monovette, Sarsted). MNCs were isolated by density gradient centrifugation using histopaque-1077 (Sigma), using the manufacturer's protocol, and washed twice with PBS containing $2 \mathrm{mM}$ EDTA. $10 \times 10^{6}$ cells were plated in fibronectin-coated-plates and cultured in EGM2 (Clonetics) with 20\% FCS and incubated in $5 \% \mathrm{CO}_{2}$ at $37^{\circ} \mathrm{C}$. Patient procedures were approved by the medical ethics committee of the St. Antonius Hospital. The investigation conformed to principles in the Declaration of Helsinki.

For MNC injection, mice underwent $\mathrm{Ml}$, as above, received $5 \times 10^{6}$ human MNCs in $40 \mu \mathrm{l} \mathrm{PBS}$ via tail vein injection I-3h later and were immunosuppressed with tacrolimus ( $5 \mathrm{mg} / \mathrm{kg} / \mathrm{day}$ ) subcutaneously. Mice were divided randomly into groups for follow-up at 4, 7, 14 or 30 days, to assess homing of human MNCs to the infarct area, angiogenesis and cardiac function.

Analysis of myocardial function by M RI.

Cardiac and respiratory triggered cine MR Images were acquired on a 9.4-T scanner (Bruker Biospin GmbH, Rheinstetten, Germany) using a birdcage RF coil. A gradient echo pulse sequence was used to acquire data with repetition time $=9.8 \mathrm{~ms}$, echotime $=1.9 \mathrm{~ms}$, matrix of $256 \times 256$, field of view of $3.0 \times 3.0$ $\mathrm{cm}$, slice thickness of $\mathrm{I} \mathrm{mm}$, flip angle $18^{\circ}$, and four signal averages. The number of phases was II-I3 depending on the heart rate. Seven to eight short-axis slices were needed to image the entire left ventricle. Images were processed with dedicated imaging software (CAAS-MRV, Pie Medical Imaging BV, Maastricht, The Netherlands).

Isolation and processing of hearts.

The hearts were dissected from euthanized mice 7, 14 or 30 days post-MI, fixed overnight $(\mathrm{o} / \mathrm{n})$ in $4 \%$ paraformaldehyde (PFA) in PBS, washed twice in $0.83 \%$ $\mathrm{NaCl}$, once each in $0.42 \% \mathrm{NaCl}, 50 \% \mathrm{EtOH}$ and $70 \% \mathrm{EtOH}$, all o/n at $4^{\circ} \mathrm{C}$. After paraffin embedding, hearts were sectioned $(6 \mu \mathrm{m})$ onto coated slides (Klinipath) and stored at $4^{\circ} \mathrm{C}$. For MNC homing experiments, hearts were isolated 4 days post-MI and processed for cryosections as described ${ }^{28}$. Human fetal hearts were collected after elective abortion and with informed consent as previously 29. Biopsies from adult human cardiac tissue were obtained from the Pathology Department after autopsy. Formalin fixed samples were embedded in paraffin and $6 \mu \mathrm{m}$ sections used for immunohistochemical analysis. 
RNA isolation and Real-time RT-PCR.

Total RNA from dissected atria and ventricles was isolated using TRIzol $\circledast$ Reagent (Invitrogen) using manufacturer's instructions. Samples were DNAse I treated to eliminate genomic DNA and I $\mu$ g RNA was reversed transcribed. Real-time PCR was performed in a $\mathrm{MyiQ}^{\mathrm{TM}}$ single-color real time detection system (Bio-RAD). Samples were normalized using GAPDH.

Immunohistochemistry and immunofluorescence on sections.

Paraffin sections were stained using Tyramide Signal Amplification (TSA) Biotin System (Perkin Elmer, Life Science). Briefly, sections were treated with $0.25 \%$ trypsin in $9 \mathrm{mM} \mathrm{CaCl} / 50 \mathrm{mM}$ Tris- $\mathrm{HCl}, \mathrm{pH} 7.8$ for $30 \mathrm{~m}$ at room temperature (RT) for antigen retrieval. Primary antibodies were rat anti-mouse PECAM (Clone MECI3.3, dilution I:I00, BD Biosciences), rat anti-mouse endoglin (Clone 2QI707, dilution I:100, USBiological), rat anti-mouse CD68/macrosialin (Clone FA-II, dilution I:100, Serotec Ltd), rat anti-mouse Mac-3 (Clone M3/40, dilution I:I00, BD Biosciences-Pharmingen), and rat anti-CD45 (Clone 30FII.I, dilution I:100, Biosciences-Pharmingen), incubation o/n at $4^{\circ} \mathrm{C}$. Biotin-conjugated goat anti-rat IgG (DAKO, I:250) was used as a secondary antibody, incubation for Ih at RT. Peroxidase activity was detected using 3,3'-diaminobenzidine tablet set (Fast DAB, Sigma), as manufacturer's instructions.

Paraffin sections used for Ki67 immunohistochemistry were treated as described previously ${ }^{30}$. Primary antibody was mouse anti-Ki67 (Clone MMI, dilution I:500, Monosan) incubation $\mathrm{o} / \mathrm{n}$ at $4^{\circ} \mathrm{C}$. Secondary antibody was goat anti-mouse PowerVision ${ }^{\text {TM }}$ Poly-HRP-Conjugates (ImmunoVision Technologies), incubation for $30 \mathrm{~m}$ at RT. Peroxidase activity was detected using 3,3'-diaminobenzidine tablet set (Fast DAB, Sigma), as manufacturer's instructions. Sections were counterstained with hematoxylin, dehydrated and mounted in DePex.

Cryosections of hearts containing human MNC-derived ECs were fixed in acetone for 10 minutes at $4^{\circ} \mathrm{C}$, dried for $30 \mathrm{~m}$ at RT, permeabilized for $5 \mathrm{~m}$ with $0.2 \%$ Triton X-100 in PBS and blocked with 2\% BSA in PBS at RT for Ih. Slides were then incubated with rat anti-mouse PECAM antibody (Clone MEC 13.3, dilution I:I00, BD Biosciences) o/n at $4^{\circ} \mathrm{C}$, washed $4 \mathrm{x}$ in PBS and incubated Ih simultaneously with goat anti-rat Cy3 (Jackson ImmunoResearch Laboratories) and Ulex europaeus agglutinin-I (UEA-I) lectin coupled to FITC (I:I00 dilution from I mg/ml stock, Sigma) diluted in 2\% BSA in PBS. Cryosections of human fetal 
hearts were incubated with UEA-I and with goat anti-human PECAM antibody (Clone M-20, dilution I:100, Santa-Cruz). The slides were then washed $4 x$ in PBS and mounted in Mowiol before confocal laser microscope analysis.

In situ hybridization.

The endoglin probe was generated from a BamH I fragment (266-1039bp) from full-length mouse endoglin (clone pCDNAI-7//8) cloned into Bluescript and linearised with $X$ mal. The anti-sense RNA probe was generated by transcription of the T7 RNA polymerase in the presence of [ $\left.\alpha^{35} \mathrm{~S}\right]$-UTP (Amersham). Autoradiography was performed using Ilford photo emulsion. The slides were exposed for I-2 weeks at $4^{\circ} \mathrm{C}$. Photography consisted of combining bright-field (blue filter) and dark-field (red filter) images.

\section{Statistics.}

Statistical significance was evaluated using Mann-Whitney $U$ test for comparison between two groups and the Median test for multiple group comparisons using SPSS vII.5 for Windows. Results are expressed as medians \pm interquartile range (IQR). A value of $p<0.05$ or $p<0.0$ I denoted statistical significance.

The authors had full access to the data and take responsibility for the integrity. All authors have read and agree to the manuscript as written.

\section{Results}

We examined endoglin expression by in situ hybridization and immunohistochemistry in hearts of normal adult mice (Fig.IA-E) and one week after CA ligation induced MI (Fig. IF-I). Endoglin mRNA was predominantly expressed in the atria but was detectable at low levels in the ventricles of normal hearts (Fig. IB-C). One week after MI, expression was strongly increased in the infarcted area compared to healthy tissue in sham-operated hearts (Fig. ID,H). Staining of comparable sections from sham-operated and $\mathrm{Ml}$ hearts with anti-PECAM and anti-endoglin antibodies one week post operatively revealed overlapping protein expression, indicating that endoglin is only expressed in ECs in the infarct zone and not in myofibroblasts (Fig. II), as previously described ${ }^{30}$, nor in vessels in the non-infarcted zone (Fig.IE). Neoangiogenesis within the scar 
is an integral component of the remodeling process occuring after $\mathrm{MI}^{31,32}$. To compare the prevalence of activated blood vessels in hearts from shamoperated mice, sections from healthy non-infarcted zones and corresponding infarcted zones of adult mice one-week post-MI, were stained with antibodies against Ki67, a marker for cycling cells, PECAM and endoglin. In both the sham operated hearts and the non-infarcted zone one-week post-MI, $5-8 \%$ of blood vessels were $\mathrm{Ki} 67^{+}$. By contrast, approximately $50 \%$ of blood vessels were $\mathrm{Ki}^{+} 7^{+}$in the infarct zone (Fig.2A). Staining of sections from biopsies of human hearts with $\mathrm{Ml}$ taken from within and outside the infarct zone showed similar differences in the prevalence of activated vessels (Fig. 2B).

Because our data indicated that endoglin expression was highly associated with sites of active neoangiogenesis in both mice and humans, we used endoglin heterozygous $\left(\mathrm{Eng}^{+/}\right)$mice to investigate its function in adult neovascularization. $\mathrm{Eng}^{+/-}$mice survive into adulthood but have reduced endoglin levels and can develop HHT symptoms ${ }^{33}$. Hearts from $\mathrm{Eng}^{+/+}$and $\mathrm{Eng}^{+/}$mice were stained for endoglin after MI. This revealed that expression was increased in both groups in the infarct zone but more in $\mathrm{Eng}^{+/+}$mice as previously reported (Fig. 3A) ${ }^{34}$. We also characterized the inflammatory cell accumulation in the infarct zones one-week post-MI by staining with antibodies against CD68 and Mac-3 for macrophages or with anti-CD45 for polymorphonuclear leukocytes (Fig. 3B). This revealed no significant differences in the number of immunoreactive cells in the infarct zones of $\mathrm{Eng}^{+/-}$mice compared with $\mathrm{Eng}^{+/+}$mice (Fig. 3C-E). In contrast, although we found a slight increase in the basal number of vessels in $\mathrm{Eng}^{+/-}$mice (Supplementary Fig. IA online), the number of vessels in the infarct zone of $\mathrm{Eng}^{+/-}$mice was significantly lower than in $\mathrm{Eng}^{+/+}$mice one-week postMI (657 \pm 39 versus $1138 \pm 86$ vessels $/ \mathrm{mm}^{2}$ ) (Fig. 3F), suggesting defects in angiogenesis occur during cardiac remodeling as a result of reduced endoglin levels.

We next analyzed heart function in these mice by MRI. There were no differences between $\mathrm{Eng}^{+/+}$and $\mathrm{Eng}^{+/-}$mice before $\mathrm{Ml}$ or one-week post-MI (Fig.4B, supplementary data Fig. IB-C). The survival curves of the $\mathrm{Eng}^{+/+}$and Eng $^{+/-}$mice were also identical (Supplementary data Fig. 2A. 65\% versus 67\%, respectively, $p=0.979)$. However, $M R I$ analysis one-month post-MI showed that stroke volume index $(\mathrm{SVI})$, cardiac index $(\mathrm{Cl})$ and the ejection fraction (EF) were significantly lower in $\mathrm{Eng}^{+/-}$mice compared to $\mathrm{Eng}^{+/+}$littermates (Fig. 4A-E. 
$0.914 \pm 0.286$ versus $1.348 \pm 0.556 \mathrm{ml} / \mathrm{kg}, p=0.00 \mathrm{l} ; 0.426 \pm 0.097$ versus $0.7 \pm 0.219$ $\mathrm{I} / \mathrm{min} / \mathrm{kg}, p=0.00 \mathrm{I} ; 16.7 \% \pm \mathrm{I} 4.6$ versus $35.3 \% \pm 16.0, p=0.00 \mathrm{I}$, respectively; n.b. median \pm (QR). The number of vessels was also lower in $\mathrm{Eng}^{+/-}$compared to $\mathrm{Eng}^{+/+}$ mice (Fig.4F. $260 \pm 153$ versus $476.7 \pm 75.2$ vessels $/ \mathrm{mm}^{2}, p=0.004$ ), indicating that neoangiogenesis defects in $\mathrm{Eng}^{+/}$mice were associated with markedly greater deterioration in cardiac function post-MI.

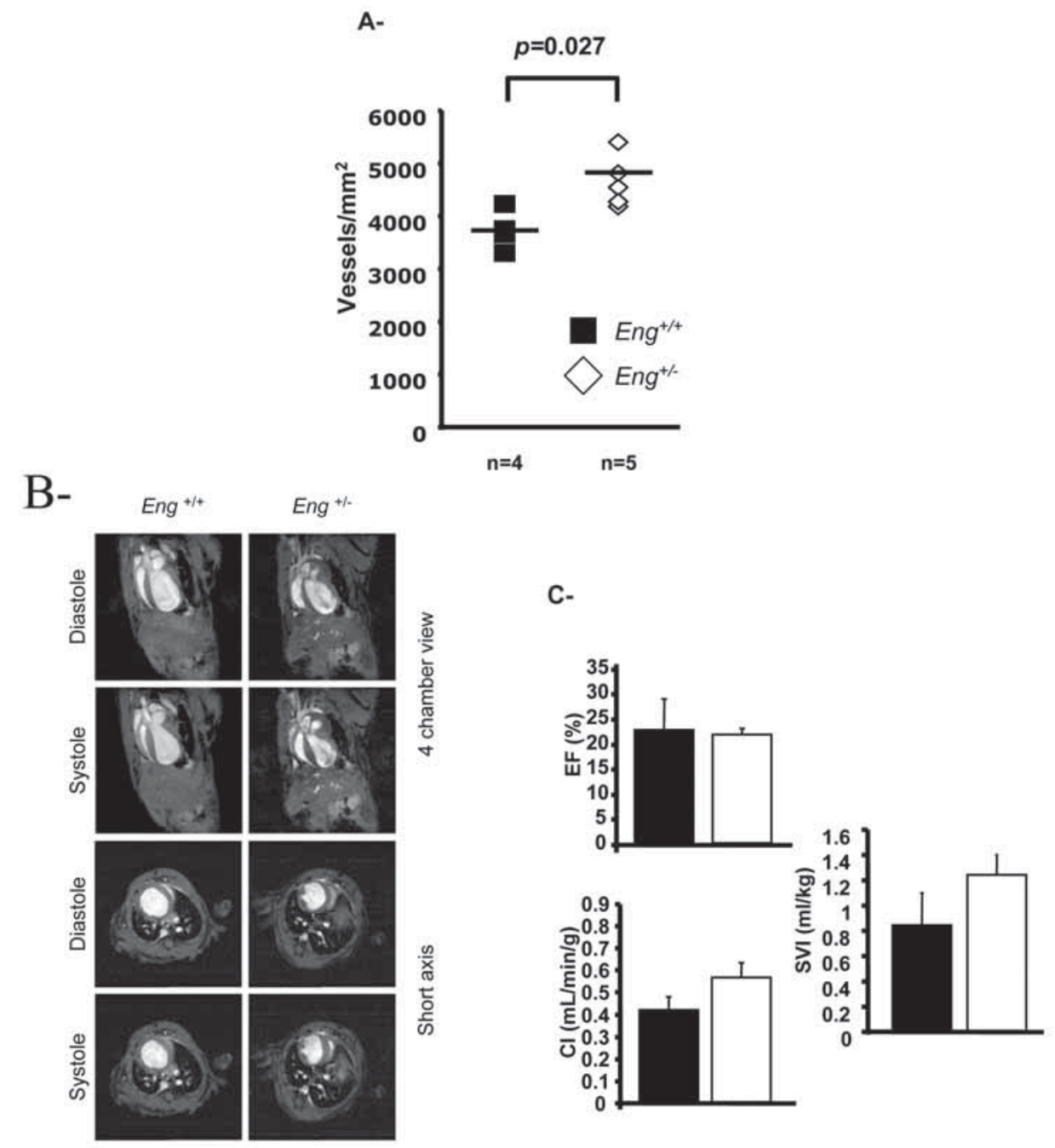

Supplementary data. Figure 1. (A) Vessel density is slightly increased in sham operated heart of Eng ${ }^{+/-}$mice compared to $\mathrm{Eng}^{+/+}$mice. (B-C): No differences in heart function of $\mathrm{Eng}^{+/-}$and $\mathrm{Eng}^{+/+}$mice one week post-MI as determined by MRI. SVI: Stroke Volume Index; CI: Cardiac Index; EF: Ejection Fraction. 
A-

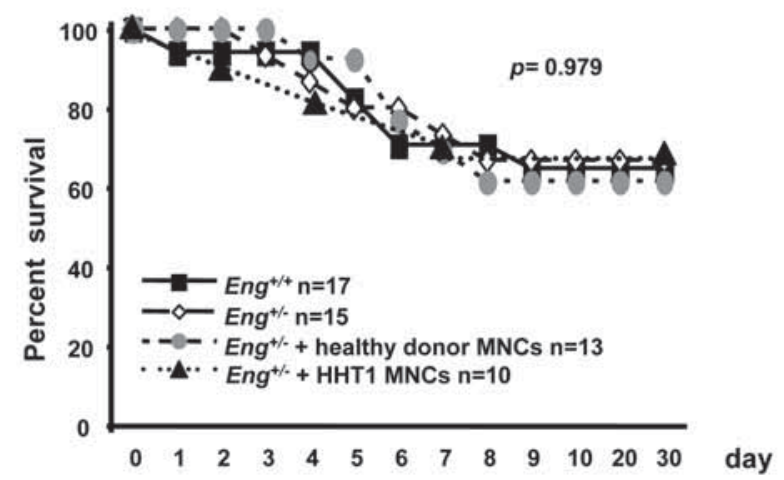

B-

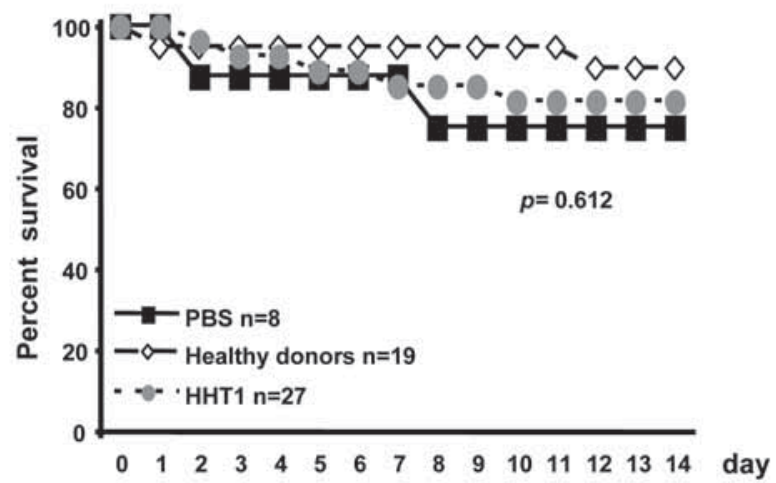

Supplementary data. Figure 2. (A) Peri- and post-operative mortality for experimental $\mathrm{Ml}$ is identical in $\mathrm{Eng}^{+/+}$, $\mathrm{Eng}^{+/}$and Eng $\mathrm{E}^{+/}$mice receiving healthy donor or HHTIMNCs. (B) No significant difference in peri- and post-operative mortality of Balb/c mice receiving PBS, MNCs from healthy donors or fom HHTI patients after MI.

In the light of evidence that MNCs contribute to the formation of new blood vessels, we investigated whether MNCs might contribute to these angiogenesis defects by injecting MNCs from healthy human donors and MNCs from HHTI patients into the tail veins of $\mathrm{Eng}^{+/-}$mice post-MI. For ENG mutations of the patients, see supplementary table I and 2, online. Previous analysis of endoglin protein levels in affected patients strongly supported haploinsufficiency and associated reduced levels of functional protein as the underlying cause of HHTI ${ }^{4}$. This had suggested that disease heterogeneity cannot be explained by the position and type of mutations ${ }^{21-22}$. The survival curves of the injected and non- 
injected groups were identical (Supplementary Fig. 2A, online). MRI analysis one month later revealed that MNCs from healthy human donors significantly improved heart function of $\mathrm{Eng}^{+/-}$mice (Fig. $4 \mathrm{~B}$ and $4 \mathrm{E}$. EF: $16.7 \% \pm 14.6$ versus $34.9 \% \pm 3.4, p=0.004$ ) and stimulated neoangiogenesis (Fig. 4F: $260 \pm 153$ versus $460 \pm 89.5$ vessels $/ \mathrm{mm}^{2}, p=0.003$ ), whilst MNCs from HHTI patients had no effect (Fig. 4B and 4E. EF: $16.7 \% \pm 14.6$ versus $18.8 \% \pm 10.8, p=0.749$ and Fig.4F: $260 \pm 153$ versus $305.8 \pm 55.0$ vessels $/ \mathrm{mm}^{2}, p=0.317$, respectively). To confirm the difference in the ability of MNCs from healthy donors and HHTI patients to contribute to vascular repair, we injected MNCs intravenously into wild-type mice I-3h post-MI. $75 \%$ of mice receiving PBS vehicle alone, $89 \%$ receiving healthy donor MNCs and $81 \%$ receiving HHTI MNCs, recovered normally from the procedure (Supplementary Fig. 2B online). The number of vessels in the infarct zone was determined 14 days post-MI. Vessel formation was efficiently stimulated by intravenous injection of MNCs from healthy donors (271.8 \pm 106.5 versus $418 \pm 265.8$ vessels $/ \mathrm{mm}^{2}, p=0.028$ ) (Fig. $5 \mathrm{~A}$ ). However, MNCs from HHTI patients showed consistently impaired ability to stimulate neoangiogenesis (269.8 $\pm I 8 I .2$ versus $27 I .8 \pm I 06.5$ vessels $/ \mathrm{mm}^{2} ; p=0.884$; median $\left.\pm I Q R\right)$ (Fig. $\left.5 A\right)$ even though FACS analysis of blood from the patients and controls used for injection into the mice indicated no difference in the number of $\mathrm{CD} 34^{+}$cells or the number of $\mathrm{CD} 34^{+} / \mathrm{KDR}^{+}$cells. In this respect, the composition of control and patient blood samples was identical. In addition, there was no difference in cell numbers in MNC cultures from patients versus controls after 8 days. Since endoglin is expressed in vascular and various hematopoietic lineages, MNCderived ECs homing to the infarct zone were traced by co-staining with mouse specific anti-PECAM antibody and human Ulex europaeus agglutinin-I (UEA-I) lectin, a marker commonly used for human cells with endothelial characteristics (Fig. 5B) ${ }^{35}$. MNCs homed only to the infarcted zone, as previously reported (Fig. 5C) ${ }^{25,26}$. The number of UEA-I $\mathrm{I}^{+}$cells that accumulated in the infarct zone of mice receiving cells from $\mathrm{HHTI}$ patients was significantly lower than mice receiving cells from healthy donors $(4.01 \pm 12.33$ versus $32.4 \pm 26.7 \mathrm{MNC}$ derived $\mathrm{ECs} / \mathrm{mm}^{2}, \mathrm{p}=0.003$ ) (Fig. $5 \mathrm{D}$ ). These $\mathrm{MNC}$ defects did not seem to depend on obvious differences in their ability to attach (Fig. $5 \mathrm{E}$ ), survive or proliferate (Post S., Goumans M.J., unpublished), at least as determined in vitro on fibronectin-plated wells. In addition, we found no changes in expression of any major components of the TGF- $\beta$ signaling pathway (Fig. 5E). 


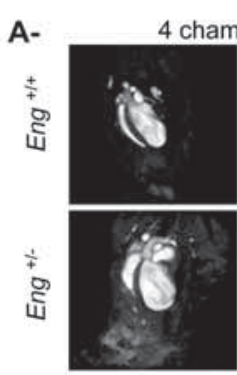

Diastole

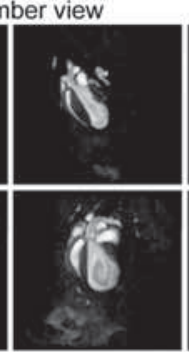

Systole

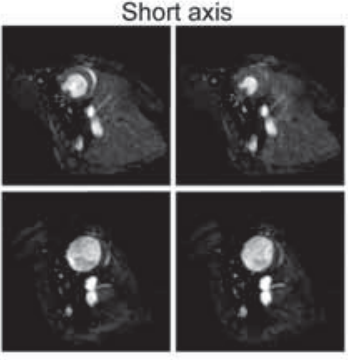

Diastole

Systole

\begin{tabular}{|c|c|c|c|c|c|c|c|}
\hline \multirow[t]{2}{*}{ B- } & \multicolumn{2}{|c|}{ Non $\mathrm{MI}$} & \multicolumn{5}{|c|}{4 weeks post-MI } \\
\hline & $\mathrm{Eng}^{* / *}(n=2)$ & $\mathrm{Eng}^{* / /}(\mathrm{n}=2)$ & Eng*t & Eng* & $\begin{array}{c}\text { Eng }^{*} \\
+ \\
\text { Healthy MNCs }\end{array}$ & $\begin{array}{c}\text { Eng }^{*} \\
+ \\
\text { HHT1 MNCs }\end{array}$ & $\begin{array}{l}\text { P values } \\
\text { (corrected for } \\
\text { multiple group } \\
\text { comparisons) }\end{array}$ \\
\hline Age (weeks) & 18.5 & 18.5 & $12.5 \pm 9.7$ & $12.0 \pm 9.0$ & $18.0 \pm 13.0$ & $15.0 \pm 14.0$ & 0.402 \\
\hline Weight (g) & 23.50 & 23.55 & $24.4 \pm 4.1$ & $25.2 \pm 4.1$ & $28.5 \pm 5.1$ & $28.3 \pm 3.9$ & 0.128 \\
\hline HR (bpm) & 542.5 & 550.0 & $455.5 \pm 85.8$ & $442.7 \pm 54.0$ & $500.0 \pm 90.0$ & $484.0 \pm 115.0$ & 0.174 \\
\hline $\operatorname{EDV}(\mathrm{ml})$ & 0.0371 & 0.0369 & $0.100 \pm 0.102$ & $0.124 \pm 0.046$ & $0.067 \pm 0.082$ & $0.125 \pm 0.070$ & 0.827 \\
\hline $\operatorname{ESV}(\mathrm{ml})$ & 0.0116 & 0.0114 & $0.062 \pm 0.089$ & $0.104 \pm 0.052$ & $0.045 \pm 0.065$ & $0.105 \pm 0.062$ & 0.364 \\
\hline $\operatorname{EDVI}(\mathrm{m} / / \mathrm{kg})$ & 1.598 & 1.571 & $3.485 \pm 3.770$ & $4.800 \pm 1.458$ & $2.367 \pm 3.626$ & $4.432 \pm 1.779$ & 0.073 \\
\hline ESVI $(\mathrm{ml} / \mathrm{kg})$ & 0.500 & 0.486 & $2.335 \pm 3.748$ & $4.126 \pm 1.597$ & $1.595 \pm 2.818$ & $3.697 \pm 1.843$ & 0.364 \\
\hline $\mathrm{SV}(\mathrm{ml})$ & 0.026 & 0.026 & $0.036 \pm 0.019$ & $0.022 \pm 0.006$ & $0.022 \pm 0.021$ & $0.022 \pm 0.008$ & 0.066 \\
\hline SVI (ml/kg) & 1.097 & 1.084 & $1.348 \pm 0.556$ & $0.914 \pm 0.286$ & $0.771 \pm 0.805$ & $0.872 \pm 0.189$ & 0.002 \\
\hline $\mathrm{CO}(\mathrm{ml} / \mathrm{min})$ & 0.014 & 0.014 & $0.018 \pm 0.008$ & $0.011 \pm 0.002$ & $0.012 \pm 0.007$ & $0.012 \pm 0.003$ & 0.008 \\
\hline $\mathrm{Cl}(\mathrm{l} / \mathrm{min} / \mathrm{kg})$ & 0.596 & 0.600 & $0.700 \pm 0.219$ & $0.426 \pm 0.097$ & $0.423 \pm 0.384$ & $0.421 \pm 0.058$ & 0.005 \\
\hline MM (g) & 0.072 & 0.073 & $0.106 \pm 0.035$ & $0.094 \pm 0.015$ & $0.094 \pm 0.036$ & $0.114 \pm 0.038$ & 0.106 \\
\hline EF $(\%)$ & 68.9 & 69.0 & $35.3 \pm 16.0$ & $16.7 \pm 14.6$ & $34.9 \pm 3.4$ & $18.8 \pm 10.8$ & 0.005 \\
\hline
\end{tabular}

C-

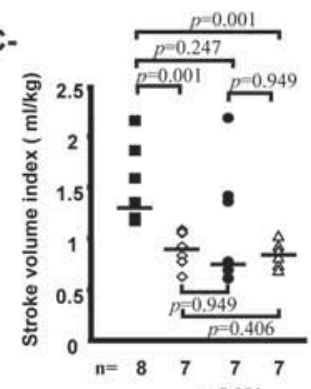

D-

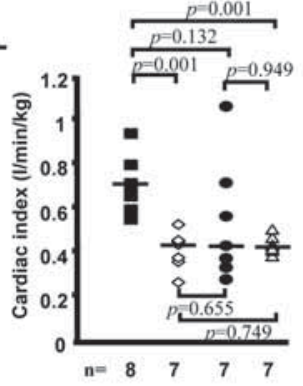

- Eng ${ }^{+/+}$

- Eng + -

- Eng ${ }^{+1-}+$ healthy donor MNCs

$\Delta$ Eng $^{+1-}+$ HHT1 MNCs

E-

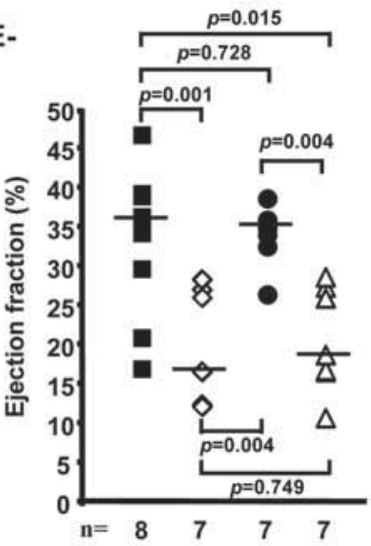

F-

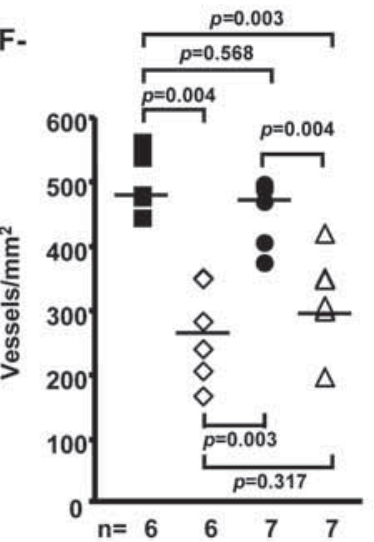

Fig. 4. Injection of healthy donor but not HHT1 MNCs into Eng ${ }^{\text {t- }}$ mice with acute MI rescues neoangiogenesis and deterioration in cardiac function associated with reduced endoglin. (A) MRI analysis of $\mathrm{Eng}^{+/+}$and Eng ${ }^{+/-}$mice four weeks post-MI. (B) Table shows analysis of heart function of $\mathrm{Eng}^{+/+}$and Eng ${ }^{+/-}$mice without and one-month post-MI. (C-E) Cardiac functions of Eng ${ }^{+/}$mice are reduced compared to Eng ${ }^{+/+}$mice. (E-F) After healthy donor but not HHTI MNC injection, $(E)$ ejection fraction is improved and $(F)$ neoangiogenesis is rescued in $\mathrm{Eng}^{+/-}$mice. HR: heart rate; EDV: end diastolic volume; ESV: end systolic volume; EDVI: end diastolic volume index; ESVI: end systolic volume index; SV: stroke volume; SVI: stroke volume index; CO: cardiac output; $\mathrm{Cl}$ : cardiac index; MM: myocardial mass; EF: ejection fraction. 


\section{Discussion}

Neovascularization is a normal component of remodeling that occurs after MI. Its promotion has been proposed as an important target for therapeutic improvement of heart function ${ }^{36}$. However, the mechanisms underlying neovascularization following $\mathrm{MI}$ are still not fully understood although signaling pathways activated by TGF- $\beta$, vascular endothelial growth factor (VEGF) and insulin-like growth factor (IGF) are thought to be involved ${ }^{37}$. Here, we examined the function of endoglin, a TGF- $\beta$ receptor involved in angiogenesis during development. We demonstrated that endoglin has a crucial role in normal remodeling post-MI that coincides with upregulation of its major ligand, TGF$\beta$, in myofibroblasts in the infarct zone ${ }^{38}$. Specifically, upregulation of endoglin in ECs, possibly stimulated by local TGF- $\beta{ }^{39}$, correlates with neoangiogenesis. Further, Eng ${ }^{+/-}$mice showed impaired angiogenesis post-Ml, which resulted in enhanced deterioration of cardiac function; this confirmed recent findings using an ischemic hindlimb injury model ${ }^{34}$. Our results are consistent with reports demonstrating that (I) endoglin is a marker of angiogenesis ${ }^{40}$; (2) endoglin activates TGF- $\beta / A L K I$ signaling and inhibits TGF- $\beta / A L K 5$ signaling to promote EC proliferation ${ }^{20}$; (3) down regulation of endoglin expression induces EC apoptosis ${ }^{41}$. More generally, impaired angiogenesis in $\mathrm{Eng}^{+/}$mice may at least in part be mediated by EC defects.

Compelling evidence indicates that recruitment of circulating vascular as well as hematopoietic cells contributes to the revascularization of ischemic tissues ${ }^{42}$. Because endoglin is expressed in various cell lineages comprising the mononuclear cell fraction, we investigated the effects of reduced endoglin expression in these circulating cells using experimental $\mathrm{Ml}$ in mice as a model system. With respect to the disease $\mathrm{HHTI}$, our study provides the first evidence that MNCs derived from patients are impaired in their capacity to stimulate vessel formation. Moreover, injection of healthy MNCs in $\mathrm{Eng}^{+/-}$mice was sufficient to restore vessel formation and improve heart function defects associated with reduced levels of endoglin but MNCs from HHTI patients were not, demonstrating that the etiology of $\mathrm{HHTI}$ is possibly associated with defective ability of MNCs to repair local vessel damage.

It is unclear which cell populations are affected by decreased endoglin expression. Previous studies have shown that (I) blood outgrowth ECs from HHT have 
abnormalities that would be compatible with a role in vascular lesions ${ }^{43}$; (2) endoglin functions to support lineage-specific hematopoietic development from Flk-I precursors ${ }^{44}$, and defines Long Term Repopulating hematopoietic populations ${ }^{45}, 46$; (3) endoglin is expressed in activated monocytes ${ }^{47,48}$. We demonstrated that MNC-derived ECs from HHTI patients have a reduced ability to accumulate in the infarct zone in vivo and stimulate vessel formation in mice that had undergone MI. One possible explanation is that there are differences in the MNC populations between patients and controls. However, we found no differences in the numbers of $\mathrm{CD} 34^{+}$or $\mathrm{CD} 34^{+} / \mathrm{KDR}^{+}$cells in the MNC population, nor any differences in adhesion and differentiation to endothelial-like cells in culture. Therefore, the differential behavior in the heart rescue experiments may be due to defective homing, transdifferentiation, proliferation or secretion of angiogenic factors, which will require investigation in future studies. Although we found no differences in TGF- $\beta, T \beta R I I, A L K I$ or ALK5 expression in HHTI MNCs in vitro, we have shown previously that in mouse development, ECs lacking endoglin entirely are defective in their ability to process and secrete active TGF- $\beta{ }^{49}$, which in turn affects their ability to differentiate and recruit smooth muscle cells to the vessel wall. Defective processing of TGF- $\beta$ or other cytokines could play a role in patients and also directly or indirectly affect neoangiogenesis.

In conclusion, since vessel damage may occur randomly in HHT patients as a result of trauma, UV exposure, inflammation or multiple individual pathological or physiological differences, this defect in normal repair may contribute to explaining why families or even individual family members with the same mutation present with highly variable symptoms of the disease. Secondly, and more generally, in the light of ongoing trials investigating the use of autologous bone marrow in vascular repair after MI, the results suggest that HHTI patients and others with intrinsic defects in their capacity to form endothelial progenitors may derive greater benefit from transplantation with matched heterologous bone marrow.

\section{Acknowledgements}

We thank J.Korving, R.vd Nagel, and all blood donors. 
Chapter 7 | I5 |

\section{Funding sources}

The Netherlands Heart Foundation (NHS 1999B46), EU (QLGI-CT-200I01032 and IP 'Angiotargeting' contract no 504743), Janivo Stichting Zeist, the Netherlands Organization for Scientific Research (NWO-VIDI grant 016.056.319), BSIK (Dutch Programme for Tissue Engineering) and the British Heart Foundation (to HMA; EX/03/002).

\section{References}

I. Risau W. Mechanisms of angiogenesis. Nature. 1997; 386: 67I-674.

2. Asahara T, Murohara T, Sullivan A, Silver M, van der Zee R, Li T,Witzenbichler B, Schatteman G, Isner JM. Isolation of putative progenitor endothelial cells for angiogenesis. Science. 1997; 275: 964-967.

3. Rehman J, Li J, Orschell CM, March KL. Peripheral blood "endothelial progenitor cells" are derived from monocyte/macrophages and secrete angiogenic growth factors. Circulation. 2003; 107: I I64- I I69.

4. Abdalla SA, Letarte M. Hereditary Haemorrhagic Telangiectasia:current views on genetics and mechanisms of disease.J Med Genet. 2006; 43: 97-II0.

5. Van den Driesche S, Mummery CL, Westermann CJ. Hereditary hemorrhagic telangiectasia: an update on transforming growth factor- $\beta$ signaling in vasculogenesis and angiogenesis. Cardiovasc Res. 2003; 58 : 20-31.

6. Johnson DW, Berg JN, Gallione CJ, McAllister KA, Warner JP, Helmbold EA, Markel DS, Jackson CE, Porteous ME, Marchuk DA. A second locus for hereditary hemorrhagic telangiectasia maps to chromosome 12. Genome Res. 1995; 5: 21-28.

7. McAllister KA, Grogg KM, Johnson DW, Gallione CJ, Baldwin MA, Jackson CE, Helmbold EA, Markel DS, McKinnon WC, Murrell J, et al. Endoglin, a TGF- $\beta$ binding protein of endothelial cells, is the gene for hereditary haemorrhagic telangiectasia type I. Nat Genet. 1994; 8: 345-35I.

8. Gallione CJ, Repetto GM, Legius E, Rustgi AK, Schelley SL, Tejpar S, Mitchell G, Drouin E, Westermann CJ, Marchuk DA. A combined syndrome of juvenile polyposis and hereditary haemorrhagic telangiectasia associated with mutations in MADH4 (SMAD4). Lancet. 2004; 363: 852-859.

9. Cole SG, Begbie ME, Wallace GM, Shovlin CL. A new locus for hereditary haemorrhagic telangiectasia (HHT3) maps to chromosome 5.J Med Genet. 2005; 42: 577-582.

10. Gougos A, Letarte M. Identification of a human endothelial cell antigen with monoclonal antibody 44G4 produced against a pre-B leukemic cell line.J Immunol. 1988; 14I: 1925-1933.

II. Arthur HM, Ure J, Smith AJ, Renforth G, Wilson DI, Torsney E, Charlton R, Parums DV, Jowett T, Marchuk DA, Burn J, Diamond AG. Endoglin, an ancillary TGF- $\beta$ receptor, is required for extraembryonic angiogenesis and plays a key role in heart development. Dev Biol. 2000; 217: 42-53.

12. Li DY, Sorensen LK, Brooke BS, Urness LD, Davis EC, Taylor DG, Boak BB, Wendel DP. Defective angiogenesis in mice lacking endoglin. Science. 1999; 284: 1534-1537.

13. Barbara NP, Wrana JL, Letarte M. Endoglin is an accessory protein that interacts with the signaling receptor complex of multiple members of the transforming growth factor- $\beta$ superfamily. J Biol Chem. 1999; 274: 584-594. 
14. Cheifetz S, Bellon T, Cales C,Vera S, Bernabeu C, Massague J, Letarte M. Endoglin is a component of the transforming growth factor- $\beta$ receptor system in human endothelial cells.J Biol Chem. 1992; 267: 1902719030.

15. Roberts AB, Sporn MB. Physiological actions and clinical applications of transforming growth factor- $\beta$ (TGF- $\beta$ ). Growth Factors. 1993; 8: I-9.

16. Derynck R, Zhang YE. Smad-dependent and Smad-independent pathways in TGF- $\beta$ family signalling. Nature. 2003; 425: 577-584.

17. Ten Dijke P, Hill CS. New insights into TGF- $\beta$-Smad signalling. Trends Biochem Sci. 2004; 29: 265-273.

18. Goumans MJ,Valdimarsdottir G, Itoh S, Rosendahl A, Sideras P, ten Dijke P. Balancing the activation state of the endothelium via two distinct TGF- $\beta$ type I receptors. Embo J. 2002; 21: 1743-1753.

19. Blanco FJ, Santibanez JF, Guerrero-Esteo M, Langa C, Vary CP, Bernabeu C. Interaction and functional interplay between endoglin and ALK-I, two components of the endothelial transforming growth factor- $\beta$ receptor complex.J Cell Physiol. 2005; 204: 574-584.

20. Lebrin F, Goumans MJ, Jonker L, Carvalho RL, Valdimarsdottir G, Thorikay M, Mummery C, Arthur HM, ten Dijke P. Endoglin promotes endothelial cell proliferation and TGF- $\beta / A L K I$ signal transduction. Embo J. 2004; 23: 4018-4028.

21. Paquet ME, Pece-Barbara N,Vera S, Cymerman U, Karabegovic A, Shovlin C, Letarte M.Analysis of several endoglin mutants reveals no endogenous mature or secreted protein capable of interfering with normal endoglin function. Hum M ol Genet. 200 I; 10: I347- 1357.

22. Pece-Barbara N, Cymerman U, Vera S, Marchuk DA, Letarte M. Expression analysis of four endoglin missense mutations suggests that haploinsufficiency is the predominant mechanism for hereditary hemorrhagic telangiectasia type I. Hum M ol Genet. 1999; 8: 2171-218I.

23. Lebrin F, Deckers M, Bertolino P,Ten Dijke P.TGF- $\beta$ receptor function in the endothelium. Cardiovasc Res. 2005; 65: 599-608.

24. Shovlin CL, Letarte M. Hereditary haemorrhagic telangiectasia and pulmonary arteriovenous malformations: issues in clinical management and review of pathogenic mechanisms. Thorax. 1999; 54: 7/4-729.

25. Kocher AA, Schuster MD, Szabolcs MJ, Takuma S, Burkhoff D, Wang J, Homma S, Edwards NM, Itescu S. Neovascularization of ischemic myocardium by human bone-marrow-derived angioblasts prevents cardiomyocyte apoptosis, reduces remodeling and improves cardiac function. Nat M ed. 200I; 7: 430436.

26. Ma N, Stamm C, Kaminski A, Li W, Kleine HD, Muller-Hilke B, Zhang L, Ladilov Y, Egger D, Steinhoff G. Human cord blood cells induce angiogenesis following myocardial infarction in NOD/scid-mice. Cardiovasc Res. 2005; 66: 45-54.

27. Nakajima H, Nakajima HO,Tsai SC, Field LJ. Expression of mutant pl 93 and $\mathrm{p} 53$ permits cardiomyocyte cell cycle reentry after myocardial infarction in transgenic mice. Circ Res. 2004; 94: 1606-1614.

28. Bajanca F, Luz M, Duxson MJ,Thorsteinsdottir S. Integrins in the mouse myotome: developmental changes and differences between the epaxial and hypaxial lineage. Dev Dyn. 2004; 23I: 402-4I5.

29. Chuva de Sousa Lopes SM, Hassink RJ, Feijen A, van Rooijen MA, Doevendans PA, Tertoolen L, Brutel de la Riviere A, Mummery CL. Patterning the heart, a template for human cardiomyocyte development. Dev Dyn. 2006.

30. Chen K, Mehta JL, Li D, Joseph L, Joseph J.Transforming growth factor- $\beta$ receptor endoglin is expressed in cardiac fibroblasts and modulates profibrogenic actions of angiotensin II. Circ Res. 2004; 95: I I67-I I 73.

31. Kalkman EA, Bilgin YM, van Haren P, van Suylen RJ, Saxena PR, Schoemaker RG. Determinants of coronary reserve in rats subjected to coronary artery ligation or aortic banding. Cardiovasc Res. 1996; 32: 10881095.

32. Nelissen-Vrancken HJ, Debets JJ, Snoeckx LH, Daemen MJ, Smits JF. Time-related normalization of maximal coronary flow in isolated perfused hearts of rats with myocardial infarction. Circulation. 1996; 93: 349-355. 
33. Bourdeau A, Faughnan ME, McDonald ML, Paterson AD, Wanless IR, Letarte M. Potential role of modifier genes influencing transforming growth factor- $\beta$ I levels in the development of vascular defects in endoglin heterozygous mice with hereditary hemorrhagic telangiectasia. Am J Pathol. 200 I; I58: 20 I I-2020.

34. Jerkic M, Rodriguez-Barbero A, Prieto M, Toporsian M, Pericacho M, Rivas-Elena JV, Obreo J, Wang A, Perez-Barriocanal F,Arevalo M, Bernabeu C, Letarte M, Lopez-Novoa JM. Reduced angiogenic responses in adult Endoglin heterozygous mice. Cardiovasc Res. 2006; 69: 845-854.

35. Rafii S, Lyden D. Therapeutic stem and progenitor cell transplantation for organ vascularization and regeneration. Nat M ed. 2003; 9: 702-7I2.

36. Losordo DW, Dimmeler S. Therapeutic angiogenesis and vasculogenesis for ischemic disease: part II: cellbased therapies. Circulation. 2004; 109: 2692-2697.

37. Rafii S, Meeus S, Dias S, Hattori K, Heissig B, Shmelkov S, Rafii D, Lyden D. Contribution of marrowderived progenitors to vascular and cardiac regeneration. Semin Cell Dev Biol. 2002; 13:61-67.

38. Chuva de Sousa Lopes SM, Feijen A, Korving J, Korchynskyi O, Larsson J, Karlsson S, ten Dijke P, Lyons KM, Goldschmeding R, Doevendans P, Mummery CL. Connective tissue growth factor expression and Smad signaling during mouse heart development and myocardial infarction. Dev Dyn. 2004; 23I: 542550.

39. Sanchez-Elsner T, Botella LM, Velasco B, Langa C, Bernabeu C. Endoglin expression is regulated by transcriptional cooperation between the hypoxia and transforming growth factor- $\beta$ pathways. J Biol Chem. 2002; 277: 43799-43808.

40. Duff SE, Li C, Garland JM, Kumar S. CDI05 is important for angiogenesis: evidence and potential applications. Faseb J. 2003; 17: 984-992.

4I. She X, Matsuno F, Harada N, Tsai H, Seon BK. Synergy between anti-endoglin (CDI05) monoclonal antibodies and TGF- $\beta$ in suppression of growth of human endothelial cells. Int J Cancer. 2004; 108: 25 I257.

42. Kopp HG, Ramos CA, Rafii S. Contribution of endothelial progenitors and proangiogenic hematopoietic cells to vascularization of tumor and ischemic tissue. Curr Opin Hematol. 2006; I3: 175- I8I.

43. Fernandez LA, Sanz-Rodriguez F, Zarrabeitia R, Perez-Molino A, Hebbel RP, Nguyen J, Bernabeu C, Botella LM. Blood outgrowth endothelial cells from Hereditary Haemorrhagic Telangiectasia patients reveal abnormalities compatible with vascular lesions. Cardiovasc Res. 2005; 68: 235-248.

44. Cho SK, Bourdeau A, Letarte M, Zuniga-Pflucker JC. Expression and function of CDI05 during the onset of hematopoiesis from Flk (+) precursors. Blood. 200I; 98: 3635-3642.

45. Chen CZ, Li L, Li M, Lodish HF.The endoglin(positive) sca-I (positive) rhodamine(low) phenotype defines a near-homogeneous population of long-term repopulating hematopoietic stem cells. Immunity. 2003; 19: 525-533.

46. Chen CZ, Li M, de Graaf D, Monti S, Gottgens B, Sanchez MJ, Lander ES, Golub TR, Green AR, Lodish HF. Identification of endoglin as a functional marker that defines long-term repopulating hematopoietic stem cells. Proc Natl Acad Sci U SA. 2002; 99: I5468-15473.

47. Fernandez Pujol B, Lucibello FC, Gehling UM, Lindemann K, Weidner N, Zuzarte ML, Adamkiewicz J, Elsasser HP, Muller R, Havemann K. Endothelial-like cells derived from human CD I4-positive monocytes. Differentiation. 2000; 65: 287-300.

48. Fujiyama S, Amano K, Uehira K, Yoshida M, Nishiwaki Y, Nozawa Y, Jin D, Takai S, Miyazaki M, Egashira K, Imada T, Iwasaka T, Matsubara H. Bone marrow monocyte lineage cells adhere on injured endothelium in a monocyte chemoattractant protein-I-dependent manner and accelerate reendothelialization as endothelial progenitor cells. Circ Res. 2003; 93: 980-989.

49. Carvalho RL, Jonker L, Goumans MJ, Larsson J, Bouwman P, Karlsson S, Dijke PT, Arthur HM, Mummery CL. Defective paracrine signalling by TGF- $\beta$ in yolk sac vasculature of endoglin mutant mice: a paradigm for hereditary haemorrhagic telangiectasia. Development. 2004; 131: 6237-6247. 


\section{Supplementary data}

Table 1. Characteristics of HHTI patients used in the homing experiments (Fig.5D). Statistical analysis has been performed by comparison with the healthy donor control group.

\begin{tabular}{|c|c|c|c|c|c|}
\hline $\begin{array}{l}\text { Mutations } \\
\text { Type }\end{array}$ & Exon & DNA & Protein & Gender & Age \\
\hline \multirow{2}{*}{ Nonsense } & 2 & cl57C>A & $\mathrm{pC} 53 \mathrm{X}$ & $W$ & 36 \\
\hline & 3 & $c 247 C>T$ & PQ83X & W & 39 \\
\hline \multirow[t]{3}{*}{ Deletion/insertion } & 7 & c887-918del; c919-920ins & & M & 55 \\
\hline & & $\begin{array}{l}\text { del22bplns I l bp } \\
\text { CAAGCTCCCAG }\end{array}$ & & M & 55 \\
\hline & 8 & c. $1083 \mathrm{AA}$ & & W & 57 \\
\hline \multirow[t]{2}{*}{ Splice site } & I & c. $I A>G$ & p.MIV & w & 30 \\
\hline & $9 b$ & c.1310delG & & W & 19 \\
\hline \multirow[t]{2}{*}{ Missense } & 7 & c.99|G>A & p.G33IS & W & 32 \\
\hline & 7 & c. $991 \mathrm{G}>\mathrm{A}$ & p.G33IS & M & 60 \\
\hline
\end{tabular}

Gender. No significant difference (Fisher's exact test $p=1.000$ )

Age. No significant difference (M ann-W hitney U test. HHT1 patients: $42.56 \pm 14.59$; H ealthy donors: $35.80 \pm 10.49$; $\overline{5} 5 \mathrm{p}=0.278$ ).

Table 2. Characteristics of HHTI patients used to measure the effect of the injected MNCs on neoangiogenesis and heart function associated with MI (Fig.4 and Fig.5A). Statistical analysis has been performed by comparison with the healthy donor control group.

\begin{tabular}{|c|c|c|c|c|c|}
\hline $\begin{array}{c}\text { Mutations } \\
\text { Type }\end{array}$ & Exon & DNA & Protein & Gender & Age \\
\hline \multirow[t]{5}{*}{ Nonsense } & 2 & c. $157 C>A$ & $\mathrm{pC} 53 \mathrm{X}$ & W & 36 \\
\hline & 3 & c. $247 \mathrm{C}>\mathrm{T}$ & pQ83X & W & 39 \\
\hline & 3 & c. $247 C>T$ & pQ83X & W & 44 \\
\hline & 3 & c. $247 C>T$ & pQ83X & W & 62 \\
\hline & 3 & c. $247 C>T$ & PQ83X & M & 36 \\
\hline \multirow[t]{4}{*}{ Deletion/insertion } & 7 & $\begin{array}{l}\text { c887-918del; c919-920ins } \\
\text { del22bplns I Ibp } \\
\text { CAAGCTCCCAG }\end{array}$ & & M & 28 \\
\hline & 8 & c.III7_III8insT & p.K373fs & M & 48 \\
\hline & 8 & c.III7_III8insT & p.K373fs & M & 50 \\
\hline & 8 & c.III7_III8insT & p.K373fs & W & 15 \\
\hline \multirow[t]{2}{*}{ Splice site } & $9 b$ & c.|3||G>AAGCGGggag & p.R437R & M & 20 \\
\hline & $9 b$ & c.I3I0delG & & W & 19 \\
\hline Missense & 7 & c. $99 \mid \mathrm{G}>\mathrm{A}$ & p.G33IS & M & 60 \\
\hline
\end{tabular}

Fig.4: Gender. No significant difference (Fisher's exact test $p=1.000$ )

Age. No significant difference (Mann-W hitney U test. HHT1 patients: $35.30 \pm 16.80$; Healthy donors: $29.20 \pm 6.40$; $\mathrm{p}=0.461)$.

Fig.5A: Gender. No significant difference (Fisher's exact test $p=0.592$ )

Age. No significant difference (Mann-W hitney U test. HHT1 patients: $39.50 \pm 5.90$; Healthy donors: $44.80 \pm 11.30$; $\mathrm{p}=0.524$ ). 


\section{Human cardiomyocyte progenitor cells regenerate infarcted myocardium and preserve long-term cardiac function in mice}

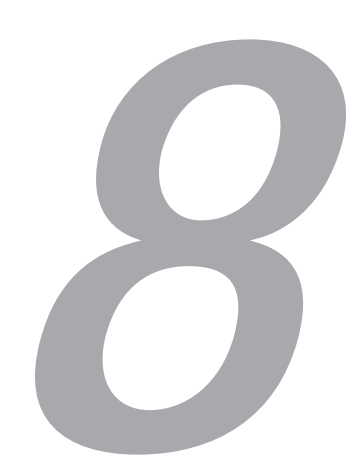

Submitted

L.W. van Laake*,A.M. Smits*, K. den Ouden, C. Schreurs, C.J. van Echteld, C.L. Mummery, P.A. Doevendans, M-J. Goumans.

*Authors contributed equally 


\section{Abstract}

Background

We recently identified a population of cardiomyocyte progenitor cells (CMPCs) in human fetal hearts, capable of differentiating into beating cardiomyocytes, endothelial cells and smooth muscle cells in vitro. Here, we investigated the long-term effect of CMPCs and CMPC-derived cardiomyocytes (CMPC-CM) on regeneration of the heart and cardiac function after transplantation into ischemic murine myocardium.

\section{Methods and Results}

CMPCs were isolated from human fetal hearts and induced to differentiate into CMPC-CM by the addition of 5 -azacytidine and TGF $\beta$ in vitro. Myocardial infarction was induced in immunodeficient mice, followed by 2 intramyocardial injections of $0.25 \times 10^{6}$ CMPCs $(n=10)$ or CMPC-CM $(n=10)$; or $5 \mu l$ PBS $(n=9)$. Cardiac function was measured using 9.4T MRI, 2 days, 4 weeks and 12 weeks after surgery. The end-systolic and end-diastolic volume remained lower in the cell-treated animals at 4 and 12 weeks compared to the PBS-injected animals, whereas the ejection fraction was higher at all time points. Cell transplantation partially preserved the wall thickness of the infarct compared to the PBS group. After 12 weeks, a significantly higher vessel density was observed in the borderzone of CMPC-injected animals.

Immunohistochemical analysis revealed that CMPC and CMPC-CM transplantation led to regeneration of cardiac tissue, with addition of new cardiomyocytes and blood vessels. Surprisingly, CMPCs differentiated in vivo, with equal efficiency, into the same cell types as the in vitro differentiated CMPC-CM.

\section{Conclusions}

Transplantation of human CMPCs or CMPC-CM into the ischemic myocardium can preserve the long-term cardiac function and partially regenerate the cardiac tissue. Human CMPCs are a promising candidate for cell-based therapy. 


\section{Introduction}

Cardiovascular disease is the leading cause of death in the western world.' Following myocardial infarction (MI), massive cell death in the myocardium initiates fibrosis and scarring, which negatively affects cardiac function and can ultimately lead to heart failure and cardiac death. Repairing the damaged tissue with healthy myocytes provides an attractive therapeutic option to restore cardiac function and structure after Ml. ${ }^{2}$ However, replacing cardiomyocytes is complicated by the fact that the majority of the adult cardiomyocytes have permanently exited the cell cycle. Therefore other cell types have been investigated for their potential to differentiate into cardiomyocytes. ${ }^{3}$ The ideal cell for transplantation should be able to give rise to cardiomyocytes, as well as form vessels to restore blood flow to the ischemic area.

Bone marrow was the first cell source reported to generate new myocardium in vivo. ${ }^{4-6}$ Fueled by these intriguing results, many clinical trials were launched where bone marrow (-derived) cells were injected into the injured myocardium. ${ }^{7}$ Most trials showed only very small or transient positive effects on cardiac function. ${ }^{8 ; 9}$ Furthermore, the transdifferentiation of these cells into cardiac tissue has been questioned, ${ }^{10-12}$ shifting the focus to other cardiomyocyte sources.

Embryonic stem cells (ESCs) can be differentiated into cardiomyocytes in vitro. ${ }^{13-15}$ When human ESC-derived cardiomyocytes were injected into healthy or ischemic murine myocardium, new cardiac tissue was formed. ${ }^{16 ; 17}$ Although transplantation initially led to an augmented cardiac function compared to the non-cardiomyocyte fraction, this effect was no longer significant 12 weeks post-MI. These data together with the transient results from the clinical trials demonstrate the requirement for long-term analysis of cardiac function before robust conclusions on effectivity can be made.

The heart itself was shown to contain pools of progenitor cells, that are committed to become cells of non-muscle and muscle cardiac lineages including cardiomyocytes. ${ }^{18-21}$ We recently identified a population of human cardiomyocyte progenitor cells (CMPCs), isolated from the fetal and adult human heart that efficiently and robustly differentiated into beating cardiomyocytes in vitro ( $M$. Goumans, unpublished). CMPC-derived cardiomyocytes (CMPC-CM) have an electrophysiological profile comparable to that of fetal ventricular myocytes, confirming their suitability for transplantation into the infarcted ventricle and 
increasing their chances of survival and integration. ${ }^{22}$ Additionally, CMPCs were shown to differentiate into endothelial cells and smooth muscle cells. Importantly, differentiation was achieved without the need for co-culture with neonatal cardiomyocytes, which is a great advantage with respect to safety and reproducibility in any future clinical application. These observations make CMPCs an excellent candidate source of human cardiomyocytes for cell-based therapy.

In the present study we have compared the potential of CMPCs and CMPC-CM to regenerate the infarcted mouse heart, and their influence on cardiac function in a long-term study. After transplantation of CMPCs or CMPC-CM into the acutely ischemic mouse heart, cardiac function was measured longitudinally for 12 weeks. Both CMPCs and CMPC-CM prevented cardiac dilatation and deterioration of cardiac function for at least 3 months after infarction. Interestingly, CMPCs were able to differentiate in vivo into cardiomyocytes, smooth muscle cells and endothelial cells. This emphasizes the unique regenerative capability of this recently identified pool of progenitor cells.

\section{Material and Methods}

\section{PC isolation, culture and differentiation to CM PC-CM}

Human fetal hearts were collected after elective abortion on the basis of individual informed consent, after approval by the Medical Ethics committee of the University Medical Center Utrecht. CMPCs were isolated from human fetal hearts as described previously (M. Goumans, unpublished). CMPCs were isolated from the suspension by magnetic cells sorting, using magnetic Sca-I coupled beads (Miltenyi Biotec). Cells were cultured on gelatin coated dishes for continued propagation or on coverslips for immunofluorescent staining. Differentiation towards cardiomyocytes was induced by treating the cells with 5 MM 5-azacytidine for 72 hours in differentiation medium (Iscove's Modified Dulbecco's Medium /HamsFI2 (I:I) (Gibco) supplemented with L-Glutamine (Gibco), 2\% horse serum, non-essential amino acids, Insulin-Transferrin-Selenium supplement, and 10-4 $\mathrm{M}$ Ascorbic Acid (Sigma)), followed by stimulation with Ing/ml TGF $\beta$ I (Sigma). The cells started beating 2-3 weeks after stimulation, and were designated CMPC-CM. For short-term engraftment testing, CMPCs 
were transduced with adenoviral-eGFP (Ad-EGFP, a kind gift from Twan de Vries, LUMC).

For long-term transplantation experiments, CMPCs (passage 7) of 5 different isolations were used. Transplanted CMPC-CM had been beating in culture for at least 2 weeks. Cells were trypsinized, washed twice in PBS and counted. Cells were kept at RT prior to transplantation.

\section{RT-PCR}

RNA was isolated from cultured cells using Tripure isolation reagent (Roche) according to the manufacturer's protocol. cDNA was synthesized with the iScript cDNA synthesis kit (Biorad). Quantative RT-PCR was performed using Sybr green mastermix (Biorad). Primer sequences are shown in supplementary table I. Human $\beta$-actin expression was used to normalize the data.

Animals

All experiments were carried out in accordance with the Guide for the Care and Use of Laboratory Animals, prepared by the institute of Laboratory Animal Resources and with prior approval by the Animal Ethical Experimentation Committee, Utrecht University.

M yocardial infarction and cell transplantation

Male NOD-SCID mice (Charles River), aged 10-12 weeks were used in these experiments. Myocardial infarction (MI) was induced by ligation of the left anterior descending coronary artery (LAD) following left-sided thoracotomy using isoflurane anesthesia, as described previously. ${ }^{23}$ The ligation was placed $2 \mathrm{~mm}$ below the inferior of the left auricle to obtain reproducible infarct size. Infarction was confirmed by the degree of blanching and akinesia of the tissue. Immediately after the ligation of the LAD, 2 injections of $0.25 \times 10^{6}$ CMPCs $(n=I I)$ or CMPC-CM $(n=10)$ each in $5 \mu$ I PBS were placed in the borderzone of the infarct using a $29 \mathrm{G}$ needle with a bended tip. As a negative control, 2 injections of $5 \mu$ PBS were given $(n=9)$. The surgeon (A.S.) was blinded for the cell type or control injected.

\section{RI measurements}

In the long-term experiments, cardiac parameters were determined 2 days, 4 
weeks and I 2 weeks post-MI. End-diastolic volume, end-systolic volume, ejection fraction, stroke volume were determined by magnetic resonance imaging on a 9.4 Tesla scanner (Bruker Biospin $\mathrm{GmbH}$, Rheinstetten, Germany) as described previously. ${ }^{23 ; 24}$ Analysis was performed using Q-mass for mice digital imaging software (Medis, Leiden, the Netherlands) by a blinded investigator (K.d.O.). Infarct size was estimated by determining the akinetic or dyskinetic proportions of the circumference of the left ventricle. Additionally, wall thickness was determined at the level of the papillary muscles, and 3 axial slices apical-wards from there. The circumference of the LV was divided into 6 equal pieces. The inferior septal part was used to determine the septal thickness, the lateral, anterolateral and inferior lateral values were pooled to represent the infarct thickness. The anterolateral septal value and the inferior value were pooled to give the borderzone value.

\section{Immunofluorescent staining of cells on coverslips}

Cells were fixed with $2 \%$ paraformaldehyde, washed with PBS and stained as described previously ${ }^{25}$ with antibodies against human integrin $\beta I$ (undiluted) (mouse, a kind gift from A. Sonnenberg, Netherlands Cancer Institute), troponin- I (I:500) (rabbit, Chemicon), and $\alpha$-actinin (I:800) (mouse, Sigma).

\section{Histology}

Mice were sacrificed 2 weeks or 3 months post-MI and the hearts were fixed as described previously ${ }^{26}$ and embedded in Tissue Tec. Hearts were cut into $7 \mu \mathrm{m}$ cryosections, which were stained as described ${ }^{23}$ using the following antibodies and dilutions: human integrin $\beta$ I (undiluted) (mouse, a kind gift from A. Sonnenberg, Netherlands Cancer Institute), troponin- I (I:500) (rabbit, Chemicon), myosin light chain (MLC)2A (I:100) (mouse, Synaptic Systems), MLC2V (I:50) (mouse, Synaptic Systems), connexin-43 (I:200) (rabbit, Zymed), smooth muscle actin (I:I00) (rabbit, Abcam), human CD3I (I:300) (mouse, DAKO), Ki-67 (I:I00) (rabbit, Abcam), human mitochondria (I:500) (mouse, Chemicon), desmoplakin (undiluted) (mouse, Progen Biotechnik). Isotype controls (DAKO) were performed for each class of antibody used. Cy-3 labeled secondary antibodies were obtained from Jackson Immuno Research Laboratories and Alexa 488 labeled secondary antibodies from Invitrogen. DAPI (in Vectashield mounting medium) was used for nuclear counterstaining. 
Immunohistochemical staining

For quantification of vessel density, sections were post-fixed with acetone, and blocked for endogenous peroxidase activity. After blocking with $1 \%$ bovine serum albumin (BSA), the sections were incubated overnight at $4^{\circ} \mathrm{C}$ with rat-antimouse CD3I (Cell Signaling) diluted I:20. A second blocking step was performed using TNB (Perkin Elmer TSA-kit). Subsequently, the sections were, incubated with rabbit-anti rat antibody (Dako, diluted I:250). Rabbit Powervision-HRP (Immunologic), followed by incubation with diamino benzidine (DAB) substrate was used to visualize the CD3I antibody. Nuclei were counterstained with hematoxylin before dehydrating and mounting with Pertex. Vessel density was averaged in 6 hearts per group from 20 fields per heart divided over 3 to 5 sections at standardized locations along the long axis of the infarct area using an Olympus-BH2 microscope with AnalySIS software. The number of small vessels per $0.25 \mathrm{~mm}^{2}$ in the borderzone and infarct region was determined and corrected for the number of vessels in healthy tissue. Infarct, borderzone and healthy myocardium were analyzed separately.

\section{M icroscopical analysis}

Whole heart fluorescent imaging was performed on a Leica MZ I6FA/ DFC480.

Confocal laser scanning microscopy (sequential scanning for DAPI with excitation laser $405 \mathrm{~nm}$, alexa 488 with $488 \mathrm{~nm}$, and Cy3 with $532 \mathrm{~nm}$, respectively, to avoid signal leakage) was performed on a Leica TCS SPE confocal on a DMI4000B microscope using LAS-AF software (Leica application suiteadvanced fluorescence). Investigators (L.v.L. and C.S.) were blinded for the cell type injected.

\section{Statistical analysis}

Statistical significance was evaluated with SPSS vII.5 for Windows using ANOVA (with Bonferroni correction for multiple-group comparisons) or Mann-Whitney $\mathrm{U}$ test, as applicable. Survival was analyzed with the Kaplan-Meier test. Results are expressed as mean \pm SEM. A value of $p \leq 0.05$ was considered statistically significant. 


\section{Results}

\section{PC survival}

As a pilot study to investigate whether CMPCs survived in the hostile ischemic conditions after $\mathrm{Ml}$ and to validate tracking methods, Ad-eGFP transduced CMCPs were injected into the borderzone immediately after ligation of the LAD. Two weeks post-MI, eGFP positive grafts were detected in the borderzone and infarcted region (Figure la and Ib). The human origin of the cells was confirmed by colocalization of EGFP fluorescence with expression of the human specific $\beta I$-integrin protein (Figures Ic, Id and Ie) and human specific mitochondria (not shown).

\section{Cell transplantation sources}

CMPCs were grown to passage seven to exclude contamination with surviving fetal cardiomyocytes. After induction of differentiation, CMPC-CM started beating in culture after approximately 2-3 weeks. Figures $2 a$ shows representative gene expression analysis of one cell isolate from the same donor, before and after induction of differentiation. The cardiac genes myosin light chain $2 \mathrm{~V}$ (MLC2V), $\beta$-myosin heavy chain (MHC), cardiac-actin (c-Actin) and tropinin-T were highly expressed in CMPC-CM compared to CMPCs. Double staining of cultured cells for human $\beta \mathrm{I}$-integrin and troponin- I (Figure 2b-g) or $\alpha$-actinin (not shown) revealed that CMPCs did not express any sarcomeric proteins (Figure $2 b-d$ ), whereas $50-60 \%$ of the CMPC-CM in culture had a marked striated sarcomeric pattern (Figure $2 \mathrm{e}-\mathrm{g}$ ). This indicated the undifferentiated state of the CMPCs, and confirmed the differentiation of CMPC-CM into cardiomyocytes.

General health and survival of mice

During the three months after surgery, there was no significant difference in the survival of mice in the PBS, CMPCs or CMPC-CM injected groups (Figure 3a).

Starting two days after surgery, the average body weight increased in all groups (Figure 3b). However, after 3 months, the PBS injected animals lost weight compared to the CMPC treated animals $(p=0.05)$. 
a

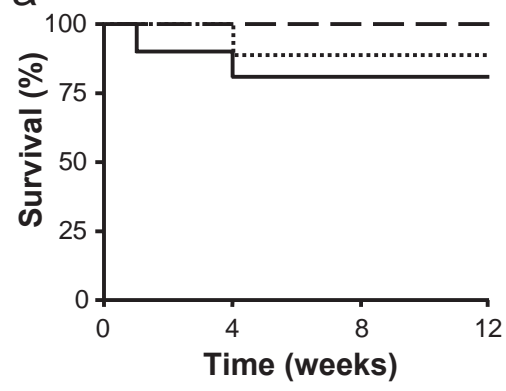

b

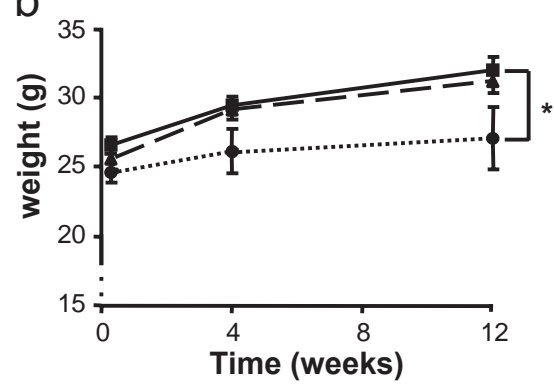

PBS,

CMPCs,

$\mathrm{CMPC}-\mathrm{CM}=-$

Figure 3. Survival rates and body weight. There were no differences in survival between the three groups during the 12 weeks after surgery. In all animals body weight increased steadily during the experiment. At 12 weeks, the PBS treated animals $(n=7)$ were significantly lighter than the CMPC treated mice $(n=9) . * p \leq 0.05$.

LV function

Two days after MI, the end diastolic volume (EDV) was comparable in all three groups (Figure 4a). The end systolic volume (ESV) was slightly, but significantly decreased in the CMPC transplanted group compared to PBS injected animals (Figure $4 b, p=0.036$ ). Four and twelve weeks post-MI, the EDV and ESV of the cell injected groups were significantly lower compared to the PBS recipients. Whereas the EDV and ESV continued to rise after 4 weeks in the PBS group, these values remained stable in the cell treated animals, indicating that further dilatation was prevented (Figure $4 \mathrm{a}$ and $4 \mathrm{~b}$ ).

Ejection fraction (EF, Figure 4c) was higher at two days and 4 weeks post-MI in the CMPC-injected animals compared to the PBS group. After 12 weeks EF was increased in both cell-transplantation groups compared to the PBS controls. 
In all groups, the EF was significantly lower 4 and 12 weeks post-MI compared to 2 days. In the cell treated animals, the EF did not decrease further after 4 weeks, whereas in the PBS injected animals, the decrease seemed to continue although was not statistically significant. Stroke volume (SV, Figure 4d) was not significantly different in the cell treated groups compared to PBS.
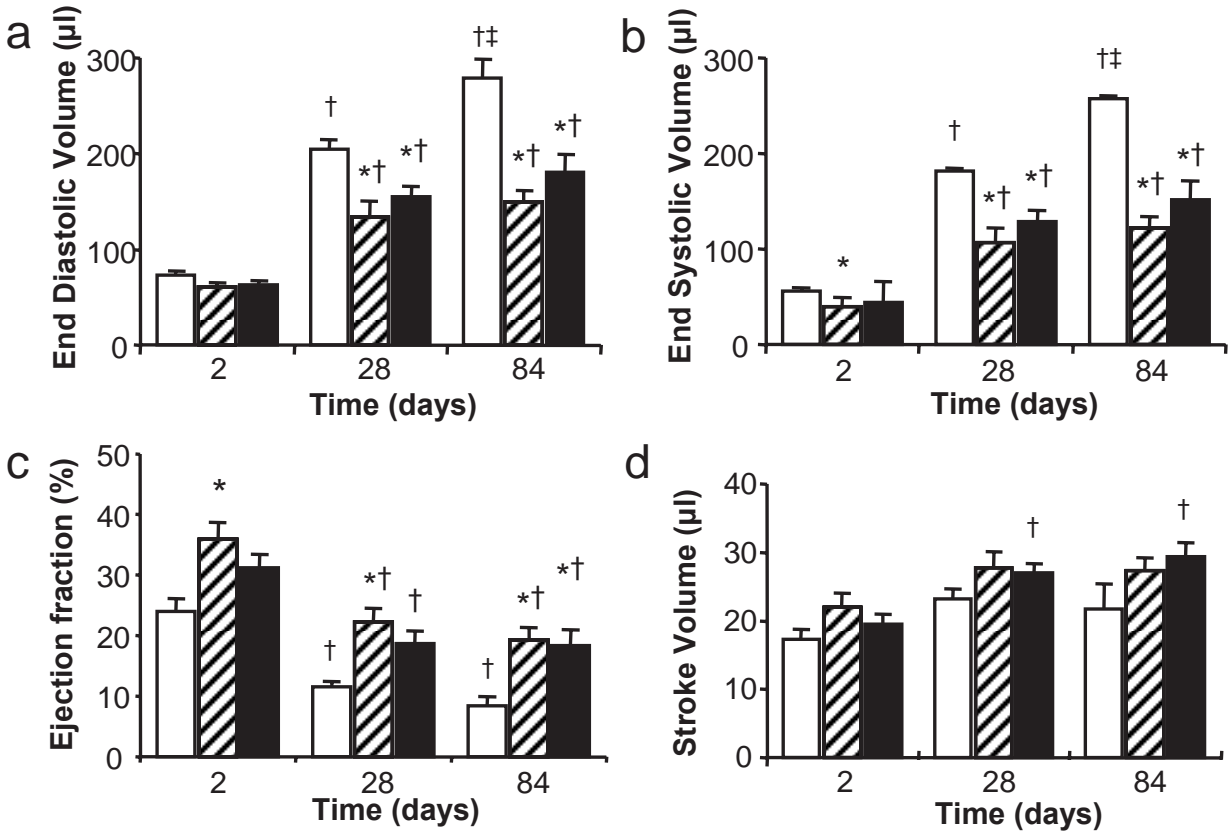

PBS

$\mathbb{Z}$ cMPCs

CMPC-CM

Figure 4. Left Ventricular Function. EDV, ESV and EF were determined 2 days, 4 weeks and twelve weeks post-surgery by high resolution MRI. * $\mathrm{p}<0.05$ compared to PBS, $\dagger \mathrm{p}<0.05$ compared to two days measurement of the same group, $\ddagger \mathrm{p}<0.05$ compared to 4 weeks measurement of the same group.

\section{Characteristics of the Left Ventricle}

The MRI analysis showed an increase in the size of the heart (Figure $5 \mathrm{a}$ and $5 b$ ), which was most pronounced in the PBS injected animals (Figure 5b). The infarct size, estimated by the percentage of the circumference of the LV that was a- or dyskinetic, was not different at 2 days post-MI (Figure 5c). At 4 weeks the infarcted region in the PBS group was larger compared to the CMPC-CM injected animals and tended to remain higher at 12 weeks (Figure 5c). 
The wall thickness was determined by measuring the average thickness in 6 regions covering the left ventricle. During the experiment, the wall thickness of the septum remained constant (Figure 5d). The wall of the borderzone was thicker in the cell treated-animals compared to the PBS group at 4 weeks. The wall of the infarcted region also remained thicker in the CMPC-CM treated animals at 4 weeks, and in the CMPC injected animals at 4 and 12 weeks, both compared to PBS injection.

a
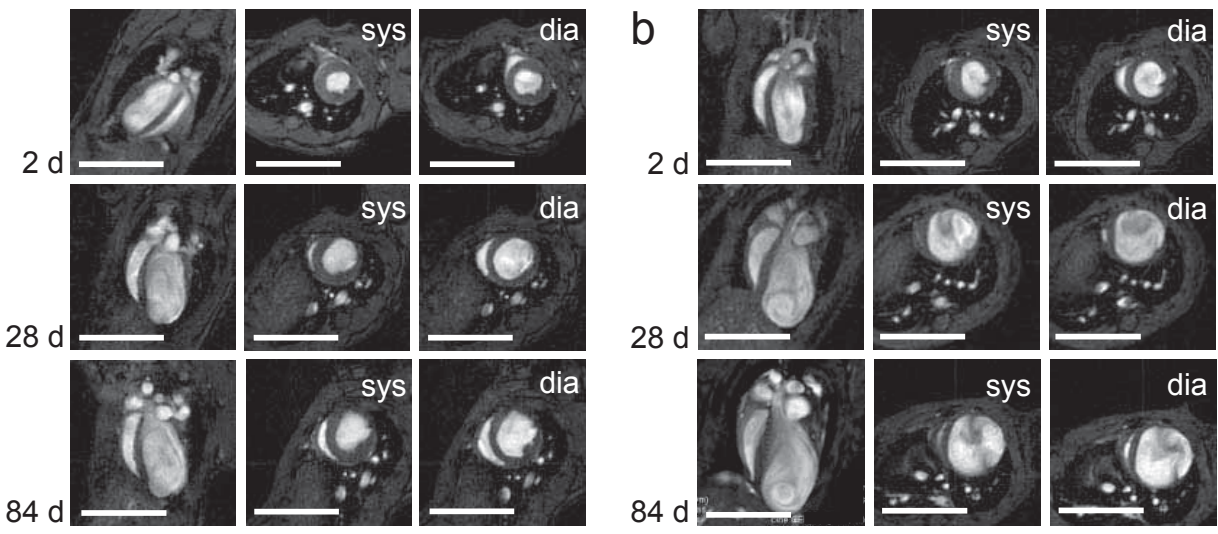

C

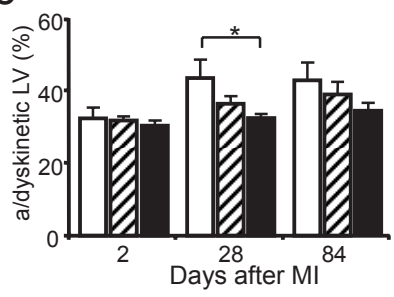

d
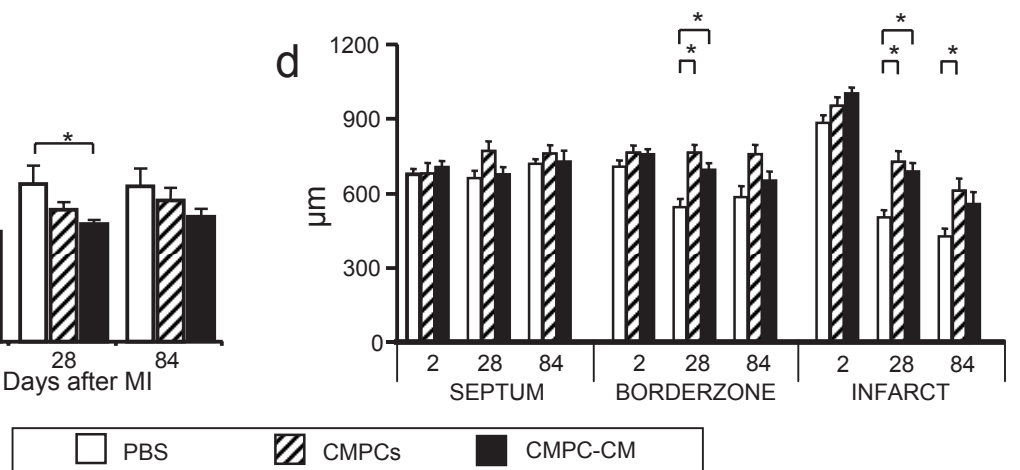

$\mathbb{Z}$ CMPCs

CMPC-CM

Figure 5. Series of MRI images showing the same CMPC (a) or PBS receiving animal in time. A four-chamber view is provided for each time-point as well as the axial view in systole (sys) and diastole (dia). (c) Infarct size was determined as the percentage of the circumference of the LV that was a- or dyskinetic. (d) The wall thickness is shown, measured in 3 different regions: septum, borderzone and infarct. The thickness was determined at 3 time points post-MI. Scale bars: I cm, ${ }^{*} \mathrm{p}<0.05$.

Vessel density

Cell injection might have a paracrine effect, leading for example to the induction of new vessels. Therefore we determined the number of small vessels in the 
borderzone, as well as in the infarcted region (Figure 6a-c). Only the injection of CMPCs led to more vessels in the borderzone, and showed the same trend in the infarcted region.

Localization and number of cells after transplantation

To characterize the fate of the transplanted CMPCs and CMPC-CM, cells were traced with an antibody recognizing exclusively human integrin $\beta I$, which is expressed constitutively on their plasma membrane. Anti-human mitochondria antibody recognized the same cells, but was less suitable for quantifying cells since the cell borders were not as clear as with integrin $\beta \mid$ and was therefore only used as an additional control to confirm the human origin of the cells (e.g. Figure 7l).

Human cells formed large patches of viable tissue in the borderzone as well as in the infarcted region, indicating that they were not confined to the site of injection. We were able to retrieve $0.4-10 \%$ of the initial injected cell population and there was no difference between the injected cell types (not shown).The cell patches were generally isolated from the surviving mouse cardiomyocytes by connective tissue although some appeared to be in contact with the host myocardium (Figure 7e).

In vivo differentiation and maintenance of phenotype

Whereas CMPCs did not express any sarcomeric proteins at the time of transplantation, intracardiac grafts formed subsequently contained large numbers of troponin-I positive human cells (Figure 7a). Likewise, CMPC-CM derived grafts consisted predominantly of troponin-I positive cells (Figure 7b). In contrast to the mouse ventricular myocardium, nearly all of these human cardiomyocytes expressed MLC2A, in accordance with their fetal-like phenotype. ${ }^{27}$ (Figure 7cd). The majority of them was also positive for MLC2V. Both cardiomyocytes from CMPCs and CMPC-CM in grafts had clearly distinguishable sarcomeres visualized by staining for MLC2A and troponin-I (Figure 7e-f). To assess coupling of the donor cardiomyocytes, we looked for the presence of desmosomal and gap junction proteins. Desmoplakin was abundant in the graft area (not shown); connexin-43 was present at gap junctions between the human cardiomyocytes, although in smaller quantities than between adult mouse cardiomyocytes (Figure $7 g-h)$. 
While cardiomyocytes were the major cell type in the grafts, a minority of the CMPCs had differentiated into smooth muscle cells (Figure 7i) or endothelial cells, forming vessel-like structures (Figure 7j). Cell cycle activity, as indicated by positive nuclear staining for $\mathrm{Ki}-67$, was present in a small proportion of the donor cells (Figure 7k).

Quantification of cardiomyocyte, smooth muscle and endothelial phenotype in CMPC- and CMPC-CM derived grafts revealed no significant differences between the two groups (Figure $7 \mathrm{~m}$ ).

\section{Discussion}

This is the first study to compare the long-term efficacy of undifferentiated CMPCs with in vitro differentiated CMPC-CM after MI. Transplantation of either cell type resulted in long-term functional improvement of cardiac function compared with carrier control, prevented progression of cardiac dilatation and wall thinning. CMPCs as well as CMPC-CM regenerated the myocardium by forming new cardiomyocytes and blood vessels. Strikingly, CMPCs differentiated in vivo, with the same high efficiency, into the same cell types as CMPC-CM that were differentiated in vitro prior to injection.

\section{Cell characteristics}

Our previous work has shown that fetal and adult human hearts contain a pool of progenitor cells, characterized by their ability to bind Sca-I antibody, which can differentiate into cardiomyocytes, endothelial cells and smooth muscle cells in vitro (M. Goumans, unpublished).

In the present study, we used CMPCs isolated from human fetal hearts, since they are more abundant and easily isolated. During the isolation of CMPCs, contamination of the cell culture with fetal cardiomyocytes can sometimes occur. Given that fetal cardiomyocytes can engraft very efficiently in the infarcted myocardium ${ }^{22}$ we cultured CMPCs for 7 passages prior to transplantation since from experience we know that no cardiomyocyte will survive these culture conditions. Although mRNA of the cardiac transcription factors GATA-4 and $\mathrm{Nkx2.5}$ was present in CMPCs, their undifferentiated state was confirmed by the lack of expression of cardiac specific sarcomeric RNA (Supplementary 
figure la) or protein. Differentiation of CMPCs into cardiomyocytes resulted in spontaneously beating cells after approximately 3 weeks in culture. Expression of cardiac genes (see also Supplemental figure Ib) was highly upregulated compared to CMPCs and $50-70 \%$ of the cells expressed the proteins troponin$I$ and $\alpha$-actinin (not shown), indicating a high efficiency of differentiation. In comparison, the maximum differentiation rate for human ESCs reported to date is only $20-30 \% .{ }^{16 ; 28}$

Twelve weeks after transplantation CMPCs and CMCP-CM had generated new myocardium consisting of endothelial cells, smooth muscle cells and cardiomyocytes. The cardiomyocytes did not reach a fully mature state, but remained fetal in phenotype, as indicated by their morphology and the expression of MLC2A. ${ }^{27}$ Both cell types expressed $\mathrm{Ki}-6712$ weeks after transplantation indicating that they were still in the cell cycle, although not necessarily dividing. Surprisingly, CMPCs showed the same degree of differentiation into cardiac cells in vivo as could be achieved in vitro.

Human cells formed multiple grafts containing a maximum of $10 \%$ of the total injected cell population. The loss of the remaining proportion can result from inefficient seeding (cells may leak out of the injection site) or cell death during the course of the experiment. ${ }^{29}$ Recent developments suggest that it may be possible to increase cell retention and survival by alternative injection techniques ${ }^{30}$ or the addition of pro-survival factors. ${ }^{16}$

We found no evidence of functional coupling of the cells to the surrounding tissue. Connexin-43 was present in the human graft and between human cells, but no Cx-43 was observed between mouse and human cells. However, it remains a question whether human cells are able to functionally couple to mouse myocardium, since the contraction rate of murine cardiomyocytes is much faster.

\section{Functional improvement after cell transplantation}

The need to perform long-term studies has been emphasized by clinical studies injecting bone marrow cells, or subfractions thereof, into the infarcted myocardium. ${ }^{7}$ During short-term follow-up, minor positive effects on cardiac performance have been reported; however, these were often not sustained. ${ }^{8 ; 9}$ In addition, previous work using human ESC-derived cardiomyocytes and noncardiomyocytes as sources for transplantation in a mouse model of acute MI, 
revealed that cardiomyocyte-specific favorable effects on heart function were present 4 weeks post-MI but not maintained at 12 weeks. ${ }^{17}$

In general, the induction of Ml leads to a reduced contractile function, represented by a reduced EF, and dilatation of the LV wall, indicated by increased EDV and $E \mathrm{~V}^{31}$. In the present study, the transplantation of either cell type prevented the progression of dilatation of the left ventricle, and resulted in a higher contractile function throughout the experiment. Injection of cells likely affected the postinfarction remodeling by limiting the expansion of the scar. The fact that the infarcted wall remains thicker in the cell-injected animals strongly supports this possibility.

Surprisingly, 2 days after transplantation of the cells, a positive effect on contractile function was already observed which did not result from a difference in infarct size. Instead, it either may be a consequence of mechanical support by the grafted cells and/or represent a paracrine effect. Active contribution to contraction at this stage seems unlikely but cells may provide passive support. At later time-points, when the grafts have stabilized, they could contract actively but in order to be fully functional, this would need to be in synchrony with the host myocardium, to prevent the risk of inducing arrhythmias. In view of the isolated location of the majority of the grafts and the lack of abundant gap junction formation between host and donor cells, functional coupling seems rather unlikely. However, electrical signals are able to travel certain distances through fibrotic layers and still remain intact. ${ }^{32}$

Paracrine stimulation is certainly important in the increased vascular density of the border zone that was observed. Interestingly, this effect was much more pronounced in the mice receiving CMPCs than those receiving CMPCCMs. CMPCs in their undifferentiated or early differentiated state may thus secrete more or other growth factors, such as vascular endothelial growth factor, than their differentiated derivatives. Enhancement of neovascularization contributes to preservation of cardiac function after myocardial infarction. ${ }^{24}$ However, additional cell- or growth factor based contributions may exist. The identification of these mechanisms should lead to determination of the best cell source for each type of patient (for example, acute MI for example may require a different transplantation strategy than chronic heart failure), and will be the subject of future studies. 


\section{PCs as a source for transplantation}

The ideal cell source for transplantation should be multipotent, not only giving rise to cardiomyocytes, but also capable of forming vessels in order to restore blood flow to the ischemic area. The newly formed cardiomyocytes should couple functionally with the surrounding tissue, and beat in synchrony without causing arrhythmias. In our previous studies we found that CMPCs meet these criteria, at least in vitro. CMPCs differentiated with high efficiency into cardiomyocytes, endothelial cells and smooth muscle cells. The cells were able to beat spontaneously, and showed action potentials resembling fetal ventricular cardiomyocytes. Furthermore, the cells coupled electrically and metabolically. CMPCs isolated from the fetal heart may not represent the ideal source for transplantation, since their routine use would be ethically challenging, and their availability limited. However, CMPCs isolated from the adult human heart were also shown to possess similar differentiation characteristics in vitro, indicating that the CMPCs may be used ultimately for autologous transplantation.

Our results confirm that human heart-derived progenitor cell populations can realize myocardial regeneration as reported previously. 21:33;34 However, this is the first study to investigate long-term effects, and directly compare the potential of the undifferentiated and differentiated offspring of the same cell source. Whilst very different at the time of transplantation, CMPCs and CMPC-CMs gave strikingly similar results in terms of engraftment, phenotype and effect on cardiac function after acute MI. This is likely a consequence of the abundance of growth factors and cytokines in the ischemic tissue. For example, TGF $\beta$ is known to be strongly upregulated after MI. ${ }^{35}$ Given the response of CMPCs to this growth factor in vitro, it is conceivable that stimulation by TGF $\beta$ in vivo is a major contribution to the efficient differentiation.

In conclusion, human CMPCs and CMPC-CM formed viable grafts consisting of cardiomyocytes, endothelial cells, and smooth muscle cells, and preserved cardiac function for at least 12 weeks after acute myocardial infarction in immunodeficient mice. Considering that the cells can be obtained from atrial tissue biopsies, they represent a very promising candidate cell source for future clinical application. 


\section{Acknowledgements}

This work is supported by the European Community's Sixth Framework Programme contract ('Heart Repair') LSHM-CT-2005-0I8630 (L.v.L) and a VIDIgrant (M.G.)

We are grateful to Jantine Monshouwer-Kloots and Anne Boeter for their help with immunofluorescence.

\section{References}

I. Rosamond W, Flegal K, Furie K, Go A, Greenlund K, Haase N, Hailpern SM, Ho M, Howard V, Kissela B, Kittner S, Lloyd-Jones D, McDermott M, Meigs J, Moy C, Nichol G, O’Donnell C, Roger V, Sorlie P, Steinberger J, Thom T, Wilson M, Hong Y. Heart Disease and Stroke Statistics 2008 Update. A Report From the American Heart Association Statistics Committee and Stroke Statistics Subcommittee. Circulation. 2007.

2. Evans SM, Mummery C, Doevendans PA. Progenitor cells for cardiac repair. Semin Cell Dev Biol. 2007;18:153-160.

3. Guan K, Hasenfuss G. Do stem cells in the heart truly differentiate into cardiomyocytes? J M ol Cell Cardiol. 2007;43:377-387.

4. Orlic D, Kajstura J, Chimenti S, Bodine DM, Leri A, Anversa P. Bone marrow stem cells regenerate infarcted myocardium. Pediatr Transplant. 2003;7 Suppl 3:86-88.

5. Toma C, Pittenger MF, Cahill KS, Byrne BJ, Kessler PD. Human mesenchymal stem cells differentiate to a cardiomyocyte phenotype in the adult murine heart. Circulation. 2002; 105:93-98.

6. Kajstura J, Rota M,Whang B, Cascapera S, Hosoda T, Bearzi C, Nurzynska D, Kasahara H, Zias E, Bonafe M, Nadal-Ginard B, Torella D, Nascimbene A, Quaini F, Urbanek K, Leri A, Anversa P. Bone marrow cells differentiate in cardiac cell lineages after infarction independently of cell fusion. Circ Res. 2005;96:127137.

7. Murry CE, Field LJ, Menasche P. Cell-based cardiac repair: reflections at the 10-year point. Circulation. 2005; II2:3|74-3/83

8. Lipinski MJ, Biondi-Zoccai GG,Abbate A, Khianey R, Sheiban I, Bartunek J,Vanderheyden M, Kim HS, Kang $H J$, Strauer BE, Vetrovec GW. Impact of intracoronary cell therapy on left ventricular function in the setting of acute myocardial infarction: a collaborative systematic review and meta-analysis of controlled clinical trials. J Am Coll Cardiol. 2007;50:1761-1767.

9. Rosenzweig A. Cardiac cell therapy--mixed results from mixed cells. N Engl J M ed. 2006;355:1274-1277.

10. Balsam LB, Wagers AJ, Christensen JL, Kofidis T, Weissman IL, Robbins RC. Haematopoietic stem cells adopt mature haematopoietic fates in ischaemic myocardium. Nature. 2004;428:668-673.

II. Murry CE, Soonpaa MH, Reinecke H, Nakajima H, Nakajima HO, Rubart M, Pasumarthi KB, Virag JI, Bartelmez SH, Poppa V, Bradford G, Dowell JD, Williams DA, Field LJ. Haematopoietic stem cells do not transdifferentiate into cardiac myocytes in myocardial infarcts. Nature. 2004;428:664-668.

12. Nygren JM, Jovinge S, Breitbach M, Sawen P, Roll W, Hescheler J, Taneera J, Fleischmann BK, Jacobsen SE. Bone marrow-derived hematopoietic cells generate cardiomyocytes at a low frequency through cell fusion, but not transdifferentiation. $N$ at M ed. 2004; 10:494-50 I. 
13. Kehat I, Kenyagin-Karsenti D, Snir M, Segev H, Amit M, Gepstein A, Livne E, Binah O, Itskovitz-Eldor J, Gepstein L. Human embryonic stem cells can differentiate into myocytes with structural and functional properties of cardiomyocytes. J Clin Invest. 200 I; 108:407-4I4.

14. Xu C, Police S, Rao N, Carpenter MK. Characterization and enrichment of cardiomyocytes derived from human embryonic stem cells. Circ Res. 2002;91:501-508.

15. Mummery C, Ward-van OD, Doevendans P, Spijker R, van den BS, Hassink R, van der HM, Opthof $T$, Pera M, de la Riviere AB, Passier R, Tertoolen L. Differentiation of human embryonic stem cells to cardiomyocytes: role of coculture with visceral endoderm-like cells. Circulation. 2003; 107:2733-2740.

16. Laflamme MA, Chen KY, Naumova AV, Muskheli V, Fugate JA, Dupras SK, Reinecke H, Xu C, Hassanipour M, Police S, O'Sullivan C, Collins L, Chen Y, Minami E, Gill EA, Ueno S, Yuan C, Gold J, Murry CE. Cardiomyocytes derived from human embryonic stem cells in pro-survival factors enhance function of infarcted rat hearts. Nat Biotechnol. 2007;25:1015-1024.

17. van Laake LW, Passier R, Monshouwer-Kloots J, Verkleij AJ, Lips DJ, Freund C, den Ouden K, Wardvan Oostwaard D, Korving J, Tertoolen LG, van Echteld CJ, Doevendans PA, Mummery CL. Human Embryonic Stem Cell-Derived Cardiomyocytes Survive and Mature in the Mouse Heart and Transiently Improve Function after Myocardial Infarction. Stem Cell Research. 2007; 1:9-24.

18. Beltrami AP, Barlucchi L, Torella D, Baker M, Limana F, Chimenti S, Kasahara H, Rota M, Musso E, Urbanek K, Leri A, Kajstura J, Nadal-Ginard B, Anversa P. Adult cardiac stem cells are multipotent and support myocardial regeneration. Cell. 2003; I 14:763-776.

19. Oh H, Bradfute SB, Gallardo TD, Nakamura T, Gaussin V, Mishina Y, Pocius J, Michael LH, Behringer RR, Garry DJ, Entman ML, Schneider MD. Cardiac progenitor cells from adult myocardium: homing, differentiation, and fusion after infarction. Proc Natl Acad Sci U SA. 2003; 100:123/3-123 I8.

20. Laugwitz KL, Moretti A, Lam J, Gruber P, Chen Y,Woodard S, Lin LZ, Cai CL, Lu MM, Reth M, Platoshyn O, Yuan JX, Evans S, Chien KR. Postnatal isl I + cardioblasts enter fully differentiated cardiomyocyte lineages. Nature. 2005;433:647-653.

21. Messina E, De AL, Frati G, Morrone S, Chimenti S, Fiordaliso F, Salio M, Battaglia M, Latronico MV, Coletta M, Vivarelli E, Frati L, Cossu G, Giacomello A. Isolation and expansion of adult cardiac stem cells from human and murine heart. Circ Res. 2004;95:91 I-921.

22. Reinecke H, Zhang M, Bartosek T, Murry CE. Survival, integration, and differentiation of cardiomyocyte grafts: a study in normal and injured rat hearts. Circulation. 1999; 100:193-202.

23. van Laake LW, Passier R, Monshouwer-Kloots J, Nederhoff MG, Ward-van OD, Field LJ, van Echteld CJ, Doevendans PA, Mummery CL. Monitoring of cell therapy and assessment of cardiac function using magnetic resonance imaging in a mouse model of myocardial infarction. Nat Protoc. 2007;2:2551-2567.

24. van Laake LW, van den DS, Post S, Feijen A, Jansen MA, Driessens MH, Mager J], Snijder RJ, Westermann CJ, Doevendans PA, van Echteld CJ, ten DP, Arthur HM, Goumans MJ, Lebrin F, Mummery CL. Endoglin has a crucial role in blood cell-mediated vascular repair. Circulation. 2006; | | 4:2288-2297.

25. Passier R, Oostwaard DW, Snapper J, Kloots J, Hassink RJ, Kuijk E, Roelen B, de la Riviere AB, Mummery $C$. Increased cardiomyocyte differentiation from human embryonic stem cells in serum-free cultures. Stem Cells. 2005;23:772-780.

26. Bajanca F, Luz M, Duxson MJ,Thorsteinsdottir S. Integrins in the mouse myotome: developmental changes and differences between the epaxial and hypaxial lineage. Dev Dyn. 2004;231:402-4I5.

27. Chuva de Sousa Lopes SM, Hassink RJ, Feijen A, van Rooijen MA, Doevendans PA, Tertoolen L, Brutel de la RA, Mummery CL. Patterning the heart, a template for human cardiomyocyte development. Dev Dyn. 2006;235:1994-2002.

28. Graichen R, Xu X, Braam SR, Balakrishnan T, Norfiza S, Sieh S, Soo SY, Tham SC, Mummery C, Colman $A$, Zweigerdt R, Davidson BP. Enhanced cardiomyogenesis of human embryonic stem cells by a small molecular inhibitor of p38 MAPK. Differentiation. 2007. 
29. Muller-Ehmsen J, Krausgrill B, Burst V, Schenk K, Neisen UC, Fries JW, Fleischmann BK, Hescheler J, Schwinger RH. Effective engraftment but poor mid-term persistence of mononuclear and mesenchymal bone marrow cells in acute and chronic rat myocardial infarction.J M ol Cell Cardiol. 2006;41:876-884.

30. Zhang H, Song P, Tang Y, Zhang XL, Zhao SH,Wei YJ, Hu SS. Injection of bone marrow mesenchymal stem cells in the borderline area of infarcted myocardium: heart status and cell distribution. J Thorac Cardiovasc Surg. 2007; 134:1234-1240.

31. Lutgens E, Daemen MJ, de Muinck ED, Debets J, Leenders P, Smits JF. Chronic myocardial infarction in the mouse: cardiac structural and functional changes. Cardiovasc Res. 1999;41:586-593.

32. Gaudesius G, Miragoli M, Thomas SP, Rohr S. Coupling of cardiac electrical activity over extended distances by fibroblasts of cardiac origin. Circ Res. 2003;93:42I-428.

33. Bearzi C, Rota M, Hosoda T, Tillmanns J, Nascimbene A, De AA, Yasuzawa-Amano S, Trofimova I, Siggins RW, Lecapitaine N, Cascapera S, Beltrami AP, D'Alessandro DA, Zias E, Quaini F, Urbanek K, Michler RE, Bolli R, Kajstura J, Leri A, Anversa P. Human cardiac stem cells. Proc Natl Acad Sci U S A. 2007; 104: 14068 14073.

34. Smith RR, Barile L, Cho HC, Leppo MK, Hare JM, Messina E, Giacomello A, Abraham MR, Marban E. Regenerative potential of cardiosphere-derived cells expanded from percutaneous endomyocardial biopsy specimens. Circulation. 2007; I 15:896-908.

35. Chuva de Sousa Lopes SM, Feijen A, Korving J, Korchynskyi O, Larsson J, Karlsson S, ten DP, Lyons KM, Goldschmeding R, Doevendans P, Mummery CL. Connective tissue growth factor expression and Smad signaling during mouse heart development and myocardial infarction. Dev Dyn. 2004;23 I:542-550. 


\section{Discussion}

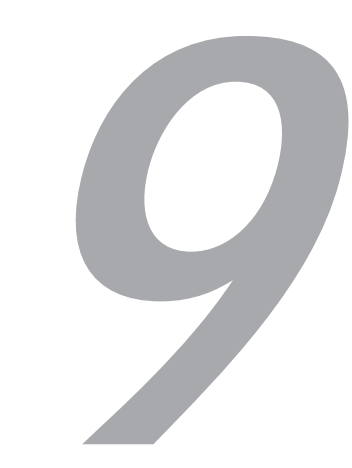

Submitted in part as invited review

R. Passier, L.W. van Laake, C.L. Mummery. Transplantation for cardiac repair meets the cardiomyocyte versus stem cell dilemma. Nature. 2008 
Cardiac recovery by stem- and progenitor cells is a concept that fascinates scientists, clinicians, patients, ethicists and even governments alike, all from their own perspectives that sometimes overlap but are just as often opposite. Most of them agree however on one thing: its unprecedented theoretical potential. Nevertheless, several obstacles were encountered when bringing theory into practice: as naturally as cardiac regeneration occurs in the zebrafish and newt, so difficult has it proven to obtain in mammals. The work described in this thesis has contributed to a realistic view of the possibilities and current limitations of cell transplantation to restore injured myocardium. While keeping eventual clinical implications in mind, stem cell research was taken from basic to translational levels and, where necessary, back to the basics again to follow the effects of several cell sources in detail.

\section{Transplantation is the major obstacle for successful stem cell therapy}

As reviewed in chapter 2 , many cell sources have been investigated over the past years for their capacity to restore the injured myocardium. The focus was on identifying the richest and most effective cellular sources for forming new tissue for transplantation into animals or humans to correct experimentally induced or naturally occurring defects. Postnatal or adult stem cells could in principle be used directly, without predifferentiation or culture and often autologously, if derived from a rich stem cell source like bone marrow or cord blood, hence their rapid clinical application. By contrast, the focus of much human embryonic stem cell ( $\mathrm{hESC}$ ) research was on basic biology: how to maintain self renewal and how to make enough of the right cells under defined conditions without unwanted cellular or other (xeno) contaminants. Methods for defined culture, directed differentiation and upscale of hESCs are now close to solution for many lineages so that transplantation itself is now emerging as the largest hurdle to implementing stem cell therapy successfully.

\section{A model for cell transplantation to the heart}

For transplantation, cell delivery methods, integration and establishing correct functional connections with the host tissue, the immune and inflammatory response and long term cell survival in grafts are currently the major challenges both in animal models and humans, independent of the stem cell source. Although it was initially thought that hESCs and their derivatives could 
escape immune rejection ', recent literature ${ }^{2 ; 3}$ and the experiments described in chapter 3 suggest otherwise. Determinants of the immune response are upregulated as hESC differentiate. Just as other heterologous cells therefore, hESC-derived cardiomyocytes ( $\mathrm{hESC}-\mathrm{CM}$ ) were rejected after transplantation in wild type mice and caused artifacts that may be misinterpreted as signs of cell survival and differentiation. High dose immunosuppressive therapy in mice, as in chapter 7, is useful for a limited period of time but, in contrast to rats and pigs, is less suitable for long term application; it would also not be the most desirable approach in patients. It is therefore likely that any eventual clinical therapy will involve immune-matched hESCs or (reprogrammed) autologous cells, such as cardiomyocyte progenitor cells (CMPCs; chapter 8 ) and induced pluripotent stem cells (iPS cells). Thus, to maximize comparability with possible clinical applications, we used immunodeficient NOD-SCID mice for the long term evaluation of human cell transplantations (chapter 3 ). In combination with the genetic green fluorescent protein (GFP) label in the hESCs and their derivatives, this enabled us to establish methods for tracking donor cells in the infarcted mouse heart and measuring their impact on cardiac function, that proved applicable to all human cells including hESC-CM (chapters 4-6), CMPCs (chapter 8) and mononuclear cells (chapter 7). A drawback of using immunodeficient animals may be a potentially altered response to myocardial damage, since inflammatory and immunological factors are involved in the intrinsic cardiac repair process. However, NOD-SCID mice are deficient in B-, T-, and natural killer cells, but do have some non-specific immune response 4 that appears sufficient to effectuate this process. Correspondingly, the formation of extracellular matrix (ECM) after myocardial infarction (MI) was similar to that in immunocompetent animals as we show in chapter $6^{5 ; 6}$. The mouse is a valuable model for $\mathrm{Ml}$ and cell transplantation, not only because of the availability of immunodeficient mice but also in view of the possibility to introduce or inactivate genes of interest, as in chapter 7. Myocardial remodeling and functional implications after $\mathrm{Ml}$ in mice are accelerated compared to humans but otherwise highly similar ${ }^{5 ; 7 ; 8}$. Nevertheless, an important issue in evaluating the function of human cardiomyocytes in rodents is the difference in their intrinsic beating frequency. Human cardiomyocytes beating 60 to 100 times per minute are transplanted into a rodent heart beating 300-600 times per minute. Unsuccessful coupling, demonstrated by intracellular calcium imaging $9 ; 10$, could 
contribute to failure to improve long term cardiac function. On the other hand prolonged periods of tachycardia that would result from coupling of hESC-CM and host cardiac cells may induce cardiac dysfunction. Experiments in larger animals such as pigs or primates are needed to resolve the issue. These would preferably be ESCs of the same species or iPS-cells derived from adult (skin) cells, which could be autologous.

\section{Safety issues}

Although we did not find teratomas or ectopic donor cell survival from any of the cell types investigated, studies in large animals will be necessary for assessing the risk of tumor formation since this may be species-dependent ". This additional safety issue is specifically associated with ESCs since contaminating undifferentiated cells are able to give rise to teratomas if inadvertently co-transplanted with differentiated cells. Evidence for complete removal of these cells from any therapeutic preparation will be an absolute regulatory requirement although it may also be necessary to show that any early commitment after transplantation is irreversible. Clearly cells isolated from patients and transplanted directly into the same individual (autologous transplantation), without expansion in culture, are likely to present fewer safety issues than any cultured cells, since culture can result in development of chromosome abnormalities ${ }^{12}$. Undifferentiated CMPCs represent a unique cell source in this respect, since they could be transplanted shortly after isolation and differentiate in vivo into cardiomyocytes and vascular cells (chapter 8 ), thus avoiding the need for prolonged exposure to culture conditions.

Recent advances inducing reprogramming of adult human (skin) cells have created a new generation of pluripotent cells ${ }^{13 ; 14}$ that seem comparable to ESCs but without the associated ethical issues. It is likely that these will cause an explosion of scientific and financial investment which will result in many patient/disease specific cell lines suitable for use as disease models and drug screening (Figure I). However, even with methodological refinement so that viral gene insertion is not required to induce conversion to an ESC-like state, the same issues of chromosome stability and integration into host tissues and organs will need to be resolved. 
Improvement of cardiac function independently of long term survival of donor cells

As it became apparent that functional improvement was not necessarily correlated with simultaneous detection of engrafted cells, animal models have been used to investigate whether other mechanisms, independent of large-scale cardiomyocyte replacement, are involved (reviewed in ${ }^{15}$ ). Many cell types, derived from tissues as varied as cord blood, adipose tissue, peripheral blood, appear to behave similarly to BMCs after injection directly into the heart or homing to the ischemic site and any reported improvements in cardiac function are likely to be mediated predominantly by paracrine effects ${ }^{16 ; 17}$. This hypothesis is supported by evidence from studies in rodents and larger mammals showing induction of neovascularization and rescue of ischemic myocardium ${ }^{18 ; 19}$ and physiological benefit without stable engraftment of cells ${ }^{20-22}$. Potential risks of engraftment have been suggested for cells like mesenchymal stem cells (MSCs) which have the capacity to differentiate to cartilage, bone and adipocytes in culture. One report described bone and cartilage formation in the heart after transplantation ${ }^{23}$ although this could have been calcification resulting from injection of foreign tissue. Likewise, transplantation of multipotent adult progenitor cells (MAPC), a cultured BMC-derived population reported to differentiate into derivatives of all germ layers, improved cardiac function through the release of inflammatory and vascular growth factors, again in the absence of permanently engrafted cells $24: 25$. Thymosin $\beta 4$ has been reported to affect the migration of and vascularization by an endogenous epithelial progenitor cell population recently identified in human epicardium ${ }^{26-28}$. These cells were as effective in the short term as any others in restoring post-infarct function and reducing dilatation of the heart chambers in immunodeficient mice receiving the cells ${ }^{29}$. In this context, it is of interest to note that spontaneous cardiac regeneration in zebrafish following removal of the apex is initiated by reprogramming of the epicardium followed by epithelial-mesenchymal transition ${ }^{30}$.

We investigated human vasculogenic mononuclear cells (MNCs) from peripheral blood for their potential to rescue the impaired angiogenesis after MI in endoglindeficient mice. Endoglin is an accessory receptor for transforming growth factor $\beta$ (TGF $\beta$ ), a cytokine controlling proliferation, migration, adhesion and apoptosis of many cell types which, amongst others, enhances angiogenesis after MI. In chapter 7 we demonstrate that MNCs are affected by decreased endoglin expression and as a consequence heterozygous mice suffer from decreased 
vascularization and cardiac function in the recovery phase after MI. While the defects could be rescued to a large extent by intravenous injection of healthy donor MNCs, MNCs from hereditary hemorrhagic telangiectasia (HHT) patients with similar same gene defects as the mice failed to enhance vascularization and cardiac function. Likewise, healthy donor MNCs but not patients' MNCs had a positive effect on these parameters in wild type mice which was associated with the cells' capacity to home to the site of myocardial injury. Although donor cellderivatives may have incorporated in the recipient vasculature, the low frequency with which this was observed favors the explanation that the MNC-derived endothelial progenitor cells (EPCs) and endothelial cells (ECs) stimulated a hostderived angiogenic response. Both secretion of growth factors and cytokines by the injected cells and upregulation of recipient-derived cytokines ${ }^{31}$ have a role in this mechanism. Our findings underline the importance of identifying the best subset of cells for transplantation, especially since cardiovascular patients seem to have defects in their MNCs and EPCs ${ }^{32}$. Recently, a correlation between serum endoglin (i.e., the soluble form of endoglin) levels and prognosis after acute MI has been reported, the patient group with the lowest endoglin levels having the highest mortality ${ }^{33}$. Such patients may benefit from transplantation of a selection of cells with high endoglin expression, and matched heterologous cells may be preferred in those cases.

Taken together, infarcted hearts seem to benefit from transplantation of numerous cell types that are not retained or do not form cardiomyocytes. No adverse events in patients have been linked with transplantation itself so that the procedures appear safe. Therefore even if benefits are short term, these may nevertheless be of value to patients. Present focus on understanding the underlying mechanisms may lead to optimization in the choice of cell number and type for these short term effects.

\section{Cardiomyocyte grafting for cardiac functional enhancement}

Using cardiomyocytes to replace functional myocardium once it has been destroyed represents a greater challenge. Providing functional cardiomyocytes is especially important for restoring long term function to prevent or reverse heart failure, the principle purpose of cardiac cell therapies. The newly formed muscle will provide passive mechanistic support but, it will also need to couple and contract in synchrony with the host myocardium to be effective and safe. 
To distinguish between cardiomyocyte-specific effects and general cell-based functional enhancement (for example, by triggering an inflammatory response), we included a group of mice receiving non-cardiomyocyte derivatives of the same hESC line that was used to generate cardiomyocytes (chapter 4). Even compared to this most strict control, hESC-CM improved cardiac function for at least 4 weeks after $\mathrm{MI}$ and cell transplantation, although the difference was no longer significant after 12 weeks. In all studies, the choice of controls for comparison with the test sample is crucial. No injection, carrier alone or control cell populations not relevant for the mechanism under study are likely to make a significant impact on the outcome and conclusions of any study (Table I).

\section{hESCs and CM PCs as sources of cardiomyocytes}

Of all stem cell sources, hESC are amongst the more promising for realizing cardiac repair through cardiomyocyte replacement because of their capacity to undergo directed differentiation into bona fide cardiomyocytes and supportive cardiac cells ${ }^{34-36}$ in vitro with high efficiency. These cells have already been characterized extensively in vitro by marker expression and electrophysiology 37-43.

The first reports of transplantation of hESC-derived cardiomyocytes (hESC-CM) in pigs and guinea pigs demonstrated their potential to act as biological pacemakers in electrophysiologically silenced or AV-blocked hearts ${ }^{44 ; 45}$. These experiments required relatively few ( $\sim 100$ 's) hESC-CM to exert their effect. Through recent developments to generate hESC-CM in higher numbers ( millions) it has now become possible to investigate their regenerative potential. After transplantation into the healthy myocardium of immunodeficient rats or mice, $\mathrm{hESC}-\mathrm{CM}$ survived 2;46;47, and matured ${ }^{2 ; 46}$ for at least 12 weeks ${ }^{46}$ (Figures 2 and 3 and chapter 4). In all studies to date, mixtures of cardiomyocytes and other differentiated hESCderivatives have been injected into the heart. Where this has been examined in detail, preferential survival of cardiomyocytes over non-cardiomyocytes has been observed, with non-cardiac cells lost over time without being detected in any other organs. Although grafted cells formed a syncytium with each other, they were usually separated from the rodent myocardium by a layer of fibrotic tissue. As presented in chapter 6 , donor and host cells each secrete specific types of ECM, opening possibilities for intervention to facilitate electrophysiological coupling. When transplanted into the infarcted heart, hESC-CM were the only 


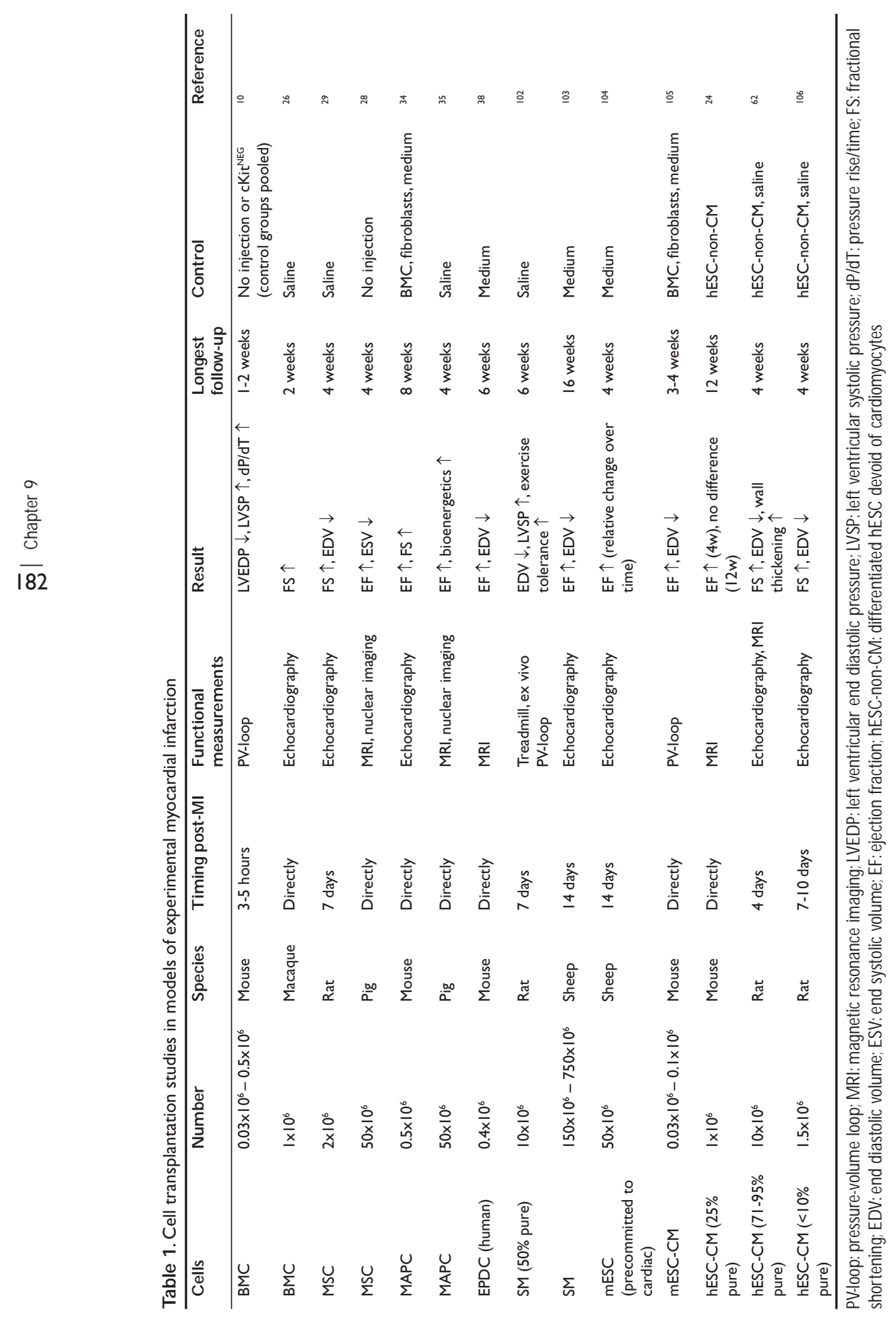


cells that formed significant grafts, although in one study this depended on the addition of a pro-survival cocktail ${ }^{48}$. In addition, co-transplanted hESC-derived ECs formed a functional vascular network around the grafts, that appeared to be connected to the mouse vasculature and support survival of the donor cells in spite of their isolation by ECM. Cardiac function was improved several (up to 4) weeks after transplantation in mice receiving hESC-CM compared to those receiving non-cardiomyocyte derivatives ${ }^{46 ; 48 ; 49}$. Notably, however, the rodents receiving non-cardiac hESC-derived cells also showed some improvement compared the vehicle-injected animals. Hence, cardiomyocyte-specific benefits were detected over and above those from non-cardiomyocyte cell types but as a cautionary note, if the vehicle alone had been taken as reference, the relative functional improvements would have appeared much higher. In addition, only one study to date has extended analysis of heart function up to 12 weeks (table 2). At this time-point the benefit of hESC-CM over hESC-non-CM was no longer present ${ }^{46}$, although it was still higher than the vehicle control (chapter 5). Functional enhancement by hESC-CM with the current strategies may thus be limited to mid-term at most and there is no evidence that the underlying mechanism depends on the contractile properties of hESC-CM.

Similar considerations apply to the results obtained from transplantation of CMPCs and CMPC-CM described in chapter 8. Although the origin of the matrix surrounding CMPC-derived grafts remains to be determined, the major part of the grafts were separated from the surviving host myocardium by scar tissue and did not form gap junctions therewith. A major advantage of the consistent use of our NOD-SCID mouse MI model is that separate cell types and controls can be compared. In this thesis, MNCs are the only cells applied to a different mouse strain because of the requirement for endoglin heterozygous mice in our study. Nonetheless, MNCs from patients and healthy subjects could be injected in NOD-SCID mice for a quantification of their effects compared to other cell types. Plotting the comparable studies of chapters 4 , 5 and 8 in one graph reveals that transplantation of either hESC-CM, other differentiated hESC-derivatives, CMPCs or CMPC-CM can improve short, mid- and long term cardiac performance and survival in infarcted mice (Figure 4). Cardiomyocytes provide additional functional benefit at mid term (4 weeks) and are the predominant cells present in grafts 12 weeks after injection. The 
associated finding that only cardiomyocytes survive and mature long term after transplantation, does not automatically entail that their mechanism of action is graft-dependent. In chapter 5 , we sought to prolong the cardiomyocytespecific functional enhancement observed 4 weeks, but not 12 weeks, after MI by increasing graft size. Surprisingly however, increased graft size was correlated with decreased rather than improved cardiac function and increased infarct size, implying negative side-effects from large grafts. For example, whereas both hESC-CM and CMPCs increased vascular density in the infarct border zone probably by paracrine effects, large grafts in the borderzone may conversely block blood supply in the early phases after MI. In light of our observations, there is almost certainly an important role for paracrine mechanisms by hESCCM and CMPCs independent of long term grafting. The passive and active contribution of the grafts to contraction of the heart remains questionable and needs further investigation, preferably in larger animals. Paracrine actions should be further specified and augmented, either via cell transplantation or by application of the growth factors and cytokines.

The question remains why cardiomyocytes lose their advantage over other cells after 4 weeks of engraftment. As discussed in chapter 5, this may have several reasons, some of which are inherent to the large-to-small-animal transplantation model and will likely be solved in the near future now that pre-clinical studies in pigs are being initiated. Nevertheless, the mouse will still be essential in unraveling molecular mechanisms that contribute to repair of the infarcted heart. Although on one hand the lack of long term cardiomyocyte-specific functional improvement may be disappointing, on the other hand the obtained results are still remarkable when mice receiving no cells are considered the most relevant control group. If the enhancement in left ventricular function by transplantation of hESC- or CMPC derived cells (Figure 4) could be translated to patients, this would be a spectacular improvement.

\section{Optimizing cell-based therapy for heart repair}

Parameters that warrant further investigation include later injection of cells, for example after the initial inflammatory phase when the environment may be hostile to the donor cells. Waiting too long may however reduce the rescue of the recipient myocardium, one of the mechanisms by which transplanted cells may act ${ }^{50}$. The optimal and possible timing to apply cells after an acute MI 
depends on the cell type. Application of cardiomyogenic cells shortly after MI, as performed in this thesis, is feasible only for "of-the shelf" sources such as hESCCM and heterologous iPS cells or CMPCs. Autologous cells entail a process of isolation and preparation after the onset of the event and as a consequence the therapy cannot be started directly. In pre-clinical trials, this would involve a two-step procedure: creating the infarction in a first session and injecting the cells in a second, either by opening the thorax or under echo-guidance ${ }^{51}$. There may not be one single optimal cell type for all types of myocardial cell loss. We need to identify the best therapeutic strategy for each patient, considering the duration of the disease (for example, acute MI vs. chronic heart failure and everything in between), severity (large vs. small MI), possible genetic defects (preference for heterologous cells), whether the patient is having heart surgery or catheterization (opportunity to isolate CMPCs), and so on. Most therapeutic protocols will likely implement a combination of cells (like cardiomyocytes and angiogenic cells).

Moreover, a given stem- or progenitor cell is not a fixed entity. Between the undifferentiated state and the final cardiomyocyte (or other cardiac cell) are several progenitors that may be more suitable for transplantation than fully differentiated cardiomyocytes. Identifying the stage at which the cells are still highly proliferative, yet already committed towards differentiation into the preferred cell type, may significantly enhance repopulation of the infarct area over time, without the negative effects associated with large initial graft size. Since the myocardium seems to provide strong clues that guide cardiac progenitors to differentiate into more mature cardiac cells (chapter 8), manipulation may be necessary to protect an overly fast transition. For instance, up- or downregulation of specific microRNAs ${ }^{52 ; 53}$ could prolong the period during which the transplanted cells remain proliferative by delaying terminal differentiation.

Whatever the cell type, proper electrical coupling is a major concern. Although hESC-CM have already been reported to pace the porcine heart, it might be necessary to upregulate gap-junctional proteins in some cells. A recent study showed that skeletal myoblasts (SMs) could be engineered to express connexin $43{ }^{54}$. This improved electrical coupling between the infarct region and the surrounding myocardium. Similar approaches have been suggested to 
drive cardiomyocytes towards electrophysiological maturation ${ }^{55}$, although this could also be a potential disadvantage for intramyocardial transplantation since (immature) fetal myocytes survive better after injection in the heart than adult counterparts ${ }^{56}$. It does however, seem to be important that grafted cells are muscle cells and not myofibroblasts, since these can cause ectopic electrical activity, increasing the risk of arrhythmias ${ }^{57}$.

Overall, it is clear that although clinical studies using cells from different sources for transplantation are presently being actively pursued, many questions at the bench are still unanswered. Apart from understanding the mechanism underlying potentially beneficial effects and the best cell type and timing of cell therapy, the delivery methods in most cases still need to be determined. Tissue engineering ${ }^{58-60}$ or intramyocardial injection of combinations of cell types seem more appropriate than intracoronary injection of single cell suspensions since the latter may not pass the endothelial barrier and may cause micro-infarctions ${ }^{61}$, but much more research is needed before clinical strategies can be properly defined. In general, the present discrepancy between mid- and long term results and the dependence of outcome on the particular control taken argues for careful re-evaluation of reported improvements by any cell type ${ }^{62}$.

\section{Towards the future}

Motivated by the recent advances in isolation of CMPCs and the generation of iPS cells, while building on experience obtained with hESC-CM and BMCs, a significant increase in the number of transplantation studies can be expected. However, for successful translation from experimental studies to clinical trials many problems have to be solved. It has become clear that making conclusions on restoration of heart function by replacing myocardium, requires long term integration and establishment of functional connections with the host tissue, in all cases taking multiple controls that include non-functional cells, carrier, immunosuppression alone and sham injections. Animal experiments should therefore include strategies to prove that transplanted cells actually cause the effect observed. These could be through inclusion of constructs which contain conditionally expressed suicide genes. These could be activated after function had been restored with the expectation that the functional benefit would be reversed. Alternatively, in specific situations, grafted tissue could be removed 
after recovery, as has been shown for transplantation of pancreatic cells ${ }^{63}$. The majority of transplantation studies have used single cell suspensions or small groups of cells. This is generally accompanied by extensive cell death and inadequate integration. Particularly in a hostile immunoreactive, ischemic or necrotic environment, survival of the grafted tissue is a major challenge. Instead of direct injection of cells into the site of injury or disease, an alternative delivery method could be to seed cells ex vivo on a biodegradable polymeric scaffold, followed by in vivo engraftment. 3-D multicellular culture systems may also have the advantage of supporting cell proliferation, maturation and organization of cells more effectively. Depending on the specific disease or injury in question, injection of cells or grafting tissue-engineered constructs may be the preferred choice ${ }^{64}$.

In addition to improving delivery methods, it will be important that further progress is made in refining effective differentiation protocols that despite recent advances, yield highly purified cell populations for transplantation. This could best be achieved by cell sorting using cell-type specific membrane markers although genetic methods using cell-type specific promoter constructs driving, for example, GFP 65-67; or selected survival by antibiotic resistance, could be alternatives for some purposes. Besides increasing the density of the cell-type of interest at the site of transplantation, the use of highly purified populations will also minimize the chance of co-transplanting contaminating undifferentiated stem cells and hence the risk of teratoma formation. Furthermore, the question remains on what the optimal differentiation state of the cell for successful transplantation. Lineage and cell-type specific promoters could be used to select precursors or more differentiated cells for comparison of effectiveness and safety in animal models. In general, mature cells have a lower proliferation rate and a lower survival after transplantation when compared to precursor cells. In addition, the microenvironment of transplanted cells often provides cues for further differentiation into mature cells. These issues need to be elaborated in future transplantation studies, which will lead to fine-tuning of transplantation therapy and eventually repair of diseased or damaged organs. 


\section{References}

I. Drukker M, Katchman H, Katz G, Even-Tov FS, Shezen E, Hornstein E, Mandelboim O, Reisner Y, Benvenisty N. Human embryonic stem cells and their differentiated derivatives are less susceptible to immune rejection than adult cells. Stem Cells. 2006;24:22I-229.

2. Dai W, Field LJ, Rubart M, Reuter S, Hale SL, Zweigerdt R, Graichen RE, Kay GL, Jyrala AJ, Colman A, Davidson BP, Pera M, Kloner RA. Survival and maturation of human embryonic stem cell-derived cardiomyocytes in rat hearts. J Mol Cell Cardiol. 2007;43:504-516.

3. Kofidis T, deBruin JL, Tanaka M, Zwierzchoniewska M, Weissman I, Fedoseyeva E, Haverich A, Robbins RC. They are not stealthy in the heart: embryonic stem cells trigger cell infiltration, humoral and Tlymphocyte-based host immune response. Eur J Cardiothorac Surg. 2005;28:46I-466.

4. Shultz LD, Schweitzer PA, Christianson SW, Gott B, Schweitzer IB, Tennent B, McKenna S, Mobraaten L, Rajan TV, Greiner DL, . Multiple defects in innate and adaptive immunologic function in NOD/LtSz-scid mice.J Immunol. 1995; 154:180-191.

5. Dobaczewski M, Bujak M,Zymek P, Ren G, Entman ML, Frangogiannis NG. Extracellular matrix remodeling in canine and mouse myocardial infarcts. Cell Tissue Res. 2006;324:475-488.

6. Lindsey ML, Mann DL, Entman ML, Spinale FG. Extracellular matrix remodeling following myocardial injury. Ann M ed. 2003;35:316-326.

7. Creemers E, Cleutjens J, Smits J, Heymans S, Moons L, Collen D, Daemen M, Carmeliet P. Disruption of the plasminogen gene in mice abolishes wound healing after myocardial infarction. Am J Pathol. 2000;156:1865-73.

8. Patten RD, Aronovitz MJ, Deras-Mejia L, Pandian NG, Hanak GG, Smith JJ, Mendelsohn ME, Konstam MA. Ventricular remodeling in a mouse model of myocardial infarction. Am J Physiol. 1998;274:HI8I2HI820.

9. Rubart M, Wang E, Dunn KW, Field LJ. Two-photon molecular excitation imaging of Ca2+ transients in Langendorff-perfused mouse hearts. Am J Physiol Cell Physiol. 2003;284:CI 654-CI 668.

10. Rubart M, Pasumarthi KB, Nakajima H, Soonpaa MH, Nakajima HO, Field LJ. Physiological coupling of donor and host cardiomyocytes after cellular transplantation. Circ Res. 2003;92:1217-I 224.

II. Erdo F, Buhrle C, Blunk J, Hoehn M, Xia Y, Fleischmann B, Focking M, Kustermann E, Kolossov E, Hescheler J, Hossmann KA, Trapp T. Host-dependent tumorigenesis of embryonic stem cell transplantation in experimental stroke.J Cereb Blood Flow M etab. 2003;23:780-785.

12. Draper JS, Smith K, Gokhale P, Moore HD, Maltby E, Johnson J, Meisner L, Zwaka TP,Thomson JA,Andrews PW. Recurrent gain of chromosomes $17 \mathrm{q}$ and $\mathrm{I} 2$ in cultured human embryonic stem cells. Nat Biotechnol. 2004:22:53-54.

13. Takahashi K, Tanabe K, Ohnuki M, Narita M, Ichisaka T, Tomoda K, Yamanaka S. Induction of pluripotent stem cells from adult human fibroblasts by defined factors. Cell. 2007;131:861-872.

14. Yu J,Vodyanik MA, Smuga-Otto K, Antosiewicz-Bourget J, Frane JL, Tian S, Nie J, Jonsdottir GA, Ruotti V, Stewart R, Slukvin II, Thomson JA. Induced Pluripotent Stem Cell Lines Derived from Human Somatic Cells. Science. 2007.

15. Rubart M, Field LJ. Cardiac regeneration: repopulating the heart. Annu Rev Physiol. 2006;68:29-49.

16. Gnecchi M, He H, Liang OD, Melo LG, Morello F, Mu H, Noiseux N, Zhang L, Pratt RE, Ingwall JS, Dzau V]. Paracrine action accounts for marked protection of ischemic heart by Akt-modified mesenchymal stem cells. Nat M ed. 2005; I I:367-368.

17. Mirotsou M, Zhang Z, Deb A, Zhang L, Gnecchi M, Noiseux N, Mu H, Pachori A, Dzau V. Secreted frizzled related protein 2 (Sfrp2) is the key Akt-mesenchymal stem cell-released paracrine factor mediating myocardial survival and repair. Proc Natl Acad Sci U S A. 2007; 104:1643-1648. 
18. Fazel S, Cimini M, Chen L, Li S,Angoulvant D, Fedak P,Verma S,Weisel RD, Keating A, Li RK. Cardioprotective c-kit+ cells are from the bone marrow and regulate the myocardial balance of angiogenic cytokines.J Clin Invest. 2006; I 16:1865-1877.

19. Yoshioka T, Ageyama N, Shibata H, Yasu T, Misawa Y, Takeuchi K, Matsui K, Yamamoto K, Terao K, Shimada $\mathrm{K}$, lkeda U, Ozawa K, Hanazono Y. Repair of infarcted myocardium mediated by transplanted bone marrow-derived CD34+ stem cells in a nonhuman primate model. Stem Cells. 2005;23:355-364.

20. Limbourg FP, Ringes-Lichtenberg S, Schaefer A, Jacoby C, Mehraein Y, Jager MD, Limbourg A, Fuchs M, Klein G, Ballmaier M, Schlitt HJ, Schrader J, Hilfiker-Kleiner D, Drexler H. Haematopoietic stem cells improve cardiac function after infarction without permanent cardiac engraftment. Eur J Heart Fail. 2005;7:722-729.

21. Feygin J, Mansoor A, Eckman P, Swingen C, Zhang J. Functional and bioenergetic modulations in the infarct border zone following autologous mesenchymal stem cell transplantation. Am J Physiol Heart Circ Physiol. 2007;293:HI772-HI780.

22. Amsalem Y, Mardor Y, Feinberg MS, Landa N, Miller L, Daniels D, Ocherashvilli A, Holbova R, Yosef O, Barbash IM, Leor J. Iron-oxide labeling and outcome of transplanted mesenchymal stem cells in the infarcted myocardium. Circulation. 2007; 1 16:138-145.

23. Breitbach M, Bostani T, Roell W, Xia Y, Dewald O, Nygren JM, Fries JW,Tiemann K, Bohlen H, Hescheler J, Welz A, Bloch W, Jacobsen SE, Fleischmann BK. Potential risks of bone marrow cell transplantation into infarcted hearts. Blood. 2007; 1 10:1362-1369.

24. Pelacho B, Nakamura Y, Zhang J, Ross J, Heremans Y, Nelson-Holte M, Lemke B, Hagenbrock J, Jiang Y, Prosper F, Luttun A, Verfaillie CM. Multipotent adult progenitor cell transplantation increases vascularity and improves left ventricular function after myocardial infarction. JTissue Eng Regen M ed. 2007; 1:5 1-59.

25. Zeng L, Hu Q, Wang X, Mansoor A, Lee J, Feygin J, Zhang G, Suntharalingam P, Boozer S, Mhashilkar A, Panetta CJ, Swingen C, Deans R, From AH, Bache RJ, Verfaillie CM, Zhang J. Bioenergetic and functional consequences of bone marrow-derived multipotent progenitor cell transplantation in hearts with postinfarction left ventricular remodeling. Circulation. 2007; II 5:1866-1875.

26. Bock-Marquette I, Saxena A,White MD, Dimaio JM, Srivastava D.Thymosin beta4 activates integrin-linked kinase and promotes cardiac cell migration, survival and cardiac repair. Nature. 2004;432:466-472.

27. Smart N, Risebro CA, Melville AA, Moses K, Schwartz RJ, Chien KR, Riley PR. Thymosin beta4 induces adult epicardial progenitor mobilization and neovascularization. Nature. 2007;445: 177- 182.

28. Limana F, Zacheo A, Mocini D, Mangoni A, Borsellino G, Diamantini A, De Mori R, Battistini L, Vigna E, Santini M, Loiaconi V, Pompilio G, Germani A, Capogrossi MC. Identification of myocardial and vascular precursor cells in human and mouse epicardium. Circ Res. 2007; 101:1255-1265.

29. Winter EM, Grauss RW, Hogers B, van Tuyn J, van der GR, Lie-Venema H, Steijn RV, Maas S, DeRuiter MC, deVries AA, Steendijk P, Doevendans PA, van der LA, Poelmann RE, Schalij MJ,Atsma DE, Gittenberger-De Groot AC. Preservation of left ventricular function and attenuation of remodeling after transplantation of human epicardium-derived cells into the infarcted mouse heart. Circulation. 2007;116:917-927.

30. Lepilina A, Coon AN, Kikuchi K, Holdway JE, Roberts RW, Burns CG, Poss KD.A dynamic epicardial injury response supports progenitor cell activity during zebrafish heart regeneration. Cell. 2006; 127:607-619.

31. Cho HJ, Lee N, Lee JY, Choi YJ, li M, Wecker A, Jeong JO, Curry C, Qin G, Yoon YS. Role of host tissues for sustained humoral effects after endothelial progenitor cell transplantation into the ischemic heart. Exp M ed. 2007;204:3257-3269.

32. Walter DH, Haendeler J, Reinhold J, Rochwalsky U, Seeger F, Honold J, Hoffmann J, Urbich C, Lehmann R, Arenzana-Seisdesdos F,Aicher A, Heeschen C, Fichtlscherer S, Zeiher AM, Dimmeler S. Impaired CXCR4 signaling contributes to the reduced neovascularization capacity of endothelial progenitor cells from patients with coronary artery disease. Circ Res. 2005;97: I I42-I I5 I. 
33. Cruz-Gonzalez I, Pabon P, Rodriguez-Barbero A, Martin-Moreiras J, Pericacho M, Sanchez PL, Ramirez V, Sanchez-Ledesma M, Martin-Herrero F, Jimenez-Candil J, Maree AO, Sanchez-Rodriguez A, MartinLuengo C, Lopez-Novoa JM. Identification of serum endoglin as a novel prognostic marker after acute myocardial infarction. J Cell M ol Med. 2007.

34. Ferreira LS, Gerecht S, Shieh HF, Watson N, Rupnick MA, Dallabrida SM, Vunjak-Novakovic G, Langer R. Vascular progenitor cells isolated from human embryonic stem cells give rise to endothelial and smooth muscle like cells and form vascular networks in vivo. Circ Res. 2007;101:286-294.

35. Huang H, Zhao X, Chen L, Xu C, Yao X, Lu Y, Dai L, Zhang M. Differentiation of human embryonic stem cells into smooth muscle cells in adherent monolayer culture. Biochem Biophys Res Commun. 2006;351:321-327.

36. Levenberg S, Golub JS,Amit M, Itskovitz-Eldor J, Langer R. Endothelial cells derived from human embryonic stem cells. Proc Natl Acad Sci U S A. 2002;99:4391-4396.

37. Kehat I, Kenyagin-Karsenti D, Snir M, Segev H, Amit M, Gepstein A, Livne E, Binah O, Itskovitz-Eldor J, Gepstein L. Human embryonic stem cells can differentiate into myocytes with structural and functional properties of cardiomyocytes. J Clin Invest. 200 I;108:407-4I4.

38. Kehat I, Gepstein A, Spira A, Itskovitz-Eldor J, Gepstein L. High-resolution electrophysiological assessment of human embryonic stem cell-derived cardiomyocytes: a novel in vitro model for the study of conduction. Circ Res. 2002;91:659-661.

39. Mummery C, Ward-van Oostwaard D, Doevendans P, Spijker R, van den BS, Hassink R, van der HM, Opthof T, Pera M, de la Riviere AB, Passier R, Tertoolen L. Differentiation of human embryonic stem cells to cardiomyocytes: role of coculture with visceral endoderm-like cells. Circulation. 2003; 107:2733-2740.

40. He JQ, Ma Y, Lee Y,Thomson JA, Kamp TJ. Human embryonic stem cells develop into multiple types of cardiac myocytes: action potential characterization. Circ Res. 2003;93:32-39.

4I. Xu C, Police S, Rao N, Carpenter MK. Characterization and enrichment of cardiomyocytes derived from human embryonic stem cells. Circ Res. 2002;91:501-508.

42. Beqqali A, Kloots J, Ward-van Oostwaard D, Mummery C, Passier R. Genome-wide transcriptional profiling of human embryonic stem cells differentiating to cardiomyocytes. Stem Cells. 2006.

43. Passier R, Oostwaard DW, Snapper J, Kloots J, Hassink RJ, Kuijk E, Roelen B, de la Riviere AB, Mummery $C$. Increased cardiomyocyte differentiation from human embryonic stem cells in serum-free cultures. Stem Cells. 2005;23:772-780.

44. Kehat I, Khimovich L, Caspi O, Gepstein A, Shofti R, Arbel G, Huber I, Satin J, Itskovitz-Eldor J, Gepstein L. Electromechanical integration of cardiomyocytes derived from human embryonic stem cells. Nat Biotechnol. 2004;22:1282-1289.

45. Xue T, Cho HC, Akar FG, Tsang SY, Jones SP, Marban E, Tomaselli GF, Li RA. Functional integration of electrically active cardiac derivatives from genetically engineered human embryonic stem cells with quiescent recipient ventricular cardiomyocytes: insights into the development of cell-based pacemakers. Circulation. 2005; I I I: I I-20.

46. van Laake LW, Passier R, Monshouwer-Kloots J, Verkleij AJ, Lips DJ, Freund C, Den Ouden K, Wardvan Oostwaard D, Korving J, Tertoolen LG, van Echteld CJ, Doevendans PA, Mummery CL. Human embryonic stem cell-derived cardiomyocytes survive and mature in the mouse heart and transiently improve function after myocardial infarction . Stem Cell Research. 2007;1:9-24.

47. Laflamme MA, Gold J, Xu C, Hassanipour M, Rosler E, Police S, Muskheli V, Murry CE. Formation of human myocardium in the rat heart from human embryonic stem cells. Am J Pathol. 2005;167:663-67I.

48. Laflamme MA, Chen KY, Naumova AV, MuskheliV, Fugate JA, Dupras SK, Reinecke H, Xu C, Hassanipour M, Police S, O'sullivan C, Collins L, Chen Y, Minami E, Gill EA, Ueno S, Yuan C, Gold J, Murry CE. Cardiomyocytes derived from human embryonic stem cells in pro-survival factors enhance function of infarcted rat hearts. Nat Biotechnol. 2007;25:1015-1024. 
49. Leor J, Gerecht-Nir S, Cohen S, Miller L, Holbova R, Ziskind A, Shachar M, Feinberg MS, Guetta E, Itskovitz-Eldor J. Human embryonic stem cell transplantation to repair the infarcted myocardium. Heart. 2007.

50. Ebelt $\mathrm{H}$, Jungblut M, Zhang Y, Kubin T, Kostin S, Technau A, Oustanina S, Niebrugge S, Lehmann J, Werdan $\mathrm{K}, \mathrm{Braun}$ T. Cellular cardiomyoplasty: improvement of left ventricular function correlates with the release of cardioactive cytokines. Stem Cells. 2006.

5I. Springer ML, Sievers RE, Viswanathan MN, Yee MS, Foster E, Grossman W, Yeghiazarians Y. Closed-chest cell injections into mouse myocardium guided by high-resolution echocardiography. Am J Physiol Heart Circ Physiol. 2005;289:HI 307-HI3 4.

52. Thum T, Galuppo P, Wolf C, Fiedler J, Kneitz S, van Laake LW, Doevendans PA, Mummery CL, Borlak J, Haverich A, Gross C, Engelhardt S, Ertl G, Bauersachs J. MicroRNAs in the human heart: a clue to fetal gene reprogramming in heart failure. Circulation. 2007;1 16:258-267.

53. Zhao Y, Ransom JF, Li A, Vedantham V, von Drehle M, Muth AN, Tsuchihashi T, McManus MT, Schwartz RJ, Srivastava D. Dysregulation of cardiogenesis, cardiac conduction, and cell cycle in mice lacking miRNAI-2. Cell. 2007;129:303-3 I7.

54. Roell W, Lu ZJ, Bloch W, Siedner S, Tiemann K, Xia Y, Stoecker E, Fleischmann M, Bohlen H, Stehle R, Kolossov E, Brem G,Addicks K, Pfitzer G,Welz A, Hescheler J, Fleischmann BK. Cellular cardiomyoplasty improves survival after myocardial injury. Circulation. 2002; 105:2435-244I.

55. Liu J, Fu JD, Siu CW, Li RA. Functional Sarcoplasmic Reticulum for Calcium-Handling of Human Embryonic Stem Cell-Derived Cardiomyocytes: Insights for Driven Maturation. Stem Cells. 2007.

56. Reinecke H, Zhang M, Bartosek T, Murry CE. Survival, integration, and differentiation of cardiomyocyte grafts: a study in normal and injured rat hearts. Circulation. 1999; 100:193-202.

57. Miragoli M, Salvarani N, Rohr S. Myofibroblasts induce ectopic activity in cardiac tissue. Circ Res. 2007;101:755-758.

58. Zimmermann WH, Melnychenko I,Wasmeier G, Didie M, Naito H, Nixdorff U, Hess A, Budinsky L, Brune $\mathrm{K}$, Michaelis B, Dhein S, Schwoerer A, Ehmke H, Eschenhagen T. Engineered heart tissue grafts improve systolic and diastolic function in infarcted rat hearts. Nat M ed. 2006; 12:452-458.

59. Feinberg AW, Feigel A, Shevkoplyas SS, Sheehy S, Whitesides GM, Parker KK. Muscular thin films for building actuators and powering devices. Science. 2007;317:1366-1370.

60. Furuta A, Miyoshi S, Itabashi Y, Shimizu T, Kira S, Hayakawa K, Nishiyama N, Tanimoto K, Hagiwara Y, Satoh T, Fukuda K, Okano T, Ogawa S. Pulsatile cardiac tissue grafts using a novel three-dimensional cell sheet manipulation technique functionally integrates with the host heart, in vivo. Circ Res. 2006;98:705-7I 2.

6I. Moelker AD, Baks T,Wever KM, Spitskovsky D,Wielopolski PA, van Beusekom HM, van Geuns RJ,Wnendt S, Duncker DJ, van der Giessen WJ. Intracoronary delivery of umbilical cord blood derived unrestricted somatic stem cells is not suitable to improve LV function after myocardial infarction in swine.J M ol Cell Cardiol. 2007; 42:735-745.

62. van Laake LW, Passier R, Monshouwer-Kloots J, Nederhoff MG, Ward-van Oostwaard D, Field LJ, van Echteld CJ, Doevendans PA, Mummery CL. Monitoring of cell therapy and assessment of cardiac function using magnetic resonance imaging in a mouse model of myocardial infarction. Nat Protoc. 2007;2:255 I2567.

63. Shim JH, Kim SE, Woo DH, Kim SK, Oh CH, McKay R, Kim JH. Directed differentiation of human embryonic stem cells towards a pancreatic cell fate. Diabetologia. 2007;50:1228-1238.

64. Caspi O, Lesman A, Basevitch Y, Gepstein A,Arbel G, Habib IH, Gepstein L, Levenberg S.Tissue engineering of vascularized cardiac muscle from human embryonic stem cells. Circ Res. 2007;100:263-272.

65. Duan Y, Catana A, Meng Y, Yamamoto N, He S, Gupta S, Gambhir SS, Zern MA. Differentiation and Enrichment of Hepatocyte-Like Cells from Human Embryonic Stem Cells in Vitro and in Vivo. Stem Cells. 2007. 
66. Huber I, Itzhaki I, Caspi O,Arbel G, Tzukerman M, Gepstein A, Habib M,Yankelson L, Kehat I, Gepstein L. Identification and selection of cardiomyocytes during human embryonic stem cell differentiation. FASEB J. 2007.

67. Anderson D, Self T, Mellor IR, Goh G, Hill SJ, Denning C. Transgenic enrichment of cardiomyocytes from human embryonic stem cells. MolTher. 2007;15:2027-2036. 
Color figures 

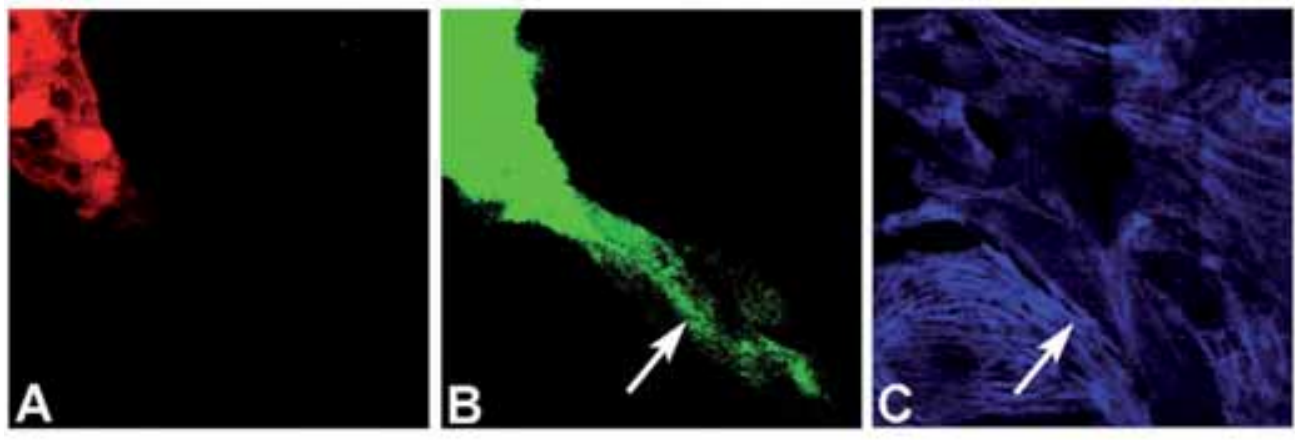

CH2, Figure 1. Co-culture of HESC-derived cardiomyocytes with human fetal cardiomyocytes leads to coupling and dye transfer between the two cell types.

PKH-26 labelled HESC cardiomyocytes (arrowhead in A) in co-culture with primary human cardiomyocytes transfer lucifer yellow, which is injected in the HESC-CM, to the primary human cells (B, arrow), indicating the ability to form de novo functional gap junctions. The identity of the injected cells as well as that of the cells to which the lucifer yellow transfers, is verified by staining with anti-tropomyosin antibodies (C; arrow indicates same cell as in panel B i.e. positive for both lucifer yellow and tropomyosin). This indicates that transfer occurs only between the
(tropomyosin-positive) cardiomyocytes. In panel A, the z-section of the CLSM is in the plane of the HESC-CM, whilst in $B$ and $C$, it is in the plane of the underlying primary human cells. Magnification 63x. 
Color figures | 195
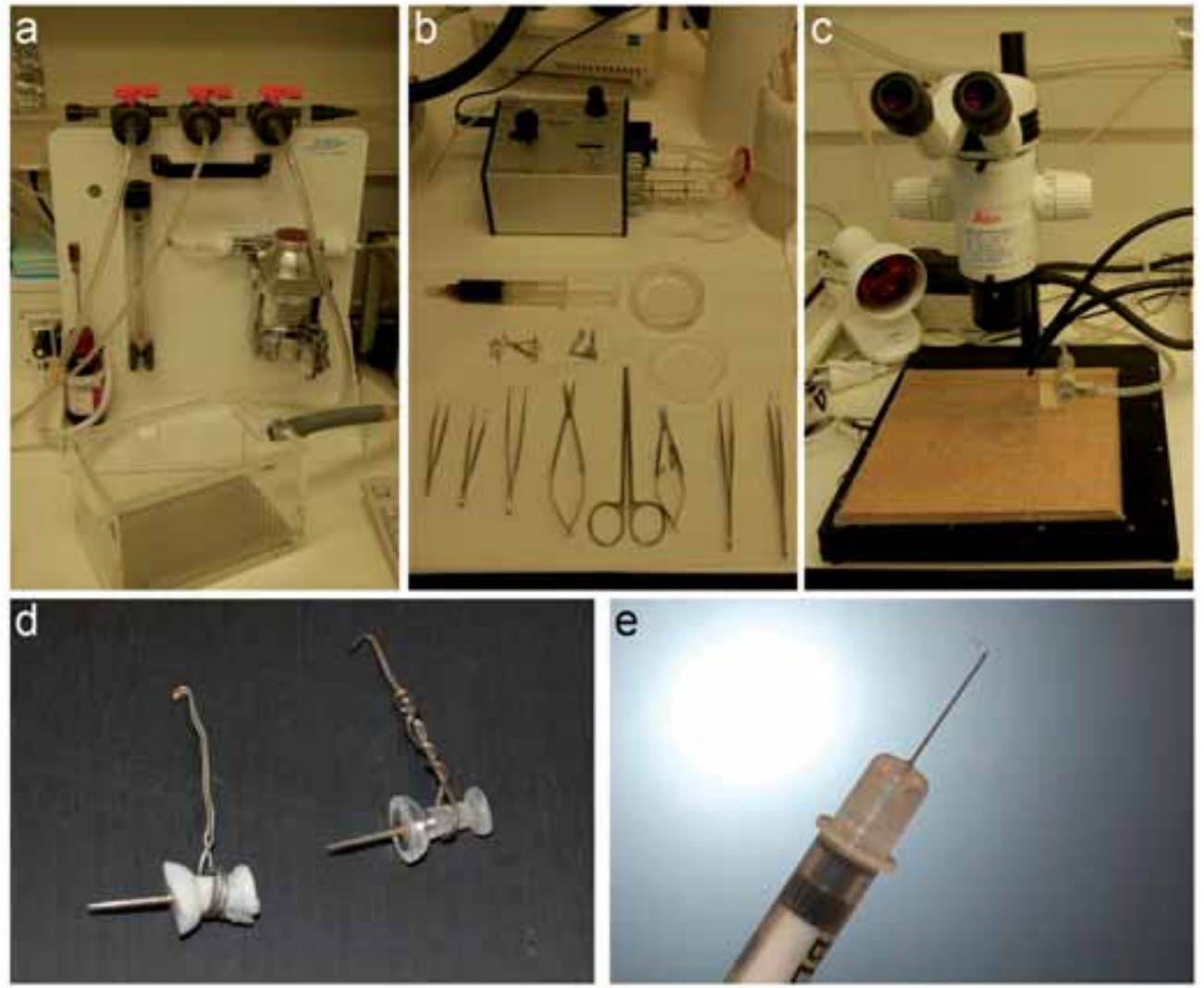

CH3, Figure 1. Surgical equipment. (a) Anesthesia system: oxygen and isoflurane flow to induction chamber, ventilator and mask. (b) Surgical tools and ventilator. (c) Surgery panel on heating plate. The anesthesia mask is attached to the panel. Note the heating lamp for recovery at $30 \mathrm{~cm}$ from where the mouse will be placed. (d) Muscle retractors. (e) Insulin syringe with attached 29G (bent) needle. 


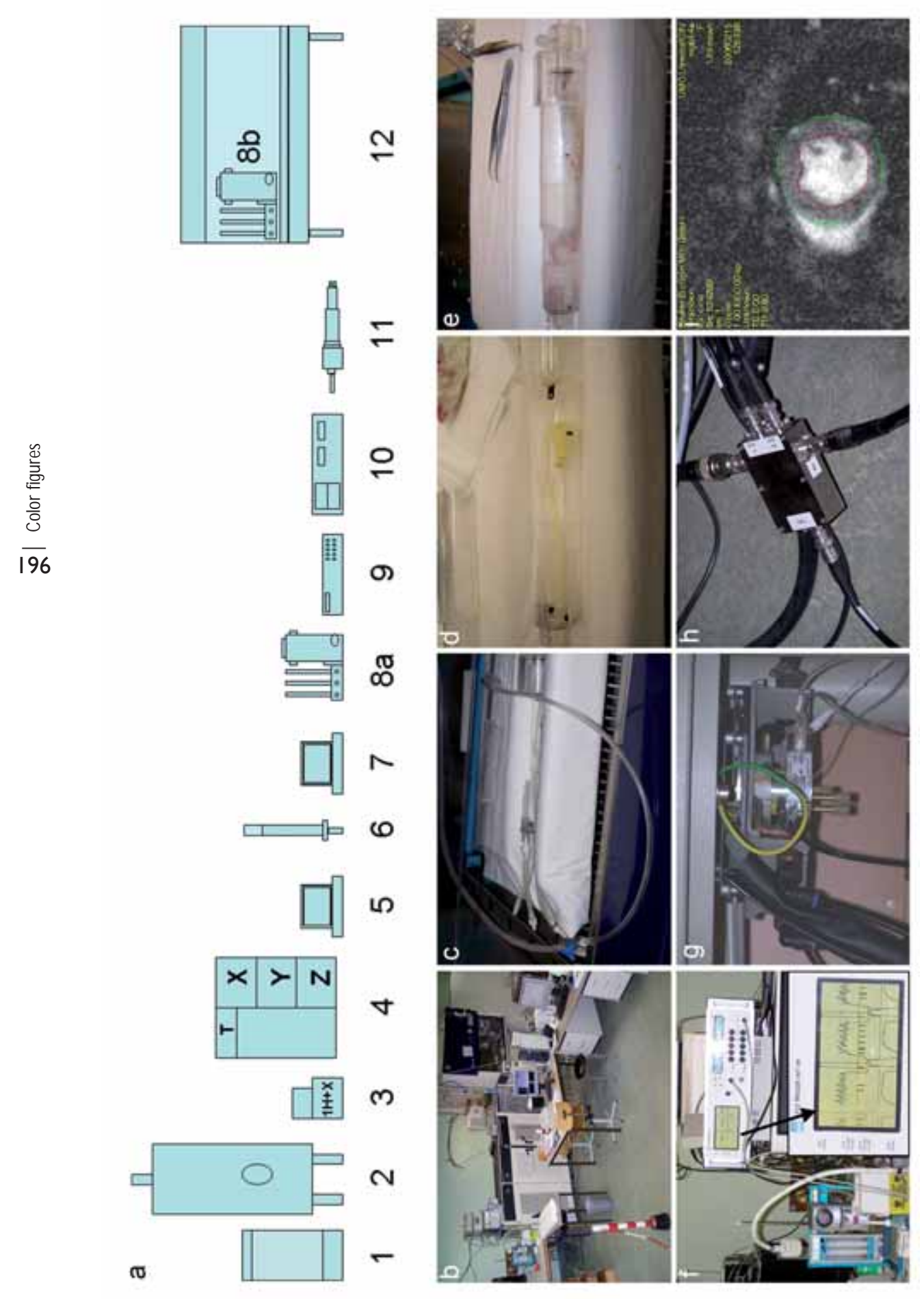


$\leftarrow$ CH3, Figure 2. Magnetic resonance imaging. (a) Schematic overview of the equipment (NB: Individual items have not been drawn to the same scale):

I= Haake water cooling unit for gradients

$2=$ Bruker $9.4 \mathrm{~T}$ magnet

$3=$ Bruker pre-amplifiers for RF-signals

$4=$ Bruker console including temperature control-unit and 3 gradient amplifiers

$5=\mathrm{PC}$ for registration of physiological parameters

6= Bruker probe head with $30 \mathrm{~mm}$ quadrature coil

$7=\mathrm{PC}$ for MRI and MRS data acquisition and processing

$8=$ Anesthesia units: 3 gas flow meters and isoflurane vaporizer

$9=$ Powerlab unit (signal converter/amplifier)

$10=$ Rapid trigger unit (in/out ECG, respiration and body temperature)

$\mathrm{II}=$ Mouse container fitting in probe head with $30 \mathrm{~mm}$ imaging coil

$12=$ Biosafety cabinet with anesthesia unit (8b)

(b) Overview of MRI accessories setup. (c) Mouse container, lid, anesthesia mask and connection of the anesthesia to the container. (d) Position of the balloon (respiration- and heart frequency sensor). (e) Mouse positioned in the container. (f) Rapid trigger unit and Powerlab. Inset: appropriate respiration- and heart frequency signals. (g) Position of the coil in the magnet and tune and match regulators (screws). (h) Rx and measuring cables connected to the quadrature splitter. (i) Circumference of the endocardial and epicardial wall. 

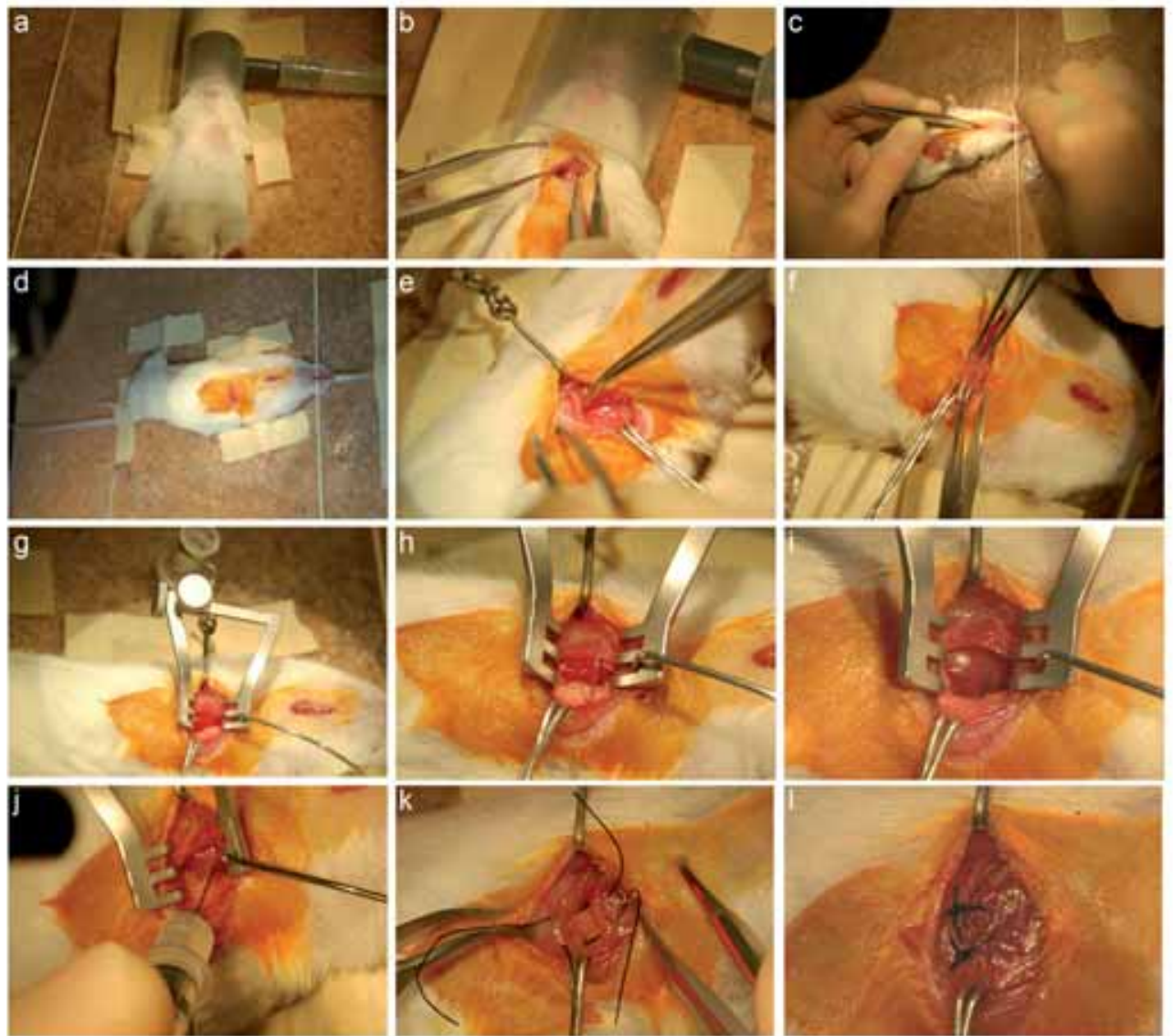

CH3, Figure 3. Myocardial infarction and cell injection. (a) Position of the mouse in the anesthesia mask. (b) Exposure of the trachea. (c) Intubation. (d) Position of the mouse for the remainder of the operation and skin incision. (e) The pectoral muscles are retracted and the intercostal space for thoracotomy is determined. (f) Thoracotomy (g) Position of the thorax retractor and sponge. (h) Insertion of the needle around the LAD. (i) Myocardial infarction after LAD ligation. (j) Insertion of the needle for cell injection. (k) Two sutures to close the thoracotomy, placed before the sponge is taken out. (I) The stitches are tightened; the ribs are approached and the thorax is closed. 

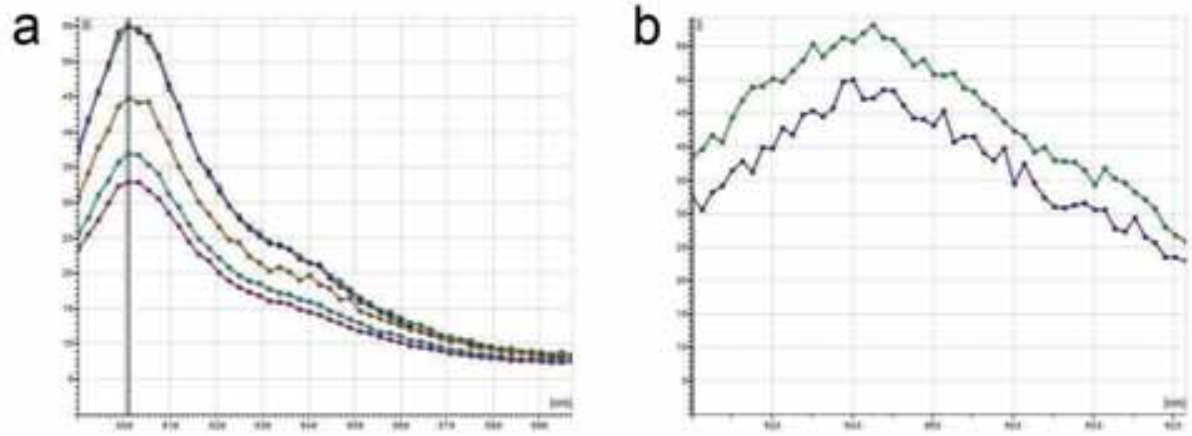

CH3, Figure 4. Emission wave length spectra. (a) GFP: sharp peak at $515 \mathrm{~nm}$ (b) Autofluorescent dead cells: broad peak around $550 \mathrm{~nm}$.
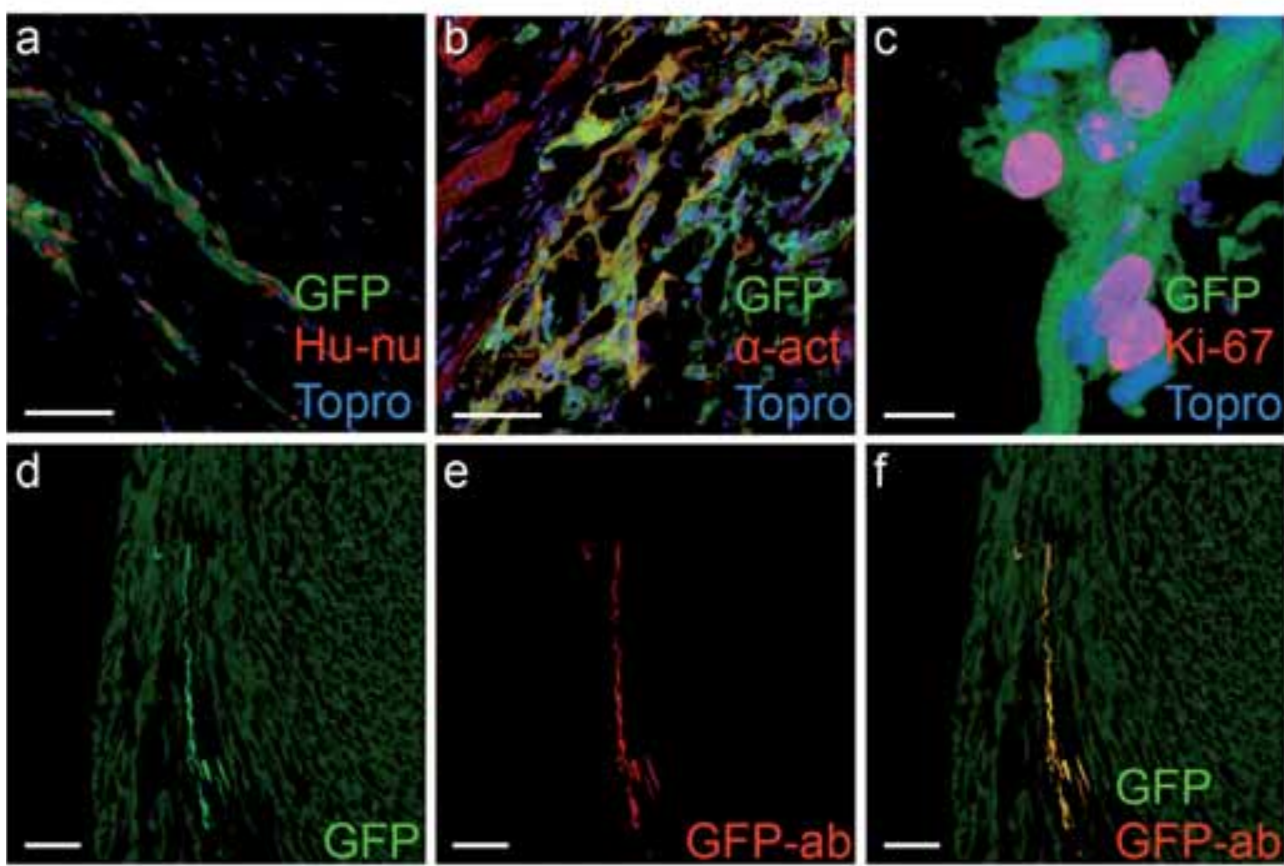

CH3, Figure 5. Immunofluorescent staining 3 weeks after injection of cardiomyocyte-enriched differentiated HES3-GFP. (a) Human nuclei. (b) $\alpha$-actinin. (c) Ki-67. (d) GFP epifluorescence. (e) GFP antibody on the same section as (d). (f) Overlay of (d) and (e). Scalebars $=50 \mu \mathrm{m}$ (a-b); $10 \mu \mathrm{m}$ (c); $100 \mu \mathrm{m}$ (d-f). 

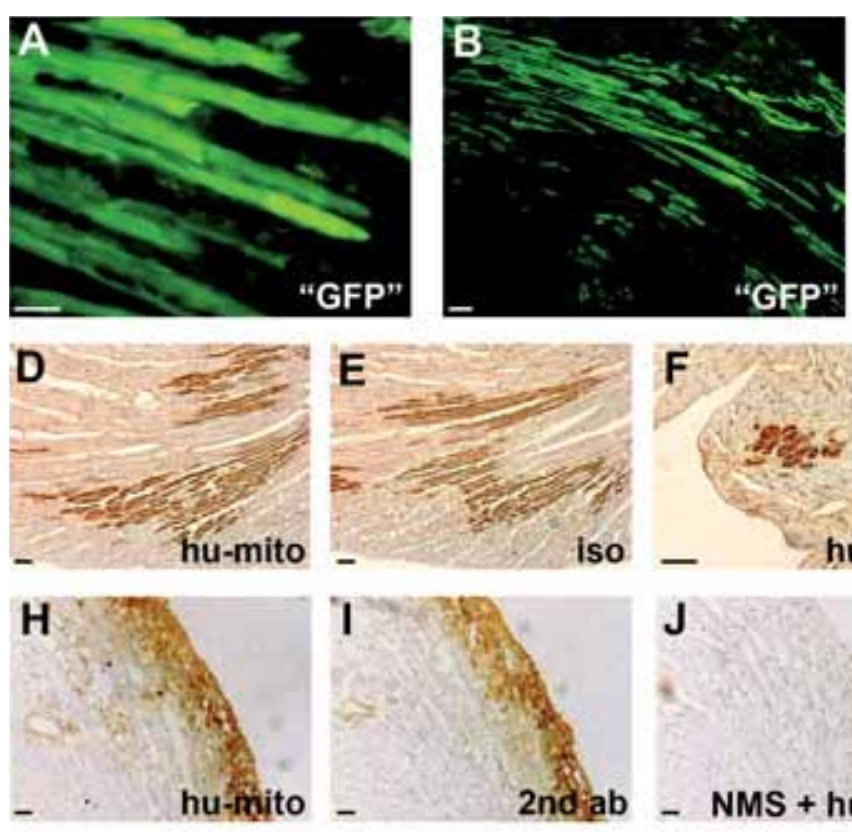

J
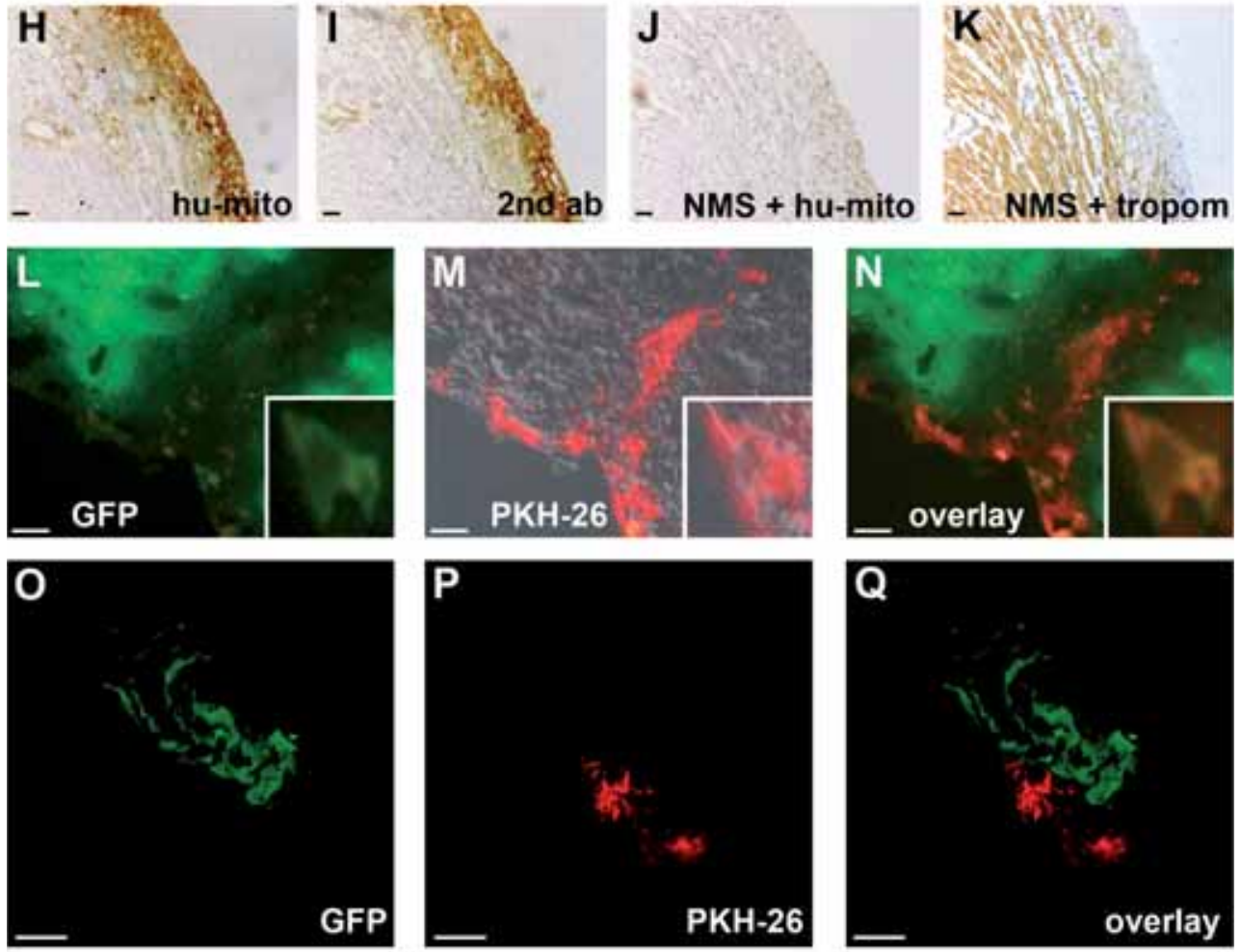

CH3, Supplementary Figure 1. Cell transplantation induces artifacts which may be mistaken for grafted cells.

(A) Sharply defined area with green cells near injection site (rehydrated paraffin section); overview of same region before (B) and after (C) DAB staining with mouse anti hu-mito.

(D-G) Complete overlap of staining with mouse anti hu-mito (D,F) and isotype control $(E, G)$ of adjacent paraffin sections. $(\mathrm{H}-\mathrm{K})$ Overlap of staining with ms anti hu-mito $(\mathrm{H})$ and secondary antibody only $(\mathrm{I})$; pre-treatment with NMS blocks non-specific staining for hu-mito $(J)$ and tropomyosin (K). (L-N) Injection of PKH-26 labeled HESCderived cells in a mouse expressing GFP constitutively in order to detect fusion events (cryo section). Inlay shows the only cell in which overlap was found: (L) GFP; (M) PKH; (N) overlay. (O-Q) PKH-26 labeled HES3-GFP derived cells injected in mouse heart: lack of overlap (Q) between GFP $(\mathrm{O})$ and PKH (P). Scale bars $50 \mu \mathrm{m}$. 
Color figures | 20 I
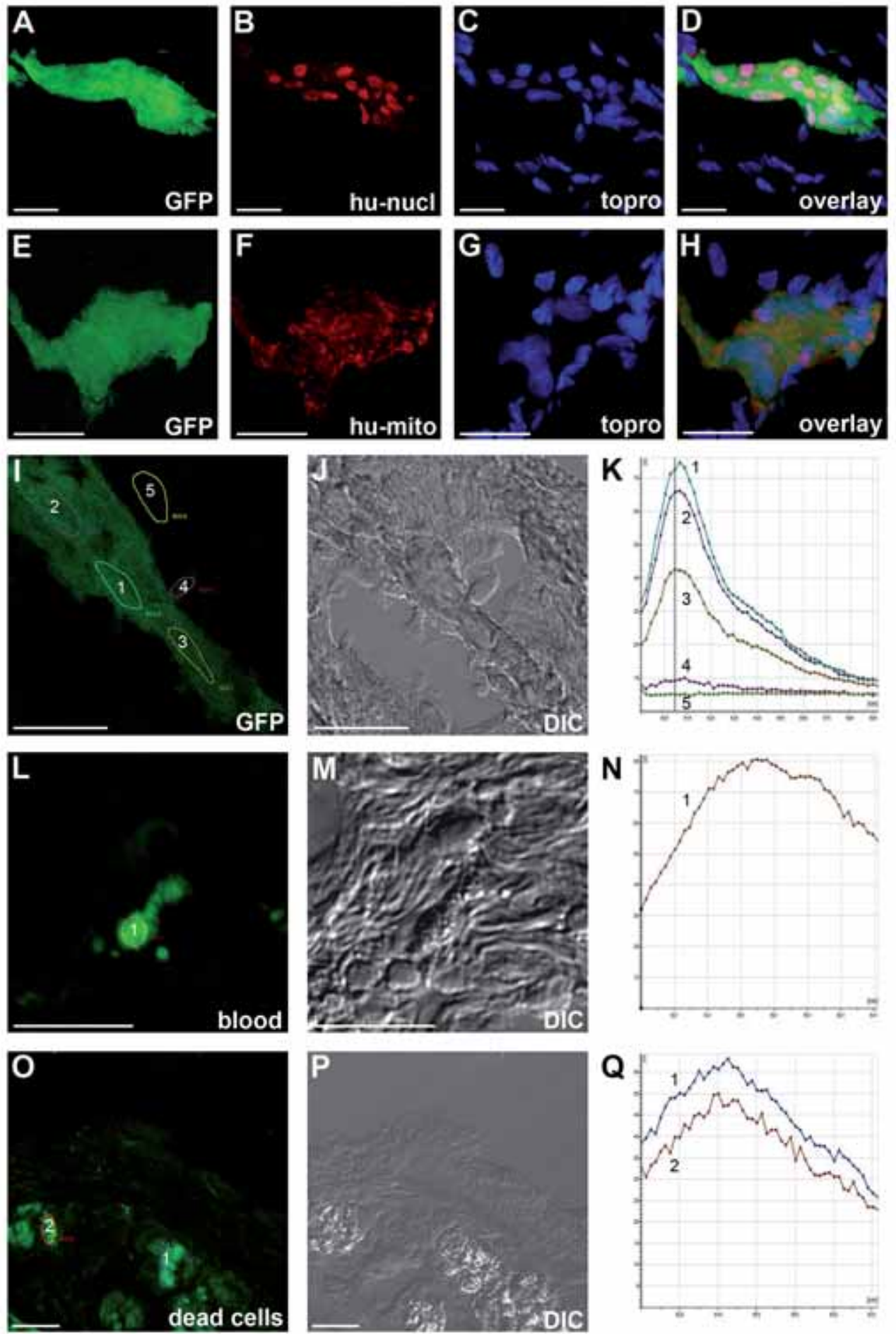

CH4, Figure 1. 

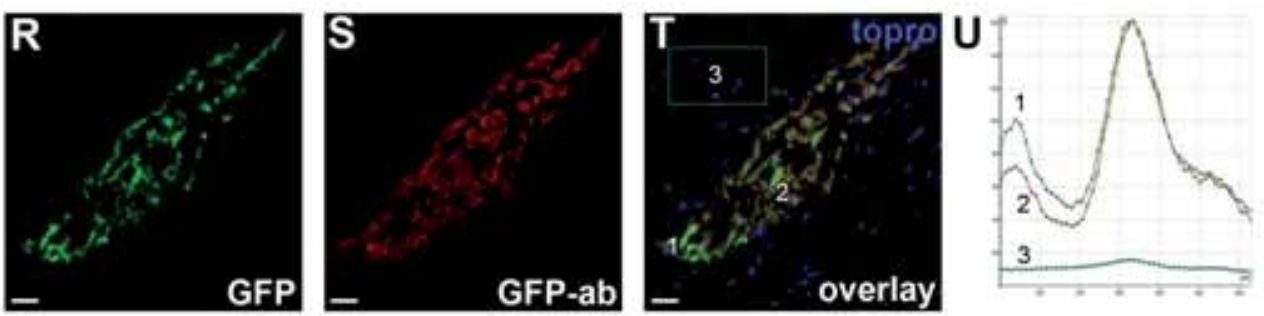

CH4, Figure 1.Tracking of grafted differentiated HESCs using multiple independent methods.

(A-H) Fluorescent staining of differentiated HES3-GFP in NOD-SCID mouse heart (A, E) GFP; (B) hu-nuclei; (C, G) topro-3; (D, H) overlay; (F) hu-mito. (I-K) Emission wave length spectrum of transplanted differentiated HES3-GFP: sharp peak at $5 I 5 \mathrm{~nm}$ (K); (I) GFP; (J) DIC. (L-N) Brightly autofluorescent erythrocytes; (L) GFP; (M) DIC; (N) emission wave length spectrum: broad peak around $570 \mathrm{~nm}$. (O-Q) Autofluorescent dead cardiomyocytes; (O) GFP; (P) DIC; (Q) emission wave length spectrum: broad peak around $550 \mathrm{~nm}$. (R-U) GFP-epifluorescence (R) overlaps with GFP-antibody staining (S); (T) overlay including topro-3; (U) double peak for GFP and cy3 (peak emission at 570 $\mathrm{nm}$ ) in emission wave length spectrum. (ROI; circles in matching color with spectrum curve) Region of interest. All panels represent observations 3 weeks after transplantation. Scale bars $20 \mu \mathrm{m}$. 
Color figures | 203
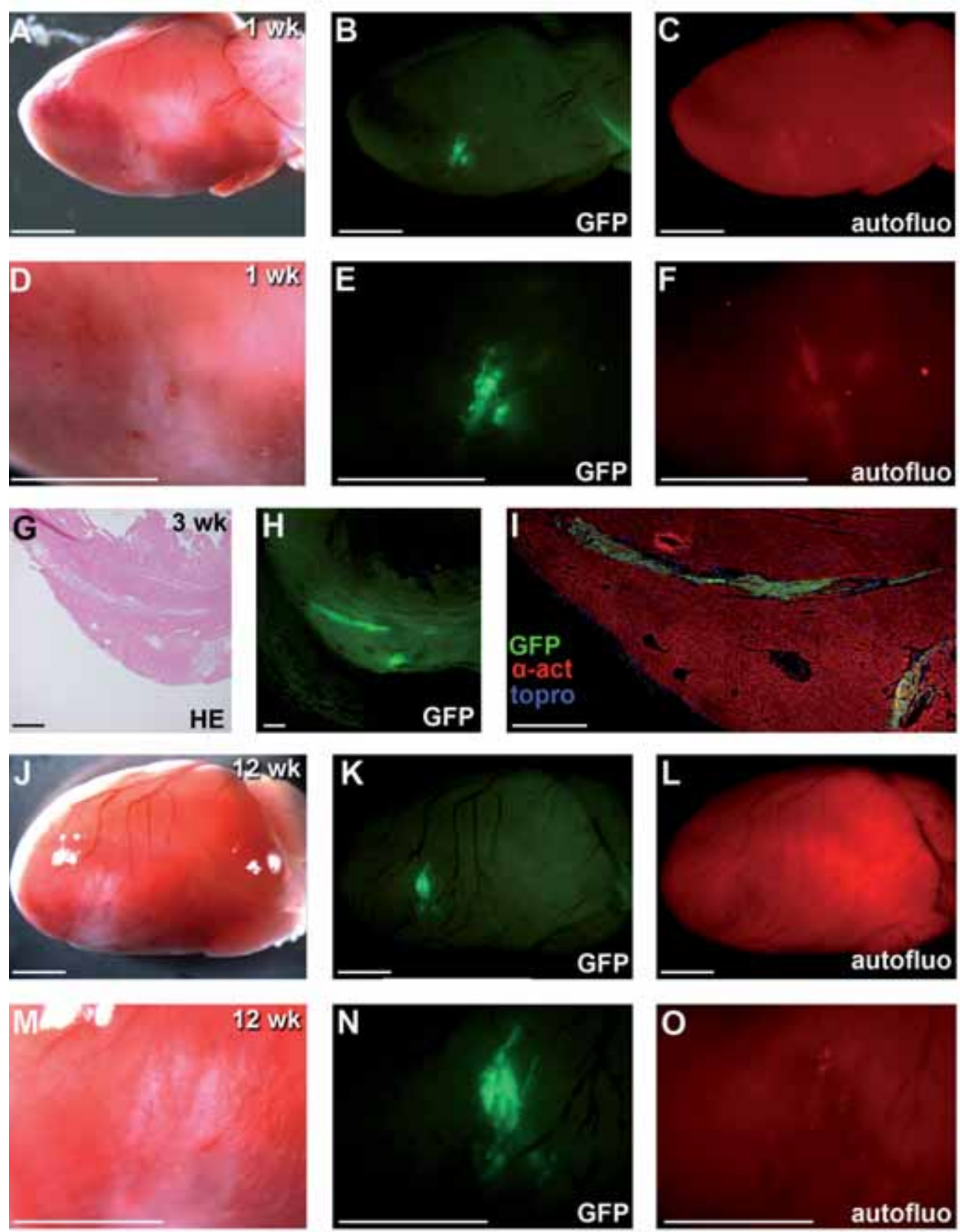

CH4, Figure 2. Graft development and maintenance in the mouse heart.

(A-F) Differentiated HES3-GFP graft in mouse heart I week after transplantation; (A, D) bright field; (B, E) GFP; (C, F) overexposure with filter for red fluorescence. (G-I) Graft 3 weeks after transplantation; (H) GFP epifluorescence in halved heart; (I) cryo section of same area (green: GFP, red: $\alpha$-actinin, blue: topro-3); (G) HE-staining of adjacent section. (J-O) Graft 12 weeks after transplantation; (J, M) bright field; (K, N) GFP; (L, O) overexposure with filter for red fluorescence. Scale bars $250 \mu \mathrm{m}$ 

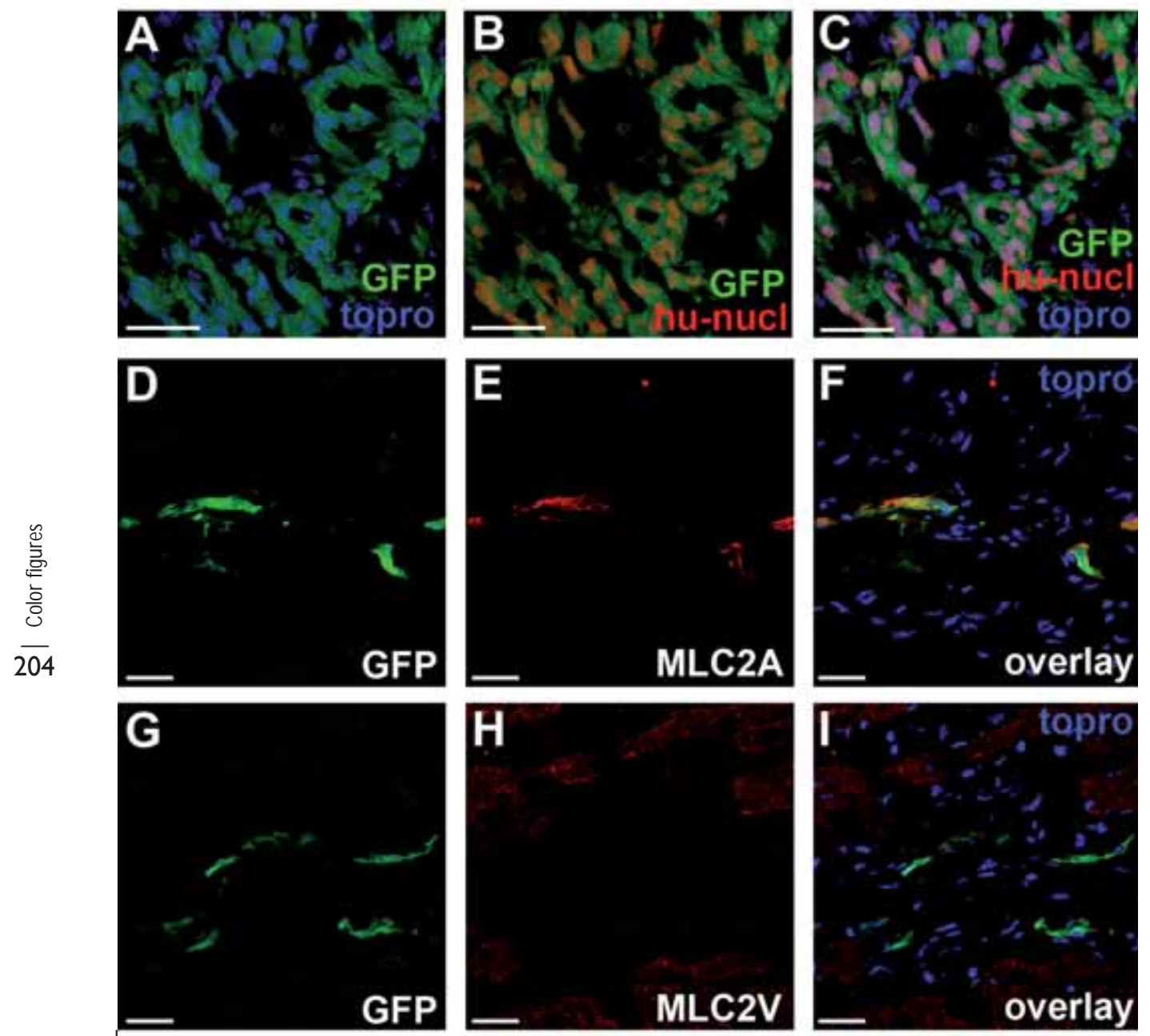

CH4, Figure 3. Survival of differentiated HESC in the mouse heart is independent of fusion with host cardiomyocytes.

(A-C) All nuclei in grafted GFP cells stain with hu-nuclei antibody; (green: GFP, red: hu-nuclei; blue: topro-3). (D-I) I week after transplantation HES3-GFP CM express only MLC2A (E) and no MLC2V protein (H); (D, G) GFP; (F, I) overlays including topro-3 (blue). Scale bars $20 \mu \mathrm{m}$.

$\rightarrow$ CH4, Figure 4. Selective survival of HESC-CM and loss of endodermal derivatives.

(A-L) Sarcomeric $\alpha$-actinin staining 2.5 days (A-D) and 3 weeks (E-L) after transplantation of HES3-GFP derived cells; (A, E, I) GFP; (B, F,J) $\alpha$-actinin; (C, G, K) overlays including topro-3 (blue); (D, H) DIC; (L) HE-staining of adjacent section to (I-K). (M-P) Identification of HES3-GFP derived endoderm I week after transplantation; (M) GFP; (N) troma-I; (O, P) overlays of GFP, troma-I and topro-3 (blue). (Q-T) Only host-derived vessels within graft; (Q) GFP: (R) PECAM-I; (S) overlay including topro-3 (blue); (T) DIC. (U) The proportion of GFP cells positive for cardiac markers increases between 2.5 days and 10 weeks; $(V)$ proportion of endoderm cells declines. $* * p<0.01$ for 2.5 days vs I week, 2.5 days vs 3 weeks and 2.5 days vs 10 weeks; \# $\mathrm{p}<0.0$ I for I week vs 3 weeks and I week vs 10 weeks; $\dagger \nmid \mathrm{p}<0.01$ for 3 weeks vs 10 weeks. Scale bars $20 \mu \mathrm{m}$. 
Color figures | 205
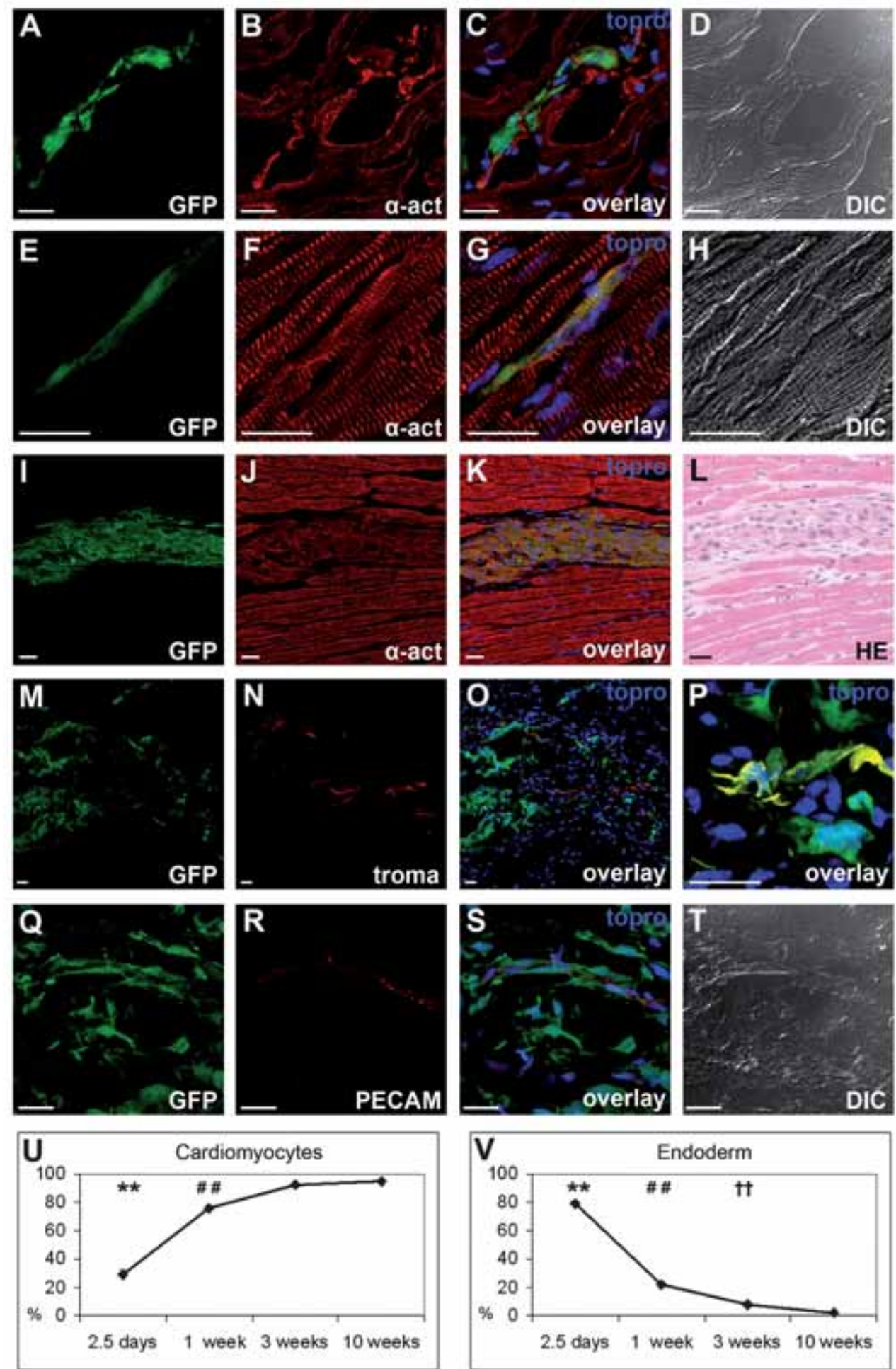

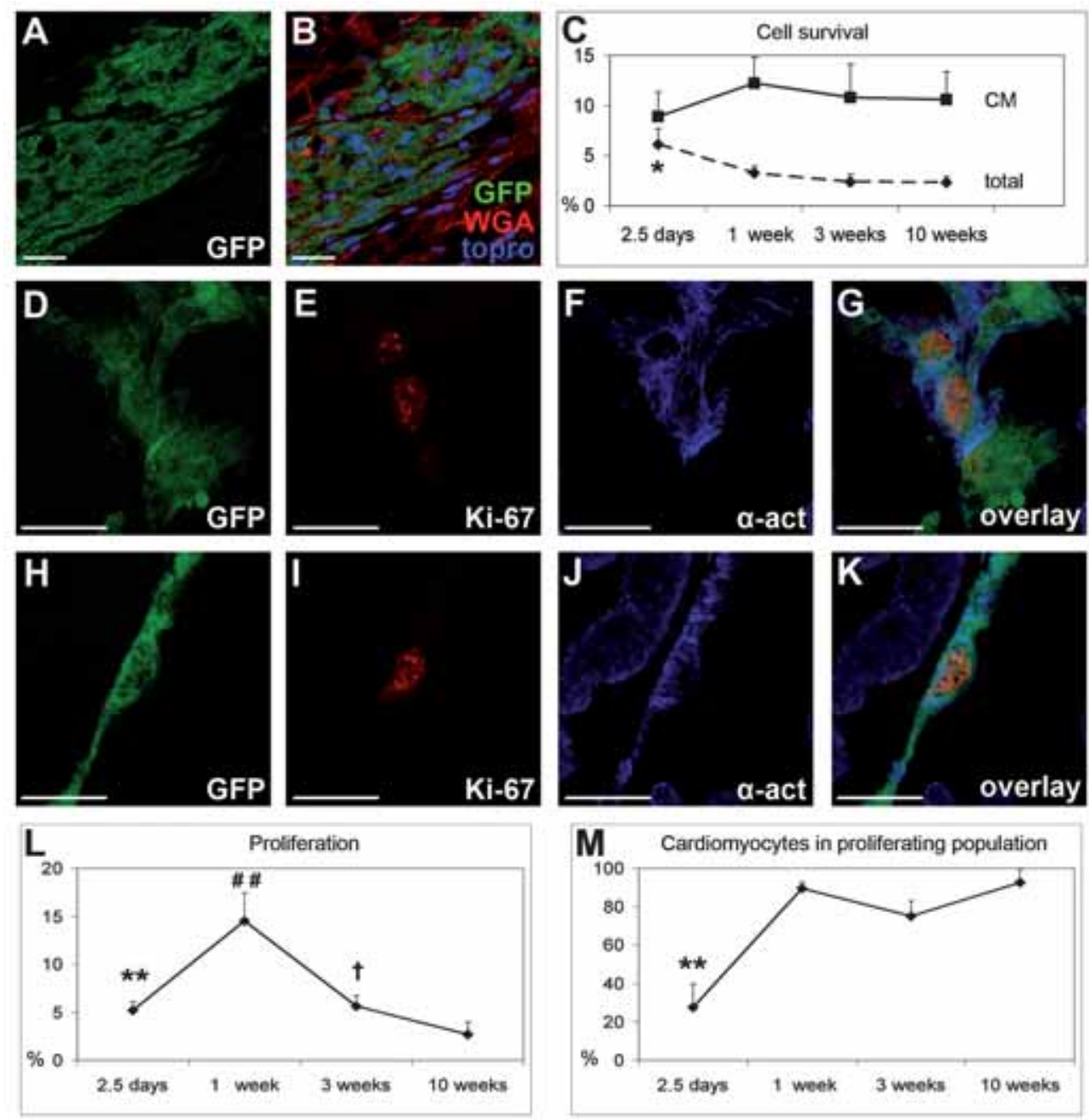

CH4, Figure 5. Quantification of transplantation efficiency and proliferation of grafted cells.

(A, B) The majority of the grafted cells are single-nucleated (green: GFP; red:WGA-TRITC as a membrane marker, blue: topro-3). (C) Percentage of cell survival at successive time-points for all cells (broken line) and CM specifically (solid line; assuming the injected cell preparation contained 20\% CM). ${ }_{p}<0.05$ for 2.5 days vs 3 weeks and 2.5 days vs 10 weeks. (D-K) Ki-67 staining of HES3-GFP CM at 2.5 days (D-G) and 10 weeks (H-K) after transplantation; (D, H) GFP; (E, I) Ki-67; (F, J) $\alpha$-actinin; (G, K) overlays. (L) Proportion of GFP cells positive for Ki-67. ** $p<0.0$ I for 2.5 days vs I week; $\mathrm{p}<0.01$ for I week vs 10 weeks and $p<0.05$ for I week vs 3 weeks; $\nmid p<0.05$ for 3 weeks vs 10 weeks. (M) Percentage of Ki-67 positive GFP cells that express cardiac markers. $* * 0<0.0$ I for 2.5 days vs I week and for 2.5 days vs 10 weeks and $p<0.05$ for 2.5 days vs 3 weeks. Scale bars $20 \mu \mathrm{m}$. 
Color figures | 207
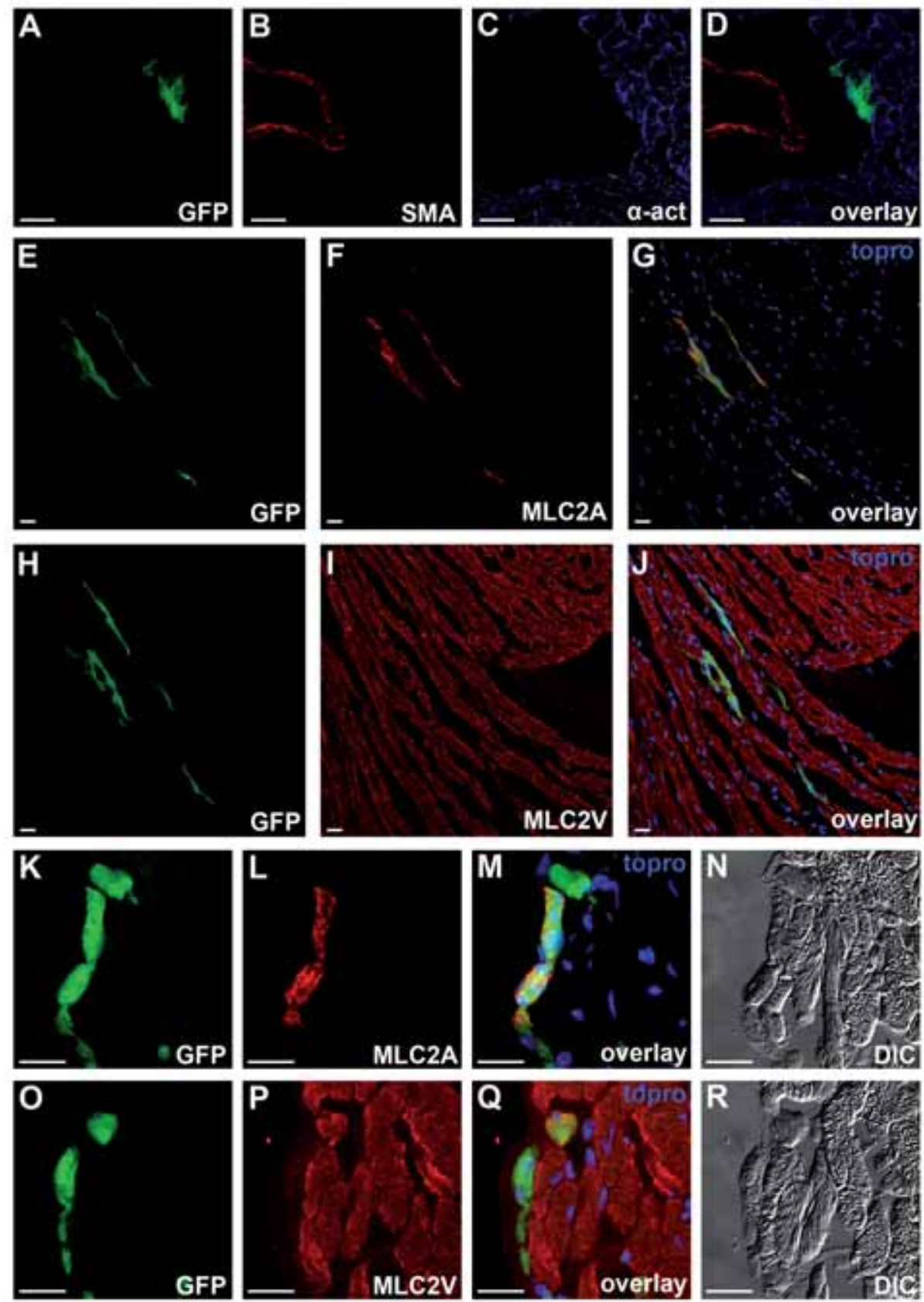

CH4, Figure 6. HESC-CM mature in vivo.

(A-D) HESC-CM lose SMA expression from I week after transplantation; (A) GFP; (B) SMA (red: vessel); (C) $\alpha$ actinin; (D) overlay. (E-J) Three weeks after transplantation HES3-GFP CM express only MLC2A or both MLC2A and MLC2V proteins (adjacent sections); (E, H) GFP; (F) MLC2A; (I) MLC2V; (G, J) overlays including topro-3 (blue). $(\mathrm{K}-\mathrm{R})$ Ten weeks after transplantation most HESC-CM express either MLC2A or MLC2V (adjacent sections); $(\mathrm{K}, \mathrm{O})$ GFP; (L) MLC2A; (P) MLC2V; (M, Q) overlays including topro-3 (blue); (N, R) DIC. Scale bars $20 \mu \mathrm{m}$. 

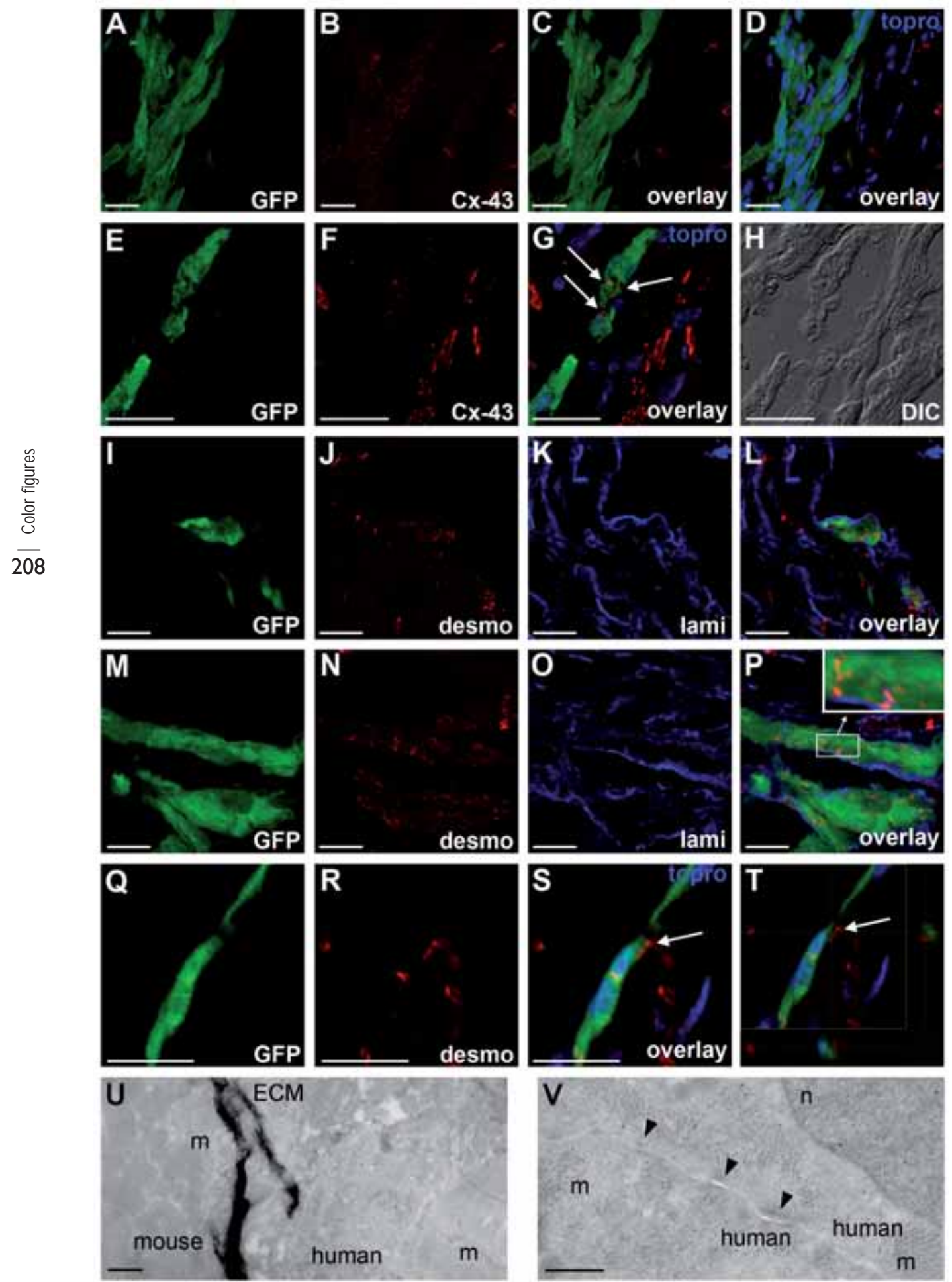
Color figures | 209

$\leftarrow$ CH4, Figure 7. HESC-CM functionally couple to each other and occasionally to mouse $\mathrm{CM}$.

(A-D) Cx-43 is present in 3 week old grafts, but not in a gap-junctional pattern; (A) GFP; (B) Cx-43; (C) overlay; (D) overlay including topro-3 (blue). (E-H) Relocation of $C x-43$ to gap junctions between donor cells 10 weeks after transplantation (indicated by arrows); (E) GFP; (F) Cx-43; (G) overlay including topro-3 (blue); (H) DIC. (I-T) Desmoplakin is unorganized at I week after transplantation (I-L), present in desmosomes within the graft at 3 weeks (M-P) and occasionally forms connections between donor and host cells at 10 weeks (indicated by arrows) (Q-T); (I, M, Q) GFP; (J, N, R) desmoplakin; (K, O) laminin as a marker of cell boundaries; (L, P) overlays; (S) overlay including topro-3 (blue); (T) overlay including topro-3 (blue) and line scans in $x$ - and y-directions. Bars $20 \mu \mathrm{m}$. (U) Electron microscopic image of a mouse (left) and human (right) cardiomyocyte 12 weeks after transplantation. Black dots represent immunogold labeling of GFP; (m) muscle fibers; (ECM) extracellular matrix. Scale bar $500 \mathrm{~nm}$. (V) Two human cardiomyocytes in a graft after 12 weeks. Black dots: GFP; (m) muscle fibers; (n) nucleus; arrowheads: desmosome. Scale bar $200 \mathrm{~nm}$.
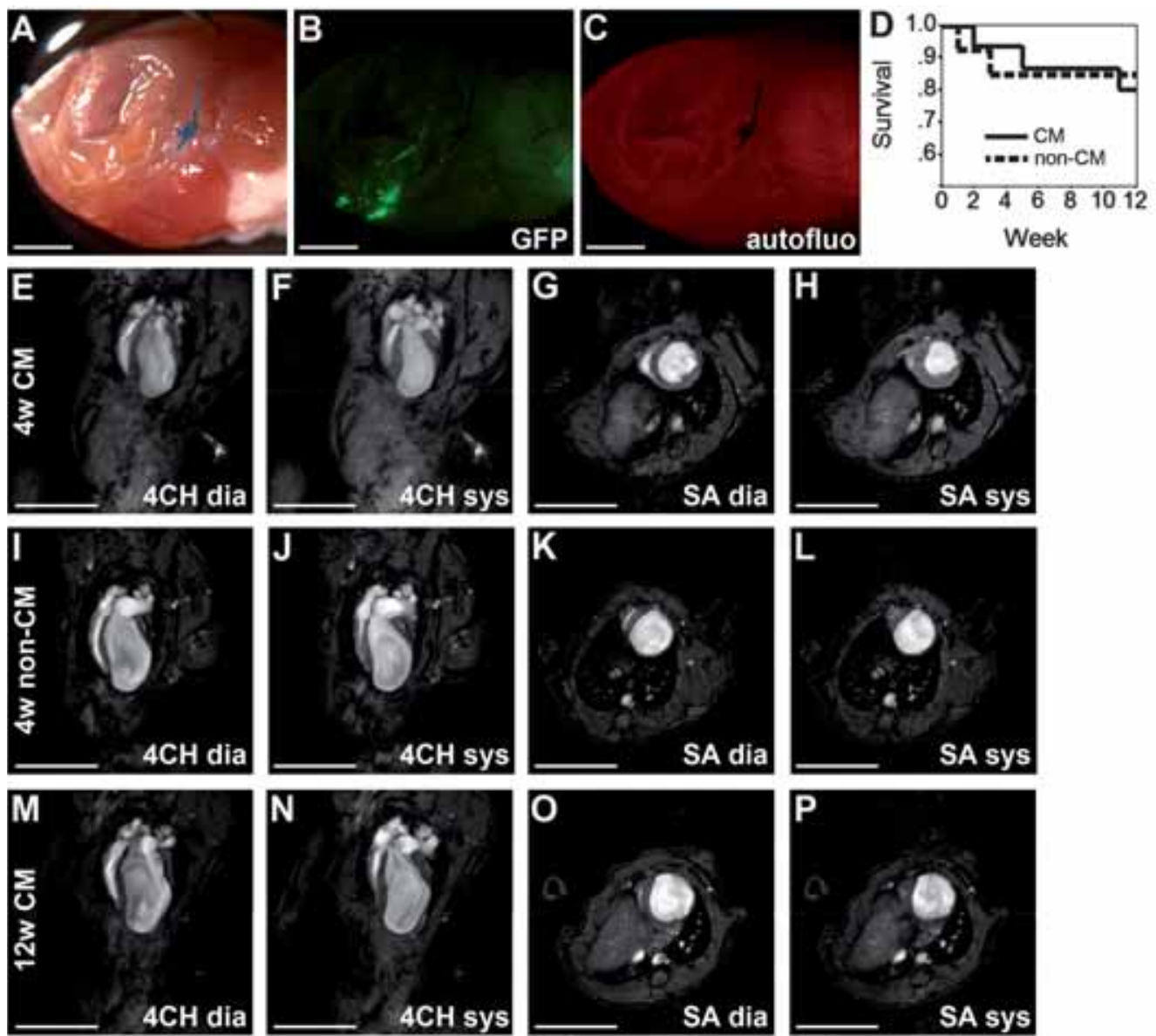

CH4, Figure 8 
Q

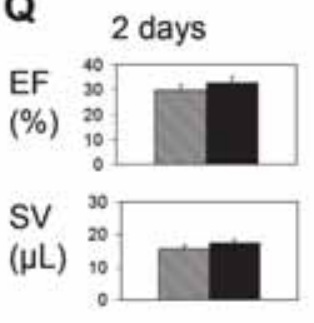

EDV

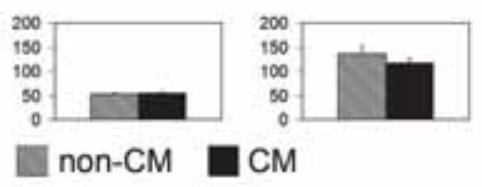

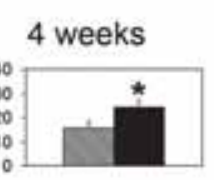

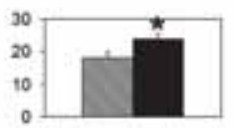

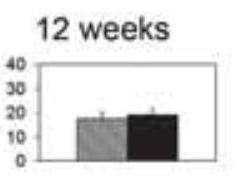
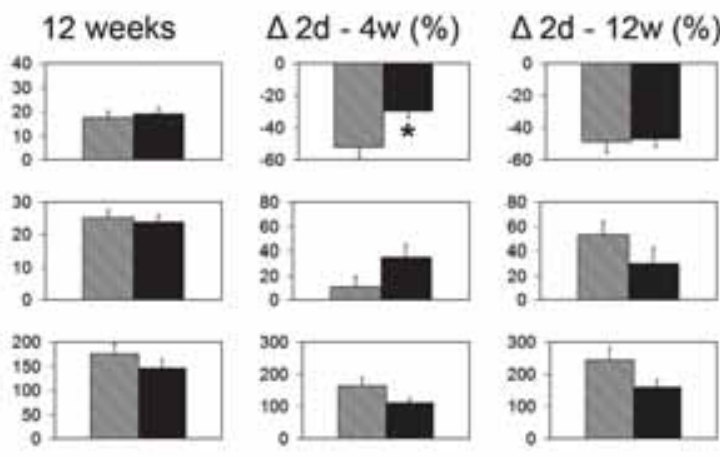

\section{CH4, Figure 8.Transplantation of HESC-CM after MI preserves mid-term heart function}

(A-C) HES3-GFP derived graft in mouse heart 4 weeks after LAD ligation and cell transplantation; (A) bright field; (B) GFP; (C) overexposure with filter for red fluorescence. Scale bars $250 \mu \mathrm{m}$. (D) Survival curves of mice that received CM (solid line) or non-CM (broken line) after MI. (E-P) MRI images of infarcted mouse hearts; (E-H) 4 weeks after $\mathrm{MI}$ and $\mathrm{CM}$ injection; (I-L) 4 weeks after $\mathrm{MI}$ and non-CM injection; (M-P) I2 weeks after MI and cell injection; (E, F, I, J, M, N) 4 chamber view; (G, H, K, L, O, P) short axis view; (E, I, M, G, K, O) end-diastolic; (F, J, N, H, L, P) end-systolic. Scale bars I cm. (Q) EF, SV and EDV at 2 days, 4 weeks and I2 weeks after $\mathrm{MI}$ and cell transplantation (repeated measurements) and relative change over time. Striped bar: non-CM injected; black bar: CM injected. * $p<0.05$ 
Color figures | 211
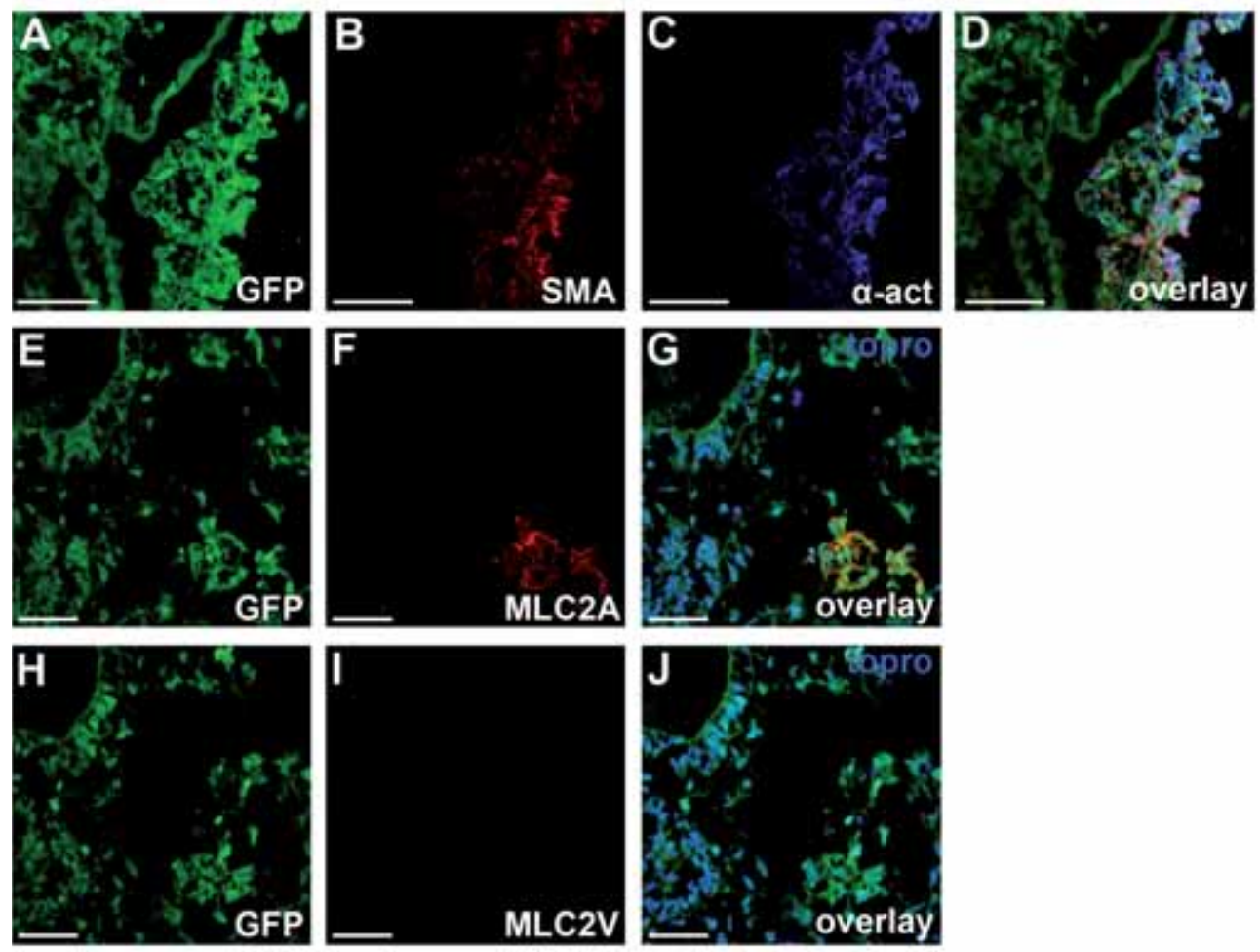

CH4, Supplementary Figure 1. Characterization of cardiomyocytes in vitro.

(A-D) HESC-CM are SMA positive in beating areas from I2 day HES3-GFP co-cultures (cryo section);(A) GFP; (B) SMA; (C) $\alpha$-actinin; (D) overlay. (E-J) MLC2A (F), but not MLC2V protein (I) is expressed in HES3-GFP derived CM in culture (cryo section of beating area); (E, H) GFP; (G, J) overlays including topro-3 (blue). 


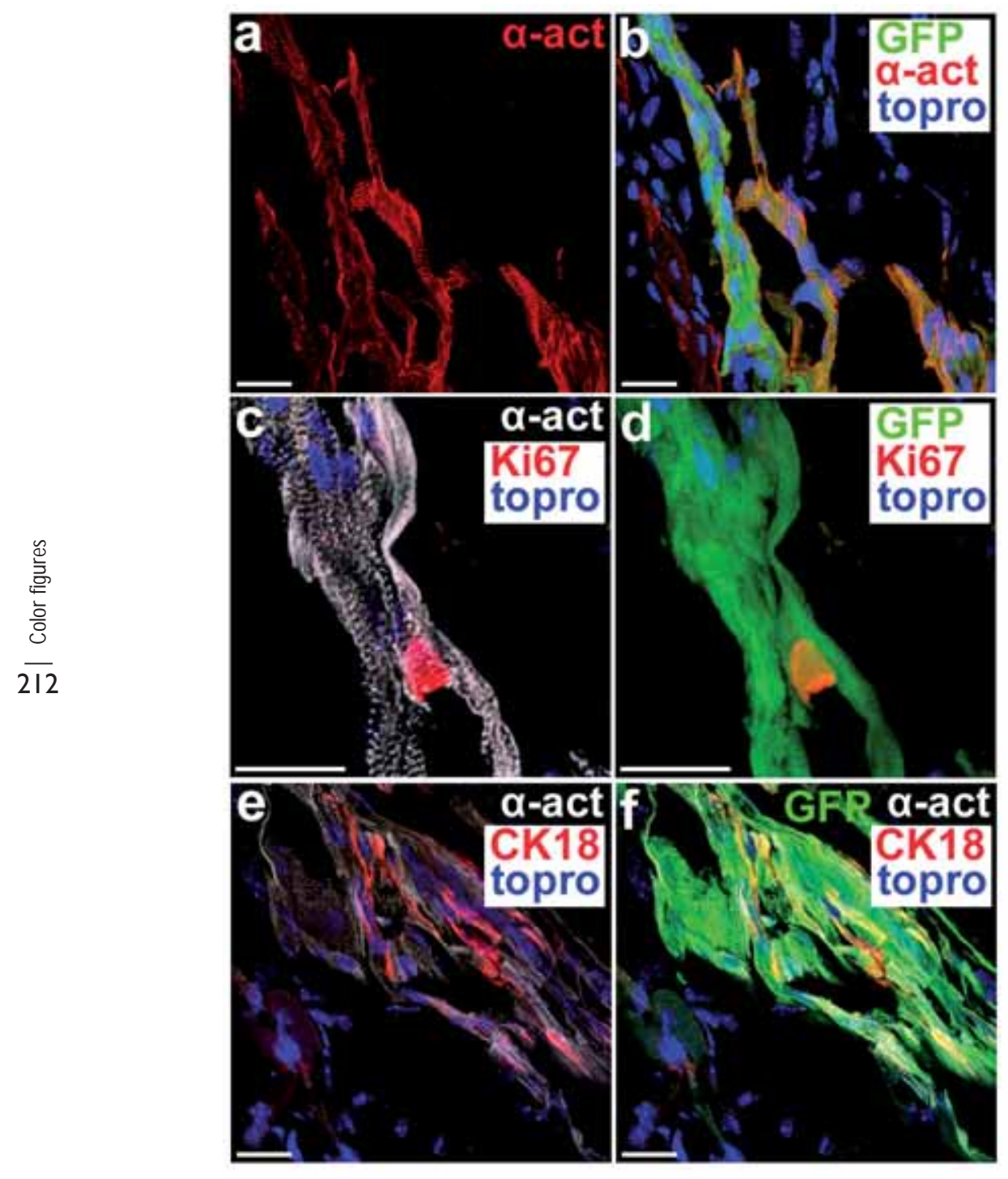

CH5, Figure 1. HESC-derived grafts in the infarcted mouse heart consist predominantly of cardiomyocytes: (a-b) Most $(\geq 90 \%)$ hESC-derived cells 12 weeks after myocardial infarction and cell injection express $\alpha$-actinin (cardiomyocyte); (c-d) some hESC-CM also stain positive for Ki67; (e-f) a minority of the hESC-derived cells express cytokeratin 8 (CK8) (endoderm). Green: GFP, blue: nuclei. Scale bars: $20 \mu \mathrm{m}$. 
Color figures $\mid 213$
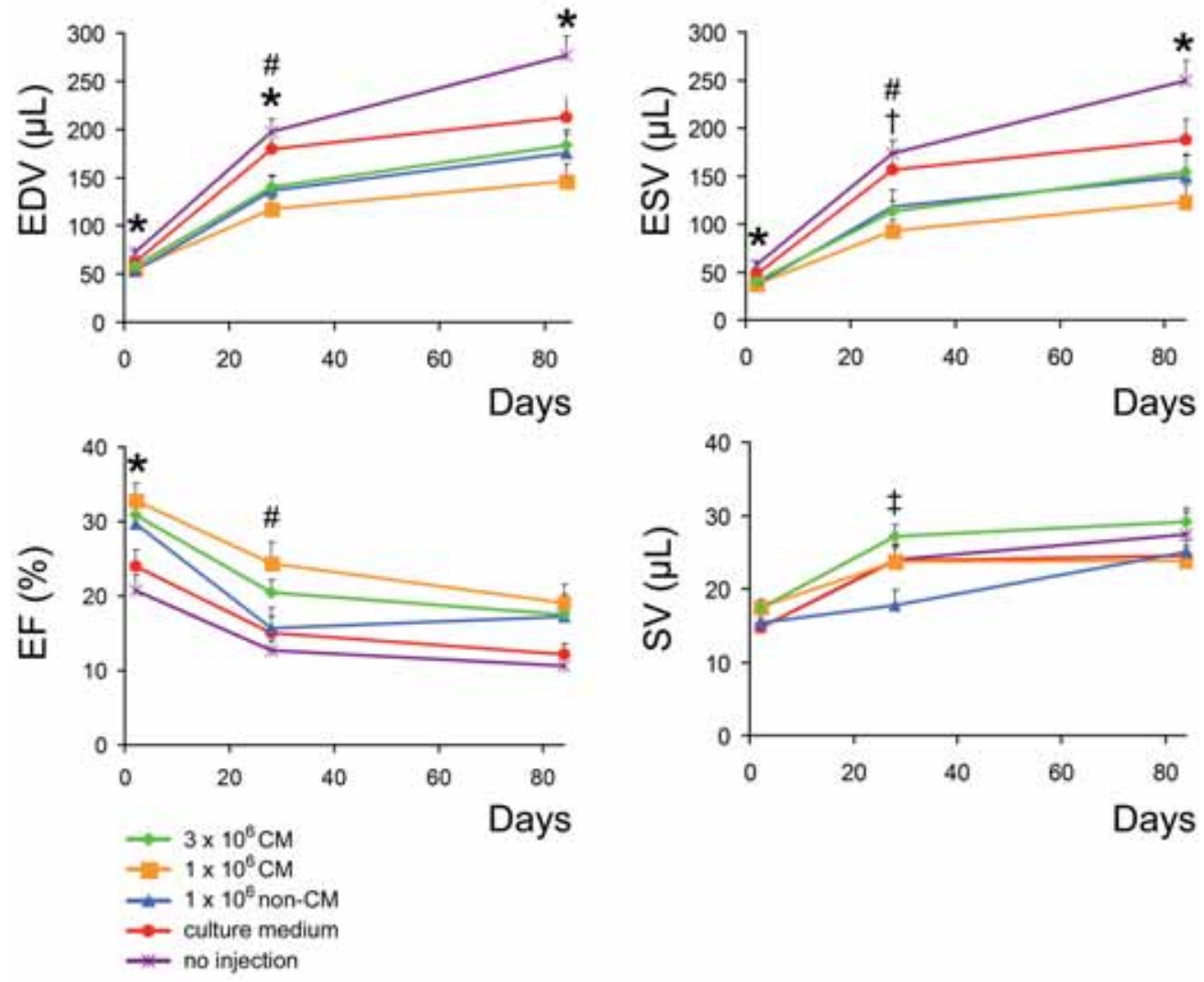

CH5, Figure 2. Cardiac function after myocardial infarction is improved by transplantation of differentiated hESCs:

Longitudinal follow-up by serial MRI measurements of mice after myocardial infarction and injection of $1 \times 10^{6}$ or $3 \times 10^{6}$ million hESC-CM, I $\times 10^{6} \mathrm{hESC}$-non-CM, medium, or no injection. Days: days post-operatively. EDV: end diastolic volume, ESV: end systolic volume, EF: ejection fraction, SV: stroke volume. ${ }^{*} \mathrm{p}<0.05$ for $1 \times 10^{6} \mathrm{CM}, 3 \times 10^{6} \mathrm{CM}$ and $1 \times 10^{6}$ non-CM vs. no injection, $\# p<0.05$ for $1 \times 10^{6} \mathrm{CM}$ vs. medium and no injection, $\dagger p<0.05$ for $1 \times 10^{6} \mathrm{CM}$ and $3 \times 10^{6} \mathrm{CM}$ vs. no injection, $\ddagger \mathrm{p}<0.05$ for $3 \times 10^{6} \mathrm{CM}$ vs. non-CM. 


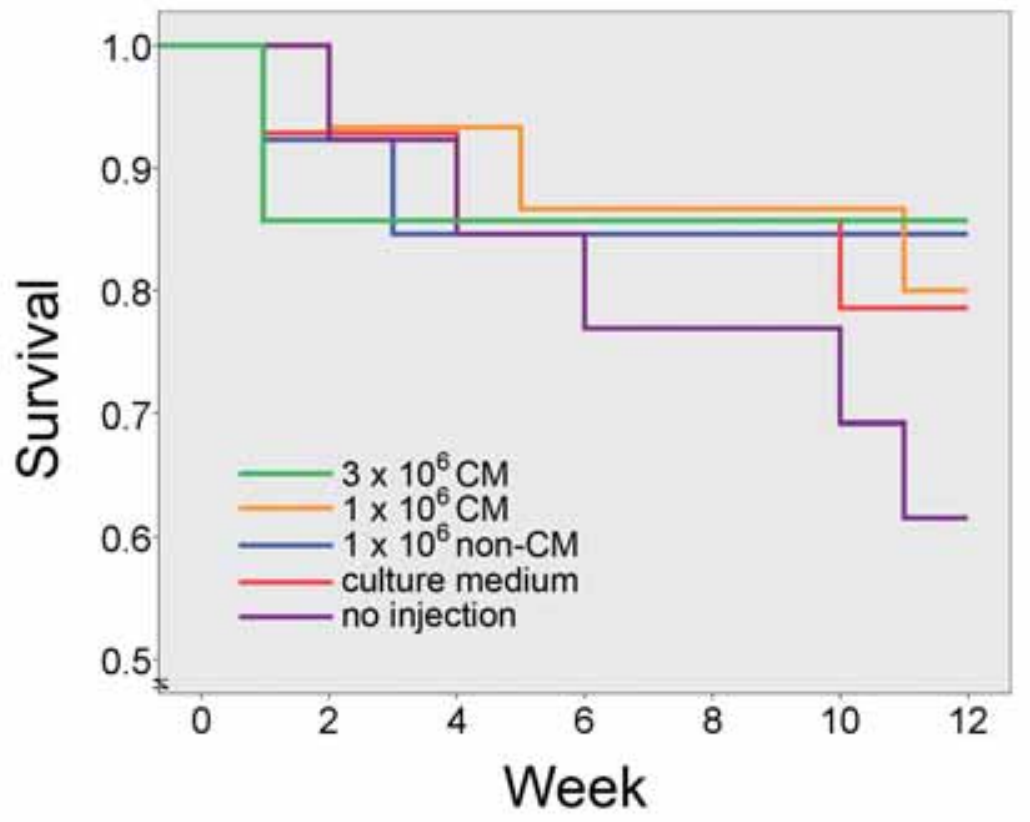

CH5, Figure 3. Survival of mice after myocardial infarction:

Survival until 12 weeks (end point) of mice after myocardial infarction and injection of $1 \times 10^{6}$ or $3 \times 10^{6}$ million hESC$\mathrm{CM}, \mathrm{I} \times 10^{6} \mathrm{hESC}$-non-CM, medium, or no injection. Week: weeks post-operatively. 
Color figures $\mid 215$

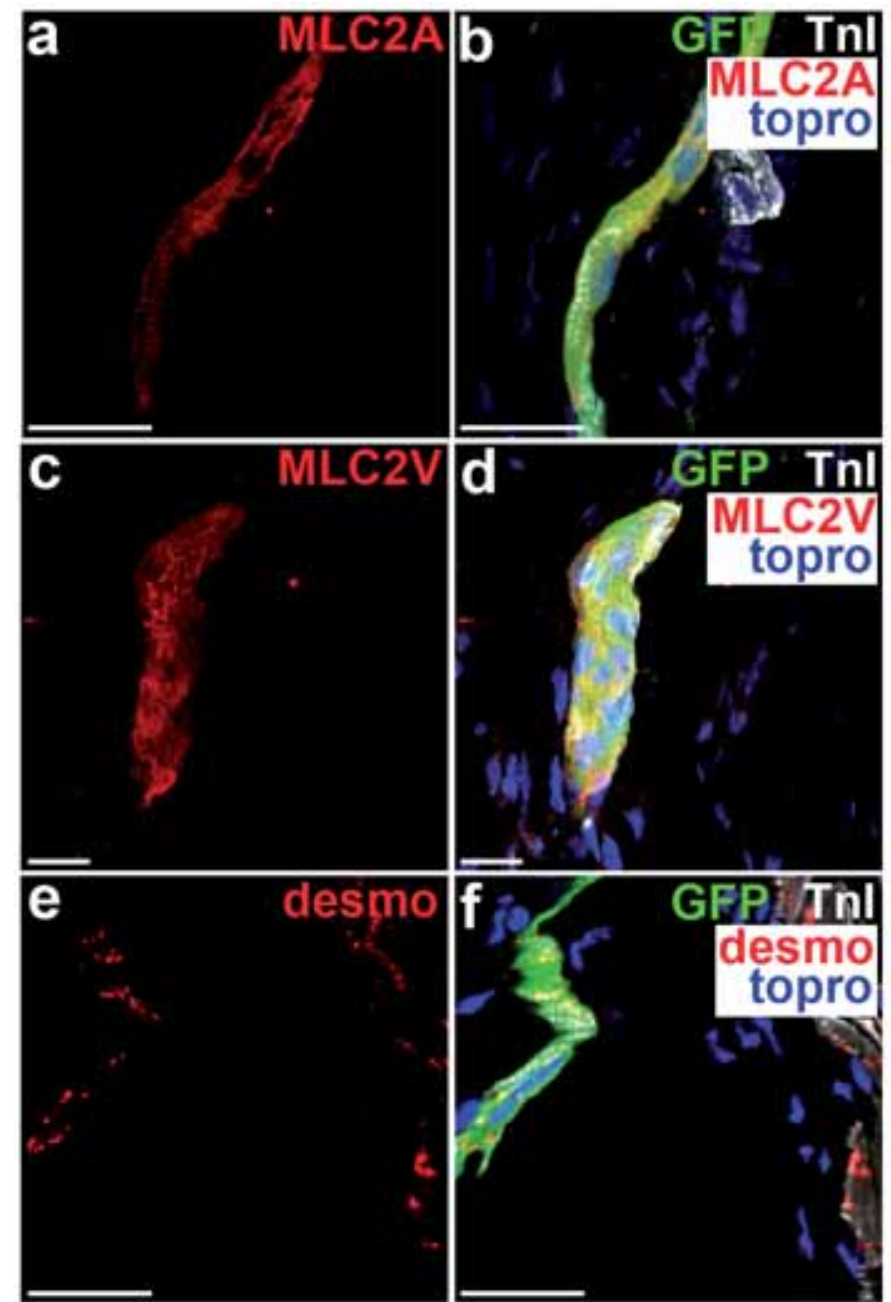

CH5, Supplementary figure 1. Cardiac markers in hESC-CM in the infarcted mouse heart:

HESC-CM express MLC2A (a-b) or MLC2V (c-d) and form desmosomes within the graft (e-f). Green: GFP, blue: nuclei (topro-3). Scale bars: $20 \mu \mathrm{m}$. 


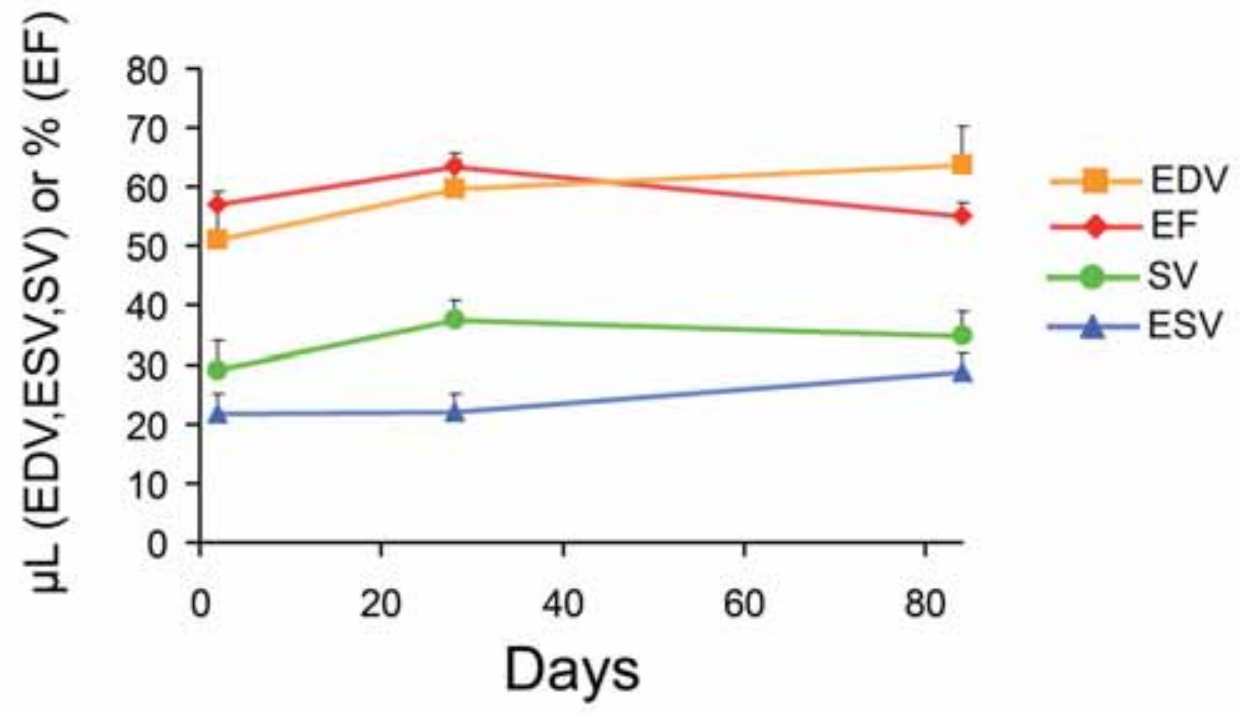

CH5, Supplementary figure 2. Cardiac function of non-infarcted NOD-SCID mice:

EDV: end diastolic volume, ESV: end systolic volume, EF: ejection fraction, SV: stroke volume. Days: days after age of 12 weeks (when operations where performed in the groups of infarcted mice).
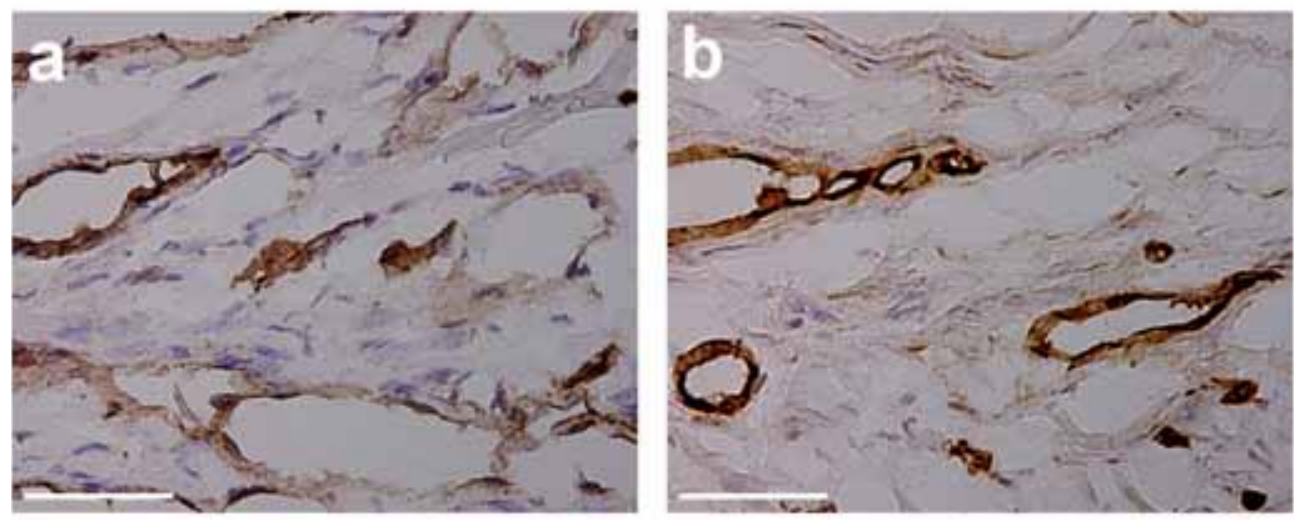

CH5, Supplementary figure 3. Transplantation of hESC-CM increases vascularization in the infarcted heart: (a) CD3 I staining in borderzone of heart from hESC-CM group, (b) CD3I staining in borderzone of heart from hESCnon-CM group. Scale bars: $50 \mu \mathrm{m}$. 
Color figures | 217

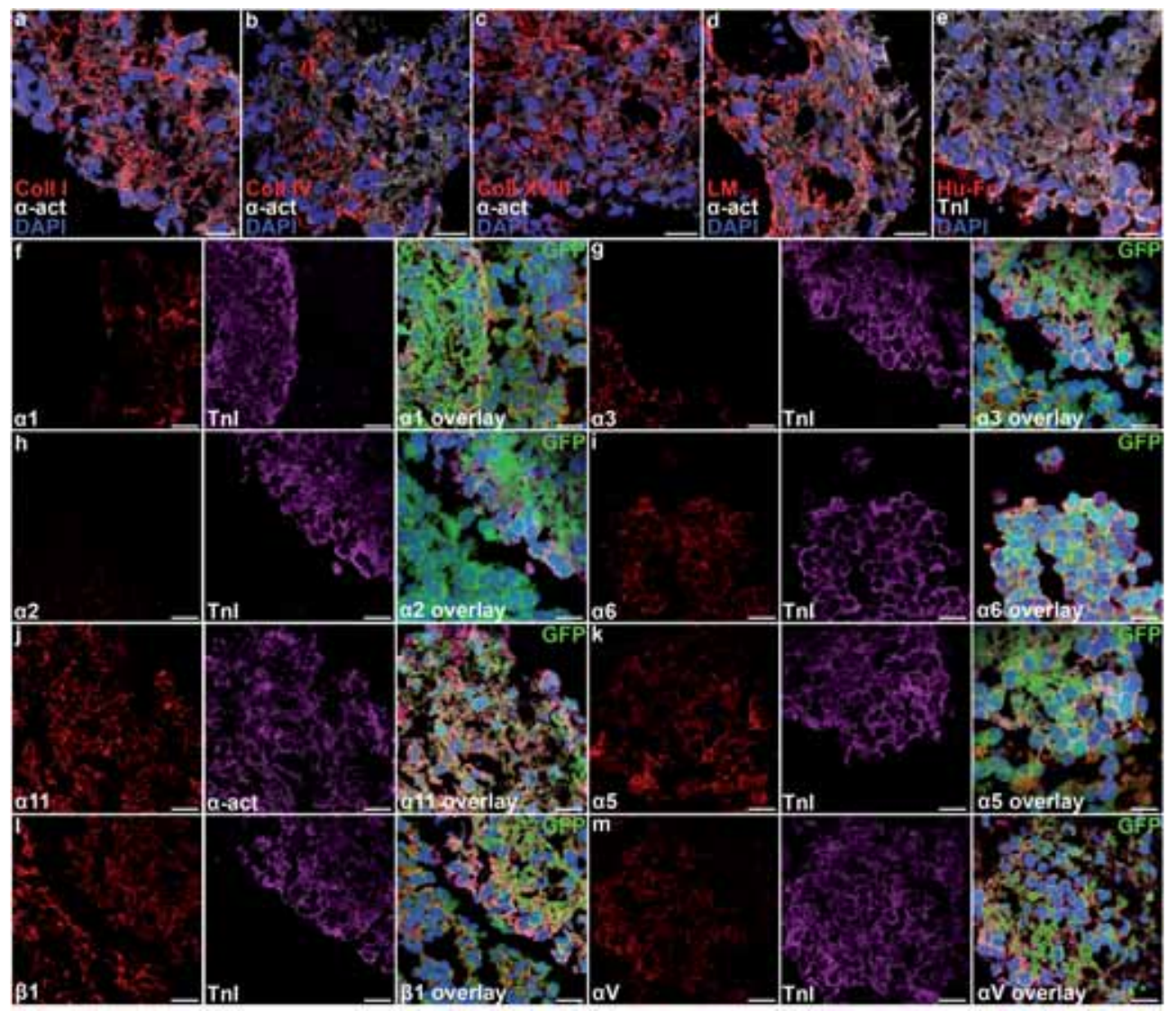

CH6, Figure 1. Extracellular matrix and integrin expression in beating areas from $\mathrm{hESCs}$.

(a-e) hESC-CM from hES3-GFP are surrounded by collagen I, collagen IV, collagen XVIII, laminin and fibronectin (GFP not shown for clarity), (f-m) hESC-CM express collagen receptor integrin $\alpha \mathrm{Il}$, some laminin receptors $\alpha 3$ and $\alpha 6$, fibronectin/vitronectin receptors integrin $\alpha 5$ and $\alpha \mathrm{V}$, and the common $\beta$-subunit integrin $\beta I$.Tnl and $\alpha$-act: cardiomyocyte markers troponin I or $\alpha$-actinin; green: GFP; blue: DAPI. Scale bars $20 \mu \mathrm{m}$. 


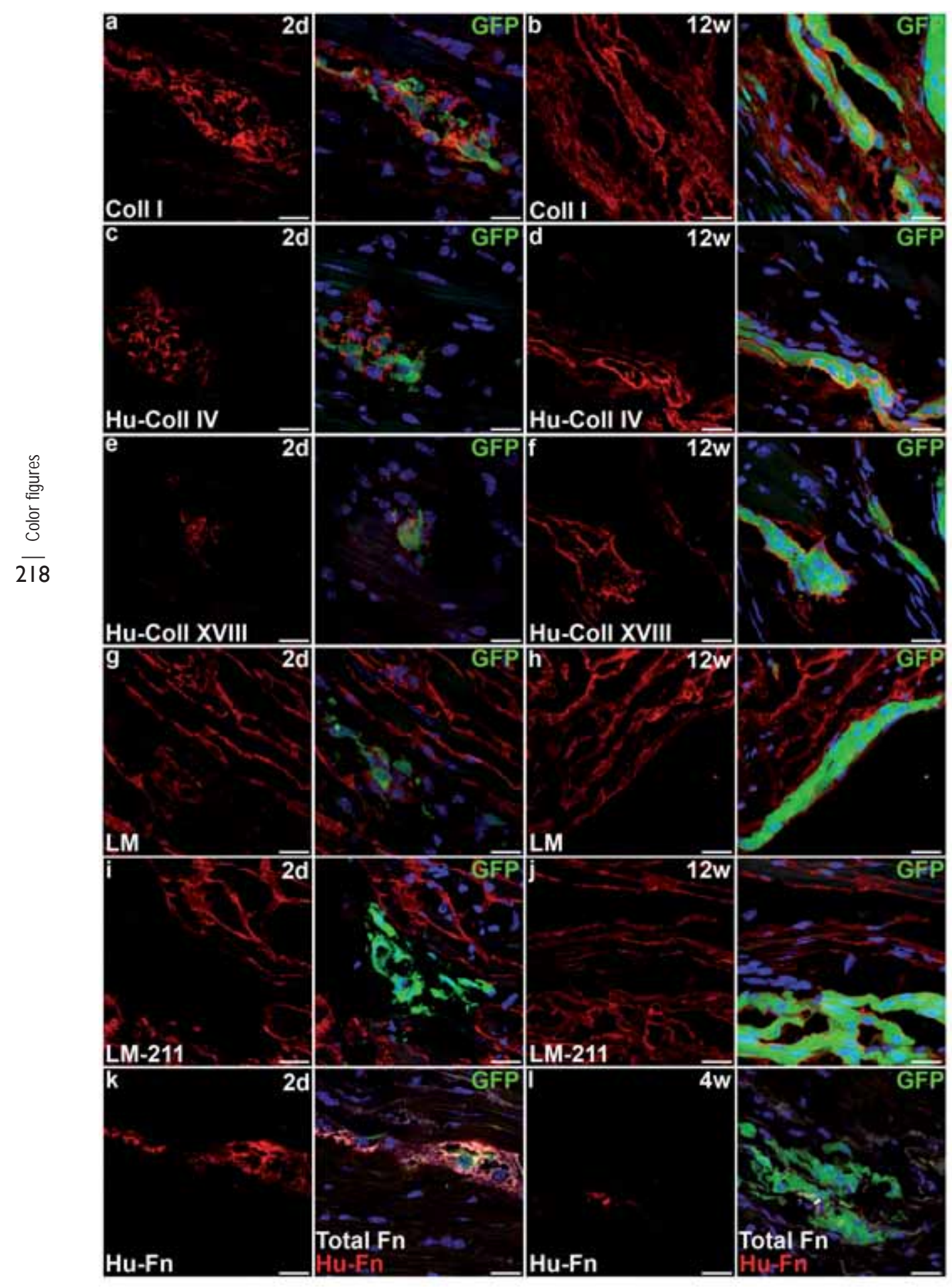


Color figures | 219

$\leftarrow$ CH6, Figure 2. hESC-CM secrete extracellular matrix and evoke excessive matrix production by host cells after intramyocardial transplantation. (a-b) large amounts of collagen I surrounding grafts 2 days and 12 weeks after transplantation, (c-d) human collagen IV in the immediate proximity of hESC-CM, (e-f) human collagen XVIII in the immediate proximity of $\mathrm{hESC}-\mathrm{CM},(\mathrm{g}-\mathrm{h})$ laminin envelops $\mathrm{hESC}-\mathrm{CM}$ in similar amounts as host cardiomyocytes, (i-j) laminin-2II is increasingly present around transplanted hESC-CM and eventually in similar amounts as with host cardiomyocytes, (k-l) hESC-CM secrete fibronectin at early time-points after transplantation, but this is reduced over time. Scale bars $20 \mu \mathrm{m}$

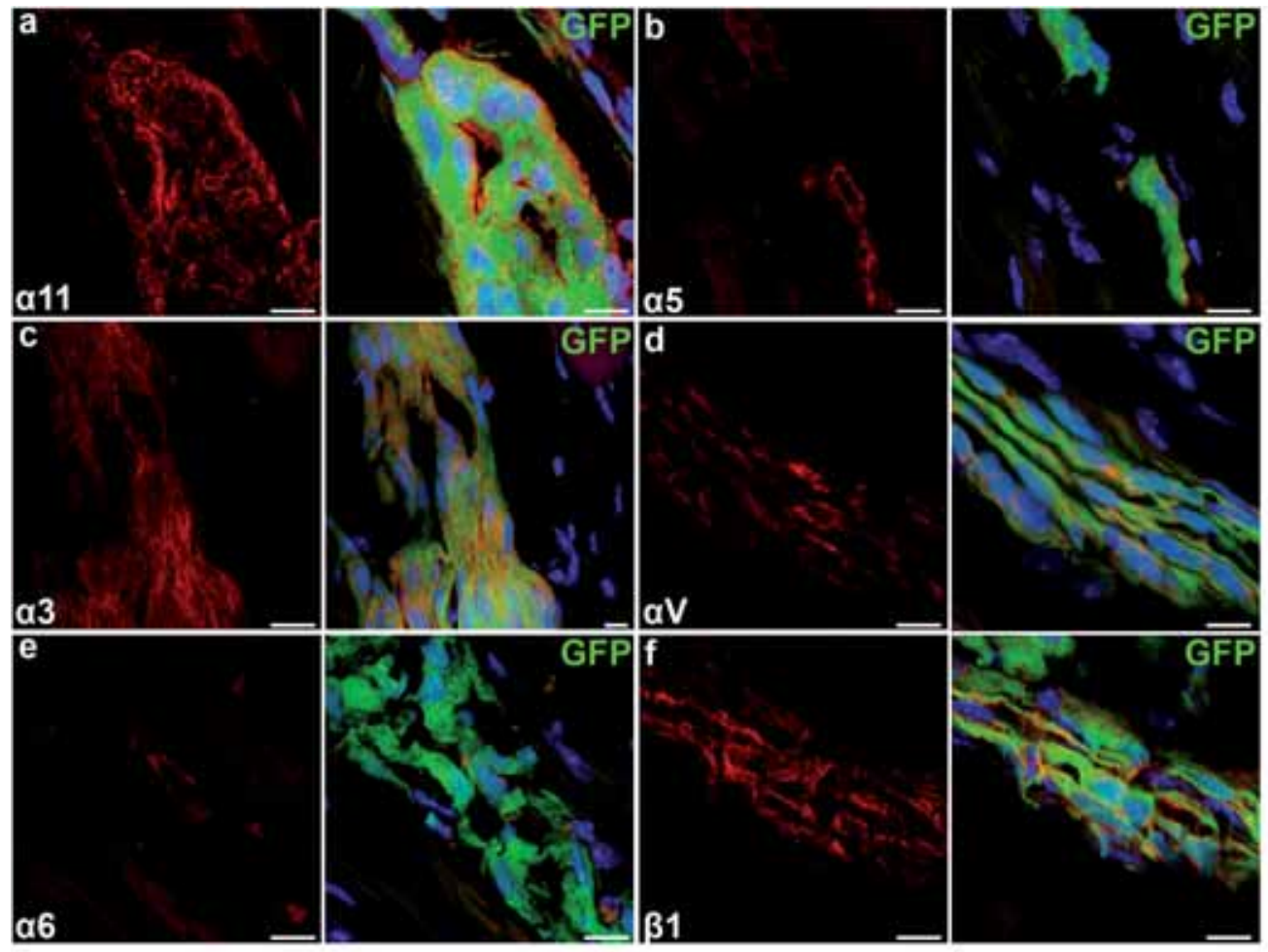

CH6, Figure 3. Integrin expression on hESC-CM after transplantation. $(a, f)$ expression of integrin $\alpha I I$ and $\beta I$ is unchanged, (c,e) expression of $\alpha 3$ is upregulated while $\alpha 6$ is slightly downregulated, (b,d) $\alpha 5$ and $\alpha V$ are decreasingly expressed. Grafts shown are 4 weeks (b,e) or 12 weeks (a, c, d, f) after transplantation. Scale bars $10 \mu \mathrm{m}$. 


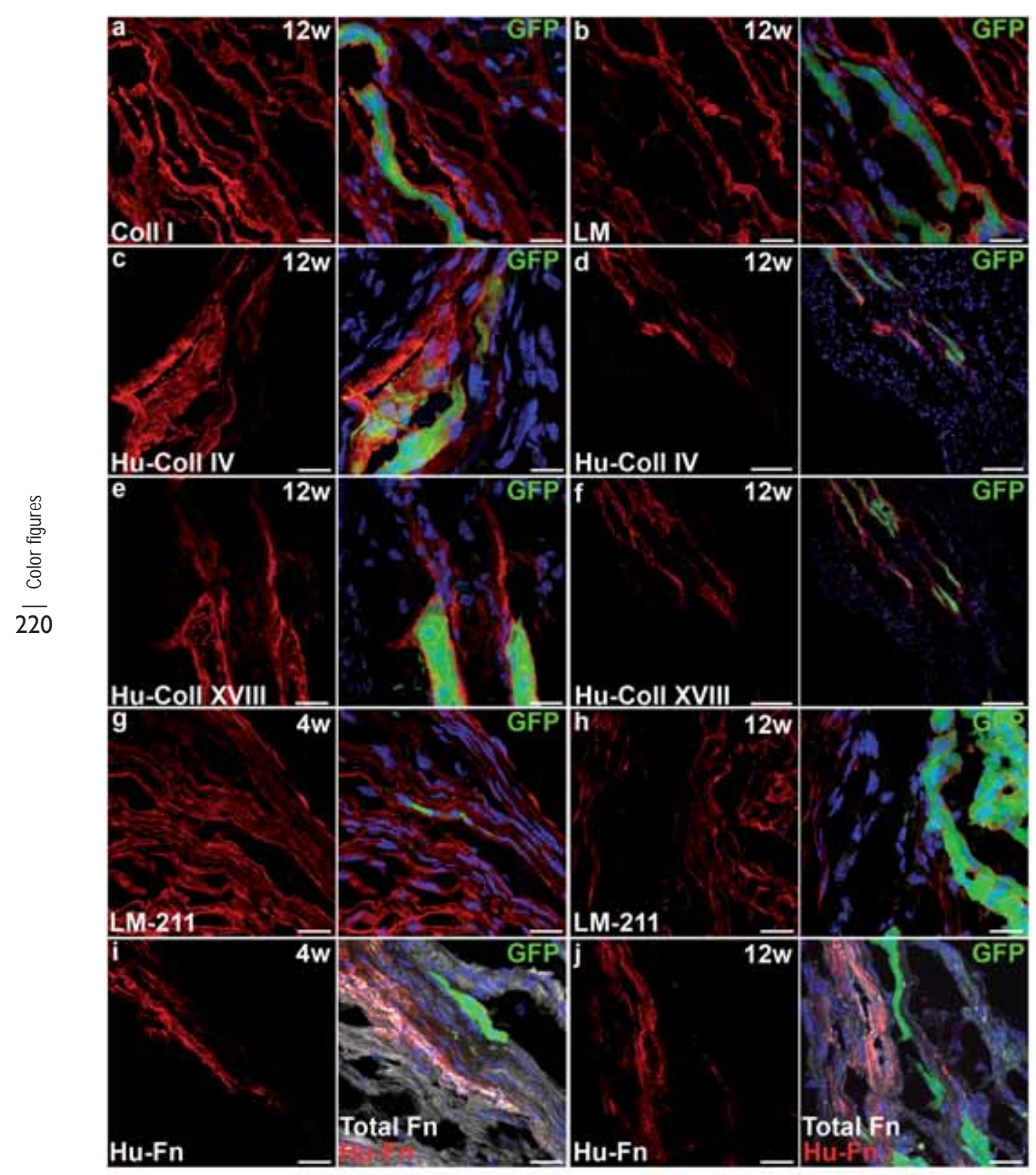

CH6, Figure 4. Extracellular matrix secretion from hESC-CM is increased when transplanted into the infarcted heart. (a) collagen I forms a large part of the infarct and is present in even larger amounts around the grafted hESCCM, (b) laminin forms part of the infarct and is present in normal quantities around hESC-CM, (c-f) human collagen IV (c, overview in $d$ ) and human collagen XVIII (e, overview in $f$ ) are secreted by hESC-CM and cover a considerable area around the graft, $(\mathrm{g}-\mathrm{h})$ laminin-2II forms part of the infarct and is present in normal quantities around hESCCM, (i-j) fibronectin forms part of the infarct and this is largely due to continuing secretion of human fibronectin by hESC-CM. Scale bars (a-c,e,g-j) $20 \mu \mathrm{m}$, scale bars (d,f) $100 \mu \mathrm{m}$. 
Color figures | 221
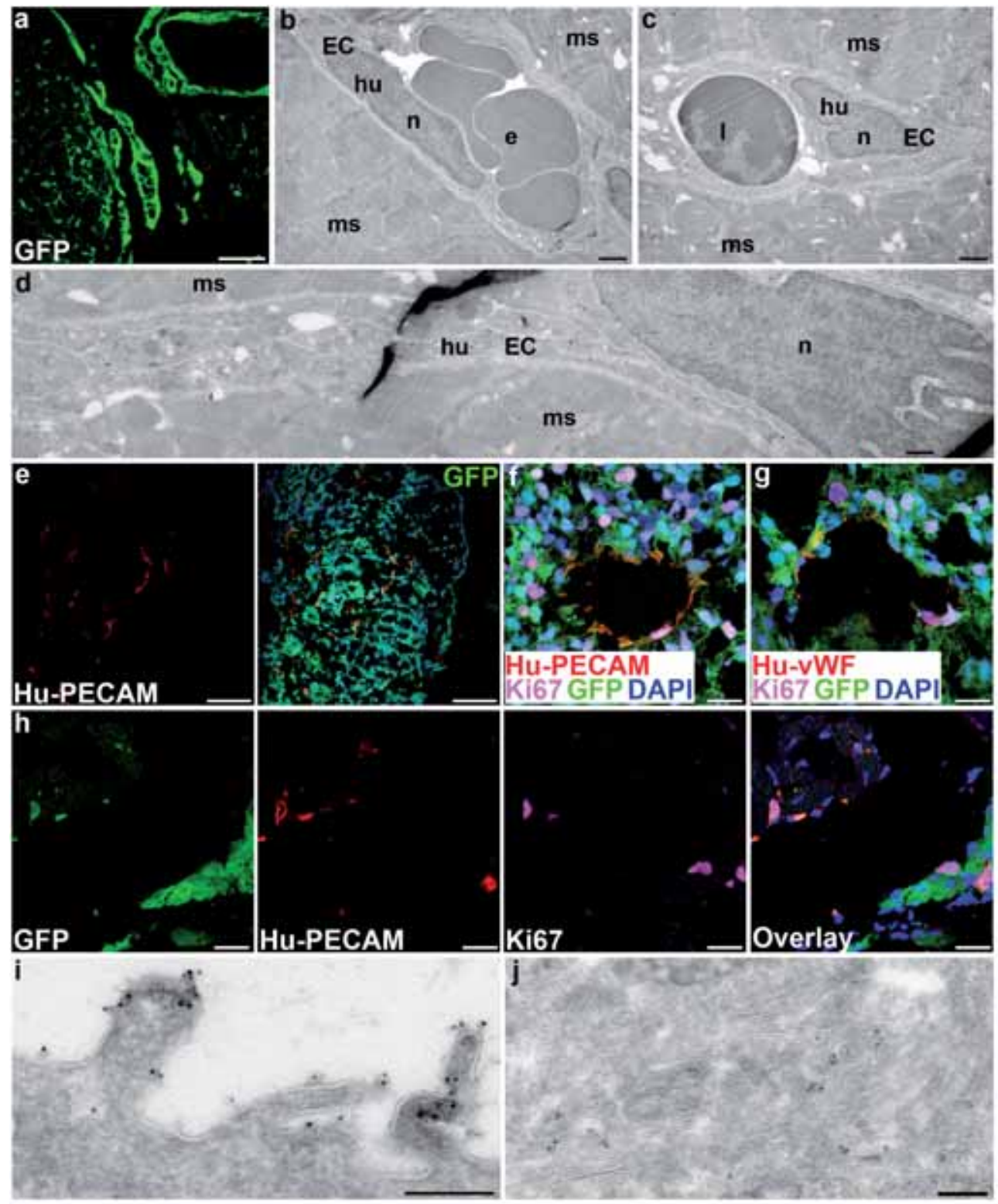

CH6, Figure 6. Co-transplanted hESC-ECs form functional vessels in the host myocardium. (a) small clusters of GFP-expressing cells scattered through the host myocardium 24 weeks after transplantation, (b-d) human endothelial cells forming capillaries in mouse myocardium; black dots: GFP; e: erythrocyte; I: leukocyte; n: nucleus; EC endothelial cell; hu: human, ms: mouse (e) overview of endothelial structures in a beating area from hES3-GFP, $(\mathrm{f}, \mathrm{g})$ Ki-67 positive endothelial cells expressing human PECAM and human von Willebrand Factor, (h) Ki-67 positive hESC-derived endothelial cells in a graft 12 weeks after transplantation, $(\mathrm{i}, \mathrm{j})$ undifferentiated hESCs; immunogold labeling for Tra-I-60 at the apical side (i) and intracellular (j); black dots:Tra-I-60; n: nucleus. Scale bars (a,e) I00 $\mu \mathrm{m}$ $(b, c) I \mu m(d) 500 \mathrm{~nm}(\mathrm{f}, \mathrm{g}) 20 \mu \mathrm{m}(\mathrm{h}, \mathrm{i}) 200 \mathrm{~nm}$. 

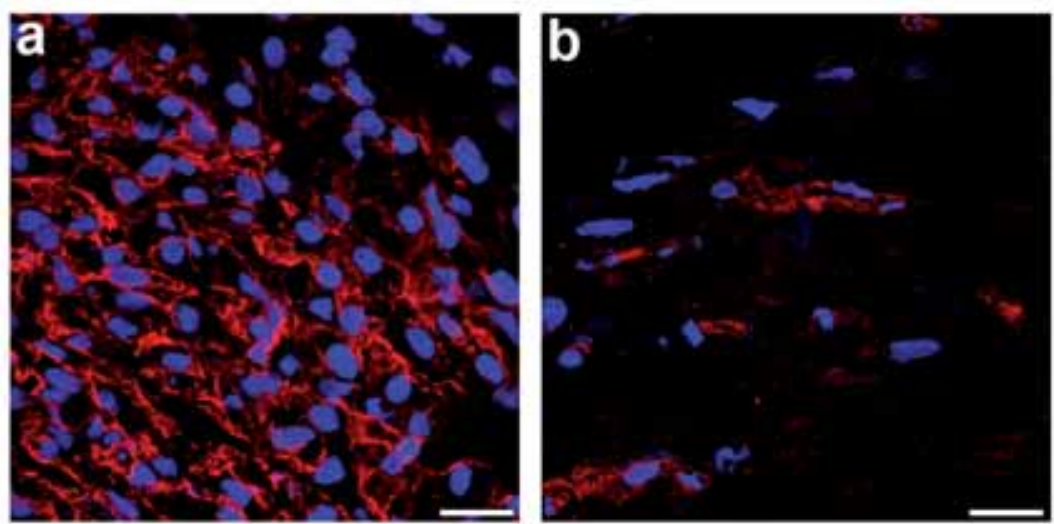

CH6, Supplementary Figure 1. Collagen XVIII is present around cardiomyocytes in human fetal hearts of 9 weeks gestational age (a), but not in human adult heart, where it is only seen in blood vessels (b).

$\rightarrow \mathrm{CH7}$, Figure 1. Upregulation of endoglin expression following myocardial infarction. (A-E) Endoglin expression in normal (sham operated) adult mouse heart. (A) Paraffin section of mouse heart. (B) Real-time PCR for endoglin using left atrium (LA), right atrium (RA), left ventricle (LV), and right ventricle (RV) cDNA. Samples normalized using GAPDH primers. Note relatively low expression of endoglin in LV and RV. (C) Radioactive in situ hybridization for endoglin showing enhanced endoglin expression in atrium (arrow). (D-E) High magnification of LV. (D, upper) AZAN-Mallory staining showing viable tissue (red/magenta); (D,lower) radio-active in situ hybridization (endoglin mRNA red) and (E) endoglin is not detectable immunohistochemically in the LV of adult heart. (F-I) Endoglin expression upregulated in the infarcted zone post-MI. (F) Macroscopic view of heart one-week post-MI. (G) Paraffin section showing dilation of LV one-week post-Ml. (H, upper) AZAN-Mallory staining showing infarcted area (blue); (H,lower) Radioactive in situ hybridization and (I) immunohistochemistry: increased endoglin expression (arrow) in infarcted zone of adult heart one-week post-MI. (E, I) PECAM staining as a marker for capillaries and blood vessels. 
Color figures | 223
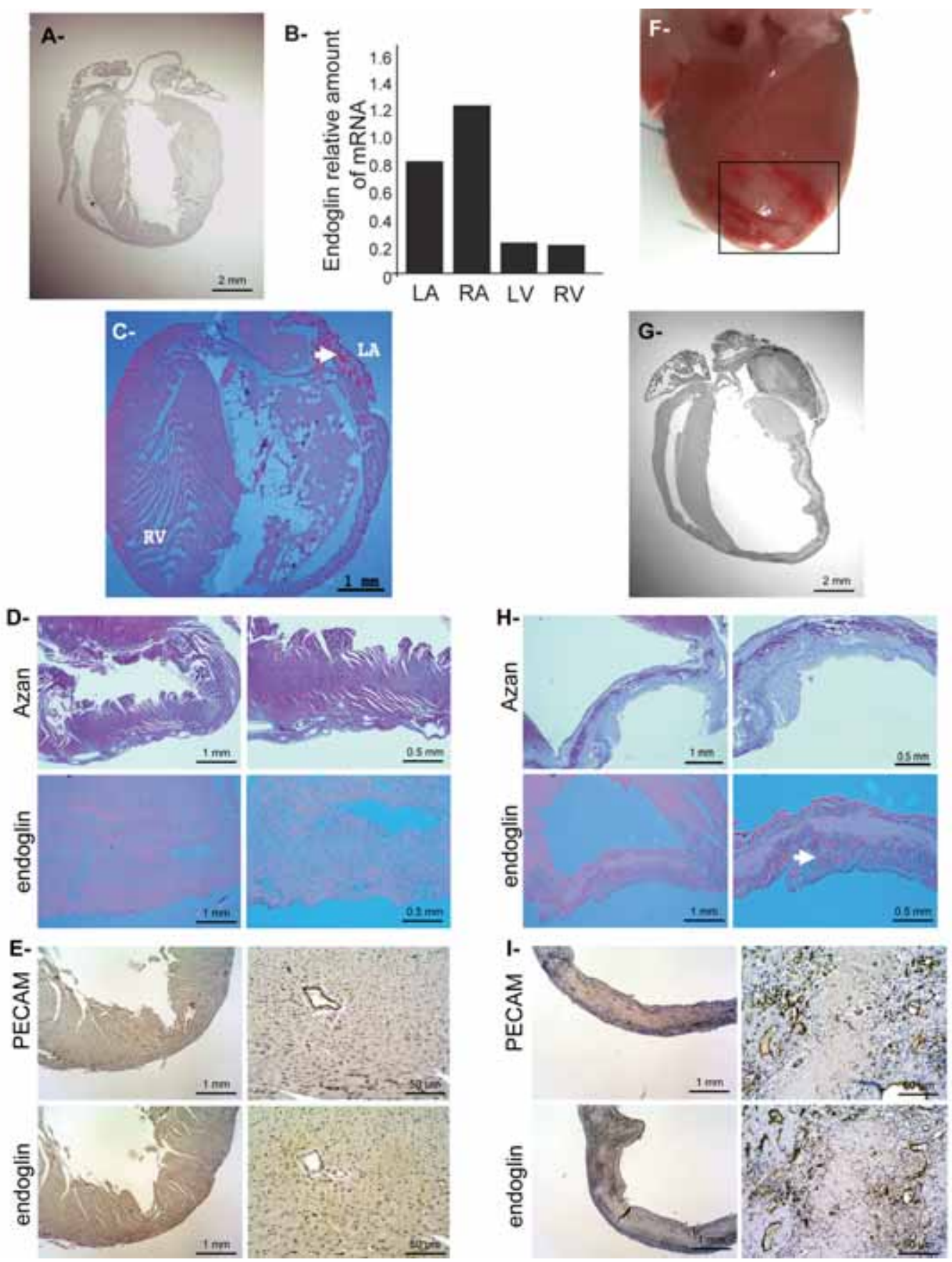


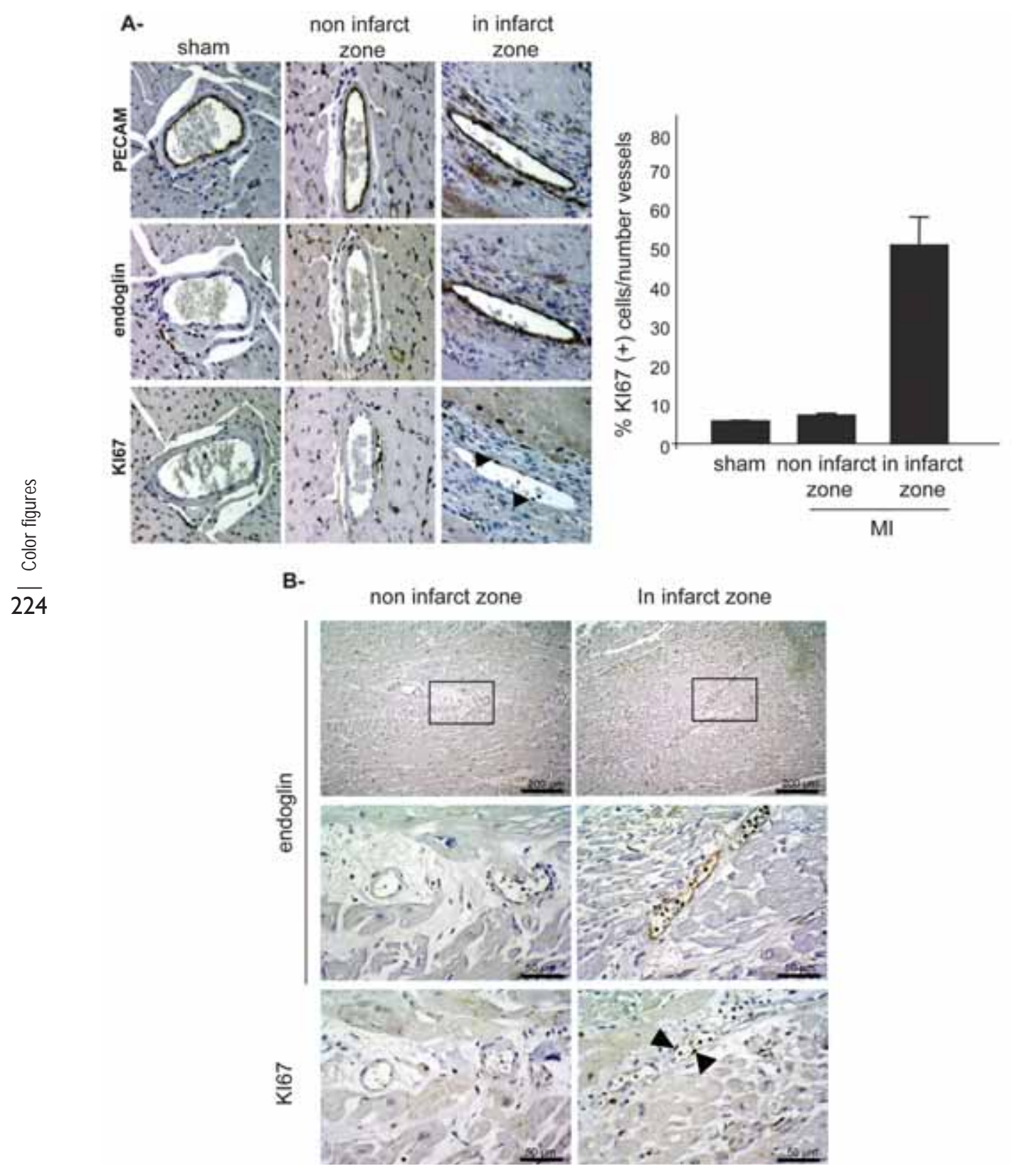

CH7, Figure 2. Endoglin is upregulated in active endothelium. (A) Upregulation of endoglin associated with neoangiogenesis post-MI. PECAM in all vessels (upper panels), endoglin specifically in the infarct zone (right panels). $\mathrm{Ki}_{67^{+}}$ECs associated with endoglin ${ }^{+}$vessels of the infarct zone (lower panels). (B) Endoglin and Ki67 immunohistochemistry of infarcted human hearts shows upregulation of endoglin associated with neoangiogenesis. Black arrows show $\mathrm{Ki} 67^{+}$cells. 
Color figures | 225

A-

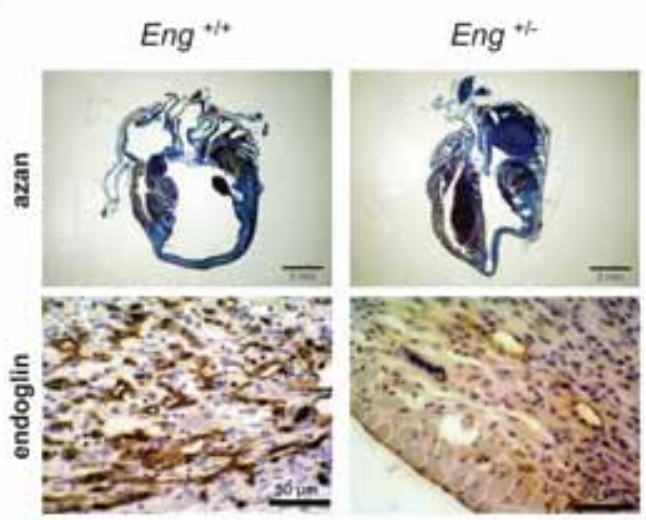

B-

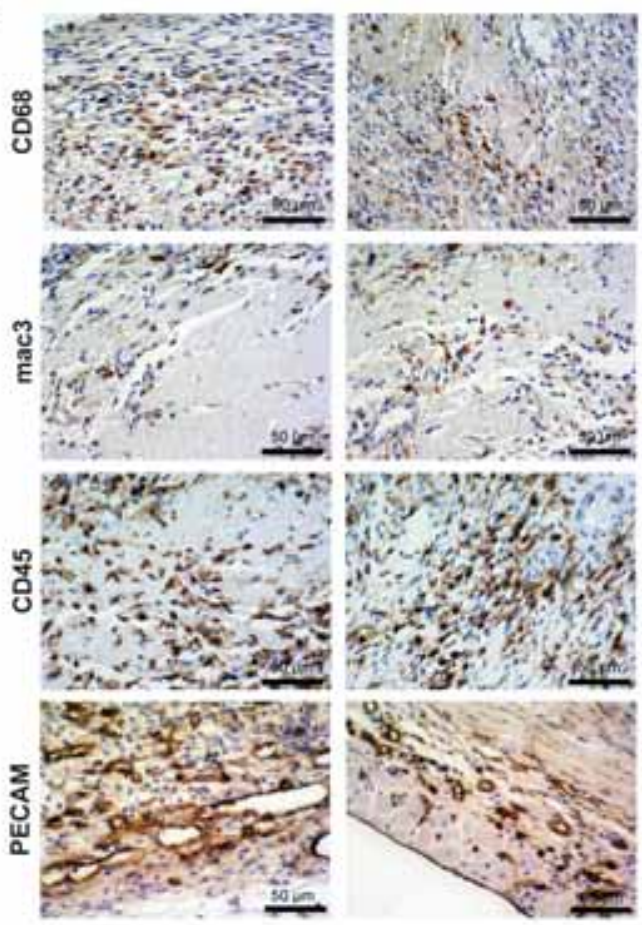

c.

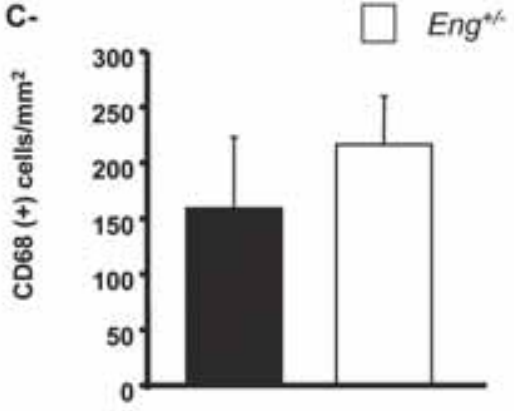

D.

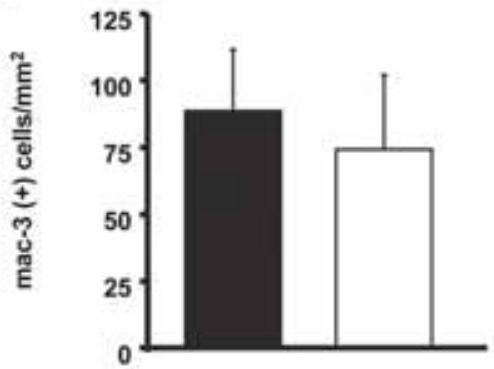

E-

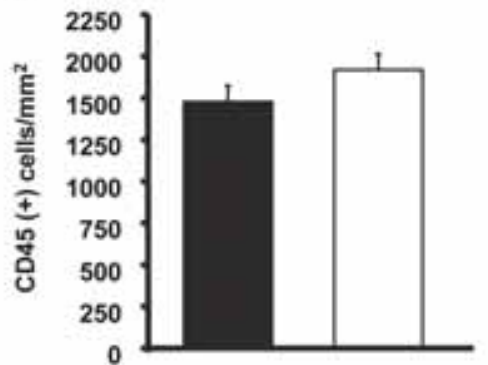

F.

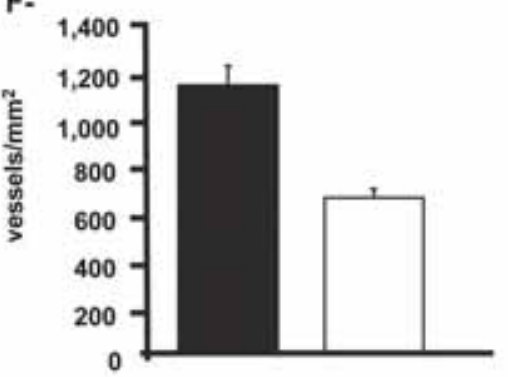

CH7, Figure 3. Inflammatory cell accumulation and angiogenesis in Eng ${ }^{\text {t- }}$ mice. (A) Representative examples of AZAN-Mallory and endoglin staining of Eng ${ }^{+/+}$(left) and $\mathrm{Eng}^{+/}$(right) adult mouse heart one-week post-MI. Endoglin protein expression was reduced in Eng ${ }^{+/}$hearts. (B) Paraffin sections immunostained for PECAM, CD68, Mac-3 and CD45. Accumulation of immunoreactive cells, quantified as number(+) cells $/ \mathrm{mm}^{2}$, did not significantly change between wild-type and Eng ${ }^{+/}$hearts (C, D, E). The total number of vessels $/ \mathrm{mm}^{2}$ was reduced in the $\mathrm{Eng}^{+/}$ compared to $\mathrm{Eng}^{+/+}$hearts one-week post-MI in the infarct area (blue area of AZAN staining). 

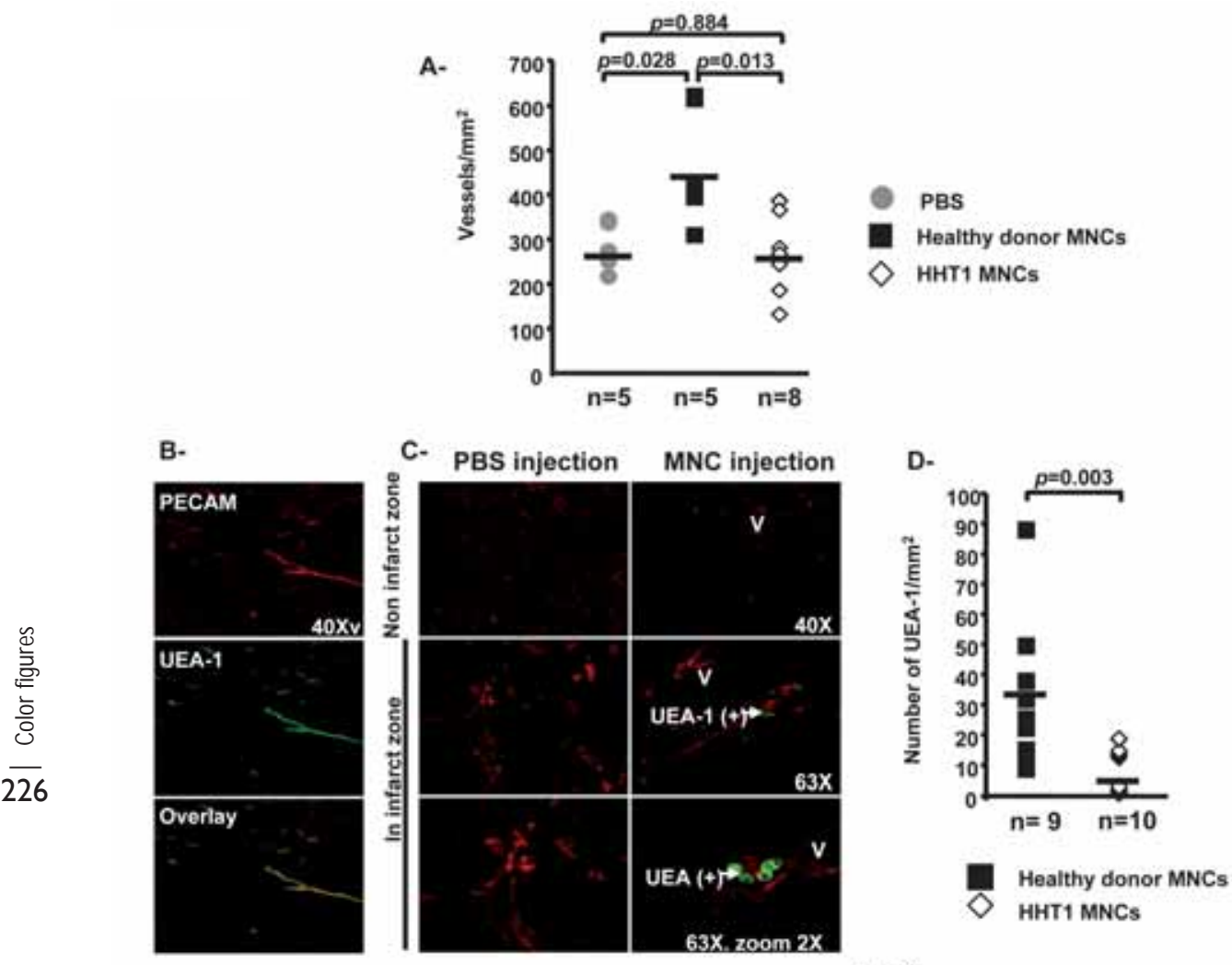

E-
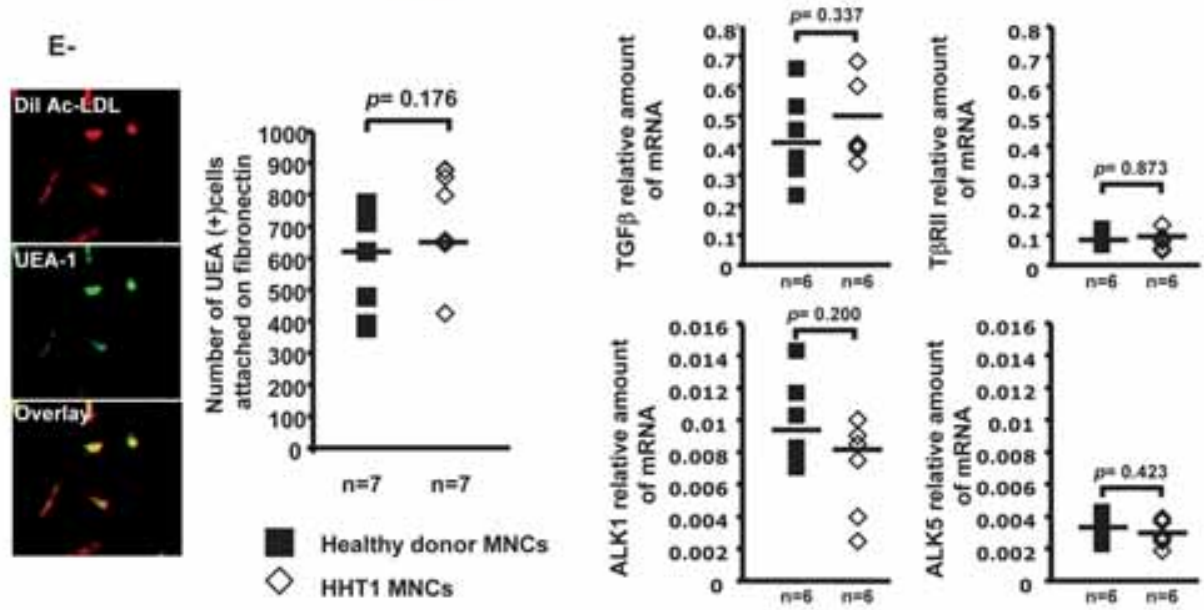

CH7, Figure 5. MNCs from HHT1 patients fail to stimulate neoangiogenesis. (A) Number of vessels in the infarcted zone of hearts of Balb/c mice 14 days post-MI was determined by counting PECAM ${ }^{+}$vessels after immunohistochemical staining. (B) Ulex europaeus agglutinin-I (UEA-I) lectin-coupled-FITC stains EC of human fetal heart and not other cell types. (C) MNC-derived ECs were only in the infarcted zone. (D) MNCs from HHTI patients are show impaired homing to infarcted mouse hearts. The number of MNC-derived ECs per $\mathrm{mm}^{2}$ in hearts of Balb/c mice 4 days post-MI was determined by counting UEA-I+ cells. (E) MNCs from healthy donors and HHTI patients showed no differences in the number of UEA-I ${ }^{+}$and Ac Dil-LDL ${ }^{+}$cells attached to fibronectin-coated plates after 8 days. Expression of TGF- $\beta$ signaling pathway components in HHTI MNCs were comparable to those in healthy donor MNCs. 


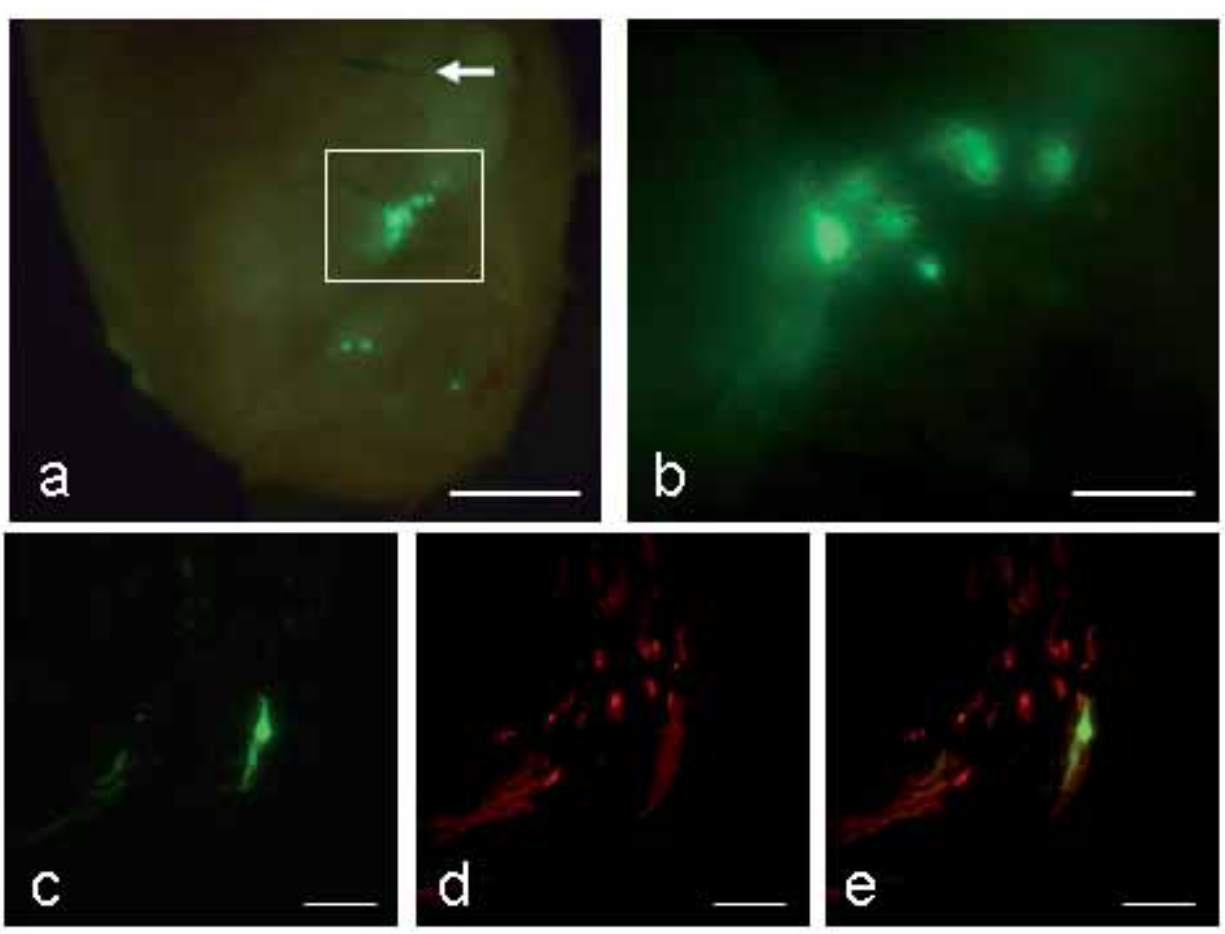

CH8, Figure 1. CMPC survival two weeks after MI. Fluorescent whole mount microscopy shows an eGFP positive graft (a, b), near the site of ligation (a:white arrow). (c) Cryosection of the same area, stained with human $\beta I$-integrin (d), colocalization of eGFP and $\beta$ I-integrin confirms human origin of the eGFP ${ }^{+}$cells (e). Scale bars: a: $2 \mathrm{~mm}$, b: $0.5 \mathrm{~mm}, \mathrm{c}-\mathrm{e}: 50 \mu \mathrm{m}$ 


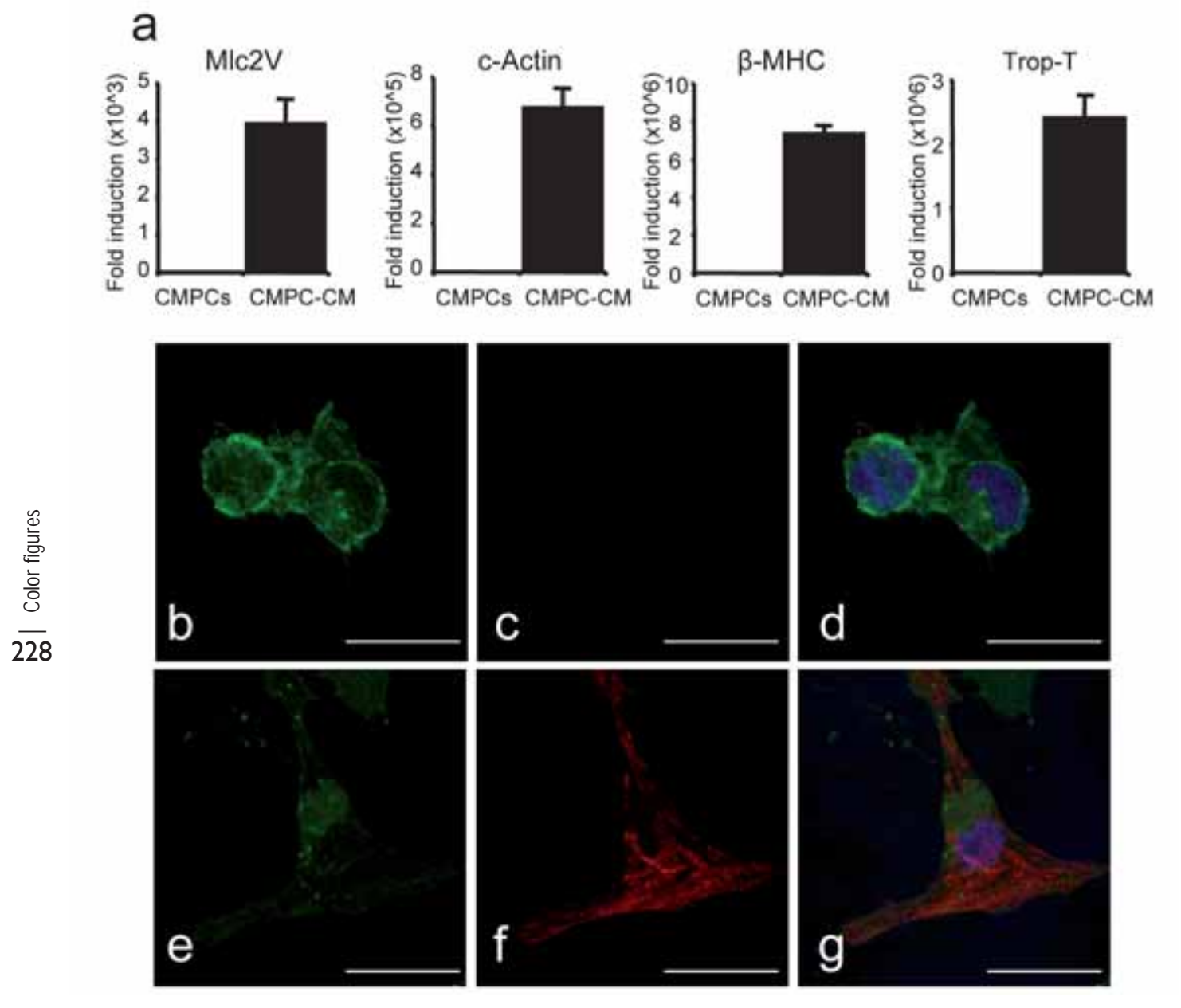

CH8, Figure 2. Differentiation state of the cell sources for transplantation. (a) Relative expression of MLC2V, $\beta$-MHC, c-Actin and trop-T determined by quantative RT-PCR. Values were normalized for $\beta$-actin and the relative increase in expression was calculated using the $\triangle \Delta C T$ method, setting the expression of CMPCs to I.

(b-g) Confocal microscopic images showing the protein expression in cultured cells. Staining with $\beta I$-integrin was used as a marker for human cells (green, $e$ and $h$ ). Troponin-I staining revealed a clearly striated sarcomeric pattern in the CMPC-CM cells (red, i) but no expression in the CMPCs (f). $G$ and j show the merged pictures, with nuclei in blue. Scale bars: $25 \mu \mathrm{m}$. 
Color figures | 229

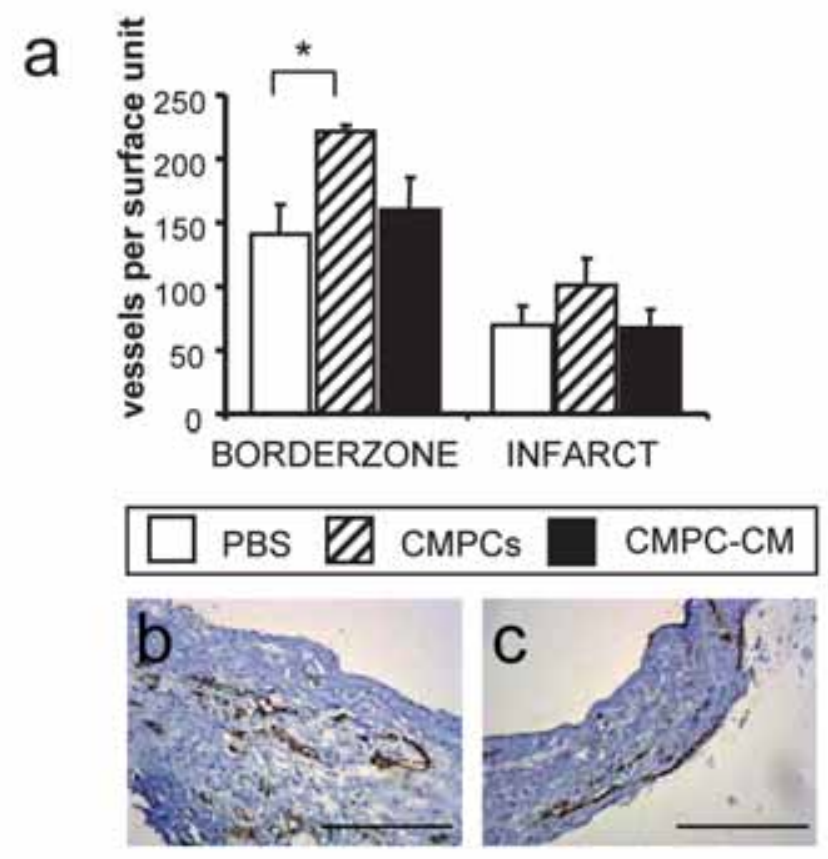

CH8, Figure 6. The vascular density in the borderzone and the infarcted region was assessed by counting the number of $\mathrm{CD}_{3} \mathrm{I}^{+}$small vessels per $0.25 \mathrm{~mm}^{2}$ (a). Representative pictures of the $\mathrm{CD} 3 \mathrm{I}$ staining are shown for the borderzone (b) and the infarcted region (c). Scale bars: $100 \mu \mathrm{m} .{ }^{*} \mathrm{p}<0.05$ 

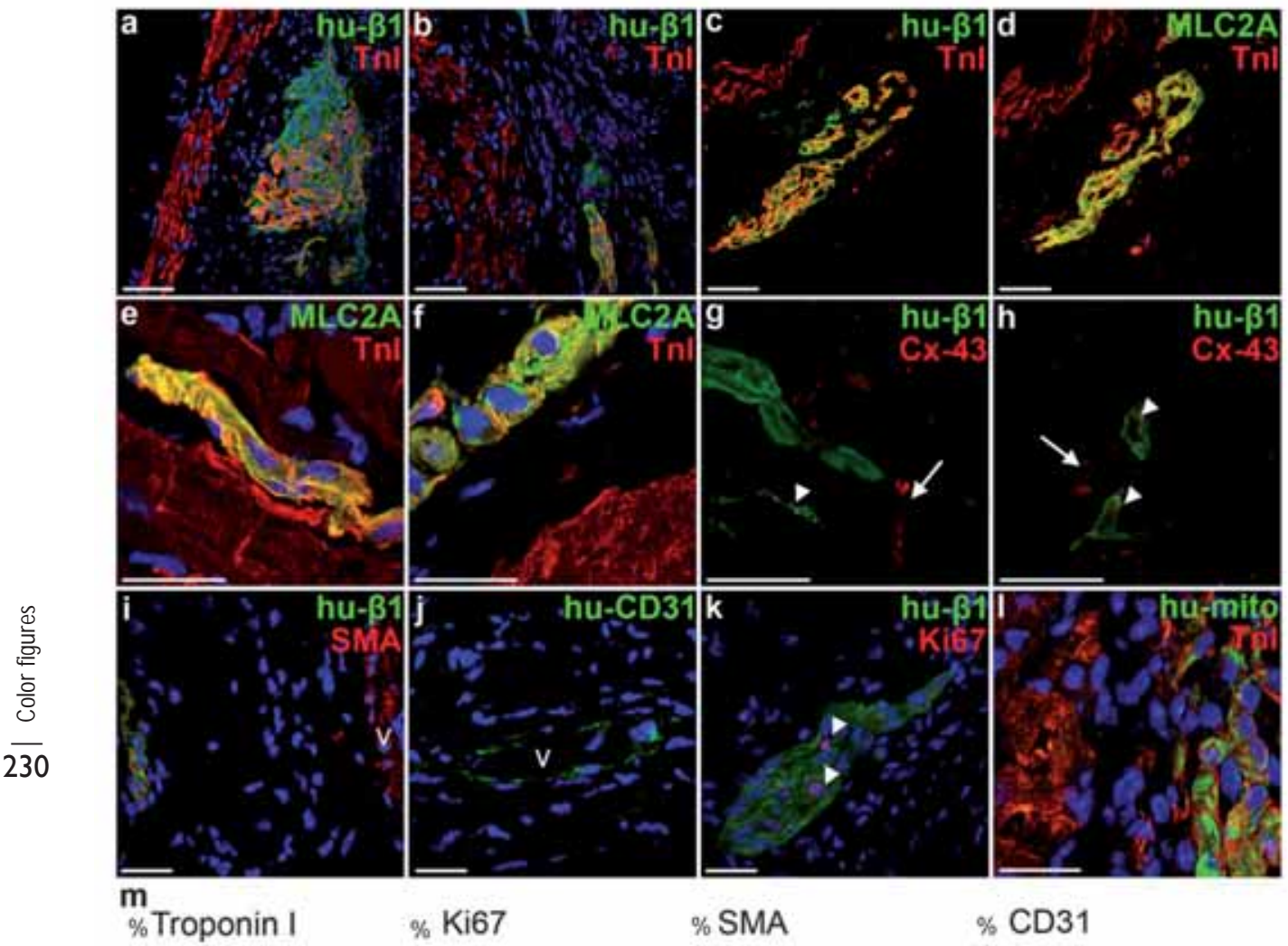

$\%$ SMA
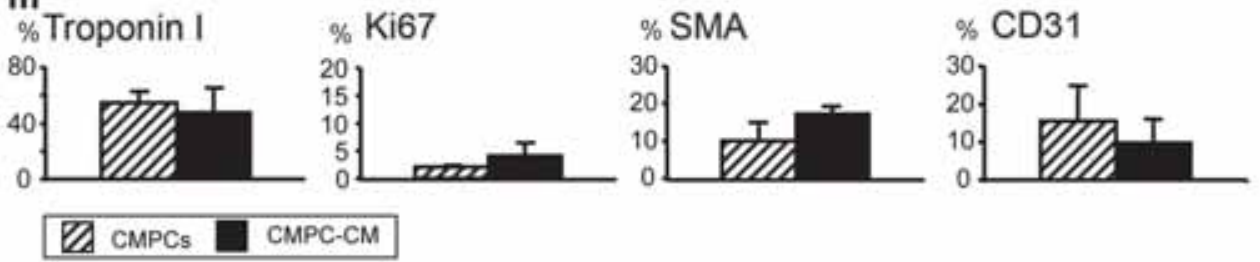

CH8, Figure 7. Composition of human CMPC-derived grafts in the infarcted mouse heart 12 weeks after MI and cell transplantation. (a-b) CMPC-derived cells form grafts in the infarcted tissue and borderzone: (a) CMPCs differentiated into cardiomyocytes after transplantation in vivo, (b) in vitro (before transplantation) differentiated CMPC-CM form similar grafts in vivo. (c-d) The majority of the CMPC-derived cardiomyocytes (c) expresses MLC2A (d; section adjacent to c), in contrast to the surrounding mouse ventricular myocardium. (e-f) Sarcomeric pattern of MLC2A and troponin I in both in vivo and in vitro differentiated CMPC-CM. (g-h) connexin-43 is present between human CMPC-derived cardiomyocytes (arrowheads), but to a lesser extent than between adult mouse cardiomyocytes (arrows); (g) from CMPCs, (h) from CMPC-CM. (i-j) A minority of the CMPCs differentiates into smooth muscle cells (V: mouse vessel) or endothelial cells (j), forming vessel-like structures (v). (k) Cell cycle activity in a small percentage of CMPC-derived cells. (I) Human-mitochondria staining to confirm the human origin of the grafted cells. $(m)$ Quantification of phenotypes in grafted cells.

Hu- $\beta$ I: human integrin $\beta$ I; Tnl: Troponin I; Cx-43: connexin-43; SMA: smooth muscle actin; hu-mito: human mitochondria. Blue: nuclei (DAPI). Scale bars (a-d) $50 \mu \mathrm{m}$, (e-l) $25 \mu \mathrm{m}$. 
Color figures | 23 |

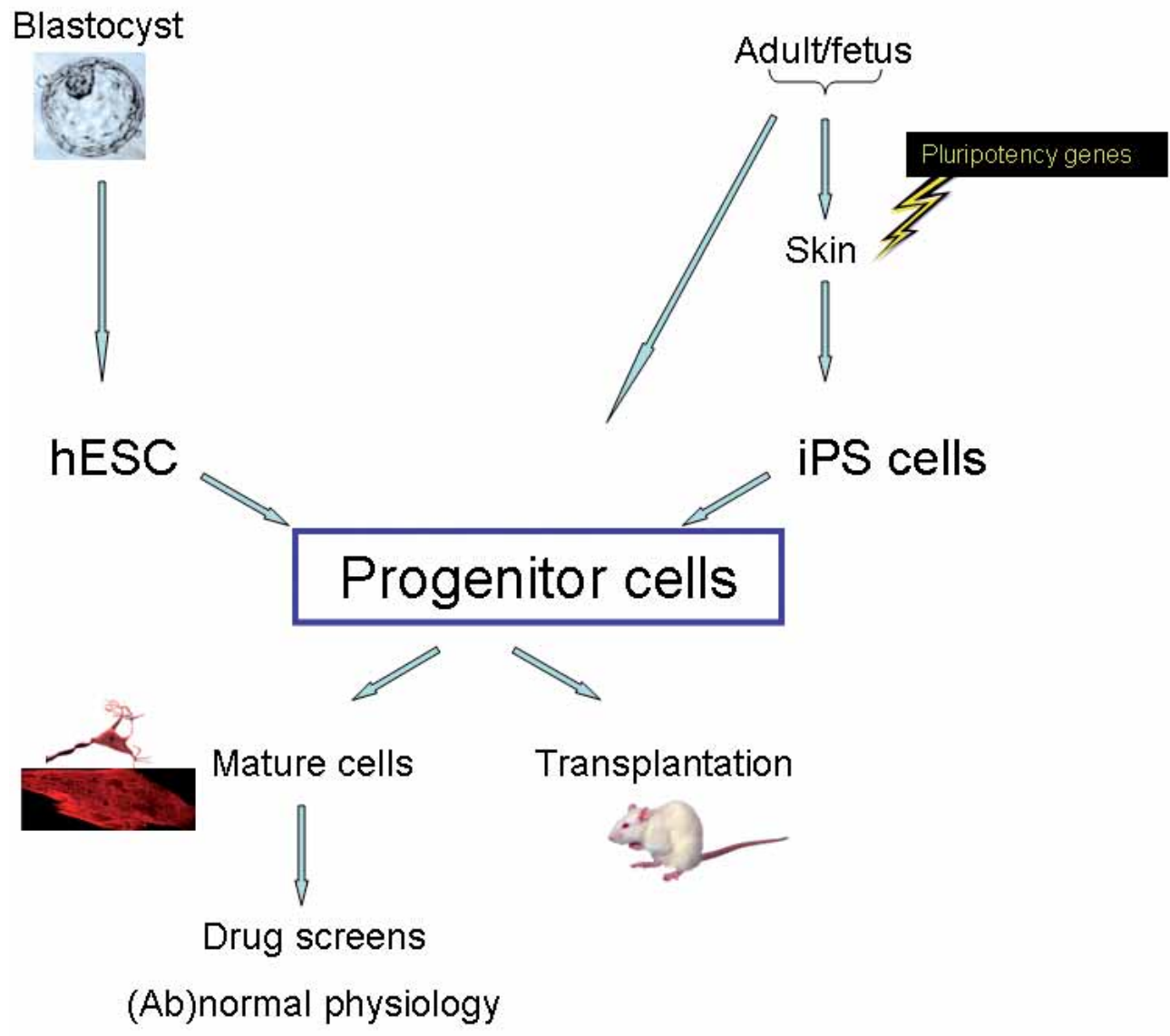

CH9, Figure 1. The use of somatic cells, iPS and hESC for transplantation and drug screening. 


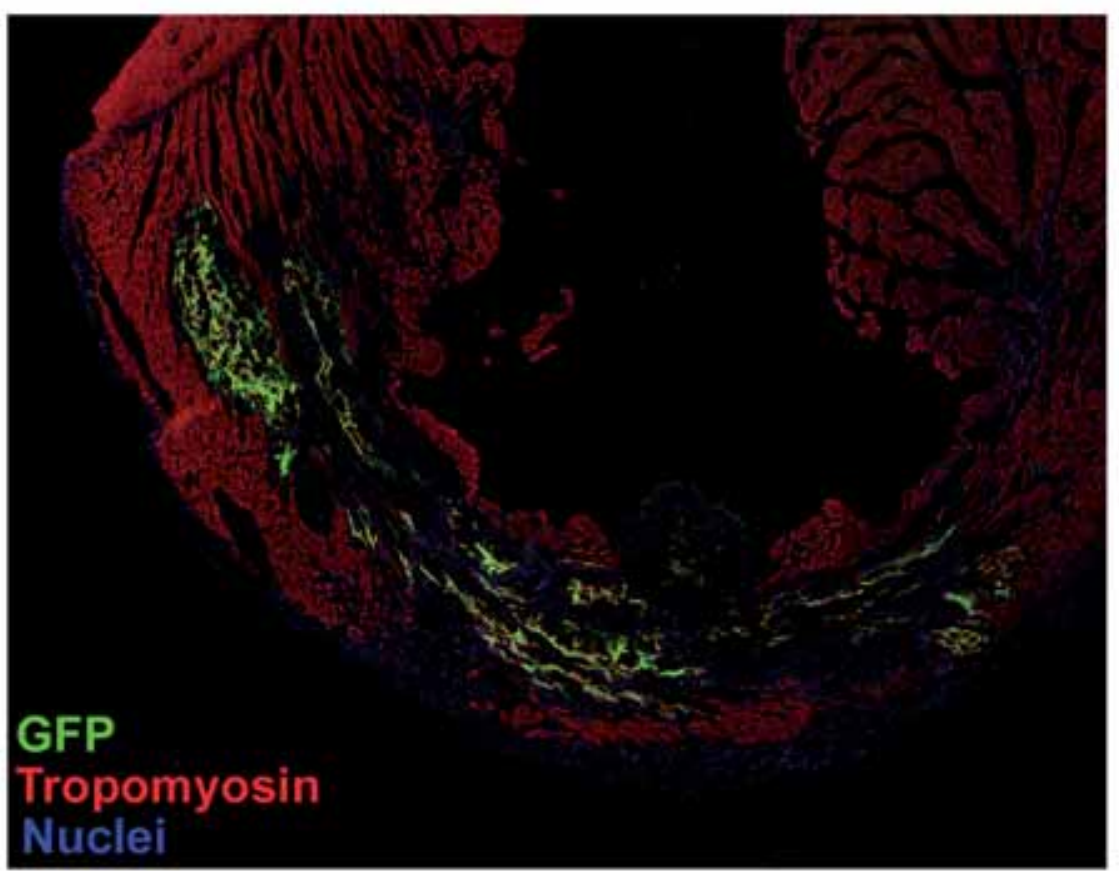

CH9, Figure 2. Cardiac regeneration by hESC-derived cardiomyocytes

Transverse section of infarcted left ventricle 3 weeks after ligation of the coronary artery and transplantation of hES3-GFP derived cardiomyocytes. Cardiomyocytes are characterized by positive staining with an antibody against tropomyosin.

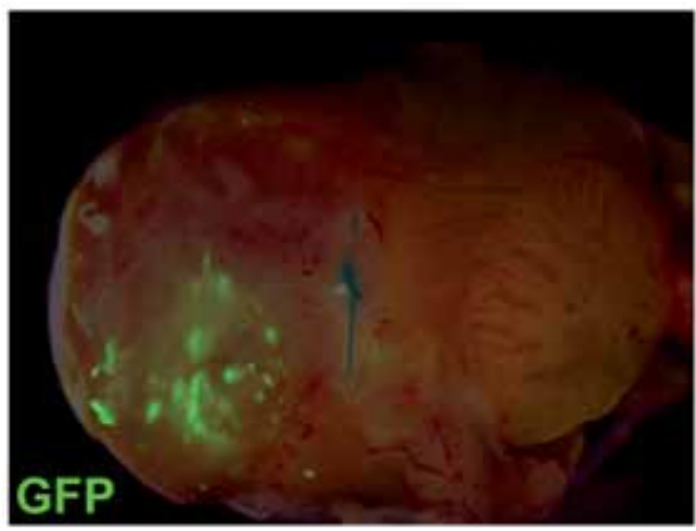

CH9, Figure 3. hESC-derived graft in the infarcted mouse heart

Mouse heart 12 weeks after induction of myocardial infarction and injection of hES3-GFP derived cardiomyocytes. 
Color figures | 233

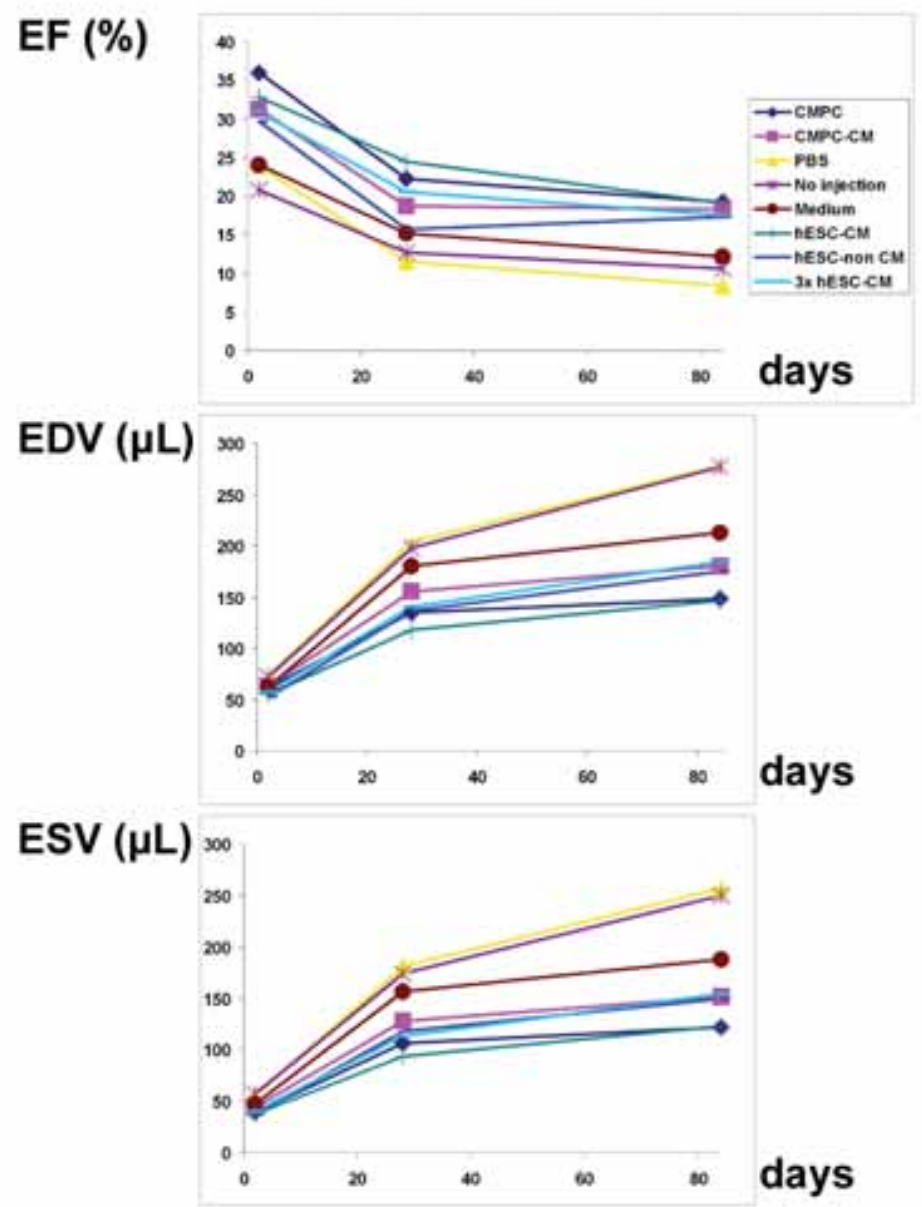

CH9, Figure 4.Cardiac function after transplantation of hESC-CM, CMPCs, CMPC-CM and multiple controls 


\section{Summary}

The adult human heart has a minimal ability to regenerate myocardium. Therefore, loss of viable cardiomyocytes in cardiac disease, such as myocardial infarction (MI), may lead to heart failure. After evaluating the regenerative potential of several stem cell sources of cardiac myocytes and vascular cells (chapter 2), we created a mouse model of $\mathrm{Ml}$ and cell transplantation which allows long term phenotypical analysis of engrafted human stem and progenitor cells, and used magnetic resonance imaging (MRI) to monitor cardiac function (chapter 3). We thus performed the first long term study of human embryonic stem cell-derived cardiomyocytes (hESC-CM) in uninjured and infarcted mouse hearts, and found that hESC-CM survive, integrate and mature in the host myocardium for at least 12 weeks. HESC-CM transplantation improved heart function post-MI at 4 weeks compared to differentiated hESCs devoid of cardiomyocytes, but this was not sustained at 12 weeks (chapter 4). Comparing the effects of injection of hESC-CM at different dosages with hESC-non-CM derivatives, culture medium or no injection in the same experimental model, we demonstrate that both hESC-CM and hESC-non-CM provide long term functional improvement compared to vehicle- or no injection even though only cardiomyocytes formed persistent grafts. Importantly, increasing numbers of hESC-CM for transplantation resulted in no additional functional benefit. In addition, we confirmed evidence of a paracrine contribution of the transplanted hESC-CM by demonstrating increased vascularization in the infarcted heart associated specifically with transplantation of these cells (chapter 5).

Because the grafted cells were usually surrounded by a fibrotic layer, we determined its composition with respect to extracellular matrix type and origin, and found a contribution of both host and donor cells. In addition, we characterized the integrin expression of hESC-CM in vitro and at various time points post-transplantation. Co-transplanted hESC-derived endothelial cells formed a capillary network through the fibrotic layer that communicated with the mouse vasculature, supporting extended graft survival and maturation over a 6 month period (chapter 6 ). We further specified the role and suitability of vasculogenic cells in cardiac regeneration using mice and human cells with a deficiency of endoglin, an accessory TGF $\beta$-receptor present on mononuclear cells (MNCs). Defects in mutant mice in vascularization and cardiac function 
post-MI could be rescued by intravenous injection of healthy donor MNCs, but not MNCs from patients with the gene mutation. This indicates that cardiovascular patients, who often have defects in their MNCs and endothelial progenitor cells, may benefit from transplantation of cells with high endoglin expression, and matched heterologous cells may be preferred (chapter 7). Finally, we show that human heart-derived cardiomyocyte progenitor cells (CMPCs) and CMPC-CM prevented cardiac dilatation and deterioration of cardiac function for at least 12 weeks after MI. In addition, CMPCs differentiated in vivo into cardiomyocytes, smooth muscle cells and endothelial cells (chapter 8). In conclusion, several cell types improve cardiac function but some problems need to be solved, and further investigation into the underlying mechanisms is required for optimization in the choice of cell number and type so that clinical strategies can be properly defined. 


\section{Samenvatting}

De overlevingskansen na een hartinfarct zijn sterk toegenomen door nieuwe en verbeterde therapieën. Op langere termijn ontstaat echter vaak hartfalen, een tekortschietende pompfunctie van het hart. De oorzaak hiervan is een groot verlies aan hartspiercellen, die het lichaam niet zelf opnieuw aanmaakt. Om toch voldoende doorbloeding van weefsels in het lichaam te behouden, kunnen kortdurende compensatie-mechanismen optreden. Na verloop van tijd schieten deze echter te kort en verergeren ze het proces zelfs. Harttransplantatie is op dit moment de enige kans op genezing, maar de mogelijkheden daartoe zijn beperkt door een groot tekort aan donoren en de kans op afstoting van het getransplanteerde hart. Transplantatie van stamcellen en voorlopercellen die hartweefsel vormen, zou mogelijk in de toekomst een oplossing kunnen bieden.

Een stamcel is een cel die zichzelf kan vernieuwen bij de vermenigvuldiging en zich kan specialiseren (differentiëren) tot tenminste een andere celsoort (hoofdstuk 1). Er zijn globaal twee categoriën stamcellen: embryonale stamcellen of gemanipuleerde cellen met dezelfde kenmerken, en adulte of somatische stamcellen. Embryonale stamcellen zijn pluripotent, wat wil zeggen dat ze kunnen differentiëren tot alle celsoorten die in het lichaam voorkomen. Ze worden gekweekt vanuit een klompje cellen, blastocyst genoemd, dat over is na een IVF-behandeling en vormen dan een stabiele "cellijn" die in principe eeuwig door kan blijven groeien. Een voorbeeld van dergelijke cellen zijn de humane embryonale stamcellen (hESCs), waaruit wij hartspiercellen (cardiomyocyten) kunnen kweken, de hESC-CM (hoofdstuk 4, 5 en 6). Adulte stamcellen zijn afkomstig van een mens of dier voor of na de geboorte en kunnen zich vaak minder gemakkelijk vermenigvuldigen. Ze zijn multipotent (differentiatie tot enkele celgroepen mogelijk, meestal die van het orgaan waaruit ze afkomstig zijn) of unipotent (zoals voorlopercellen die maar tot een bepaalde celsoort kunnen differentiëren). Voorbeelden zijn mononucleaire cellen uit het bloed (MNCs; een bepaald type witte bloedcel dat onder andere betrokken is bij ontsteking en bloedvatvorming, hoofdstuk 7), voorlopercellen uit het hart (CMPCs; hoofdstuk 8) en beenmergstamcellen. 
Hoewel inmiddels duidelijk is dat beenmergstamcellen (die als enige al veelvuldig in patiëntenstudies gebruikt zijn) een veel minder spectaculair effect hebben dan aanvankelijk gedacht, worden andere stam- en voorloper cellen als zeer veelbelovend beschouwd om in de enorme behoefte aan nieuwe methodes voor herstel van het hart te voorzien. Toch staat onderzoek in vivo (in de levende mens of dier) nog in de kinderschoenen, terwijl interpretatie van de resultaten complex en vaak omstreden is. Het creëren van een consequent model voor het onderzoeken van hartregeneratie op basis van celtherapie was dan ook een belangrijk doel van de studies beschreven in dit proefschrift. Met behulp van dit model transplanteren we vervolgens cellen afkomstig van $\mathrm{hESCs}$ en adulte stam- en voorlopercellen, waarbij alle experimenten opgezet zijn rond de volgende vragen: wat gebeurt er met de cel na transplantatie in het hart en welke gevolgen heeft dit voor hartfunctie, wat zijn de onderliggende mechanismen en hoe moeten we deze gegevens vertalen naar de ontwikkeling van eventuele klinische toepassing in de toekomst?

In hoofdstuk 2 geven we een overzicht van recente ontwikkelingen op het gebied van

stamceltransplantatie in het hart van mensen en proefdieren. We werpen een kritische blik op de verschillende celbronnen die hiervoor mogelijk gebruikt kunnen worden; in het bijzonder evalueren we hun capaciteit om tot hartspiercellen te differentiëren en de veiligheid van hun (pre)klinische toepassing. Dit resulteert in de formulering van een aantal onbeantwoorde vragen en controversiële kwesties in het onderzoeksveld, waarvan een aantal onderzocht wordt in de resterende hoofdstukken.

In hoofdstuk $\mathbf{3}$ beschrijven we de ontwikkeling van een compleet model waarmee de kweek van hartspiercellen uit stamcellen, transplantatie in het gezonde en geïnfarceerde muizenhart, functionele follow-up met magnetic resonance imaging (MRI), en microscopische analyse op een betrouwbare manier zijn gerealiseerd. Het belang van dit model is dat grote infarcten gemaakt kunnen worden, wat nodig is voor een consequente uitkomst, terwijl de muizen toch langdurig kunnen overleven. Dit in combinatie met niet-invasieve herhaaldelijke MRI-metingen, die het hart heel precies in beeld brengen, maakt dat er minder dieren nodig zijn om tot conclusies te komen. Verder 
identificeren we oorzaken van artefacten (misinterpretatie van resultaten) die ontstaan door weefselschade, ontsteking, activatie van afweermechanismen en celdood, en geven alternatieven voor een betere beoordeling van de "graft" (getransplanteerde cellen die aanwezig blijven in het ontvanger-hart).

Met dit model onderzochten we het effect van transplantatie van hartspiercellen, gekweekt uit humane embryonale stamcellen, in gezonde en geïnfarceerde muizenharten (hoofdstuk 4). Met antilichaam-kleuringen en electronenmicroscopie tonen we aan dat deze hESC-CM overleven, integreren en matureren in het hart van de ontvanger gedurende ten minste 12 weken, maar dat ze niet lijken te koppelen met de hartspiercellen van de muis. Vergeleken met andere uit hESCs gekweekte cellen (niet-hartspiercellen), verbeterden de hESC-CM hartfunctie 4 weken na het infarct. Na 12 weken was het effect van beide celsoorten echter gelijk.

Vervolgens bekeken we wat de invloed was van verschillende doseringen van $\mathrm{hESC}-\mathrm{CM}$, en vergeleken deze ook met een onbehandelde groep die alleen een infarct kreeg, en een groep waarbij kweekmedium geïnjecteerd werd na het infarct (hoofdstuk 5). Het bleek dat zowel de hartspiercellen als de andere van hESCs afkomstige cellen de functie op lange termijn verbeterden, hoewel alleen de hartspiercellen langdurig een graft vormden en tot meer functieverbetering leidden 4 weken na het infarct. Simpelweg meer hartspiercellen inspuiten versterkte het effect niet, maar stimulatie van vaatnieuwvorming door de getransplanteerde cellen was wel van belang.

In de meeste gevallen omringde een laagje bindweefsel de grafts, wat koppeling van donor- en ontvangercellen kan verhinderen en de bloedvoorziening van de donorcellen beperkt. We bepaalden daarom de samenstelling en oorsprong van deze extracellulaire matrix, en vonden dat ze uitgescheiden werd door zowel de getransplanteerde cellen als cellen in het hart van de ontvanger (hoofdstuk 6). We karakteriseerden ook de receptoren (integrines) op de getransplanteerde cellen die de matrix binden, omdat dit essentieel is bij de stap naar tissueengineering (het maken van stukjes hartspierweefsel in plaats van losse cellen) en toekomstige transplantatie in patiënten. Ondanks de bindweefselvorming bleven de donor-hartspiercellen overleven en matureren, zelfs na 6 maanden; dit was 
mogelijk te danken aan de vorming van bloedvaatjes uit meegetransplanteerde, van $\mathrm{hESC}$ s afkomstige, vaatwand- (endotheel) cellen.

We specificeerden de rol en toepasbaarheid van vaatvormende cellen in herstel van het hart nader in hoofdstuk 7. Hiervoor gebruikten we muizen en cellen van mensen met een afwijking in het gen dat codeert voor endoglin, een groeifactor (TGF- $\beta$ ) receptor die onder andere aanwezig is op mononucleaire cellen. We laten zien dat MNCs slechter functioneren in geval van verlaagde endoglin-expressie, waardoor muizen met de genetische afwijking verminderde vaatvorming en een slechtere hartfunctie hebben na een hartinfarct. Het inspuiten van gezonde MNCs in de bloedbaan na infarct hief dit defect grotendeels op, terwijl MNCs van patiënten met de genmutatie geen effect hadden. Deze bevindingen impliceren dat hart- en vaatpatiënten, die vaak slecht functionerende MNCs en endotheelvoorlopercellen hebben, mogelijk geholpen kunnen worden door een selectie van cellen met hoge endoglin-expressie; heterologe cellen (niet van de patiënt zelf maar van een donor of cellijn) hebben in dat geval de voorkeur.

Ten slotte onderzochten we voorlopercellen uit het menselijke hart en de cellen die daaruit gekweekt kunnen worden: vooral hartspiercellen, maar ook gladde spiercellen en endotheelcellen. $\mathrm{Na}$ transplantatie in het geïnfarceerde muizenhart voorkwamen ze dilatatie (overmatige vergroting en verdunning) en achteruitgang in functie van de hartkamer gedurende minimaal 12 weken (hoofdstuk 8). Bovendien differentieerden de voorlopercellen ook in vivo in het muizenhart tot hartspiercellen, gladde spiercellen en endotheelcellen.

Concluderend gaven verschillende celsoorten verbetering in hartfunctie, maar diverse problemen moeten nog opgelost worden voordat we kunnen beginnen met onderzoek in patiënten. Verder onderzoek naar de onderliggende mechanismen is nodig voor optimalisering van de keuze in dosering en celtype, zodat therapeutische toepassingen adequaat gedefinieerd kunnen worden. 


\section{Dankwoord / Acknowledgements}

Na drie jaar heel hard werken is het dan zover... mijn proefschrift is af!!! Maar ook al mag ik het liefkozend "mijn boekje" noemen, het was nooit geworden wat het is zonder de bijdrage van diverse mensen, die ik bij deze hartelijk wil bedanken.

Ik mag me zeer gelukkig prijzen met twee promotoren die me allebei ontzettend veel geleerd hebben. Christine, er is geen leukere plek om te promoveren dan in het Mummery lab en niet in het minst door jouw manier van leidinggeven. Bedankt voor het delen van je indrukwekkend grote wetenschappelijk inzicht, voor je supersnelle correcties, motiverende opmerkingen, steun en de extra "klussen" zoals reviews, presentaties en werkbezoeken die je me toevertrouwde. Je bent een groot voorbeeld voor ambitieuze dames (en heren)! Pieter, ik weet nog steeds niet of het nu echt toeval was dat we op dat promotiefeestje in gesprek raakten over wetenschappelijk onderzoek, waarop je me uitnodigde te solliciteren op de AlO-plek in Utrecht... maar ik ben blij dat het zo gelopen is. Vanaf dag één had jij een bijna grenzeloos vertrouwen in me en terwijl je altijd positief was, bleef je tegelijkertijd kritisch kijken naar mijn onderzoeks- en andere plannen. Dit heeft me absoluut vooruit geholpen; bedankt voor alles en kom maar gauw kijken wat ik ervan bak in San Francisco!

Robert, behalve dat je me regelmatig tot tranen toe kon laten lachen, was je ook een geweldige discussie-partner. Ik ben je erg dankbaar voor je grote betrokkenheid en je goede adviezen. En voor je cellen natuurlijk, zowel je eigen MNCs als de hESC-CM. Marie-José, wij hebben heel wat overlegd en samengewerkt, maar ik wil je ook bedanken voor je oprechte interesse en de gezelligheid. Franck, I am very grateful for your coaching towards "the heart paper" and the integrin work; you were very inspiring! Thank you for making me work day and night... it was great fun -especially now that it's done! Daan, geweldig dat je zoveel tijd hebt weten vrij te maken om me (bijna) net zo goed te leren opereren als jijzelf... pas toen ik zelf mensen ging trainen, wist ik hoe zwaar dat geweest moet zijn. Veel dank! 
Bijna iedereen uit de Mummery-groep heeft wel op een of andere manier geholpen aan het tot stand komen van dit proefschrift. Teamwork! Jantine, aan jou komt de meeste eer toe, je hebt mij wegwijs gemaakt in het lab en bovendien een enorme berg werk verzet: immuno's, cellen tellen (aaarg!), PCRs aan de praat krijgen, noem maar op, altijd met veel zorg en toewijding. Het was een groot plezier met je samen te werken! Dorien, bedankt voor de veeeeeele miljoenen cellen die je voor me aan het kloppen wist te krijgen, Laura voor je hulp met integrines en matrixen, Stieneke voor je kweek-expertise en commentaar op mijn kleding, Marga voor verwoede pogingen om de ingewikkelde in situ werkend te krijgen, en Christian voor het helpen opzetten van de Langendorff en de morele steun van een wijze oude postdoc! Appie, jammer dat we het niet gehaald hebben alle tafels van de Mr Jacks te proberen, maar we zijn toch goed begonnen... in ieder geval bedankt voor de pomp-instructies en meer. Dennis, Anja, Willemijn, Susana, Adam, Leonie, alle studenten en de oud-gedienden Mariette, Gudrun, Anne R, Rita, Rui, Alie, Jen, Sandy, Sander (nu kan ik eindelijk jou bedanken voor je enorme inzet voor hoofdstuk 7!), Rutger en Bas, dank voor alle hulp en plezier!

Stefan (respect voor je "just do it" motto!), je dacht toch niet dat ik je zou vergeten... met jou, Carina (top-bloedprikster!), Maaike en Anne (last but most) heb ik het laatste jaar niet alleen in, maar vooral ook buiten het lab heel veel leuke en bijzondere dingen meegemaakt. Bedankt voor jullie vriendschap en succes met alle nieuwe plannen!

Tijdens de eindsprint kwam er ineens nog een enthousiaste student binnenlopen die in record-tijd een hoop data wist te verzamelen: Chantal, super gedaan!

Zuster Korving oftewel Jeroen, mijn dank is nog groter dan de berg coupes die je voor me hebt gesneden! Je bent de enige die me dokter mag noemen in het lab... Ook Harry wil ik bedanken voor de nuttige trucjes om de immuno's te verbeteren en jullie allebei voor de fijne sfeer in het histologie-lab.

Zonder gezonde muizen waren mijn proeven onmogelijk geweest, dus het is maar goed dat deze dankzij de dierverzorgers en Mark prima verzorgd werden. Dank jullie zeer daarvoor allemaal, en ook voor de extra dingen die jullie (met name Miep, Erma en Petra verdienen een groot compliment!) voor mij en mijn harige vriendjes gedaan hebben. 
Een aantal behulpzame trio's: Jules, Richard, en Romke, fijn dat jullie af en toe voor taxi of koerier wilden spelen, en Thea, Janny en Sylvia, bedankt voor de secretariële ondersteuning! Leon, Willem en Jeroen, jullie hulp bij confocal microscopie was onmisbaar.

De rest van het Hubrecht Instituut heeft me met name van het werk afgehouden, maar dat heb ik graag laten gebeuren... Bedankt voor alle uit de hand gelopen borrels!

Cees, Maurits, en Kees van de MRI, veel dank voor jullie deskundigheid en altijd welkome ontvangst (met echte koffie...). Marcel, behalve dat was het ook erg gezellig met jou tijdens het L'dorffen enzo! Krista, jij verdient bovendien alle lof voor het uitwerken van vele scans.

De mensen van het Vrelinghuis, en met name Chita, ben ik zeer erkentelijk voor het unieke onderzoeksmateriaal en de interessante en grappige discussies op de OK.

Alle electronen-microscopische plaatjes zouden niet gemaakt zijn zonder de inspanningen van Elly, Bruno en Arie. Bedankt voor jullie prachtige beelden en de goede organisatie. Elly, vooral jij hebt er heel veel tijd en moeite in gestoken; het resultaat is ernaar!

In het experimentele cardio lab was altijd wel nieuws te halen of te vertellen... MJ, Gerard, Dominique, Leo, Anke, Piet, Joost, Corina, Simone, Pieter, Sebastian, Dik en Fatih, dank voor jullie tijd en de samenwerking. Voor degenen die erbij waren: congressen met jullie waren goed!!!

Hetzelfde geldt voor de mouse-labbers en de rest van de club van medische fysiologie!

Several other groups in and outside of Utrecht have shared their knowledge, materials or skills with us: Ronald Plasterk, Edwin Cuppen, Arnoud Sonnenberg, Cees Westermann, Hans-Jurgen Mager, Repke Snijder, Loren Field, Thomas Thum, and Embryonic Stem Cell International (Singapore), many thanks for the fruitful collaborations! 
Professor Brutel de la Rivière en professor van Herwerden wil ik graag bedanken voor hun bijdrage aan het begin van mijn aanstelling en het erkennen van het belang artsen te betrekken bij wetenschappelijk onderzoek.

Een geweldige groep mensen uit Maastricht heeft er in de eerste plaats voor gezorgd dat ik in het onderzoekswereldje verzeild raakte. Sebastian, ik ben je dankbaar voor het goede idee om student-assistent te worden en voor het feit dat je altijd achter me stond! Tryfon, ik had geen inspirerender begeleider kunnen treffen dan jou, heel erg bedankt voor de sjoene tijd in Mestreech en voor je connecties met Londen. Ruben, ook van jou heb ik zoveel geleerd (ik mocht me 3 jaar lang de statistiek-expert van het lab noemen dankzij jouw lessen)! Dr. Schurink, professor Hoeks en professor Kitslaar bedankt voor jullie aandeel in de supervisie. Gert en Sabien, dankzij jullie wist ik al hoe je een pipet vast moet houden toen ik als AIO begon... En dan nog Rick (de powerpointen beurzenexpert!), Allard, Diana, Eric en Jeroen, wat hebben we veel lol (en margarita's) gehad met zijn allen -en nog steeds!

Succes zou niets waard zijn en tegenvallers ondraaglijk als je het niet met goede vrienden kon delen. Lilian, Leonie, Geertje, Milou, Hanneke en Judith, door afstand en drukke werkschema's kunnen we elkaar soms minder zien dan we zouden willen, maar als het dan lukt, is het altijd als vanouds. En gelukkig is daar ook nog altijd de telefoon, al haalt die het natuurlijk niet bij onze wijn-avondjes waarin echt alles besproken wordt! De "dames-en-Ralf" van Overloon, vrienden door dik en dun! Maartje, Marieke, Loes, Geertje en ook Marijke, die dit feest tot ons grote verdriet niet met ons mee kan vieren, maar die er altijd bij zal blijven horen... Dank jullie wel voor legendarische vakanties en weekendjes en alles daarbuiten! Anoek, Karin, Helen, bedankt voor veel gezelligheid, een luisterend oor en jullie kookkunsten, waardoor ik niet alleen maar op koken-en-stomen hoefde te leven! Mèra, van stapmaatje tot close friend, ik kan wel zeggen dat we lief en leed gedeeld hebben de afgelopen jaren. De pre-uitnodiging zegt alles... Toda! Fantastisch dat we onze AlO-tijd nu ook samen kunnen afsluiten.

I would like to express my gratitude to everyone in the Srivastava lab for making me feel very welcome in San Francisco; I am looking forward to the rest of my stay here. 
Mijn beide lieve Brabantse families (inclusief Nienke!) bedankt dat jullie er zijn, dat jullie nieuwe familieleden zo hartelijk ontvangen en dat jullie zelfs tijdens een vakantie in Italië een tafel vrijhouden zodat er papers geschreven kunnen worden... ik heb geboft met jullie!

En tenslotte die mensen die er als eerste waren en de basis hebben gelegd van waaraf je alles opbouwt: pap, mam en Luuk, ik ben jullie heel erg dankbaar voor jullie onvoorwaardelijke steun en liefde!

Linda 


\section{Curriculum vitae}

Linda van Laake was born on May $3 \mathrm{I}^{\text {st }}$, 1980 in Overloon, the Netherlands. In 1998 she graduated cum laude (with honors) at the Raayland College in Venray. During her medical studies at Maastricht University she started her scientific career in the department of Surgery of the University Hospital Maastricht under supervision of Dr. T. Vainas and Dr. G. Schurink, investigating the role of matrix metalloproteinases in aneurysmal and obstructive aortic disease. For this work she received awards at international student congresses in Berlin and Istanbul. After her final internship in Vascular Surgery in the Charing Cross Hospital of Imperial College, London, she obtained her Medical Degree cum laude in November 2004. Subsequently she worked as a $\mathrm{PhD}$ candidate, supervised by Prof.dr. C. Mummery and Prof.dr. P. Doevendans, at the Hubrecht Laboratory and University Medical Center Utrecht; the results of the research conducted there are described in this thesis. In 2007 she received the ICIN (Interuniversity Cardiology Institute of the Netherlands) Fellowship for her research proposal on microRNAs in cardiac progenitor cells, and in December of that year she started her position as a post-doctoral researcher with Prof. D. Srivastava at the Gladstone Institutes of Cardiovascular Disease, University of California San Francisco. In 2009 she will return to the Netherlands for her clinical training to become a cardiologist. 
List of publications | 247

\section{List of publications}

1 L.W. van Laake, T. Vainas, R. Dammers, P.J. Kitslaar, A.P.G. Hoeks, G.W. Schurink. Systemic dilation diathesis in patients with abdominal aortic aneurysms: a role for matrix metalloproteinase-9? Eur J Vasc Endovasc Surg. 2005 Apr;29(4):37I-7

2. J.C.Moore, L.W. van Laake, S.R. Braam, T. Xue, S. Tsang, D. Ward, R. Passier, L.L. Tertoolen, R.A. Li, C.L. Mummery. Human embryonic stem cells: genetic manipulation on the way to cardiac cell therapies. Reproductive Toxicology. 2005 Sep-Oct;20(3):377-9I

3. L.W. van Laake, D. Van Hoof, C.L. Mummery. Cardiomyocytes derived from stem cells. Annals of Medicine. 2005;37(7):499-512

4. L.W. van Laake*, A.M. Smits*. Molecular mechanisms of cardiac disease and regeneration. A focus on stem- and progenitor cells. Netherlands Heart Journal. 2006 May;14(5):195-197

5. C.L. Mummery, L.W. van Laake. [Progress and clashes in stem cell therapy research]. NTvG. 2006 Apr 29;943-947

6. L.W. van Laake, J.A.J.L. Broeders, L.H. Baur, R. Salomonsz. [Stress echocardiography in 11 patients with symptoms of ischemia and a myocardial bridge: no indication of a causal connection in 10 cases]. NTvG. 2006 May 27;1182-7

7. E. Berezikov, G. van Tetering, M. Verheul, J. van de Belt, L. van Laake, J. Vos, R. Verloop, M. van de Wetering, V. Guryev, S. Takada, A. Jan van Zonneveld, H. Mano, R. Plasterk, E. Cuppen. Many novel mammalian microRN A candidates identified by extensive cloning and RAKE analysis. Genome Research. 2006 Oct;16(I0):1289-98

8. L.W. van Laake, R. Hassink, P.A. Doevendans, C. Mummery. Heart repair and stem cells. Journal of Physiology. 2006 Dec I;577(Pt 2):467-78

9. L.W. van Laake*, S. van den Driesche*, S. Post, A. Feijen, M.A. Jansen, M.H. Driessens, J.J. Mager, R.J. Snijder, C.J.J. Westermann, P.A. Doevendans, C.J.A. van Echteld, P. ten Dijke, H.M. Arthur, M-J. Goumans, F. Lebrin, C.L. Mummery. Endoglin has a crucial role in blood cell-mediated vascular repair. Circulation. 2006 Nov 21;1/4(2I):2288-97

10. E. Berezikov, F. Thuemmler, L.W. van Laake, I. Kondova, R. Bontrop, E. Cuppen, R.H. Plasterk. Diversity of MicroRNAs in Human and Chimpanzee Brain. Nature Genetics. 2006 Dec;38(I2):1375-7 
11 L.W. van Laake, C.L. Mummery. [Stem cell therapy]. In: [Textbook of Cardiology], Bohn Stafleu van Loghum, 2007

12. T. Thum, P. Galuppo, S. Kneitz, J. Fiedler, C. Wolf, C. Gross, L.W. van Laake, P.A. Doevendans, J. Borlak, A. Haverich, S. Engelhardt, C.L. Mummery, G. Ertl, J. Bauersachs. MicroRN As in the human heart: a clue to fetal gene reprogramming in heart failure. Circulation. 2007 Jul 17;116(3):25867

13. L.W. van Laake, R. Passier, J. Monshouwer-Kloots, A.J.Verkleij, D.J. Lips, C. Freund, K. den Ouden, D. Ward-van Oostwaard, J. Korving, L.G. Tertoolen, C.J. van Echteld, P.A. Doevendans, C.L. Mummery. Human embryonic stem cell-derived cardiomyocytes survive and mature in the mouse heart and transiently improve function after myocardial infarction. Stem Cell Research. 2007;I(I):9-24

14. L.W. Van Laake, R. Passier, J. Monshouwer-Kloots, M.G. Nederhoff, D. Ward-Van Oostwaard, L.J. Field, C. J. Van Echteld, P. A. Doevendans, C. L. Mummery. M onitoring of cell therapy and assessment of cardiac function using magnetic resonance imaging in a mouse model of myocardial infarction. Nature Protocols. 2007;2(10):255I-67

15. L.W. van Laake, R. Passier, K. den Ouden, C. Schreurs, J. MonshouwerKloots, D. Ward-van Oostwaard, C.J. van Echteld, P.A. Doevendans, C.L. Mummery. Improvement of cardiac function by transplantation of hESC-derived cardiomyocytes in infarcted mouse heart correlates with improved vascularization but not graft size. Submitted

16. L.W. van Laake, E.G. van Donselaar, J. Monshouwer-Kloots, R. Passier, L.M. Zeinstra, D. Ward-van Oostwaard, F. Lebrin, B.M. Humbel, P.A. Doevendans, A. Sonnenberg, A.J. Verkleij, C.L. Mummery. Extracellular matrix formation after transplantation of hESC-derived cardiomyocytes in mice and a pro-survival mechanism through donor-derived neovascularization. Submitted

17. L.W. van Laake*, A.M. Smits*, K. den Ouden, C. Schreurs, C.J. van Echteld, C.L. Mummery, P.A. Doevendans, M-J. Goumans. Human cardiomyocyte progenitor cells regenerate infarcted myocardium and preserve long-term cardiac function in mice. Submitted

18. R. Passier, L.W. van Laake, C.L. Mummery. Transplantation for cardiac repair meets the cardiomyocyte versus stem cell dilemma. Nature. 2008 (Invited review) 